$$
\begin{gathered}
\text { UNIVERSIDADE DE SÃO PAULO } \\
\text { ESCOLA DE ENGENHARIA DE SÃO CARLOS } \\
\text { DEPARTAMENTO DE ENGENHARIA DE MATERIAIS }
\end{gathered}
$$

RONALDO SOARES TEIXEIRA

Efeito das fibras de curauá e de polipropileno no desempenho de compósitos cimentícios produzidos por extrusão

São Carlos 

RONALDO SOARES TEIXEIRA

\section{Efeito das fibras de curauá e de polipropileno no desempenho de compósitos cimentícios produzidos por extrusão}

Tese apresentada ao Programa de PósGraduação em Ciência e Engenharia de Materiais, da Escola de Engenharia de São Carlos, Universidade de São Paulo, para obtenção do título de Doutor em Ciências.

Área de Concentração: Desenvolvimento, Caracterização e Aplicação de Materiais.

Orientador: Prof. Dr. Francisco Antonio Rocco Lahr

São Carlos 
AUTORIZO A REPRODUÇ̃̃O TOTAL OU PARCIAL DESTE TRABALHO, POR QUALQUER MEIO CONVENCIONAL OU ELETRÔNICO, PARA FINS DE ESTUDO E PESQUISA, DESDE QUE CITADA A FONTE.

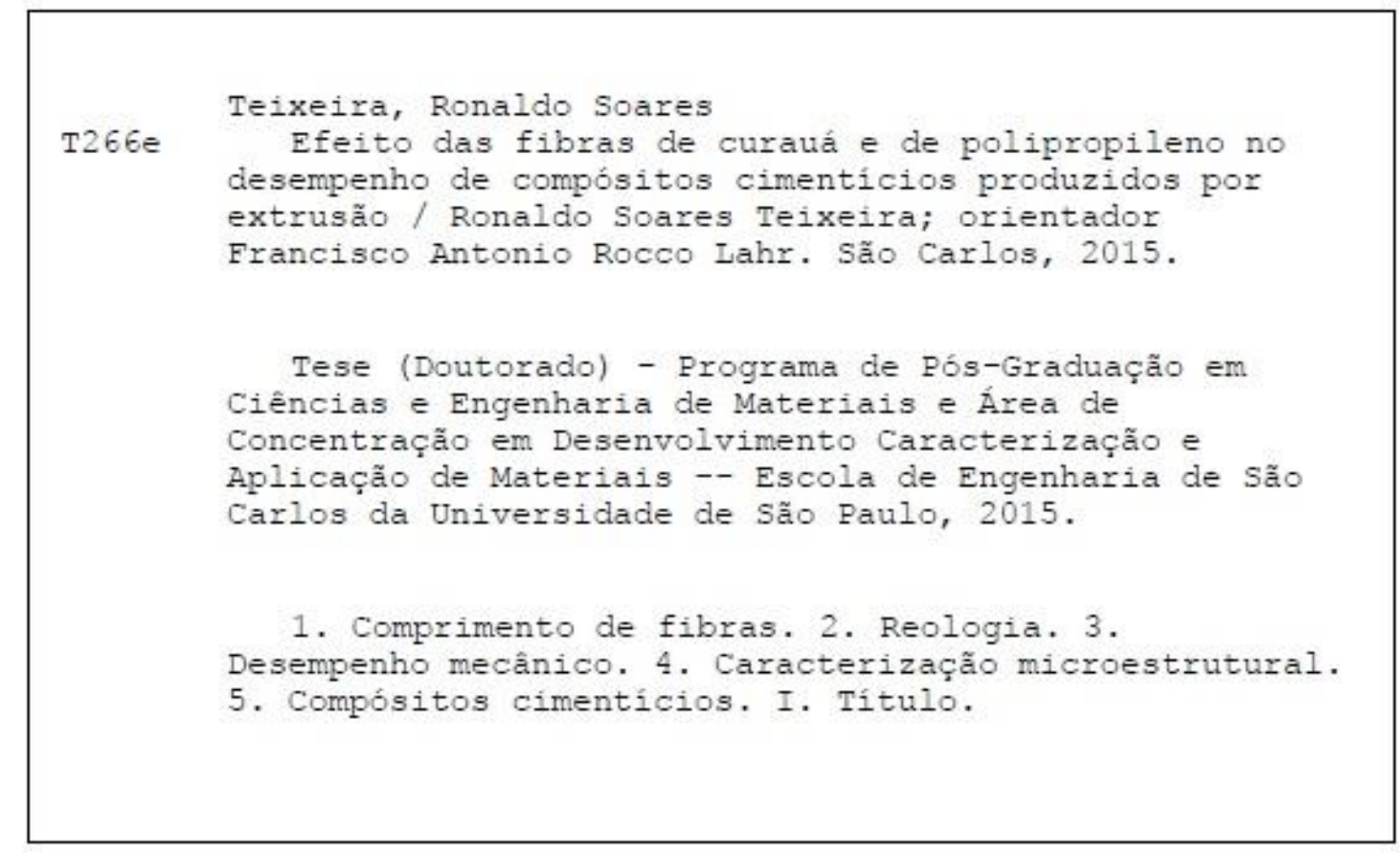




\section{FOLHA DE JULGAMENTO}

Candidato: Tecnólogo RONALDO SOARES TEIXEIRA.

Título da tese: "Efeito das fibras de curauá e de polipropileno no desempenho de compósitos cimentícios produzidos por extrusão".

Data da defesa: 23/11/2015.

Comissão Julgadora:

Resultado:

Themins gum hutris

APROUADO

Prof. Titular Francisco Antonio Rocco Lahr

(Orientador)

(Escola de Engenharia de São Carlos/EESC)

Prof. Dr. Gustavo fenrique Denzin Tonoli

APROVADO

(Universidade Feareral de Lavras/UFLA)

Prof. Titular Holmeres Gavastano Junior

(Faculdade/de Zootecnia e Engenharia de Alimentos/FZEA-USP)

Prof. Dr. Jorge Luis Akasaki

APROVADO

(Universidqde Estadual Paulista "Júlio de Mesquita Filho"/UNESP - Ilha Solteira)

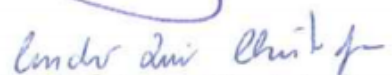

Prof. Dr. André Luis Christoforo

APROVA DO

(Universidade Federal de São Carlos/UFSCar)

Coordenador do Programa de Pós-Graduação em Ciências e Engenharia de Materiais:

Prof. Titular Antonio José Felix de Carvalho

Presidente da Comissão de Pós-Graduação:

Prof. Associado Paulo César Lima Segantine 



\section{DEDICATÓRIA}

Para minha esposa Gisele, minha "filha" Mel, aos meus pais Valter e Conceição pela paciência, compreensão, pelo amor e principalmente ao meu irmão Rodrigo (in memoriam), pelos anos vividos em sua companhia que serão eternos por toda minha 



\section{AGRADECIMENTOS}

Principalmente agradeço a Deus pela vida, pela minha família e pelos meus amigos.

Aos Profs. Dr. Francisco A. Rocco Lahr e Holmer Savastano Junior pelo contínuo incentivo, orientação e supervisão.

Aos Profs. Dr. Gustavo Henrique Denzin Tonoli e Sergio Francisco dos Santos que colaboraram diretamente na execução deste trabalho.

Aos Profs. Jordi Bernabeu Payá, Vicente Amigó da Universidade Politécnica de Valencia/Espanha pela co-orientação no exterior.

Ao técnico Emílio pelo auxílio da execução das análises de nanoindentação.

Ao prof. Dr. André Luis Christoforo no auxílio da execução das análises estatísticas.

Ao grupo de Construções \& Ambiência (C\&A) da FZEA/USP e do laboratório de Madeiras e Estruturas de Madeira (LAMEM) da EESC/USP pelo coleguismo e aprendizagem.

À Coordenação de Aperfeiçoamento de Pessoal de Nível Superior (CaPES) pela concessão da bolsa de doutorado e bolsa de intercâmbio doutorado sanduíche.

A Fundação Amparo de Pesquisa do Estado de São Paulo (FAPESP) pela concessão do projeto de auxílio pesquisa regular.

Aos alunos de Iniciação científica Jandrisson Dorta e Keylla Silva pelo auxilio nas etapas do trabalho.

A todos os familiares e amigos que incentivaram este período de dedicação exclusiva à ciência. 

"Talvez não tenha conseguido fazer o melhor, mas lutei para que o melhor fosse feito. Não sou o que deveria ser, mas Graças a Deus, não sou o que era antes". 



\section{RESUMO}

TEIXEIRA, R. S. Efeito das fibras de curauá e de polipropileno no desempenho de compósitos cimentícios produzidos por extrusão. 2015. 147p. Tese (Doutorado) - Escola de Engenharia de São Carlos, Departamento de Engenharia de Materiais, São Carlos, 2015.

O emprego de compósitos na construção civil, como os de matriz cimentícia e pasta reforçada com fibras, tem se disseminado consideravelmente nos últimos anos. Uma grande variedade de fibras sintéticas, como o polipropileno, tem sido utilizada com sucesso para reforçar compósitos cimentícios. No entanto, o interesse mundial na utilização de produtos com menor impacto ambiental estimula a busca por materiais para substituir fibras sintéticas. As fibras vegetais, biodegradáveis, pode ser ótima alternativa devido à abundância, ao baixo custo, ao menor consumo de energia para sua produção e às propriedades mecânicas apropriadas. Fibra de curauá, planta nativa do estado do Amazonas, com plantações em escala comercial, é usada na fabricação de cordas, cestos ou como reforço em matrizes orgânicas. Suas propriedades mecânicas são semelhantes às de polipropileno. A tecnologia de extrusão é viável nas indústrias de fibrocimento, pois produz compósitos com matriz de alta densidade e ótimo empacotamento, baixa permeabilidade e boa adesão fibra matriz. No entanto, o processo de extrusão bem-sucedido de produtos cimentícios depende principalmente das propriedades reológicas do cimento fresco reforçado com fibras. As fibras vegetais podem promover o sequestro de água e interferir fortemente no escoamento, na coesão e no fluxo de pasta de cimento fresco. A incorporação de fibras vegetais influencia os materiais à base de cimento no estado fresco e afeta propriedades no estado endurecido. Neste contexto, o objetivo da pesquisa é avaliar a influência das fibras de curauá e de polipropileno em propriedades reológicas e em propriedades mecânicas da pasta de cimento fresco. Foram preparadas formulações sem fibras, como referência, e com 1 e $2 \%$ de reforço em massa, fibras com comprimento de 6 e $10 \mathrm{~mm}$. Utilizaram-se duas técnicas reológicas: Squeeze flow e reômetro extrusor para analisar o fluxo de pastas cimentícias. Por meio de dados experimentais, como força/deslocamento, e de análise numérica da pressão do reômetro extrusor, foram determinados: tensão inicial de cisalhamento $(\sigma 0)$, limite de cisalhamento $(\mathrm{T} 0)$, tensão de escoamento $(\alpha)$ e 
tensão de cisalhamento $(\beta)$. As propriedades mecânicas foram determinadas em máquina de ensaio MTS. Módulo de ruptura (MOR), tenacidade à fratura (TFT) e energia de fratura (EF) foram calculados. Os resultados reológicos indicam que a pasta cimentícia reforçada com fibras de curauá apresentou maior força, menor deslocamento e aumento da pressão de extrusão em fibras de curauá em relação às pastas cimentícias reforçadas com fibras de polipropileno. O comprimento das fibras influenciou mais o fluxo da mistura do que o teor de fibra. Compósitos cimentícios reforçados com fibra de polipropileno apresentaram melhores resultados mecânicos de MOR, TFT e EF em relação aos compósitos reforçados com curauá. Após os 200 ciclos de envelhecimento, os resultados mecânicos dos compósitos reforçados com as fibras de curauá diminuíram devido a mineralização das fibras. Os resultados de nanoindentação, como dureza e módulo elástico, aumentaram após os 200 ciclos. As metodologias aplicadas para avaliar o comportamento reológico e mecânico do fibrocimento durante a extrusão facilitará a futura transferência dessa tecnologia ao setor produtivo, com produtos potencialmente de melhor qualidade.

Palavras-chave: Comprimento de fibras. Reologia. Desempenho mecânico. Caracterização microestrutural. Compósitos cimentícios. 


\begin{abstract}
TEIXEIRA, R. S. Effect of curauá and polypropylene fiber in performance composites cementitious produced by extrusion. 2015. 147p. Tese (Doutorado) - Escola de Engenharia de São Carlos, Departamento de Engenharia de Materiais, São Carlos, 2015.
\end{abstract}

The use of composites in construction, as matrix and paste cement reinforced with fibers, has spread considerably in recent years. A wide variety of synthetic fibers such as polypropylene have been successfully used to reinforce cementitious composites. However, worldwide interest in the use of products with lower environmental impact stimulates the search for materials to replace synthetic fiber. Vegetable fiber, biodegradable, can be a great alternative because of the abundance, low cost, the lowest energy consumption for its production, appropriate mechanical properties. Curauá fiber, native plant from Amazon, with crops on a commercial scale, is used in the manufacture of ropes, baskets or as reinforcement in organic matrix. Its mechanical properties are similar to those of polypropylene. Extrusion technology is feasible in the fibercement industry, because it produces composites with high density matrix and great packaging, low permeability and good adhesion fiber matrix. However, successful extrusion process of cementitious products mainly depends on the rheological properties of fresh cement reinforced with fibers. The vegetable fibers can promote water kidnapping and strongly interfere in the flow, cohesion and fresh cement slurry flow. The incorporation of vegetable fibers influences the based cementitious materials in the fresh state and affects properties in the hardened state. In this context, the objective of the research is to evaluate the influence of curauá and polypropylene fiber in rheological and mechanical properties of fresh cement paste. Formulations without fiber, used as reference, 1 and $2 \%$ content by weight of reinforcement, fibers with a length of 6 to $10 \mathrm{~mm}$ were prepared. Two rheological techniques were used: Squeeze flow and extruder rheometer to analyze the flow of cement pastes. Through experimental data, as strength/displacement and numerical analysis of the pressure extruder rheometer were determined: yield stress corresponding to zero velocity $(\sigma 0)$, initial shear stress (T0), effect of the velocity on yield stress ( $\alpha$ ) and effect of velocity in the shear stress $(\beta)$. The mechanical properties were determined in MTS testing machine. Modulus of rupture (MOR), fracture toughness (TFT) and fracture energy (EF) were calculated. 
The rheological results indicate that the cement paste reinforced with curauá fiber showed higher strength, smaller displacement and increased extrusion pressure with curauá fibers compared to cementitious paste reinforced with polypropylene fibers. The length of the fibers influence the flow of the mixture more than the fiber content. Composites reinforced with polypropylene fibers presented higher values of MOR, TFT and EF compared to composites reinforced with curauá fiber. After 200 ageing cycles, the mechanical results of composites reinforced with curauá fibers decreased due to mineralization of the fibers. The nanoindentation results, as hardness and elastic modulus, increased after 200 cycles. The methodologies used to assess the rheological and mechanical behavior of fibercement during extrusion facilitate future transfer of this technology to the productive sector, with potentially higher quality products.

Keywords: fiber length. Rheology. Mechanical performance. Microstructural characterization. Composites cementitious. 


\section{SUMÁRIO}

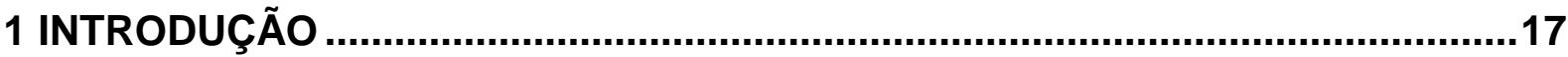

1.1 Originalidade e justificativa do tema................................................. 18

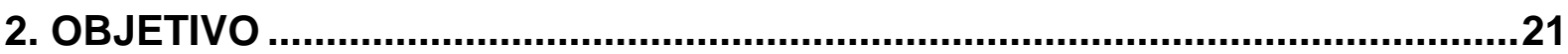

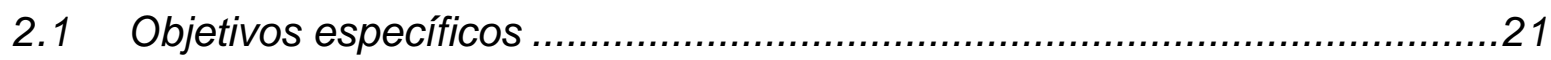

3 REVISÃO BIBLIOGRÁFICA ..................................................................23

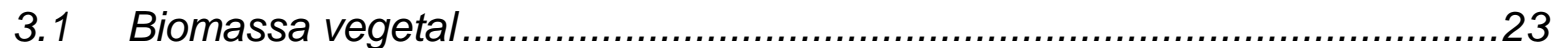

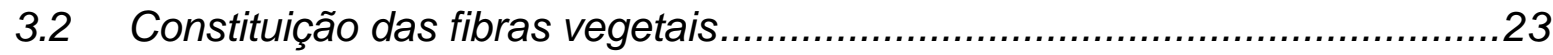

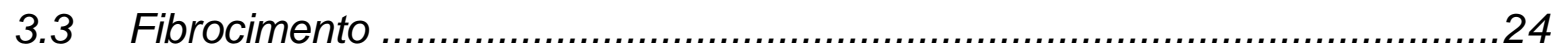

3.4 Utilização de fibras vegetais em fibrocimento ......................................25

3.5 Fibras vegetais utilizadas como reforço ...........................................26

3.5.1 Fibra de curauá ........................................................................ 26

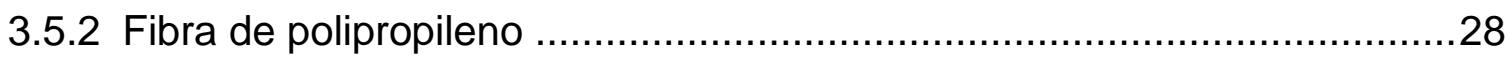

3.6 Processo de produção por extrusão .....................................................29

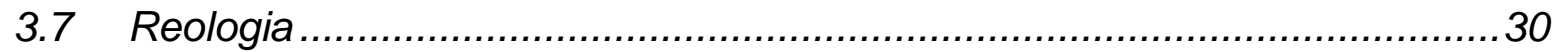

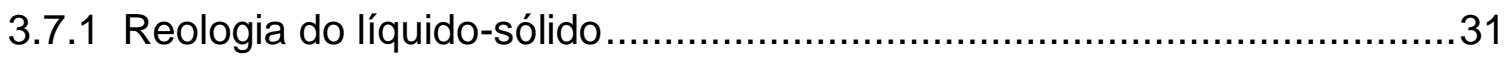

3.7.2 Reologia de misturas para extrusão .............................................. 32

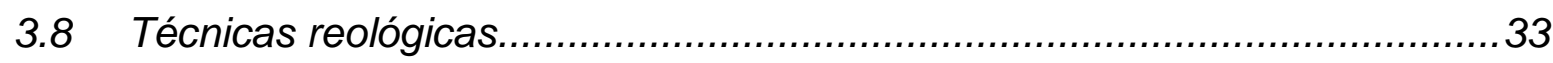

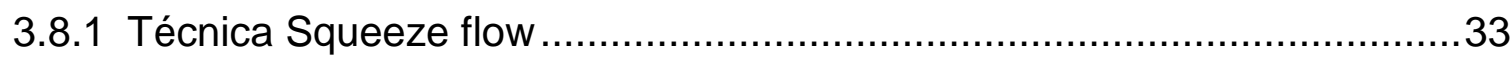

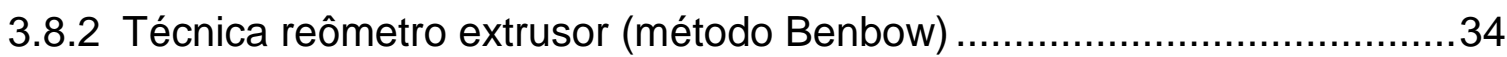

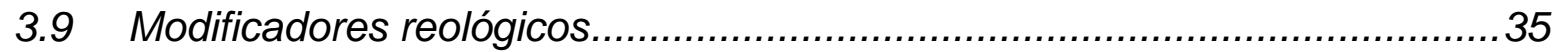

3.9.1 Aditivos orgânicos (hidroxipropilmetilcelulose)....................................35

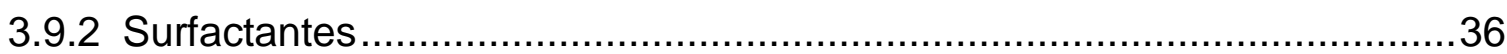

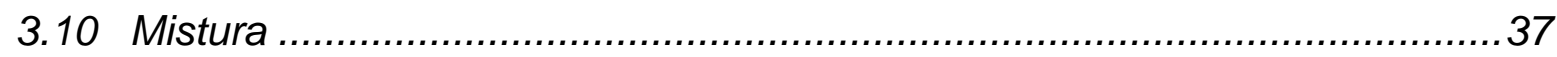

3.11 Mecanismos de tenacificação proporcionados pelas fibras .........................37

3.12 Cimento Portland e principais forças de adesão entre as fases do compósito 39

3.13 Durabilidade dos compósitos .............................................................. 41

3.14 Comentários finais sobre a revisão bibliográfica ......................................43

4 MATERIAIS E MÉTODOS.............................................................................45

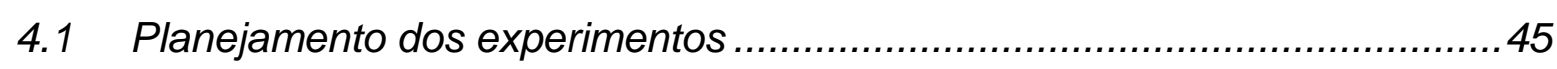

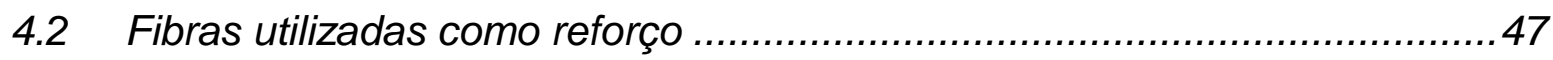

4.2.1 Fibras de processo (polpa celulósica) ............................................48

4.2.2 Procedimentos de preparação das fibras ..............................................48 
4.3 Formulação e preparação das matérias-primas ...................................... 49

4.4 Modificadores reológicos .......................................................... 51

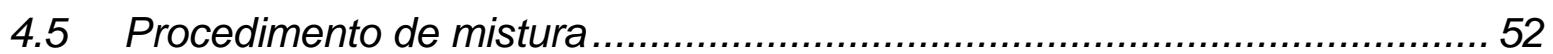

4.6 Técnica Squeeze flow.................................................................. 54

4.7 Técnica do reômetro extrusor (método Benbow) ..................................... 55

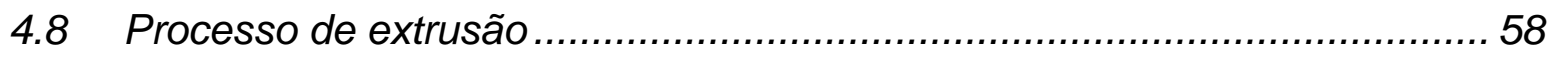

4.8.1 Características da extrusora ....................................................... 59

4.9 Envelhecimento acelerado ......................................................... 60

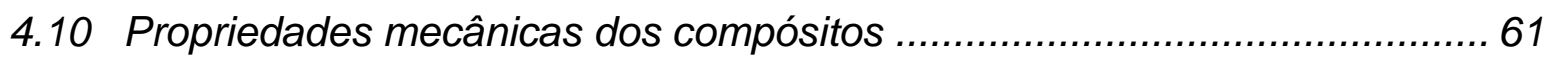

4.10.1 Módulo de ruptura $(M O R)$..................................................... 61

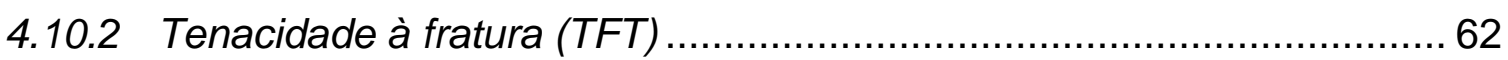

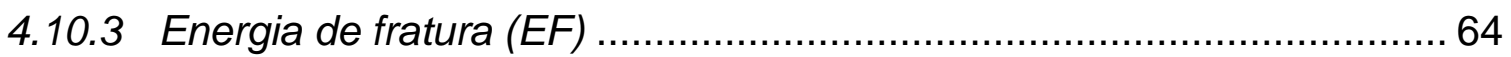

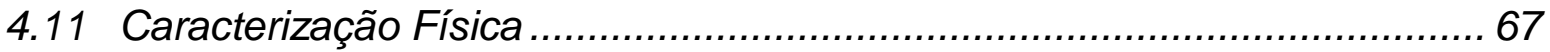

4.12 Caracterização microstrutural ........................................................... 68

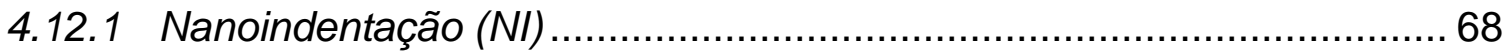

4.12.2 Microscopia eletrônica de varredura (MEV) ...................................... 69

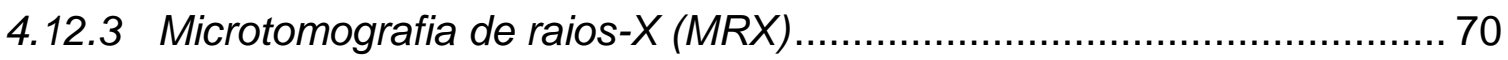

4.13 Analise estatística......................................................................... 70

5 RESULTADOS E DISCUSSÕES................................................................ 75

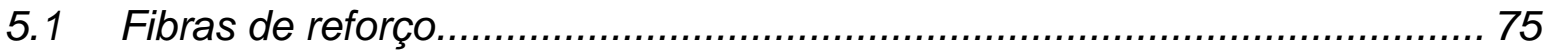

5.2 Resultado reológico da pasta cimentícia ............................................. 78

5.2.1 Técnica Squeeze flow ............................................................... 78

5.2.2 Técnica reômetro extrusor .............................................................. 80

5.3 Resultados mecânicos e físicos.......................................................... 89

5.4 Resultados microestruturais ....................................................... 112

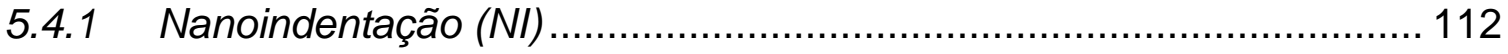

5.4.2 Microscopia eletrônica de varredura (MEV) ..................................... 121

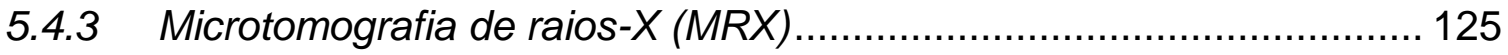

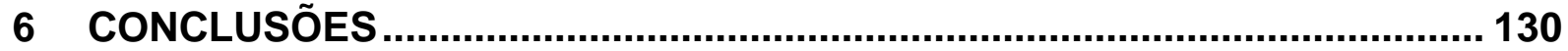

6.1 Sugestões para trabalhos futuros ............................................... 132

7 REFERÊNCIAS BIBLIOGRÁFICAS ............................................................ 133 


\section{INTRODUÇÃO}

O emprego de compósitos na construção civil, como os de matriz cimentícia e pasta reforçada com fibras, tem se disseminado consideravelmente nos últimos anos. Produtos de fibrocimento têm sido amplamente utilizados no mundo dada sua versatilidade como cobertura plana e ondulada, painéis de revestimento e forros (IKAl et al., 2010). A principal razão para a incorporação de fibras na matriz cimentícia é melhorar tenacidade, resistência à tração e características de deformação à fratura resultante do compósito. Fibras sintéticas, tais como álcool polivinílico (PVA) e polipropileno (PP), promovem melhor desempenho na ductilidade pós-fissura, sob fadiga, na resistência ao impacto e ajudam a retardar o início da fratura (BALAGURU, 1994; COUTTS, 1987; HANNANT, 1983; MINDESS, 1993).

Nos últimos anos têm surgido novas tecnologias que permitem o uso de materiais com menor impacto ambiental, alternativos para o desenvolvimento e aplicação de produtos de baixo custo e baixo consumo de energia, permitindo substituir as fibras sintéticas. Além disso, os custos de produção de fibras sintéticas são cerca de $40 \%$ mais do que o custo de produção de fibrocimento (TONOLI et al., 2010; SAVASTANO JR.; WARDEN; COUTTS, 2000).

Fibras vegetais como reforço em compósitos cimentícios têm motivado pesquisas nos países em desenvolvimento devido ao baixo custo, disponibilidade, renovabilidade e economia de energia (TEIXEIRA et al., 2012). A incorporação de fibras vegetais, principalmente resíduos de agricultura e agroindústrias, permite valorizar estes resíduos e diminuir danos ambientais (SANTOS et al., 2014). Entre as fibras vegetais, a fibra de curauá é uma boa alternativa para a substituição de fibras sintéticas (PICANÇO e GHAVAMI, 2008).

A fibra de curauá, planta nativa da Amazônia, da família das bromeliáceas, é a única fibra vegetal com propriedades mecânicas comparáveis às fibras de polipropileno (ARAÚJO; PERLAZA; MOTHÉ, 2002; SPINACÉ et al., 2009). Além disso, o Brasil tem um extenso território arável com uma das maiores biomassas do mundo, potencial que deve ser mais bem explorado. De acordo com Da Silva et al., (2008), fibras de curauá ainda apresentam a vantagem da reciclagem, enquanto o destino final da fibra sintética é o aterro sanitário.

Este processo permite o uso de uma variedade de materiais que tem sido incorporados com sucesso, como a fibra vegetal, incluindo, fibras de cana-de-açúcar 
(TEIXEIRA et al., 2012) e fibras de sisal (SANTOS et al., 2015). A vantagem de extrusão é que é um método econômico de produção em massa capaz de produzir não apenas formas planas, mas também formas estruturais e vazadas como tijolos.

\subsection{Originalidade e justificativa do tema}

A originalidade do trabalho pode ser considerada sob três aspectos principais. O primeiro deles se refere à utilização de duas técnicas reológicas para estudar 0 comportamento das fibras vegetais e sintéticas no fluxo da mistura durante a extrusão dos materiais. O segundo ponto é a utilização de fibras de curauá em matrizes cimentícias extrudadas. O terceiro ponto é a utilização diferentes teores e comprimentos de fibras de curauá em compósitos cimentícios extrudados.

Justifica-se o uso de fibras em matrizes cimentícias com o intuito de minimizar os efeitos da retração, principalmente, no que diz respeito à fissuração. De acordo com Bentur e Mindess, (2007), a diminuição da fissuração devido à incorporação de fibras pode ter um efeito sobre a durabilidade de estruturas de concreto armado, reduzindo o ingresso de agentes agressivos (umidade, oxigênio e cloretos) e diminuindo a probabilidade de ocorrência de corrosão de armaduras. Além disso, a ausência de fissuras torna o revestimento de argamassa menos permeável à penetração de chuva em fachadas, reduzindo, desta forma, os problemas causados pela umidade nas edificações.

A fibra vegetal aparece como alternativa de reforço de baixo custo, tendo em vista sua ocorrência natural e em larga escala, principalmente em países em desenvolvimento e com alto déficit de habitações. Fibras de curauá têm sido usualmente pesquisadas em temas ligados à confecção de peças decorativas e à indústria automobilística, em compósitos com resinas poliméricas. A ocorrência da planta de curauá na região norte do Brasil, sua facilidade de reprodução, e as ainda incipientes pesquisas de sua influência no desempenho de materiais à base de cimento, justificam a proposta de utilização da fibra nas pesquisas.

A fibra de polipropileno já foi bastante estudada e é utilizada com frequência em obras da construção civil, adicionada às argamassas e concretos. Pelo fato de sofrerem pouca ou nenhuma degradação em meio alcalino (RODRIGUES e MONTARDO, 2002), os compósitos com fibras de polipropileno foram selecionados 
para esta pesquisa, podendo servir de parâmetro de comparação para o desempenho de compósitos cimentícios reforçados com as de curauá. 


\section{OBJETIVO}

O objetivo deste presente projeto foi avaliar os parâmetros reológicos por meio dos métodos de Benbow e Squeeze flow e sua influência sobre o desempenho de fibrocimento extrudados, tanto nas primeiras idades como após o efeito de ciclos de envelhecimento acelerado.

\subsection{Objetivos específicos}

Os objetivos específicos são:

- Avaliação do comportamento reológico das formulações de fibrocimento com o ajuda de dois tipos de técnicas: Squeeze flow e reômetro extrusor (método de Benbow);

- Estudo do reforço comparativo das fibras de curauá e polipropileno com $6 \mathrm{~mm}$ e $10 \mathrm{~mm}$ de comprimento;

- Desempenho físico, mecânico e microestrutural dos compósitos extrudados nas primeiras idades e após os ensaios de durabilidade. 


\section{REVISÃO BIBLIOGRÁFICA}

\subsection{Biomassa vegetal}

A biomassa vegetal é fonte inesgotável de recursos naturais, renováveis e disponíveis, apresentando-se na forma de resíduos industriais (serragem, maravalhas, cavacos e talos de frutas), agroindustriais (bagaço de cana-de-açúcar, casca e palha de cereais), ou partículas obtidas no meio rural por meio da desintegração mecânica do colmo, como é o caso do bambu (SOROUSHIAN et al., 1994).

De acordo com Ramos (2001), os resíduos agroflorestais, subprodutos decorrentes dos desdobros primário e secundário da exploração da madeira, e os resíduos agrícolas, materiais oriundos de atividades associadas ao ciclo produtivo de culturas como a cana-de-açúcar e o arroz, entre outros, podem ser parcialmente utilizados como fonte de energia. A geração e o acúmulo de resíduos não só representam um sério problema econômico, como um problema ambiental de grandes proporções. De modo aproximado, estima-se que, no Brasil, sejam gerados anualmente cerca de 2,2 milhões de toneladas de casca de arroz, 23 milhões de toneladas de resíduos florestais (serrarias) e mais de 60 milhões de toneladas de bagaço de cana-de-açúcar, com teor de umidade variado. Contudo, nem todo este resíduo, somado aos derivados de outras atividades agroindustriais, tem sido desperdiçado. O setor agrícola já utiliza boa parte destes materiais para a produção de energia sob a forma de vapor. No entanto, o percentual não utilizado ainda representa um problema socioeconômico complexo, agravado pela heterogeneidade destes materiais de natureza lignocelulósica (RAMOS, 2001).

\subsection{Constituição das fibras vegetais}

As células vegetais apresentam parede celular formada por microfibrilas de celulose, imersas em uma matriz contendo polissacarídeos não celulósicos, os hemicelulósicos e as pectinas (Figura 1). A microfibrila de celulose tem diâmetro entre de 10 a $25 \mathrm{~nm}$, o que corresponde a até 100 moléculas que se unem por meio de pontes de hidrogênio, e mostra um arranjo ordenado, responsável por sua cristalinidade e birrefringência. A lignina é uma macromolécula tridimensional 
amorfa, associada à celulose na parede celular e cuja função é de conferir rigidez, impermeabilidade e resistência (KRAUS et al., 2006).

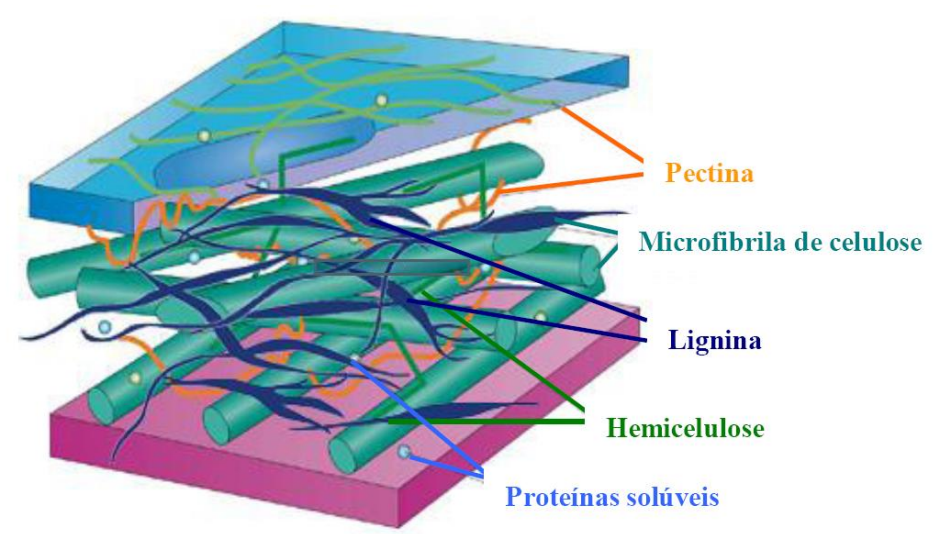

Figura 1 - llustração do modelo de parede celular com complexo lignocelulósico (STICKLEN, 2008).

\subsection{Fibrocimento}

A fabricação de produtos de fibrocimento em escala industrial é realizada principalmente pelo processo Hatschek (SAVASTANO JR. e SANTOS, 2007). Quase $85 \%$ dos produtos de fibrocimento vendidos no mundo são produzidos pelo processo Hatschek (IKAl et al., 2010). Diversas pesquisas têm sido executadas com o objetivo de encontrar fibras alternativas, como as vegetais, em substituição ao amianto em produtos de fibrocimento (SAVASTANO JR.; WARDEN; COUTTS, 2000).

A composição do fibrocimento vem sofrendo constantes mudanças pela incorporação de novos aditivos químicos e adições minerais, diferentes fibras e cimentos com novas características (BEZERRA et al., 2006). Essas mudanças são necessárias para atender a outros processos de produção, como por exemplo, o de extrusão.

Com o uso considerável de fibrocimentos nas placas e nas coberturas das habitações, das instalações agrícolas e industriais (entre 40 e $50 \%$ do total), buscam-se cada vez mais novos processos de fabricação e o aprimoramento de uma alternativa durável, sustentável e tecnicamente compatível com esse mercado consumidor (SANTOS et al., 2011). 


\subsection{Utilização de fibras vegetais em fibrocimento}

Normalmente, o concreto contém numerosas fissuras. Sua rápida propagação sob tensão é consequência da baixa resistência à tração do material. De início, considerou-se que a resistência do concreto à tração na flexão podia ser aumentada pela introdução de fibras próximas umas das outras, as quais poderiam obstruir a propagação de microfissuras. Com isso, seria retardado o início das fissuras e aumentada a resistência à tração do material. Estudos experimentais, porém, mostraram que determinadas argamassas ou concretos convencionais reforçados com fibras não proporcionam aumento substancial na resistência mecânica, em comparação às correspondentes misturas sem fibras. Entretanto, pesquisadores obtiveram considerável melhora na energia específica, criando possibilidade de trabalho no estágio pós-fissurado (Figura 2) e conferindo isolamento termo acústico aceitável (AGOPYAN e SAVASTANO JR, 1997). Fica claro que o advento do reforço com fibras aumenta a versatilidade da argamassa, propiciando um método efetivo para superar suas características de fragilidade (MEHTA e MONTEIRO, 1994).

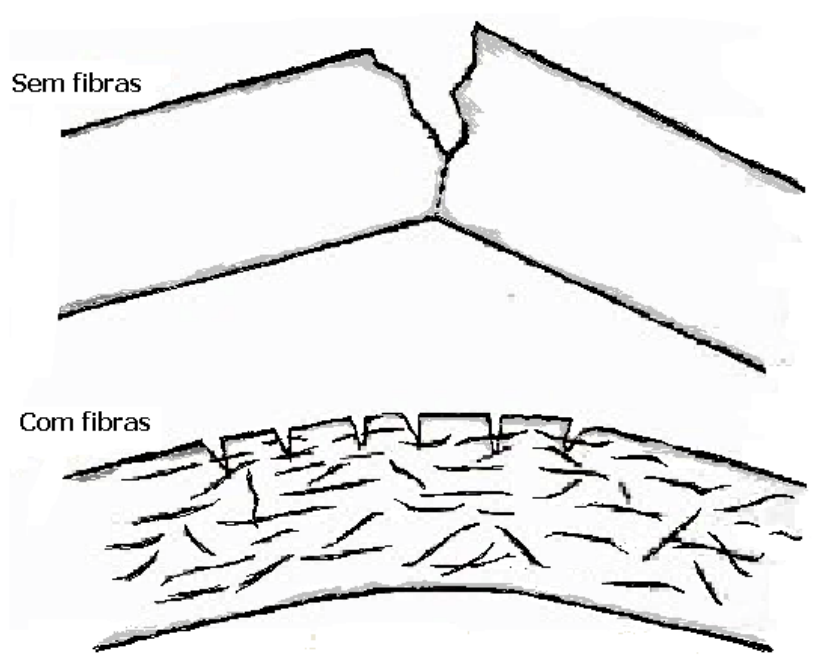

Figura 2 - Representação esquemática do comportamento à flexão de um compósito sem fibras e um reforçado com fibras (MEHTA e MONTEIRO, 1994).

Mangat e Azari (1988) e Balaguru e Shah, (1992) ressaltaram o reforço de matrizes à base de cimento com fibras para combater a retração plástica por secagem. 
Esta ocorre nas primeiras horas após a moldagem, em razão da evaporação diferenciada, ao longo do produto, da água usada na produção. Efeitos desse tipo de retração são mais evidentes em componentes com grandes áreas de exposição.

Compósitos de fibrocimento apresentam valores mais elevados para energia específica, ductilidade, capacidade de flexão e resistência à fratura ao serem comparados a materiais não fibro-reforçados. Fibras vegetais são o único material de reforço que oferece vantagens como não toxicidade, renovabilidade $e$ disponibilidade a relativamente baixo custo (MACVICAR; MATUANA; BALATINECZ, 1999).

\subsection{Fibras vegetais utilizadas como reforço}

\subsubsection{Fibra de curauá}

O curauá (Ananas erectifolius) é uma bromeliaceae, planta não lenhosa (nãomadeiravél), de origem amazônica. É fonte de fibra longa, leve, clara e flexível, extraída das folhas, podendo atingir comprimentos de 1-1,5 $\mathrm{m}$. Essa planta é muito conhecida e tradicionalmente usada para confecção de cordas e redes de pesca (SPINACÉ et al., 2009).

Atualmente o curauá possui plantios comerciais localizados na região oeste do estado do Pará, cerca 3 mil ha e produção de 5 mil t de fibra/ano, destinados à indústria automobilística. A produção brasileira é de cerca de 8 t/ano (PEMATEC, 2013). Destaca-se pelo potencial de utilização em compósitos, devido a suas características físico-mecânicas e atua como substituta às fibras tradicionais usadas na confecção de freios e peças de plástico da indústria automobilística (ZAH et al., 2007; EMBRAPA, 2007). A Tabela 1 mostra valores de propriedades físicas e mecânicas de diferentes tipos de fibras. 
Tabela 1 - Valores de densidade e propriedades mecânicas de algumas fibras naturais e sintéticas (SPINACÉ et al., 2009; SATYANARAYANA; GUIMARÃES; WYPYCH, 2007)

\begin{tabular}{lcccc}
\hline Fibra & $\begin{array}{c}\text { Densidade } \\
\left(\mathrm{g} / \mathrm{cm}^{3}\right)\end{array}$ & $\begin{array}{c}\text { Alongamento } \\
(\%)\end{array}$ & $\begin{array}{c}\text { Resistência a } \\
\text { tração }(\mathrm{MPa})\end{array}$ & $\begin{array}{c}\text { Módulo de } \\
\text { Young (GPa) }\end{array}$ \\
\hline Juta & 1,3 & $1,5-1,8$ & $393-773$ & 26,5 \\
Sisal & 1,5 & $2,0-2,5$ & $511-635$ & $9,4-22$ \\
Fibra de coco & 1,2 & 30 & 175 & $4,0-6,0$ \\
Curauá & 1,4 & 4,2 & $1250-3000$ & $30-80$ \\
Polipropileno & 0,98 & 600 & $400-550$ & 6,0 \\
\hline
\end{tabular}

A fibra de curauá apresenta-se com alta resistência comparada as fibras de coco, sisal e juta; e propriedades físicas compatíveis às fibras de linho e vidro (ZAH et al., 2007). As propriedades mecânicas são semelhantes às das fibras de polipropileno (PP), normalmente aplicado para o reforço de compósitos à base de cimento (SPINACÉ et al., 2009). O módulo de elasticidade específica em relação à densidade é considerado melhor do que em outras fibras, ocasionando redução de até $15 \%$ de peso em compósitos de matriz polimérica e fibra de curauá (LEÃO; ROWELL; TAVARES, 1998). Além disso, sua resistência à tração é de 3 vezes maior do que a de sisal e juta (SATYANARAYANA; GUIMARÃES; WYPYCH, 2007).

Estudos de caracterização de compósitos com fibra de curauá em diversos tipos de matriz polimérica são abundantes. Boa parte desse interesse pela fibra é decorrente do seu bom desempenho e por ter aplicabilidade na indústria automobilística como reforço de termoplásticos, utilizados no acabamento interno de veículos (ZAH et al., 2007).

Pesquisas com compósitos de matriz cimentícia com fibras de curauá são escassas. D'Almeida et. al., (2010) produziram dois trabalhos sobre fibrocimento reforçado com curauá e não se tem referência, na literatura, de outros autores que exploraram essa espécie de compósito.

D'Almeida et. al., (2009) foram os primeiros a pesquisar fibrocimento com curauá. Avaliaram o efeito da pressão na moldagem ( 0 e $3 \mathrm{MPa}$ ) analisando as propriedades mecânicas de compósitos com $6 \%$ de reforço de fibras de curauá (39 $\mathrm{mm}$ de comprimento), disposto em 5 camadas imersas em matriz cimentícia com adição de $50 \%$ de metacaulim (para impedir a mineralização das fibras). Houve uma 
pequena redução da resistência mecânica quando os compósitos foram prensados a $3 \mathrm{MPa}$, entretanto o trabalho posterior D'Almeida; Toledo Filho; Melo Filho (2010), consistiu na avaliação do percentual (2, 4 e 6 \%) e dimensão das fibras (25 mm e 50 $\mathrm{mm}$ ) em matriz cimentícia com adição pozolânica de 50\% de metacaulim (para minimizar $\mathrm{o}$ ataque alcalino a fibras e melhorar propriedades de dureza e resistência). As propriedades mecânicas apontaram que o compósito com $4 \%$ de reforço e $50 \mathrm{~mm}$ de comprimento apresentaram melhor desempenho.

Perante as características mecânicas das fibras e a experiência de outras fibras naturais e sintéticas tradicionalmente pesquisadas para uso em fibrocimento (fibras de eucalipto e pinus, fibras de sisal, juta e polipropileno), a fibra de curauá certamente apresenta potencial para tal aplicação, porém requer maior número de pesquisas com fibrocimento de curauá para otimizar a aplicação desse material.

\subsubsection{Fibra de polipropileno}

O desenvolvimento de polímeros no último século foi possível graças ao crescimento da indústria do petróleo. Desde 1930, o petróleo tem sido a maior fonte de matéria-prima para a fabricação de produtos químicos orgânicos, como plásticos, fibras, borracha e adesivos (RODRIGUES e MONTARDO, 2002). Em 1966, a "Shell" desenvolveu e patenteou o processo de fabricação de fibras de polipropileno para utilização em concreto. Conhecido como "Caricrete", o material foi caracterizado por permitir adição máxima de fibra de 1\% em volume (TANESI e FIGUEIREDO, 1999).

As fibras de polipropileno apresentam-se como uma malha de finos filamentos de seção circular, a qual promove aumento da adesão entre fibra e matriz, devido a um efeito de intertravamento. Entre os requisitos para as fibras de polipropileno, citam-se: boa compatibilidade com o cimento, alta resistência mecânica, habilidade de reter os grãos da matriz inorgânica durante processo, disponibilidade para o mercado consumidor e custo compatível. Adicionalmente, alta tenacidade, alto módulo de ruptura e reduzido alongamento até ruptura são considerados os atributos chave para as fibras alternativas (IKAl et al., 2010).

Fibras de polipropileno são exemplos de fibras sintéticas usadas em larga escala na indústria para fibrocimentos curados ao ar. Entretanto, é uma preocupação para as indústrias de fibrocimento a disponibilidade dessas fibras no mercado para a atual 
demanda e seu alto custo que pode tornar impraticável a produção do fibrocimento de baixo custo. Reduzir o conteúdo de fibras sintéticas é uma forma efetiva de diminuir os custos de produção de fibrocimentos curados ao ar (DIAS; SAVASTANO JR.; JOHN, 2010).

\subsection{Processo de produção por extrusão}

Estudos recentes apresentam o processo de extrusão como alternativa econômica de manufatura para produzir elementos construtivos com características mecânicas e físicas semelhantes, ou superiores, aos oriundos do processo Hatschek (SHAO; MARIKUNTE; SHAH, 1995; SHAO et al., 2000; SRINIVASAN; DEFORD; SHAH, 1999; SHAO e SHAH, 1997; QIAN et al., 2003; TAKASHIMA et al., 2003).

Segundo Horst, (2002), as extrusoras utilizadas na indústria de cerâmica são adaptáveis para o processo de extrusão de materiais de fibrocimento. Assim, assume-se que o investimento para implantar uma linha de produção de fibrocimento por extrusão seja próximo ao de uma linha de materiais cerâmicos, com capacidade de produção instalada semelhante.

Os altos custos de implantação e a grande capacidade de produção de uma linha de processo Hatschek fazem com que as plantas industriais sejam instaladas próximas a mercados capazes de amortizar os altos investimentos e de absorver esta capacidade de produção. Isto pode ser observado na distribuição das plantas industriais no território nacional. Observa-se que elas estão próximas ou dentro de uma região de alta densidade demográfica. Essa distribuição estratégica das fábricas faz com que regiões de baixa densidade não possam desfrutar em plenitude as vantagens de um produto barato, por conta da logística necessária para disponibilizá-lo (SOTO, 2010).

Assim, o setor do fibrocimento encontra-se, segundo as cinco forças competitivas de Porter (1998), protegido de novos competidores devido aos altos custos de implantação de uma linha de produção baseada no processo Hatschek, reduzindo o número de fornecedores de produtos de fibrocimento num mercado de alta demanda. Observa-se isso também no mercado nacional, atendido por apenas treze plantas industriais de fibrocimento. Como faltam opções para o consumidor, essa situação leva a melhores rendimentos aos fornecedores (SOTO, 2010). 
Implantar o processo de extrusão de materiais de fibrocimento no setor produtivo permitirá a instalação de fábricas em regiões de baixa densidade demográfica, pois o custo da linha de produção é relativamente baixo. Além disso, o processo de extrusão possibilita a flexibilidade de adequar essa linha de produção com objetivo de atender os pequenos mercados. Como efeito, a barreira de altos investimentos para a implantação da indústria de fibrocimento seria quebrada com a viabilização do processo de extrusão, permitindo o surgimento de novos fornecedores no mercado, tornando-o mais competitivo. Tal panorama beneficiaria os consumidores em função da competição mais acirrada, com produtos melhores e diversificados (SOTO, 2010).

Adicionalmente, tal cenário aumenta a probabilidade de uso de matérias-primas alternativas, tais como resíduos do setor produtivo primário ou secundário, com 0 objetivo de minimizar seus custos.

Nesse contexto, observa-se que a implantação do processo de extrusão de compósitos de fibrocimento em países em desenvolvimento, como o Brasil, pode gerar benefícios sociais, econômicos e ambientais (PORTER, 1998).

\subsection{Reologia}

A reologia dedica-se ao estudo da deformação e do fluxo da matéria. Existem dois aspectos fundamentais na reologia para descrever um material, a tensão de escoamento promovido pela tensão de cisalhamento e pela viscosidade (GLATTHOR e SCHWEIZER, 1994). A tensão de escoamento inicial é a tensão necessária para iniciar o escoamento, porém nem todos os materiais têm tensão de escoamento, como por exemplo, a água. A viscosidade é a resistência apresentada pelo material opondo-se ao movimento do sistema.

A avaliação do comportamento reológico do material é realizada por meio de reômetros, equipamentos especialmente desenvolvidos para leituras da tensão de cisalhamento resultante para obter a tensão de escoamento inicial e a viscosidade (PILEGGI, 2001).

A aplicação dos conceitos reológicos em pastas é de fundamental importância para possibilitar moldagem fácil e isenta de defeitos, minimizar a ocorrência de 
fissuras, descolamento e manchas, que podem ser decorrentes do comportamento reológico inadequado para a aplicação (CARDOSO; PILEGGI; JOHN, 2005).

$\mathrm{O}$ sucesso da extrudabilidade de materiais à base de cimento requer controle dos parâmetros de processo e reológicos (KUDER e SHAH, 2010). Os parâmetros que controlam a reologia de uma pasta de cimento podem ser classificados em dois grupos: químicos e físicos. Estes impõem significativa influência na reologia na mistura cimentícia: a densidade de empacotamento; a área superficial das matériasprimas, assim como a configuração geométrica final dos materiais cimentícios.

\subsubsection{Reologia do líquido-sólido}

O comportamento reológico de uma combinação líquido-sólido é muito diferente daquele para uma fase líquida isolada. A adição de partículas a um líquido newtoniano resulta em uma mistura que exibe comportamento não newtoniano. Barnes; Hutton; Walters, (1989) discutem a forma geral da curva viscosidade em função da taxa de cisalhamento para uma suspensão concentrada e apresentam a curva mostrada na Figura 3.

Em baixas taxas de cisalhamento, a curva apresenta o patamar A com comportamento newtoniano, seguido por um comportamento pseudoplástico na região $B$, continuando em um segundo patamar newtoniano C. O comportamento pseudoplástico é associado ao desenvolvimento de uma microestrutura durante o fluxo, o qual facilita a deformação. Uma vez atingida taxa de cisalhamento elevada, a estrutura é destruída e ocorre um comportamento de espessamento abrupto com o cisalhamento (dilatância), como observado na parte D da curva. Esse comportamento reológico tem recebido bastante atenção em estudos teóricos e experimentais. 


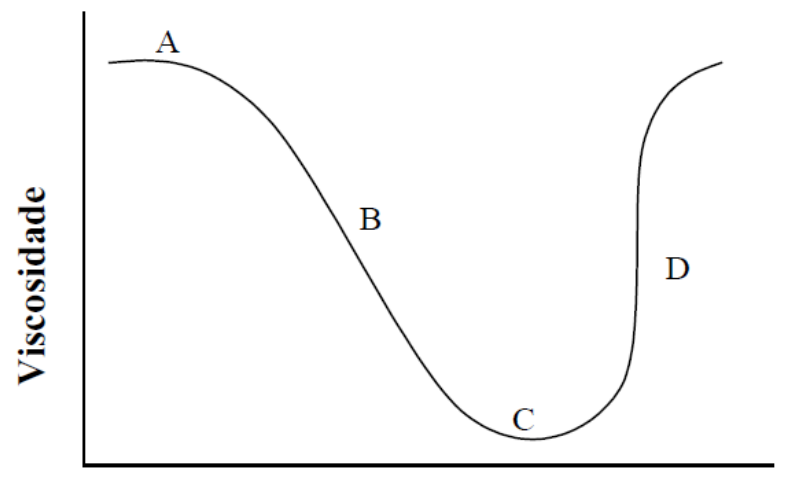

Taxa de cisalhamento

Figura 3 - Representação esquemática da relação viscosidade em função da taxa de cisalhamento de uma suspensão concentrada. (patamar A representa comportamento newtoniano, seguido por um comportamento pseudoplástico na região $\mathrm{B}$, continuando em um segundo patamar newtoniano C. Cisalhamento (dilatância), como observado na parte D da curva. (BARNES; HUTTON; WALTERS, 1989).

\subsubsection{Reologia de misturas para extrusão}

O comportamento pseudoplástico de mistura cimentícia é extremamente relevante para permitir sua extrudabilidade. Para tanto, é necessário utilizar aditivos auxiliares de processo para garantir esse comportamento reológico, além de permitir a hidratação do cimento, devido à necessidade de se utilizarem baixas quantidades de água, evitando a migração de fase (SHAO; MARIKUNTE; SHAH, 1995).

A reologia de uma mistura cimentícia para a extrusão composta de fase líquida (contínua), fase particulada (sólida) e a fase de reforço (fibra) depende fortemente da morfologia, da distribuição granulométrica, das características químicas, da área superficial, da fração de volume, do fator de empacotamento da fase particulada, além do comportamento reológico da fase líquida, assim como o grau de homogeneidade da mistura (BLACKBURN; LAWSON, 1992).

As fibras se apresentam principalmente como um obstáculo ao movimento das outras duas fases. No entanto, se no processo de extrusão elas ficarem alinhadas na direção do fluxo da pasta, atrapalharão menos o movimento dos particulados (SRINIVASAN; DEFORD; SHAH, 1999).

A água influencia o fluxo da pasta cimentícia no processo de extrusão, pois molha as superfícies dos particulados, reage quimicamente com o cimento, modifica o comportamento reológico por causa da presença de modificadores reológicos na 
mistura (SRINIVASAN; DEFORD; SHAH, 1999). Além disso, o comportamento reológico de materiais à base de cimento é complexo devido aos diferentes tipos de formulações (argamassas, fibrocimentos), condições de misturas (velocidade, tempo e confinamento) e aplicações (extrusão, por exemplo) (BETIOLI et al., 2009).

Em uma formulação inadequada para a extrusão, ao ser submetida às tensões tangenciais e normais, pode ocorrer o fenômeno da migração de fase, no qual a fase líquida da mistura chega a se separar da fase sólida, ou seja, a homogeneidade da mistura é prejudicada. Dessa forma, um misturador se torna necessário para misturar as matérias-primas, pois esse evento é extremamente importante para o processo de extrusão (CHEN et al., 2000). As propriedades do compósito estão diretamente relacionadas com sua forma de mistura que, por sua vez, influencia seu comportamento reológico. Com isso, é de conhecimento geral que a energia utilizada na máquina, a quantidade de água adicionada e o tempo de mistura são fatores que exercem grande influência nas propriedades do produto final (CARVALHO et al., 2004).

\subsection{Técnicas reológicas}

\subsubsection{Técnica Squeeze flow}

Squeeze flow é uma técnica amplamente utilizada para a caracterização dos mais diversos tipos de pastas incluindo alimentos, cosméticos, materiais cerâmicos e compósitos poliméricos (ÖZKAN et al., 1999). Estudo pioneiro em materiais de construção utilizando squeeze-flow para a caracterização de uma pasta de cimento para avaliar as alterações reológicas decorrentes da consolidação do ligante foi publicado por Min; Erwin; Jennings, (1994).

O princípio fundamental do método está baseado no fato que a deformação efetiva do material comprimido entre as placas ocorre por cisalhamento radial nos casos em que a razão entre o diâmetro e a espessura da amostra for elevada. Essa técnica possibilita a caracterização das misturas trazendo avanços no campo das formulações (CARDOSO; PILEGGl; JOHN, 2005). É um ensaio de fácil execução, que favorece a repetitividade e fornece resultados de carga em função do tempo e do deslocamento (CARDOSO; PILEGGl; JOHN, 2005). Na prática, essa técnica 
simula as condições de fluxo sofrido pela pasta de cimento entre os agregados finos e graúdos no interior de argamassas e concretos, por exemplo.

O ensaio de squeeze-flow pode gerar os parâmetros reológicos fundamentais, como viscosidade e tensão de escoamento.

Como a pasta de cimento ainda no estado fresco não possui tensão de escoamento suficiente, os testes de squeeze-flow foram realizados em amostras confinadas, conforme utilizado por Min; Erwin; Jennings, (1994), como mostra a Figura 4.

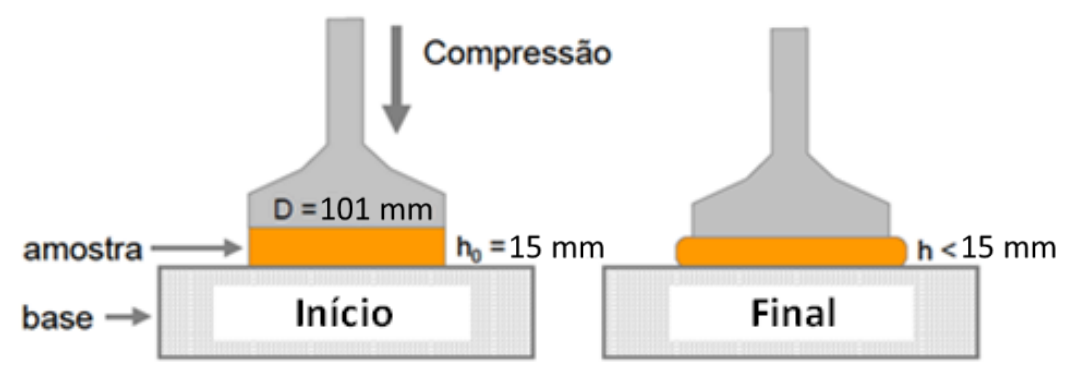

Figura 4 - Esquema do ensaio de Squeeze-flow: início e final (CARDOSO; PILEGGl; JOHN, 2005)

\subsubsection{Técnica reômetro extrusor (método Benbow)}

Benbow e Brigdwater (1993) propõem o método do reômetro extrusor com a finalidade de descrever o fluxo de pasta durante a extrusão. A pasta, nesse método, é avaliada utilizando um extrusor de pistão com diferentes comprimentos de boquilha que descreve o fluxo do material durante a extrusão.

A técnica do reômetro extrusor é capaz de caracterizar reologicamente as misturas de fibrocimento para a extrusão. A alta rigidez das pastas cimentícias não permite que estas sejam ensaiadas facilmente pelas técnicas reológicas convencionais (SRINIVASAN; DEFORD; SHAH, 1999). O reômetro extrusor consiste em um barril com diâmetro de 38,1 mm e comprimento de $150 \mathrm{~mm}$, com capacidade aproximada de $120 \mathrm{~mL}$. Este dispositivo de ensaio conta também com uma boquilha na parte frontal, conforme ilustra a Figura 5. 


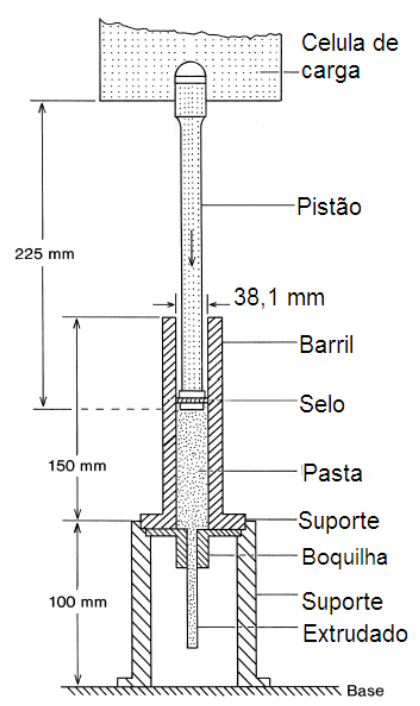

Figura 5 - Esquema do reômetro extrusor. Adaptado de Benbow e colaboradores (1991).

\subsection{Modificadores reológicos}

Braun e Rosen (1999) classificam os modificadores reológicos em orgânicos e inorgânicos, que podem ser reclassificados como plastificantes e surfactantes. Os orgânicos conseguem influenciar, fortemente, o comportamento reológico com pequenas quantidades e são os modificadores mais utilizados em compósito de fibrocimento. Entre os modificadores reológicos orgânicos, podem ser citados o hidroxipropilmetilcelulose, a carboximetilcelulose de sódio, a poliacrilamida, bem como os vários tipos de surfactantes. Entre os inorgânicos, podem ser mencionadas as argilas tais como metacaulim e bentonita, entre outros (KUDER e SHAH, 2010).

Shen (2003) e Soto (2010) mencionam a necessidade de pesquisas com a finalidade de encontrar modificadores reológicos de valor econômico inferior ao dos orgânicos, como os inorgânicos para a extrusão de fibrocimento, o que ajudaria a implantar o processo de extrusão em escala industrial.

\subsubsection{Aditivos orgânicos (hidroxipropilmetilcelulose)}

São plastificantes de alto desempenho e conhecidos, na área de materiais à base de cimento, como superplastificantes. A propriedade mais importante de um superplastificante é a habilidade de dispersar partículas de cimento. Devido à sua 
capacidade dispersiva, os dispersantes reduzem drasticamente a tensão de escoamento e a viscosidade da pasta de cimento. Para a dosagem significativa de superplastificante, a tensão de escoamento da pasta de cimento é reduzida próxima a zero e o comportamento do fluido se aproxima ao newtoniano (PETROU et al., 2000). Além de contribuir para a fluidez da pasta de cimento, os superplastificantes retardam a hidratação dessa pasta (AÏTCIN, 2000).

Muitos dos superplastificantes são polímeros lineares contendo grupos de ácidos sulfonados ligados à estrutura polimérica. Os melamina-formaldeídos sulfonados condensados e naftaleno-formaldeídos condensados são os mais comuns (PETROU et al., 2000). Dentre esses dispersantes, o hidroxipropilmetilcelulose (HPMC) tem apresentado a maior conformidade e é o mais utilizado na produção de extrudados de fibrocimento (SRINIVASAN; DEFORD; SHAH, 1999). O HPMC é um éter de celulose hidrossolúvel aniônico que apresenta grupos hidrofóbicos e hidrofílicos em sua longa estrutura, reduz a tensão superficial da água e a tensão interfacial de sistemas aquosos. O grau de hidratação do HPMC varia de acordo com suas características físico-químicas, como a massa molecular, o grau de substituição e a viscosidade (LOPES; LOBO; COSTA, 2005).

\subsubsection{Surfactantes}

Os surfactantes são aditivos que reduzem a tensão superficial da água e, assim, provocam, por meio de um aumento da área de superfície do líquido, a melhor absorção de água pela partícula, com melhor fixação da água, reduzindo o teor de água necessária. Formam uma camada de lubrificação entre a parede da extrusora e a superfície da placa de fibrocimento. Os surfactantes são agentes tensoativos, quer sejam aniônicos, catiônicos ou não-iônicos. Eles são subdivididos em catiônicos quaternários (grupos amino), aniônicos (sulfato, grupos carboxilato) e não iônicos (resíduos poliálcool, poliol, poliéter). A seleção do grupo funcional depende da carga de superfície da partícula (HÖLZGEN e QUIRMBACH, 2007). 


\subsection{Mistura}

Misturar é uma operação que visa à redução ou eliminação de heterogeneidades em um material composto por meio de ação mecânica, que também pode uniformizar a temperatura ou aumentar o rendimento de um processo.

As propriedades dos fibrocimentos estão diretamente relacionadas com a forma de mistura das matérias-primas e aditivos. É de conhecimento geral que a energia utilizada no amassamento, a quantidade de água adicionada e o tempo de mistura são fatores que exercem grande influência no produto final (CASALI et al., 2001). Numa mistura ideal, a massa deve estar isenta de aglomerados e todas as partículas envoltas em água; assim a mistura tende a exibir baixa viscosidade facilitando sua utilização (YANG e JENNINGS, 1995).

Uma massa homogênea pode ser obtida por um processo que forneça tensão suficiente para quebrar os aglomerados. Uma mistura homogênea é aquela em que a concentração em qualquer ponto selecionado aleatoriamente em uma amostra de qualquer tamanho é a mesma que a da concentração global. A variância de uma mistura perfeita tem um valor zero. Em misturas sólidas, a configuração do misturador, a velocidade da mistura, o tamanho da amostra, a área superficial da amostra, portanto, dependem tanto do misturador, quanto da configuração da amostra (WEINEKÖTTER e GERICKE, 2000).

\subsection{Mecanismos de tenacificação proporcionados pelas fibras}

Matriz sem reforço de fibras rompem repentinamente, com um comportamento frágil (Figura 6a), quando a deformação correspondente à resistência à tração na flexão for superada.

Por outro lado, um material reforçado com fibras continua a resistir a cargas consideráveis (Figura 6b), mesmo com deformações bastante superiores à deformação de fratura do compósito convencional (MEHTA e MONTEIRO, 1994), originando elevadas energias específicas (Figura 6c). 


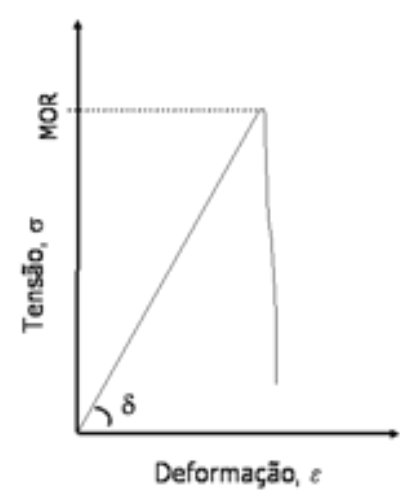

(a)

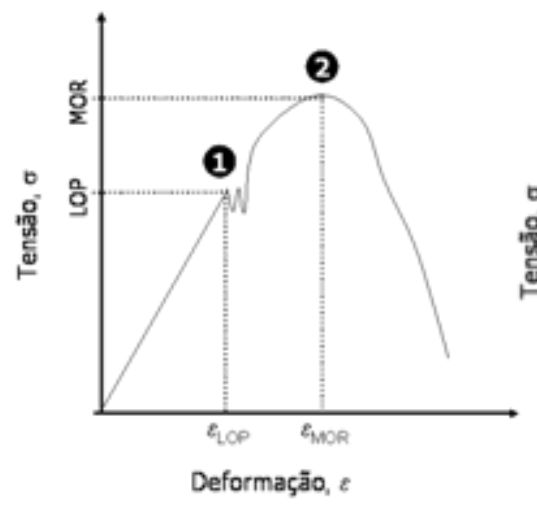

(b)

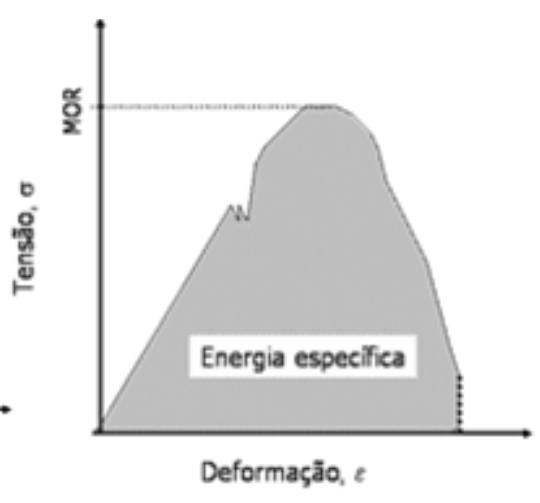

(c)

Figura 6 - Diagramas tensão $\mathrm{x}$ deformação de materiais cimentícios submetidos a ensaios de tração na flexão. (a) Comportamento frágil; (b) comportamento dúctil: 1 - limite de proporcionalidade e 2 - módulo de ruptura; e (c) área hachurada sob a curva indica a energia específica do material (MEHTA e MONTEIRO, 1994).

Durante o carregamento do material, a tensão necessária para o aparecimento da primeira fissura (final da fase elástica - Figura $6 \mathrm{~b}$ - ponto 1) costuma aumentar com a aderência e, ainda, com a relação comprimento/diâmetro e concentração de fibras (GRAY, 1984). O compósito suportará forças cada vez maiores, após o limite de proporcionalidade (LOP), se a resistência das fibras ao arrancamento na primeira fissura for maior do que a tensão na primeira fissuração, até que se atinja a tensão máxima (módulo de ruptura - Figura $6 \mathrm{~b}$ - ponto 2). Em uma seção fissurada, a matriz não resiste a nenhum esforço de tração e as fibras suportam todo o carregamento do compósito (após MOR). Com um aumento de força no compósito, as fibras tendem a transferir a tensão adicional para a matriz, por meio das tensões de aderência. Se estas não excedem a resistência de aderência, pode haver um descolamento fibra-matriz e fissurações adicionais na matriz (Figura 7 - pontos 1 e 2). Este processo de fissuração múltipla continuará até que haja o seu arrancamento (Figura 7 - ponto 3), devido à perda de aderência local acumulada. Caso contrário, a partir do momento em que o escorregamento da fibra é substituído pela sua ruptura (Figura 7 - ponto 4), ocorre a redução da ductilidade (SHAH, 1983). 


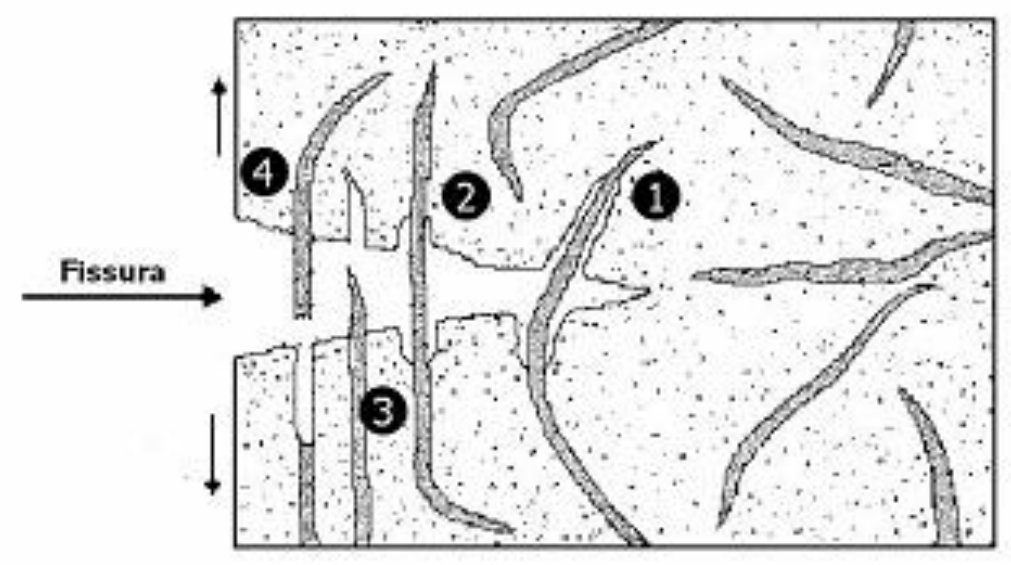

Figura 7 - Representação esquemática do caminhamento da fissura através da matriz reforçada com fibras: (1) e (2) descolamento da fibra; (3) arrancamento da fibra; (4) rompimento da fibra (COUTTS, 1988).

O tipo, a distribuição, a relação comprimento-diâmetro, a durabilidade da fibra, a umidade, assim como o seu grau de aderência com a matriz determinam o comportamento mecânico do compósito e o desempenho do componente fabricado (BARTOS, 1981; GRAY e JOHNSTON, 1987; BENTUR e MINDESS, 2007).

A energia específica é uma propriedade importante, pois evitaria a ruptura frágil durante $o$ transporte ou durante a instalação, em vista dos esforços dinâmicos envolvidos (AGOPYAN et al., 2005).

\subsection{Cimento Portland e principais forças de adesão entre as fases do compósito}

O cimento Portland é um aglomerante hidráulico constituído basicamente por silicatos e aluminatos de cálcio (TAYLOR, 1990). Logo que o grão de cimento anidro entra em contato com a água, inicia-se a dissolução dos íons $\mathrm{Ca}^{2+} \mathrm{e} \mathrm{Si}^{4+}$, oriundos dos principais componentes do cimento Portland: os silicatos tricálcico $\left(\mathrm{C}_{3} \mathrm{~S}\right)$ e bicálcico $\left(\mathrm{C}_{2} \mathrm{~S}\right)$, respectivamente, que juntos representam $75-80 \%$ do cimento Portland (RAMACHANDRAN, 1999). O mesmo ocorre a outro componente importante, o aluminato tricálcico $\left(\mathrm{C}_{3} \mathrm{~A}\right)$ que, por sua vez, contribui com os íons $\mathrm{Ca}^{2+}$ e $\mathrm{Al}(\mathrm{OH})_{4}^{-} \mathrm{em}$ solução. Com isso, formam-se os chamados embriões das fases hidratadas de silicatos e aluminatos de cálcio, produtos de hidratação do cimento, graças à diferença de solubilidades em relação à do grão ainda anidro (ROSSETTO, 2007). 
Para passarem à condição de núcleos estáveis, tais embriões precisam superar a chamada energia de ativação (Ea) conforme descrito por Rossetto (2007). De acordo com esse autor, isso representa uma redução na relação entre a área de superfície e o volume que satisfaça a redução da energia livre Gibbs. Mais detalhes sobre as teorias dos estágios iniciais de hidratação do cimento Portland se encontram nas referências (NAGELE, 1989; YANG; NEUBAUER; JENNINGS, 1998).

A hidratação prossegue até que a pressão osmótica do sistema não seja suficiente para romper a superfície dos grãos anidros. Na sequência, dois são os mecanismos responsáveis pela redução da energia livre de Gibbs: o crescimento das fases hidratadas e a densificação (ROSSETTO, 2007). A contínua disponibilidade de água favorece o crescimento dos hidratados de silicatos e aluminatos de cálcio, enquanto o maior empacotamento das partículas favorece a densificação. Em uma pasta de cimento hidratada, os produtos de hidratação formados são principalmente o silicato de cálcio hidratado (C-S-H), o hidróxido de cálcio $\left(\mathrm{Ca}(\mathrm{OH})_{2}\right)$, a etringita (fases $\mathrm{AFt}$ ), o monosulfato (fases $\mathrm{AFm}$ ) e possivelmente fases amorfas ricas em íons $\mathrm{Al}^{3+}$ e $\mathrm{SO}_{4}$ (TAYLOR, 1990).

Outro processo importante que ocorre pela difusão do $\mathrm{CO}_{2}$ presente na atmosfera através dos poros insaturados da matriz cimentícia é a carbonatação. Nela, $\mathrm{o} \mathrm{CO}_{2}$ sofre dissolução na fase aquosa presente nos poros, transformando-se em ácido carbônico $\left(\mathrm{H}_{2} \mathrm{CO}_{3}\right)$, que, por sua vez, sofre dissociação como íons $\mathrm{HCO}^{3-} \mathrm{e}$ $\mathrm{CO}^{3-}$, juntamente com a dissolução do $\mathrm{Ca}(\mathrm{OH})_{2}$ que libera íons $\mathrm{Ca}^{2+} \mathrm{e} \mathrm{OH}^{-}$, os quais precipitam e formam o carbonato de cálcio $\left(\mathrm{CaCO}_{3}\right)$. Um estudo paramétrico e aprofundado sobre a reação do $\mathrm{CO}_{2}$ em cada constituinte do cimento foi realizado por Peter et al., (2008). O Ca(OH)2 é o composto com maior grau de dissolubilidade e, portanto, o que reage mais rapidamente com $\mathrm{CO}_{2}$ para a formação do $\mathrm{CaCO}_{3}$ (PADE e GUIMARAES, 2007).

O processo de hidratação é responsável por reduzir a separação das superfícies cimentícias, pelo crescimento das fases hidratadas que confinam moléculas de água em nanocamadas ao redor dos grãos. Segundo Rossetto e colaboradores (2009), a configuração das superfícies hidratadas, em escala nanométrica, proporciona adesão ao material em função de pontos discretos de contato. De acordo com esses autores, a água confinada permite aderir duas superfícies que com ela possam realizar ligações hidrogênio. As ligações de 
hidrogênio são formadas quando a eletronegatividade do elemento covalente ao hidrogênio for suficiente para mantê-lo susceptível à interação com o outro elemento que disponibilize um par de elétrons não-conjugados (ROSSETTO; SOUZA; PANDOLFELLI, 2009). Portanto, a água, além de provocar a hidratação do cimento, também apresenta uma função importante na adesão das partículas hidratadas de cimento, pois esta é capaz de doar duas ligações hidrogênio e de aceitar outras duas (ROSSETTO, 2007; ROSSETTO; SOUZA; PANDOLFELLI, 2009).

Enquanto existe água disponível para a hidratação dos grãos anidros de cimento e a estabilidade entre a área superficial e o volume dos núcleos ou embriões não é atingida, os íons são dissociados e transportados por osmose para regiões onde a água dos poros está menos saturada. A formação e a precipitação dos núcleos ou embriões naturalmente aproximam as superfícies dos grãos adjacentes. A secagem ou o consumo da água dos poros da matriz cimentícia cessam o processo de dissolução dos íons dos componentes do cimento e, a partir daí a água confinada atua somente na adesão das fases cimentícias.

\subsection{Durabilidade dos compósitos}

Há evidências de que as fibras sofrem alterações no seu desempenho mecânico, em conjunto com a matriz, dependendo da idade do compósito e das condições de exposição. A degradação dos compósitos pode ser estudada por envelhecimento natural, mais confiável, ou por ensaios acelerados, cuja vantagem é a de fornecerem resultados em menor intervalo de tempo (SAVASTANO JR., 1992).

Muitas tentativas de produção de argamassas ou pastas de cimento Portland comum reforçadas com fibras vegetais fracassaram, por apresentarem vida útil de 2 a 4 anos (AGOPYAN, 1991). Uma das principais razões para essa rápida degradação é a elevada alcalinidade da água presente nos poros da matriz de cimento Portland, com $\mathrm{pH}$ aproximadamente igual a 13, que leva à rápida decomposição da lignina e da hemicelulose presentes nas fibras. A região da matriz em torno da fibra (zona de transição) é caracterizada pela porosidade elevada, permitindo acúmulo de água, e pela maior concentração de hidróxido de cálcio, propiciando elevada alcalinidade (SAVASTANO JR.; DANTAS; AGOPYAN, 1994). 
A zona ou auréola de transição é a região da pasta de cimento próxima à fibra, com espessura que varia de 10 a $100 \mu \mathrm{m}$, e suas propriedades são diferenciadas do restante da matriz (MINDESS; ODLER; SKALNY, 1986). Por sua maior porosidade, apresenta concentração de macrocristais de Portlandita e microfissuras, características que podem se apresentar com diferentes intensidades e estão diretamente ligadas à aderência fibra-matriz e, por decorrência, ao desempenho mecânico do compósito. $O$ aumento da aderência faz com que se torne maior a resistência à tração do compósito e, também, a sua ductilidade, desde que não haja redução excessiva do comprimento critico de ancoragem da fibra (AGOPYAN, 1991).

Gram (1988) estudou a durabilidade das fibras em materiais à base de cimento e concluiu que a primeira causa de mudança das características da fibra refere-se à decomposição química da lignina e da hemicelulose, presentes na lamela intercelular. Essa lamela é dissolvida pela ação da água capilar bastante alcalina $(\mathrm{pH}=12)$ da matriz e as células individuais perdem sua capacidade de reforço. Em seguida, os lumens são preenchidos por hidróxido de cálcio, que as torna menos flexíveis.

A durabilidade é diminuída como consequência da redução da resistência e da tenacidade (BENTUR e AKERS, 1989a). Esse comportamento está associado ao aumento da resistência da fratura da fibra e à redução do arrancamento, devida à combinação do enfraquecimento das fibras pelo ataque alcalino, mineralização da fibra e variação do volume associada à sua alta absorção de água (TOLÊDO FILHO et al., 2000). O aumento da durabilidade das fibras vegetais como reforço em cimento tem sido avaliado por vários pesquisadores, incluindo estudos com impregnação das fibras com agentes bloqueadores e repelentes à água, selando os poros da matriz; redução da alcalinidade da matriz; combinação da impregnação das fibras e modificação da matriz para prevenir a fibra da mineralização (GRAM, 1983; DELVASTO et al., 2004).

Soroushian e Marikunte, (1995) testaram, por meio de 120 ciclos de umedecimento e secagem acelerados, a durabilidade de argamassas reforçadas com fibras. Constataram a redução da tenacidade dos compósitos, provavelmente pela "petrificação" das fibras. Sabe-se, também, que a alternância entre molhagem e secagem é favorável à degradação e posterior lixiviação da lignina, presente na estrutura das fibras vegetais, o que pode reduzir ainda mais a atuação dessas fibras como reforço no interior da matriz. 


\subsection{Comentários finais sobre a revisão bibliográfica}

Esta revisão bibliográfica apresentou as informações essenciais ao entendimento do processo de produção do fibrocimento por extrusão, dos mecanismos de hidratação e da cura do cimento, das forças de adesão entre as partículas do compósito e dos mecanismos de ruptura dos compósitos reforçados com fibras. Mecanismos de degradação das fibras nos compósitos cimentícios, reportados em literatura, também constam desta revisão.

A avaliação dos tópicos apresentados nestas seções serviu de base para definição dos experimentos adotados na presente pesquisa. Ficou clara a necessidade de estudar as propriedades das fibras e os seus efeitos no desempenho dos compósitos. Entre as avaliações necessárias, destaca-se a importância dos efeitos das propriedades de superfície das fibras na aderência entre elas e a matriz cimentícia.

Observou-se a necessidade de avaliar a durabilidade dos compósitos, ou seja, o seu desempenho após exposição a intempéries. Por isso, neste trabalho adotou-se a interpretação dos resultados daqueles ensaios mecânicos, físicos e de análise microestrutural tanto nas idades iniciais (7 dias de cura térmica) como após ciclos de envelhecimento acelerado (imersão em água e secagem).

Nesta pesquisa pretendeu-se contribuir para o entendimento dos parâmetros reológicos para avaliar o comportamento das pastas cimentícias. Além disso, estudar os mecanismos de aderência entre fibras e matriz, e de degradação das fibras e dos compósitos de fibrocimento extrudados expostos à umidade. 


\section{MATERIAIS E MÉTODOS}

Esta seção aborda o planejamento dos experimentos, composto por três fases. A primeira fase visou o estudo da fibra, do corte, das análises físicas, químicas e morfológicas; na segunda fase, foram estudadas as técnicas reológicas a saber: Squeeze flow e reômetro extrusor. Na terceira fase, foram realizados os estudos da introdução de fibras como reforço em compósitos cimentícios, do processo de extrusão e da análise do desempenho mecânico, e as análises microestruturais. Além disso foram realizados ensaios de durabilidade para estudo do comportamento das fibras em ambiente úmido.

\subsection{Planejamento dos experimentos}

A Figura 8 mostra um fluxograma com a descrição das fases experimentais, que envolveram o estudo da fibra, o estudo das técnicas reológicas, da moldagem por extrusão e do envelhecimento. 


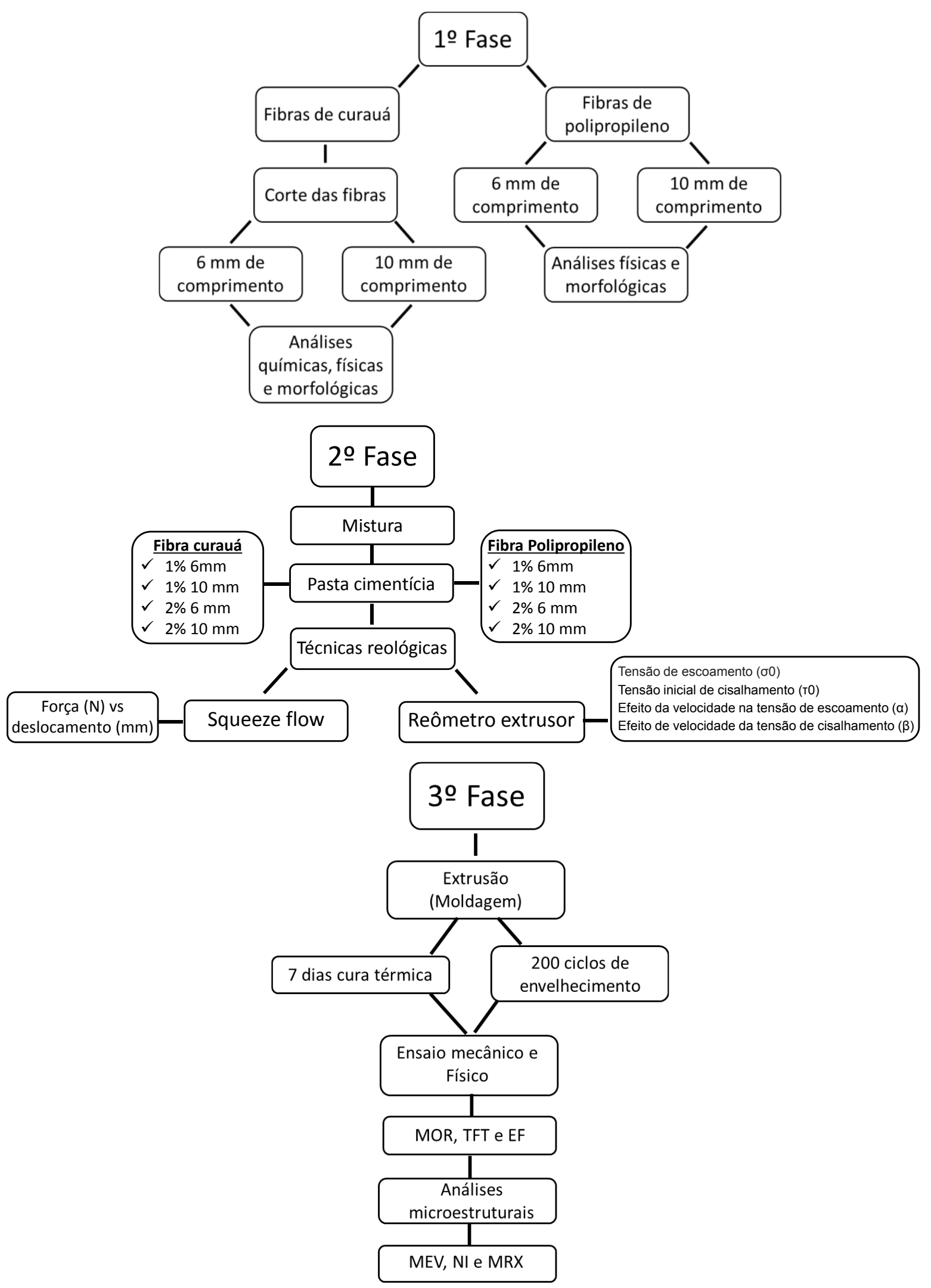

Figura 8 - Fluxograma detalhada das fases dos experimentos do projeto. MOR (módulo de ruptura), TFT (tenacidade a fratura), EF (energia de fratura), MEV (microscopia eletrônica de varredura), NI (nanoindentação) e MRX (microtomografia de raios- $\mathrm{X}$ ). 


\subsection{Fibras utilizadas como reforço}

Fibras de curauá (FC) foram doadas pela empresa PEMATEC, localizada em Santarém, estado do Pará. As fibras recebidas estavam embaladas em aglomerados com fios compridos, em média de 40 a $60 \mathrm{~cm}$ (Figura 9a). Fibras de polipropileno (FPP) foram fornecidas pela empresa SAINT GOBAIN S/A (Figura 9b) com $6 \mathrm{~mm} \mathrm{e}$ $10 \mathrm{~mm}$ de comprimento.

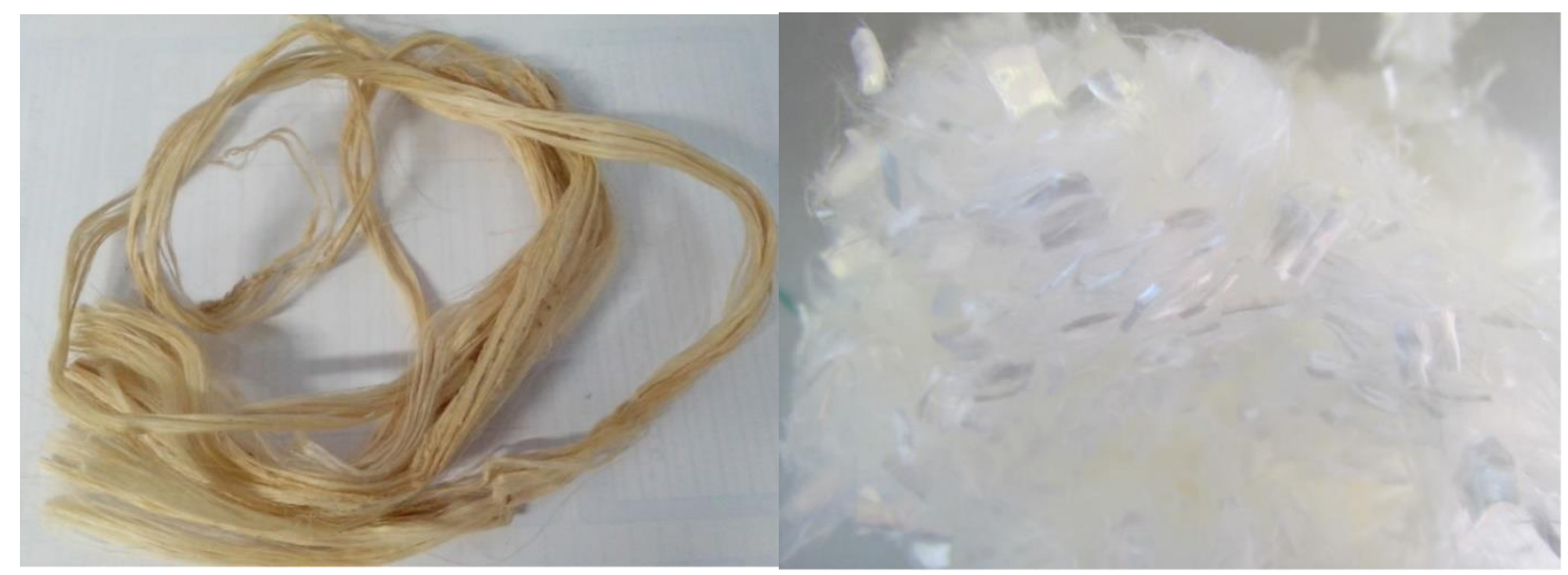

(a)

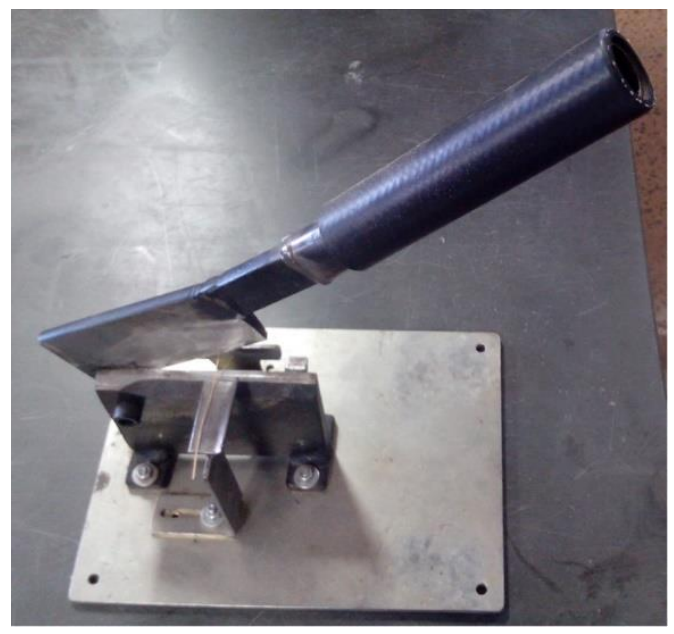

(c) (b)

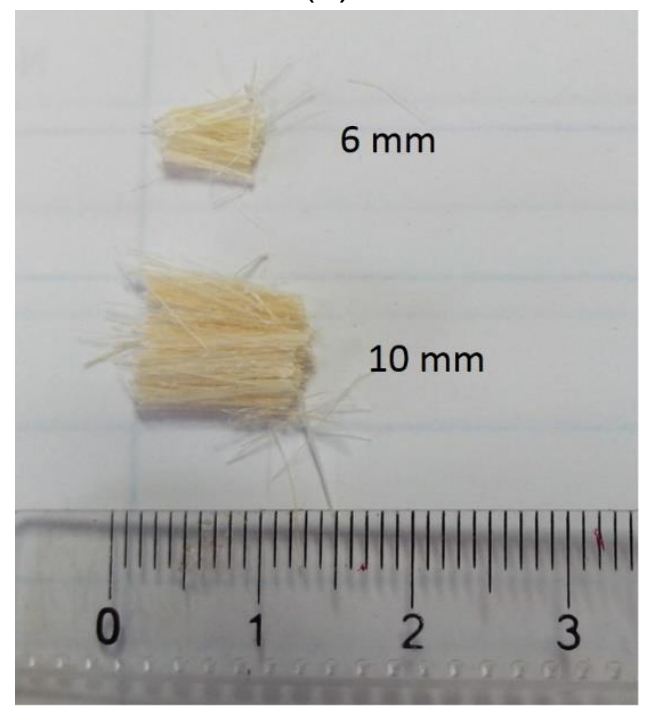

(d)

Figura 9 - (a) Aglomerados de fibras de curauá; (b) fibras de polipropileno; (c) guilhotina manual de corte e (d) fibras de curauá cortadas com 6 e 10 $\mathrm{mm}$ de comprimento. 


\subsubsection{Fibras de processo (polpa celulósica)}

A polpa celulósica de Eucalipto branqueada Kraft não refinada (Eucalyptus grandis) foi fornecida pela Fibria S/A.

As fibras de eucalipto foram utilizadas como reforço secundário (TEIXEIRA et al., 2012). Foram determinadas as suas dimensões médias (comprimento e largura) e a concentração de partículas (fibras por grama e teor de finos). Foi detectado elementos finos na fibra com dimensões menores do que as fibras (TONOLI et al., 2009a). As características físicas da fibra branqueada de eucalipto são apresentadas na Tabela 2.

Tabela 2 - Características físicas da fibra de eucalipto branqueada* (TONOLI et al., 2009a)

\begin{tabular}{ccccc}
\hline $\begin{array}{c}\text { Comprimento } \\
\text { médio }(\mathrm{mm})\end{array}$ & $\begin{array}{c}\text { Largura média } \\
(\mu \mathrm{m})\end{array}$ & $\begin{array}{c}\text { Razão de } \\
\text { Aspecto }\end{array}$ & $\begin{array}{c}\text { Material fibroso } \\
\left(10^{6} \text { fibras } / \mathrm{g}\right)\end{array}$ & $\begin{array}{c}\text { Conteúdo de finos } \\
(\%)^{\star *}\end{array}$ \\
\hline $0.83 \pm 0.05$ & $16.4 \pm 0.2$ & 51 & $18.17 \pm 1.11$ & $25.7 \pm 0.6$ \\
\hline
\end{tabular}

* Doada pela empresa Fibria; ${ }^{* \star}$ Impureza das fibras.

\subsubsection{Procedimentos de preparação das fibras}

As fibras de curauá (FC) recebidas foram cortadas por meio de uma guilhotina manual (Figura 9c) com comprimentos de $6 \mathrm{~mm}$ e $10 \mathrm{~mm}$ (Figura 9d). Análises químicas foram realizadas para determinar a composição química das fibras, como, por exemplo, teor de lignina (PEREIRA, 2012). As dimensões nominais (espessura e comprimento) bem como a área das fibras de curauá (FC) e polipropileno (FPP) foram medidas com o auxílio de um microscópio da marca Zeiss, modelo Stemi 2000 com aumento de $10 \mathrm{x}$ e de um paquímetro digital, foram realizadas 100 medições, além disso, microscopia eletrônica de varredura (MEV) com imagens de elétrons secundários foram realizadas para observar a superfície e a morfologia das fibras (TEIXEIRA et al., 2012). 


\subsection{Formulação e preparação das matérias-primas}

Foi adotado o cimento Portland CP-V ARI (NBR 5733), da empresa Caúe, por ser, comercialmente, o cimento disponível com menor teor de adições minerais. Outra importante característica do CP-V ARI está na distribuição granulométrica (diâmetro médio equivalente de partículas, $\mathrm{D}(50)$, igual a $11,82 \mu \mathrm{m}$ ). Quanto mais fino o cimento, mais rápida será sua reação de hidratação e maior sua reatividade. Adicionalmente, o cimento CP-V ARI contém teores mais elevados de $\mathrm{C}_{3} \mathrm{~S}$ e $\mathrm{C}_{2} \mathrm{~S}$ para formação de C-S-H (SANTOS et al., 2014). Calcário moído da empresa ITAÚ é utilizado como preenchimento (filler). Dessa forma, análises químicas quantitativas foram realizadas por fluorescência de raios $X$ no equipamento Axios Advanced da marca Panalytical. As composições químicas (\% em massa de óxidos) do cimento Portland CP-V ARI e do calcário moído estão listadas na Tabela 3.

Tabela 3 - Composição química (\% em massa de óxidos) dos cimentos Portland (CP-V ARI) e calcário moído.

\begin{tabular}{ccc}
\hline Óxidos & CP-V ARI & Calcário moído \\
\hline $\mathrm{SiO}_{2}(\%)$ & 14,70 & 9,40 \\
$\mathrm{CaO}(\%)$ & 67,20 & 39,10 \\
$\mathrm{Al}_{2} \mathrm{O}_{3}(\%)$ & 4,07 & 2,16 \\
$\mathrm{Fe}_{2} \mathrm{O}_{3}(\%)$ & 3,50 & 1,25 \\
$\mathrm{MgO}(\%)$ & 3,13 & 8,90 \\
$\mathrm{P}_{2} \mathrm{O}_{5}(\%)$ & - & 0,16 \\
$\mathrm{SO}_{3}(\%)$ & 5,23 & - \\
$\mathrm{K}_{2} \mathrm{O}(\%)$ & 0,75 & 0,41 \\
$\mathrm{MnO}^{(\%)}$ & - & $<0,10$ \\
$\mathrm{TiO}_{2}(\%)$ & - & 0,15 \\
$\mathrm{P} . \mathrm{F} .\left(1000^{\circ} \mathrm{C}\right)^{\star}$ & 3,29 & 39,20 \\
\hline
\end{tabular}

${ }^{*}$ Perda ao fogo

Os materiais que compõem o compósito estão classificados em dois tipos: matriz e reforço. O material da matriz (particulados) é o que confere estrutura ao compósito, preenchendo os espaços vazios que ficam entre os materiais reforços e mantendo-os em suas posições relativas. 
Os teores das matérias-primas foram definidos em volume com base no conceito de empacotamento (volume ocupado pelo material), que é condição básica para o desenvolvimento de materiais cimentícios em geral, visto ser determinante para uma série de suas propriedades. Entre elas, destaca-se o controle do comportamento reológico de suspensões e argamassas, bem como da resistência mecânica final do compósito (SANTOS et al., 2015). Para tanto, distribuições de diâmetro equivalente de partículas do cimento e calcário, foram determinadas em um equipamento Malvern Mastersizer S long bed versão 2.19, e estão apresentadas na Figura 10a e 10b. Observa-se que ambas as distribuições são monomodais e similares.

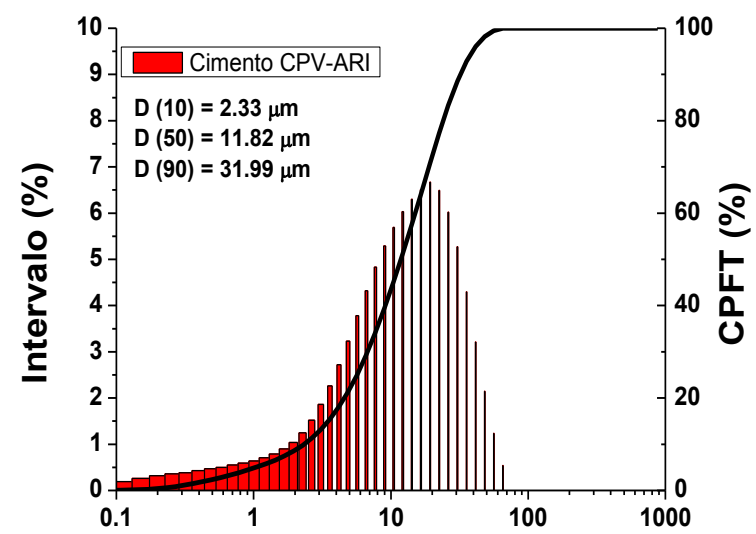

Diâmetro equivalente de particulas $(\mu \mathrm{m})$

(a)

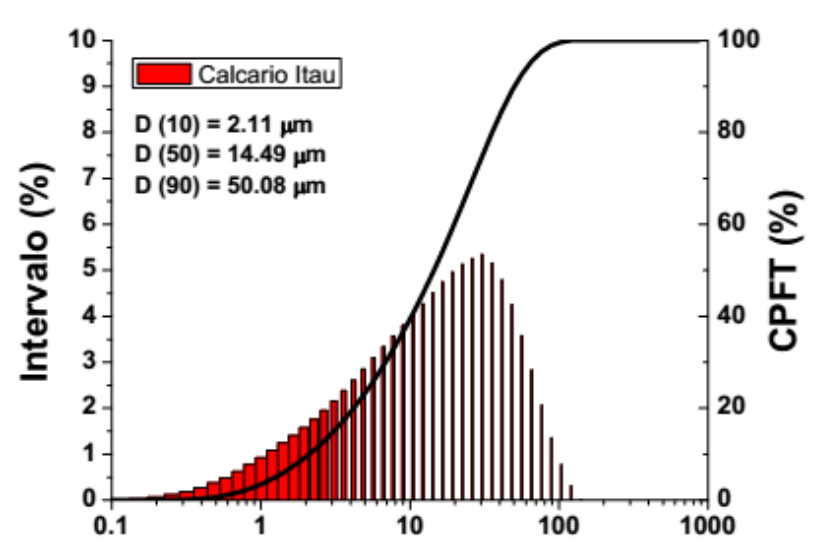

Diâmetro equivalente de particulas $(\mu \mathrm{m})$

(b)

Figura 10 - Distribuição do diâmetro de partículas: (a) cimento Portland (CP-V ARI) e (b) calcário Itaú.

As formulações estudadas estão apresentadas na Tabela 4. Cimento e calcário já são usualmente empregados por empresas do setor da construção civil, os teores escolhidos são similares aos praticados pelas indústrias de fibrocimento, assim como os teores de fibras de reforço, como as fibras de polipropileno, que foram de $1 \%$ e $2 \%$ (TONOLI et al., 2011). Como as fibras de curauá apresentaram densidades maiores $\left(1,45 \mathrm{~g} / \mathrm{cm}^{3}\right)$, os teores das fibras usadas foram ajustados em relação às fibras de polipropileno $\left(0,98 \mathrm{~g} / \mathrm{cm}^{3}\right)$ para manter o mesmo volume de reforço. 
Tabela 4 - Formulações utilizadas nas moldagens (\% em massa de matéria-prima).

\begin{tabular}{|c|c|c|c|c|c|c|c|c|c|}
\hline \multirow[b]{2}{*}{ Matéria-prima } & \multicolumn{9}{|c|}{ Conteúdo [\% em massa] } \\
\hline & REF & $\begin{array}{c}\mathrm{FC} \\
6 \mathrm{~mm} \\
1 \%\end{array}$ & $\begin{array}{c}\mathrm{FC} \\
6 \mathrm{~mm} \\
2 \%\end{array}$ & $\begin{array}{c}\mathrm{FC} \\
10 \mathrm{~mm} \\
1 \%\end{array}$ & $\begin{array}{c}\text { FC } \\
10 \mathrm{~mm} \\
2 \%\end{array}$ & $\begin{array}{c}\text { FPP } \\
6 \mathrm{~mm} \\
1 \%\end{array}$ & $\begin{array}{c}\text { FPP } \\
6 \mathrm{~mm} \\
2 \%\end{array}$ & $\begin{array}{c}\text { FPP } \\
10 \mathrm{~mm} \\
1 \%\end{array}$ & $\begin{array}{c}\text { FPP } \\
10 \mathrm{~mm} \\
2 \%\end{array}$ \\
\hline Cimento Portland [CP V-ARI] & 69,95 & 68,87 & 67,79 & 68,87 & 67,79 & 69,25 & 68,55 & 69,25 & 68,55 \\
\hline Calcário moído & 27,08 & 26,66 & 26,54 & 26,66 & 26,54 & 26,89 & 26,54 & 26,89 & 26,54 \\
\hline Fibra de eucalipto branqueada & 2,98 & 2,93 & 2,89 & 2,93 & 2,89 & 2,95 & 2,92 & 2,95 & 2,92 \\
\hline Fibra de curauá (FC) & - & 1,53 & 3,08 & 1,53 & 3,08 & - & - & - & - \\
\hline Fibra de polipropileno (FPP) & - & - & - & - & - & 1 & 2 & 1 & 2 \\
\hline Relação água/cimento & 0,33 & 0,34 & 0,36 & 0,34 & 0,36 & 0,33 & 0,35 & 0,33 & 0,35 \\
\hline
\end{tabular}

\subsection{Modificadores reológicos}

O aditivo orgânico adotado foi o hidroxipropilmetilcelulose fornecido pela empresa Aditex S.A., conforme estudo de Srinivasan et al., (1999). Nesse estudo, o teor do surfactante foi mantido fixo. A Tabela 5 apresenta as propriedades físicas.

Tabela 5 - Propriedades físicas do aditivo orgânico (Hidroxipropilmetilcelulose).

\begin{tabular}{lcc}
\hline \multicolumn{1}{c}{ Ensaio } & Unidade & Parâmetros \\
\hline $\begin{array}{l}\text { Viscosidade, Brookfield, 2\%, em água, } \\
20 \text { C, Spindle 6, 10 RPM }\end{array}$ & $\begin{array}{c}\text { mPa.s } \\
\text { (Centipoise) }\end{array}$ & $60.000-70.000$ \\
\hline Teor de Umidade & $\%$ & Máximo 5,0 \\
Teor de Cinza & $\%$ & Máximo 7,0 \\
Coloração & N.A. & $\begin{array}{c}\text { Branco, levemente } \\
\text { amarelado }\end{array}$ \\
Odor & N.A. & Característica/Leve \\
Aparência/Estado Físico & N.A. & Pó \\
Densidade Aparente & g/cm³ & $0,350-0,500$ \\
Teor de material retido \#100 & $\%$ & Máximo 10,0 \\
\hline
\end{tabular}

O surfactante adotado foi o poliéter carboxilato com o nome comercial de ADVA 175, fornecido pela empresa Grace S.A. Neste estudo, o teor do surfactante foi mantido fixo. A Tabela 6 apresenta as suas propriedades físicas. 
Tabela 6 - Propriedades físicas do surfactante.

\begin{tabular}{ccc}
\hline Teste & Especificação & Unidade \\
\hline Aparência & Liquido branco turvo & Visual \\
PH & $5,5-7,5$ & - \\
Densidade & $1,065-1,105$ & $\mathrm{~g} / \mathrm{cm}^{3}$ \\
Sólidos & $30-34$ & $\%$ \\
Viscosidade & $<150$ & $\mathrm{cps}$ \\
\hline
\end{tabular}

\subsection{Procedimento de mistura}

As propriedades do fibrocimento estão diretamente relacionadas com sua forma de mistura. A escolha da forma de mistura depende da natureza dos componentes a serem misturados. Dessa forma, foi utilizada a sequência de mistura (pó-água) das matérias-primas (ANTUNES; JOHN; PILEGGI, 2005).

Para obter uma mistura homogênea, foi utilizado um misturador de alta energia (Figura 11a) com cuba inclinada que gira no sentido horário, com rotor excêntrico e ferramenta estacionaria na parede da cuba (Figura 11b) como defletor de material que facilita sua mistura.

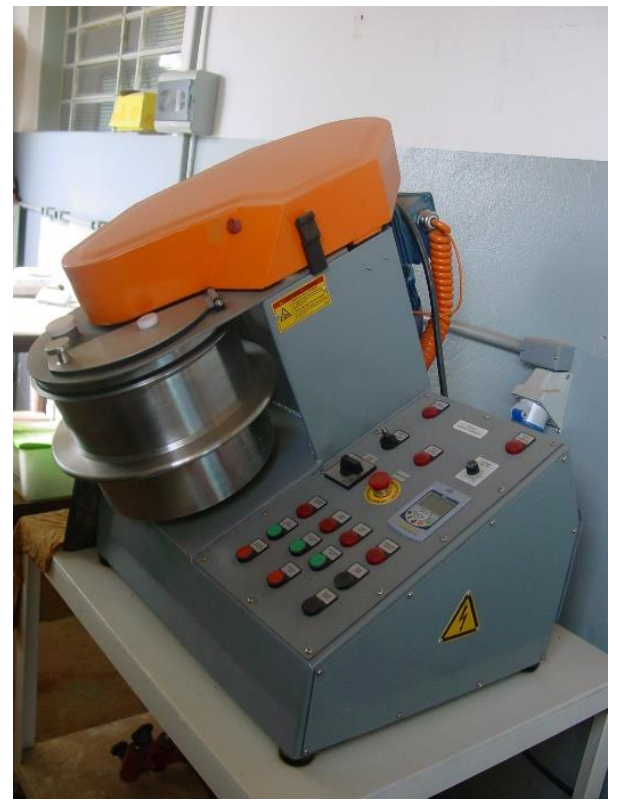

(a)

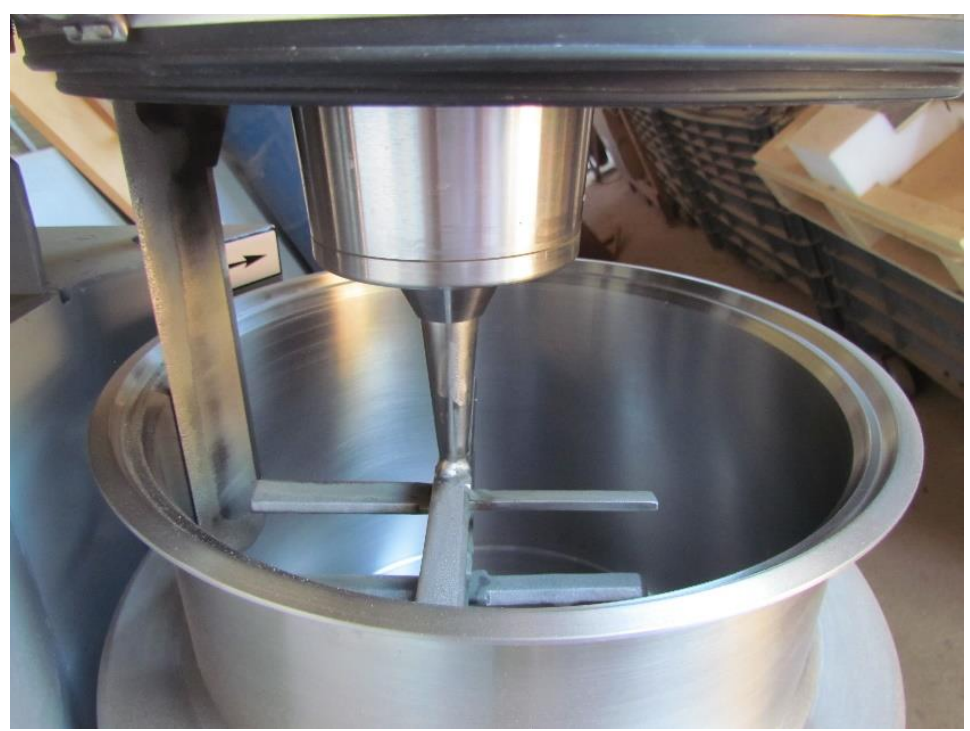

(b)

Figura 11 - (a) Misturador de alta energia e (b) configuração do rotor e ferramenta estacionaria (raspador) da cuba do misturador. 
Para avaliar a consistência da formulação após a mistura, foi utilizado um penetrômetro de bolso (Figura 12a). Este penetrômetro é indicado para medidas preliminares em misturas, para aplicações em que a camada analisada for superficial. Apresenta cinco escalas de penetração, altura e diâmetro diferentes, de acordo com a mistura coesiva ou pouco coesiva, determinando que a punção penetre completamente na massa. Expressa resultados em MPa (leitura direta), que correspondem aproximadamente à resistência não confinada ao cisalhamento (Figura 12b).

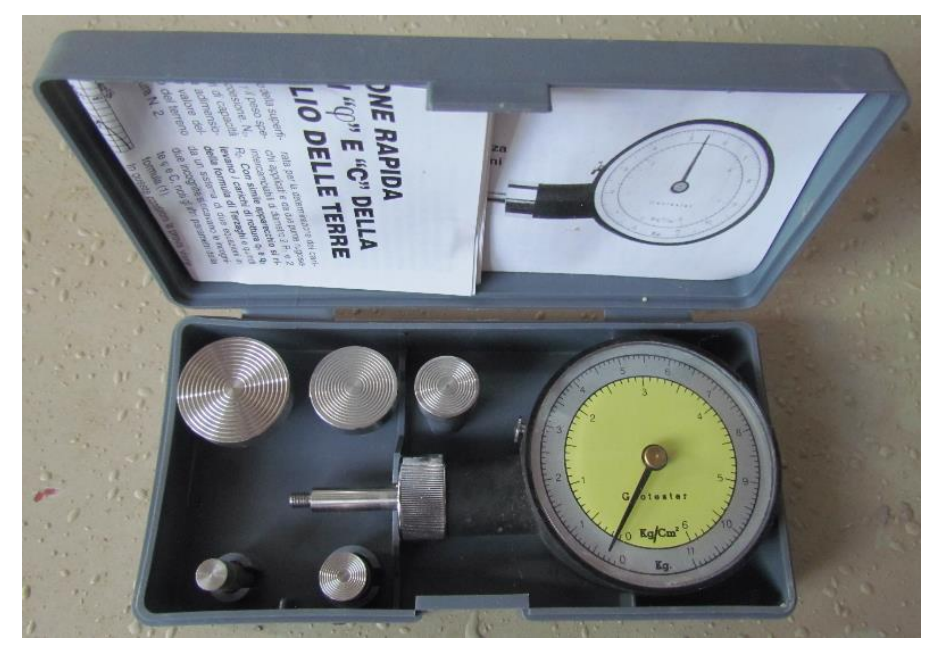

(a)

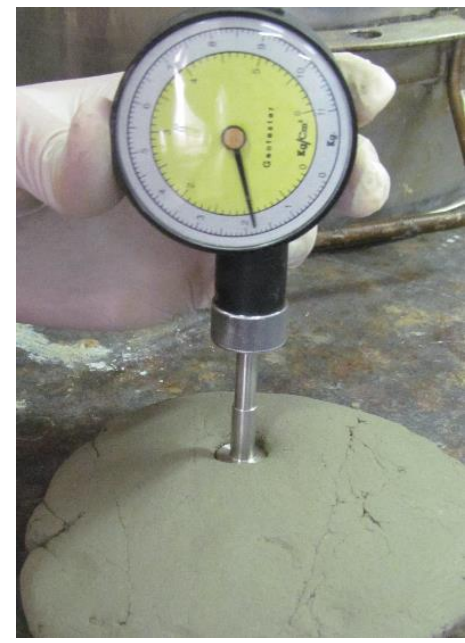

(b)

Figura 12 - Penetrômetro com escalas de penetração e (b) penetrômetro utilizado para avaliar a consistência da mistura cimentícia.

Por meio de resultados preliminares foram adotadas a sequência e a duração de cada etapa da mistura:

- 2 min de mistura do cimento, calcário e HPMC (material sólido) com velocidade baixa;

- 1 min de adição fracionada de fibras de reforço, se for o caso, com velocidade baixa;

- 2 min de adição de fibra celulósica, água e ADVA fracionada, com velocidade baixa;

- 5 min aproximadamente da mistura total das matérias-primas com velocidade alta; 
- 3 min para transferir a mistura e começar o ensaio reológico ou processo de extrusão.

O tempo total de mistura foi aproximadamente de $13 \mathrm{~min}$, até iniciar o ensaio reológico ou o processo de extrusão. Em vista de resultados preliminares, o valor de tensão entre 0,1 e 0,2 Mpa, para que a punção penetre completamente na massa, foi adotado para considerar a formulação com uma consistência satisfatória e suficientemente coesa para a extrusão. Misturas com consistências com valores de tensão inferiores à faixa previamente estabelecida, apresentaram excesso de água; e misturas com valores superiores, falta de água.

\subsection{Técnica Squeeze flow}

Os reômetros são equipamentos dedicados à avaliação de propriedades reológicas de fluidos, suspensões, argamassas e concretos. Determinam parâmetros como viscosidade e tensão de escoamento ou cisalhamento por meio de dois princípios básicos de funcionamento: (1) aplicação de torque ao fluido ou suspensão e medida do cisalhamento resultante; ou (2) o cisalhamento aplicado é controlado, sendo avaliado o torque necessário para tal (PILEGGI, 2001). Contudo, os reômetros de precisão atuam em faixas limitadas de torque, sendo incapazes de medir os elevados esforços requeridos para o cisalhamento de materiais como concretos e argamassas em taxas extremas. Considerando esse cenário, a avaliação do comportamento reológico das argamassas faz-se necessária para 0 desenvolvimento de formulações que apresentem características no estado fresco adequadas para aplicação e que não comprometam o desempenho do material no estado endurecido. Dessa forma, foi utilizada a técnica Squeeze flow para a caracterização reológica de pasta cimentícia (ANTUNES; JOHN; PILEGGI, 2005).

$O$ ensaio foi realizado em uma máquina universal de ensaios EMIC, modelo DL 30.000, com deslocamento controlado. Utilizou-se célula de carga de $5 \mathrm{kN}$. A velocidade de deslocamento adotada foi de $4 \mathrm{~mm} / \mathrm{min}$. $O$ ensaio foi limitado à carga de $2 \mathrm{kN}$ e descolamento de $6 \mathrm{~mm}$. Os dados de força, deslocamento e tempo foram coletados para avaliar as tensões de escoamento interna (cisalhamento entre as partículas) e externa (cisalhamento entre as partículas, punção e prato de apoio), da 
mistura. Todos os ensaios foram realizados segundo o conceito de compressão simples, controlada por deslocamento.

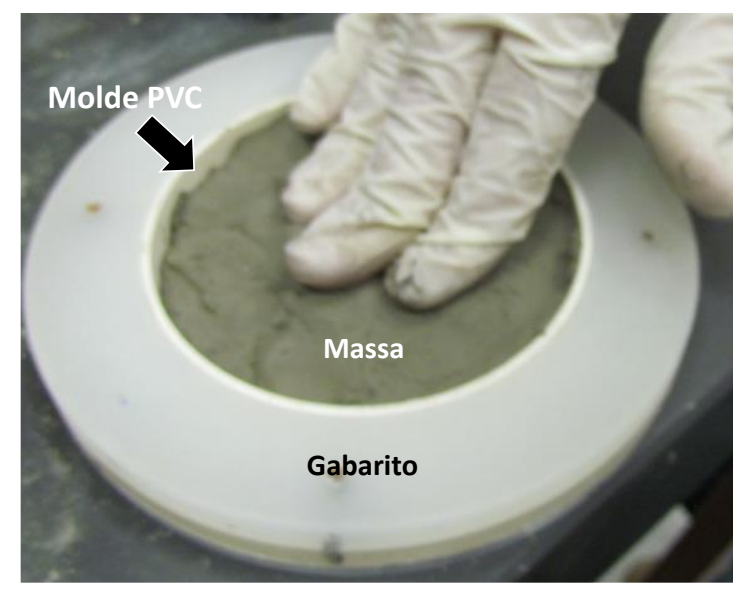

(a)

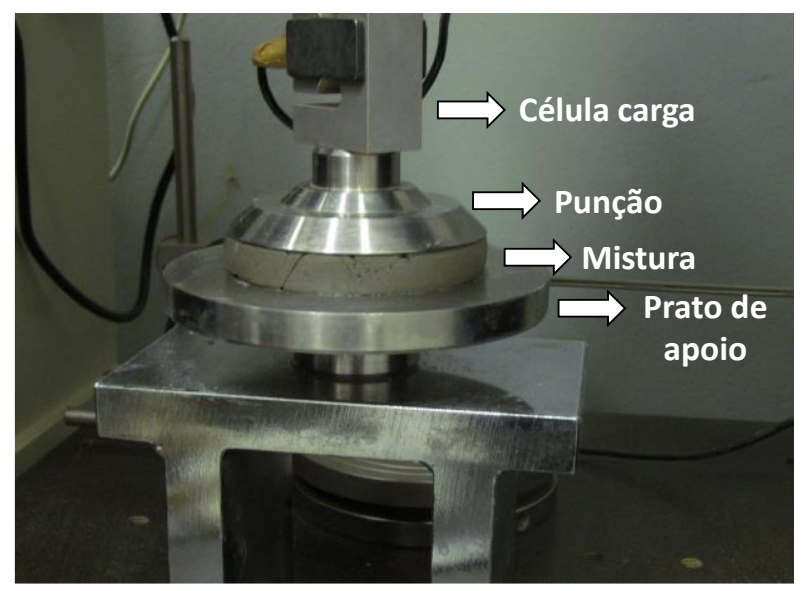

(b)

Figura 13 - (a) Molde de PVC e gabarito para auxílio da moldagem e (b) ilustração do ensaio reológico Squeeze flow.

Foi utilizado um molde feito com anel de PVC com diâmetro de $101 \mathrm{~mm}$ e altura de $15 \mathrm{~mm}$, conforme a Figura 13a. Tanto a punção quanto o prato de apoio da amostra são de aço inoxidável (Figura 13b). Imediatamente após a mistura, foi adotado, de acordo com Antunes e colaboradores (2005), o seguinte procedimento de ensaio:

- Posicionou-se o molde de PVC de $101 \mathrm{~mm}$ no centro da base de aço inox com o auxílio de um gabarito;

- Preencheu-se o molde de PVC com a mistura com auxílio de uma espátula, procurando adensar a pasta cimentícia e eliminar possíveis vazios;

- Rasou-se o molde com pasta do meio para a extremidade;

- Retirou-se o molde e posicionou-se a base na máquina e deu-se início ao ensaio.

\subsection{Técnica do reômetro extrusor (método Benbow)}

As propriedades reológicas dos compósitos à base de cimento fresco são importantes para identificar os componentes da mistura com critérios adequados 
para a utilização ótima no processo de extrusão. Estudos realizados sobre 0 comportamento reológico das fibras sintéticas curtas nas pastas de cimento fresco apresentaram uma relação água-cimento menor e mostraram diferenças das pastas de cimento puro, argamassa, suspensões (LI; MU; CHUI, 1999; 2001). Dessa forma, procurou-se otimizar esses resultados e identificar se as misturas com essas composições são extrudáveis ou não.

Para isso, foi confeccionado um reômetro extrusor baseando-se nas pesquisas de Benbow e colaboradores (1991). O esquema do reômetro extrusor com pistão é mostrado na Figura 9a. Um pistão é colocado no interior do barril. $\mathrm{O}$ pistão está ligado ao atuador, que, por sua vez, está acoplado a uma célula de carga de $50 \mathrm{kN}$, na máquina universal de ensaios mecânicos, marca EMIC, modelo DL30.000. O barril do reômetro extrusor foi preenchido com uma quantidade de pasta de cimento fresco até a borda e o pistão foi posicionado, de modo que a parte inferior do pistão estivesse em contato direto com a pasta de cimento. Essa posição do pistão foi tomada como ponto de referência para o deslocamento. A compressão começou em seguida a uma velocidade constante. Para cada trecho de deslocamento do pistão no barril, uma velocidade diferente de ensaio foi aplicada (Figura 14). Os deslocamentos foram: $70 \mathrm{~mm}, 85 \mathrm{~mm}, 100 \mathrm{~mm}, 115 \mathrm{~mm}$ até $125 \mathrm{~mm}$ respectivamente, e as velocidades foram: $6,5 \mathrm{~mm} / \mathrm{s}, 8,9 \mathrm{~mm} / \mathrm{s}, 13,3 \mathrm{~mm} / \mathrm{s}$ e $20 \mathrm{~mm} / \mathrm{s}$ respectivamente (SRINIVASAN; DEFORD; SHAH, 1999).

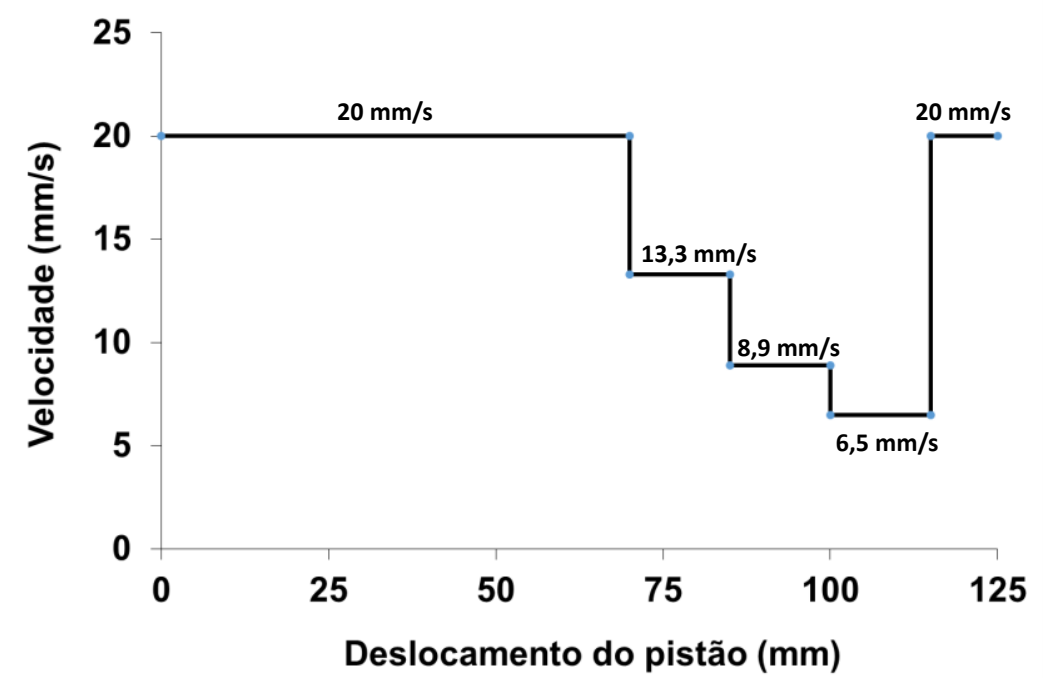

Figura 14 - Configuração do ensaio do reômetro extrusor com suas respectivas velocidades em função dos descolamentos. 
De acordo com o modelo, a pressão, $\mathrm{P}$, aplicada na formulação a fresco para gerar matrizes cilíndricas, é calculada pela Equação 3 (BENBOW e BRIDGWATER, 1993)

$$
P=2\left(\sigma_{0}+\alpha V\right) \ln \left(\frac{D_{0}}{D}\right)+4\left(\tau_{0}+\beta V\right)\left(\frac{L}{D}\right)
$$

Onde $D_{0}$ e $D$ são, respectivamente, os diâmetros do barril do reômetro extrusor e da boquilha e $\mathrm{L}$ é o comprimento da boquilha. $\mathrm{O}$ diâmetro interno do barril $D_{0}$ é de $38,1 \mathrm{~mm}$ e o diâmetro interno da boquilha $D$ é de $12,7 \mathrm{~mm}$. $V$ é a velocidade de ensaio do reômetro extrusor, $\sigma_{0}$ é um parâmetro de tensão de escoamento correspondente à velocidade zero, e $\alpha$ é um parâmetro da velocidade na tensão de escoamento, que caracteriza o efeito da velocidade na entrada da boquilha. Ambos $\sigma_{0}$ e $\alpha$ estão relacionados como constantes do material independentes da geometria da matriz e das taxas de extrusão e associados com o fluxo da pasta através do barril para a entrada da matriz na boquilha. To é uma tensão inicial de cisalhamento na parede do barril, e $\beta$ é um parâmetro que caracteriza o efeito da velocidade na tensão de cisalhamento. Ambos to e $\beta$ também são considerados constantes do material e associados com a resistência do fluxo de uma secção transversal constante.

O barril utilizado nos experimentos tem altura de $125 \mathrm{~mm}$ (Figura 15a). Foram utilizadas três boquilhas e as relações comprimento/diâmetro (L/D) das boquilhas utilizadas foram 1, 4 e 8. (Figura 15b). 


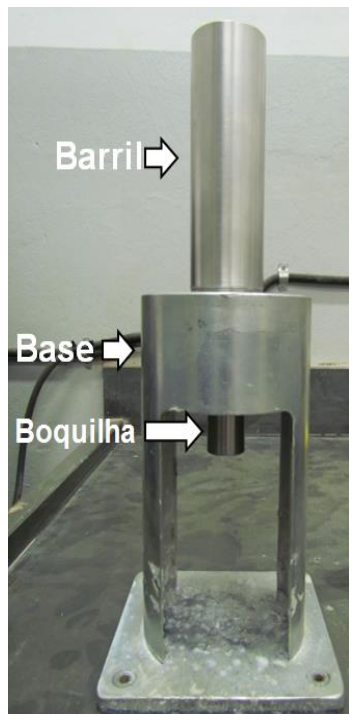

(a)

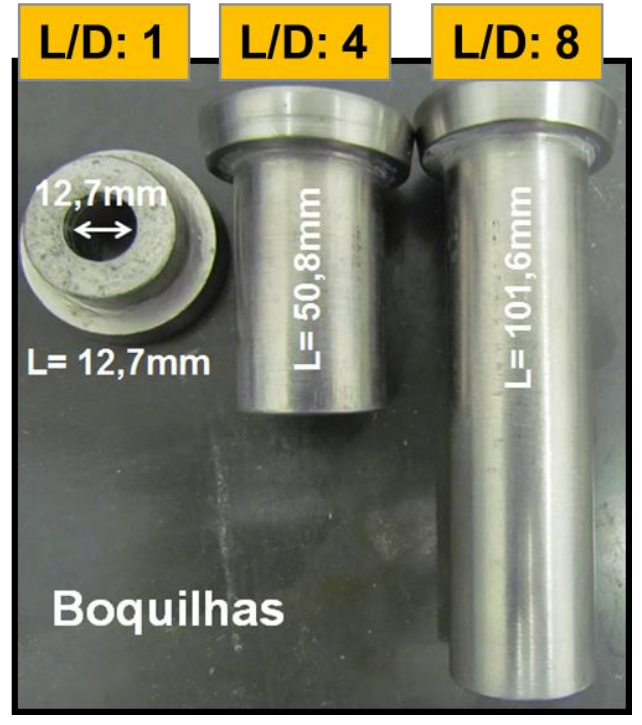

(b)

Figura 15 - (a) Reômetro extrusor e (b) boquilhas usadas no ensaio.

Quatro repetições foram realizadas por boquilha e, como consequência, foram totalizadas 12 repetições por formulação.

\subsection{Processo de extrusão}

O êxito do processo de extrusão depende do comportamento reológico da formulação e da boa homogeneização das misturas. O comportamento reológico da mistura cimentícia é um dos aspectos de importância fundamental no processo de extrusão. As características reológicas da mistura são influenciadas principalmente pela quantidade de cimento, material de enchimento (material carbonático e outras adições minerais, por exemplo), fibra, surfactante, água e modificador reológico, bem como pelas características físicas, químicas e morfológicas desses componentes a serem utilizados na mistura (PELED e SHAH, 2003).

Em todas as formulações foi usado o teor de 1\% em massa de modificadores reológicos sobre a massa do cimento. Um importante aspecto dos modificadores é a capacidade de impedir separação das fases durante a homogeneização da mistura.

Vinte corpos-de-prova prismáticos das matrizes extrudadas foram produzidos na máquina extrusora à vácuo com rosca helicoidal, com diâmetro e comprimento de $15 \mathrm{~mm}$ e $200 \mathrm{~mm}$, respectivamente. O equipamento, modelo 051, da marca Verdés, 
contém um regulador de velocidades (Figura 16a). A velocidade média utilizada foi de $4 \mathrm{~mm} / \mathrm{s}$. Foi usada uma boquilha com $100 \mathrm{~mm}$ de comprimento (Figura 16b e 16c). Esse equipamento e acessórios encontram-se disponíveis e em operação no Laboratório de Construções e Ambiência, Departamento de Engenharia de Biossistemas da FZEA USP Pirassununga.

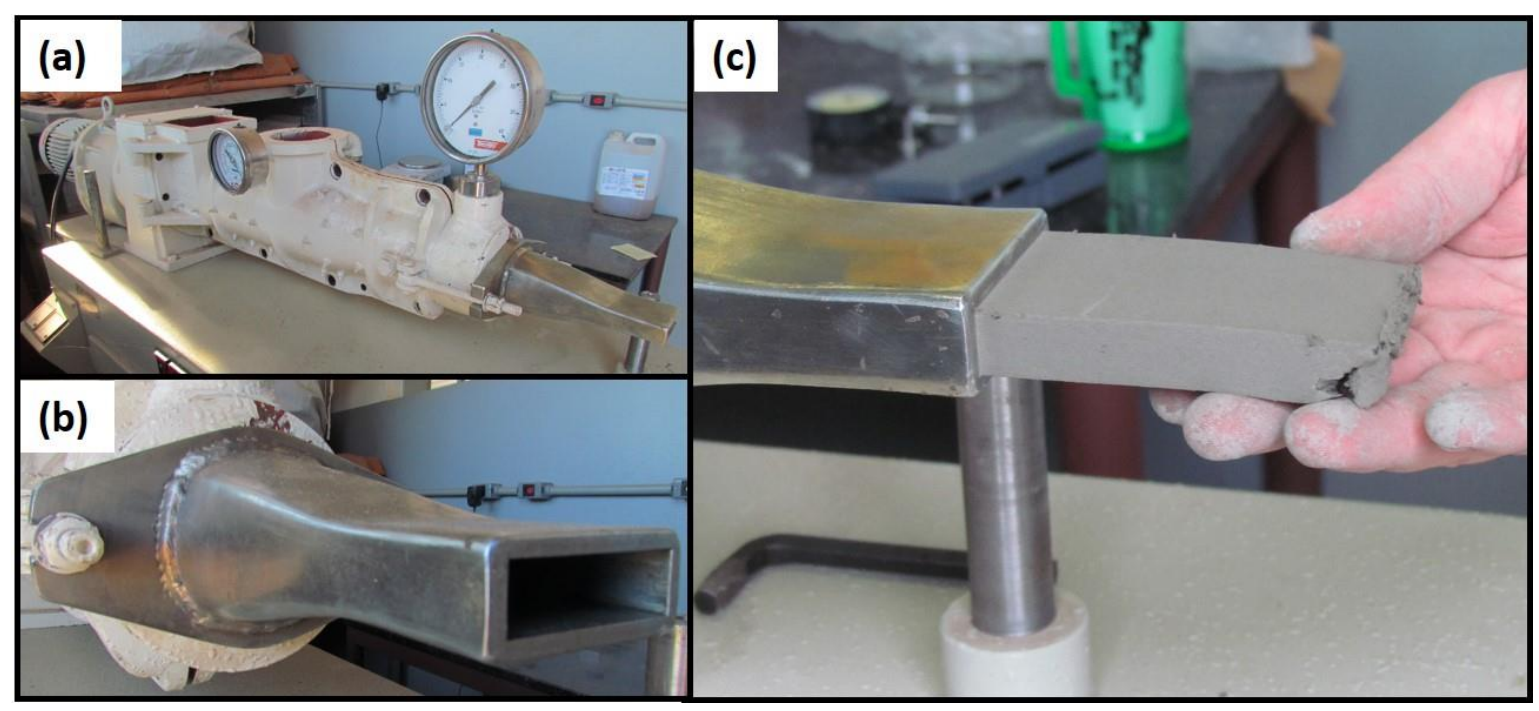

Figura 16 - (a) Máquina extrusora à vácuo; (b) boquilha utilizada na produção de fibrocimento; e (c) vista lateral mostrando a saída da mistura na boquilha.

Após a extrusão, os corpos-de-prova foram armazenados em ambiente saturado (sacos plásticos selados) por dois dias. Depois desse período, as placas em sacos plásticos foram colocadas em ambiente térmico saturado em água com temperatura de $60^{\circ} \mathrm{C}$, durante cinco dias (SANTOS et al., 2015). Ao final de 7 dias de cura, as placas foram então usinadas com dimensões nominais de $13 \times 20 \times 80$ $\mathrm{mm}$, totalizando em torno de 80 corpos-de-prova para realizar todos os ensaios propostos no estudo.

\subsubsection{Características da extrusora}

As características relevantes da máquina extrusora são: a geometria da rosca, o comprimento das secções de alimentação, de desaeração e de compactação, a velocidade da rosca e as pressões de vácuo exercido na seção de desaeração (SHAO; MARIKUNTE; SHAH, 1995). 
O propósito da boquilha é promover a compactação final da mistura cimentícia e formar a desejada geometria do produto. Para garantir a saída de produtos extrudados com bom acabamento, devem-se evitar gradientes de velocidade, para assim as misturas de formulações cimentícias fluírem uniformemente através da boquilha. Caso as misturas fluam com taxas de velocidade diferentes, geram-se gradientes de tensões durante 0 processo e 0 produto extrudado não sairá da boquilha com a geometria desejada.

As partes de uma extrusora de vácuo são apresentadas na Figura 17, sendo salientadas a câmara de mistura, a câmara de vácuo e a câmara de compactação.

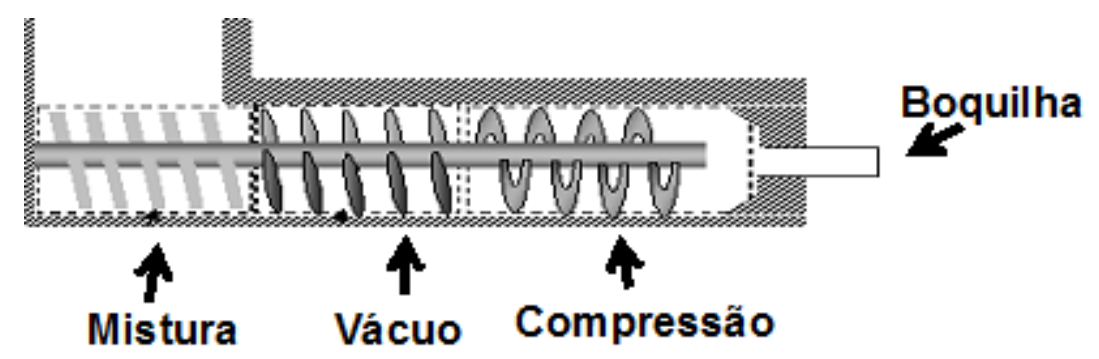

Figura 17 - Detalhes do mecanismo de funcionamento do processo de extrusão (SOTO et al., 2007)

\subsection{Envelhecimento acelerado}

O procedimento de imersão-secagem tem 0 objetivo de estudar 0 comportamento do envelhecimento de fibras sob os efeitos do ambiente, estimulando $o$ ataque da água alcalina dos poros nas fibras (por exemplo, condições envolvendo repetidas exposições à chuva e raios solares). $O$ envelhecimento acelerado de imersão-secagem para as placas foi baseado no procedimento da norma europeia EN 494 (1994).

Esse ensaio consiste em determinar comparativamente o desempenho físico e mecânico dos corpos-de-prova antes e após a realização de ciclos. Para esse propósito, foi utilizada uma câmara automática de envelhecimento acelerado que realiza os ciclos. Os compósitos são inseridos nessa câmara à imersão completa em água por $170 \mathrm{~min}$ (até que os poros capilares sejam preenchidos pela água). Os compósitos são então aquecidos até $70^{\circ} \mathrm{C} \pm 5^{\circ} \mathrm{C}$ por igual período de 170 min para secagem dos sistemas de poros capilares. Esse procedimento foi repetido até se 
completarem 200 ciclos (200C). Segundo Tonoli et al. (2009b) e Teixeira et al. (2014), sob essas condições, as fibras entram em contato com a água alcalina dos poros do cimento durante a imersão, os produtos de decomposição são formados como um resultado da reação entre os componentes da fibra e a água do poro transportada para longe da fibra durante a fase de secagem. Foram utilizados 10 corpos de prova de cada formulação para o ensaio.

\subsection{Propriedades mecânicas dos compósitos}

Após os 7 dias de cura térmica e após os 200 ciclos de envelhecimento, os corpos-de-prova foram usinados pela empresa DJ, situado em Pirassununga. Foi utilizado um disco de corte diamantado de $500 \mu \mathrm{m}$ de espessura. As dimensões dos corpos-de-prova utilizados nos ensaios foram $13 \mathrm{~mm} \times 20 \mathrm{~mm} \times 80 \mathrm{~mm}$. Para cada ensaio mecânico (módulo de ruptura (MOR), tenacidade a fratura (TFT) e energia de fratura $(E F)$ ) foi utilizado uma configuração distinta. Foram realizadas 10 repetições para cada ensaio.

\subsubsection{Módulo de ruptura (MOR)}

Para determinar o módulo de ruptura empregou-se o ensaio de flexão a três pontos (Figura 18a), utilizando-se uma máquina universal de ensaios mecânicos MTS modelo 370.02 servohidraúlica (Figura 18b), no Laboratório de Construções e Ambiência, Departamento de Engenharia de Biossistemas da FZEA USP Pirassununga. 


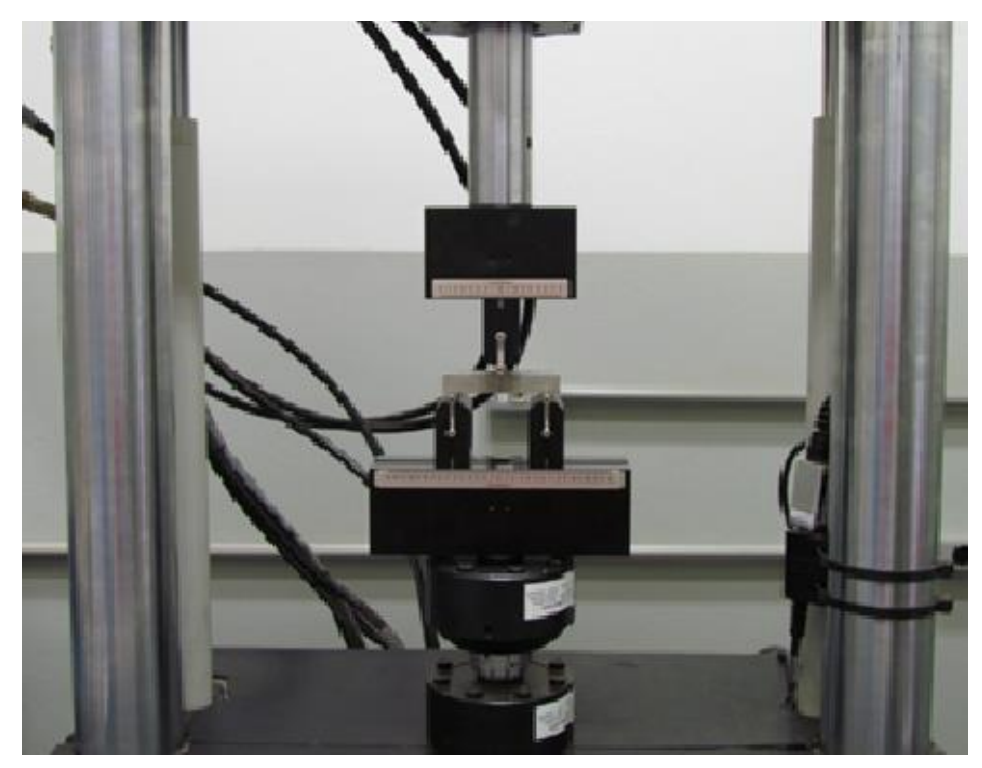

(a)

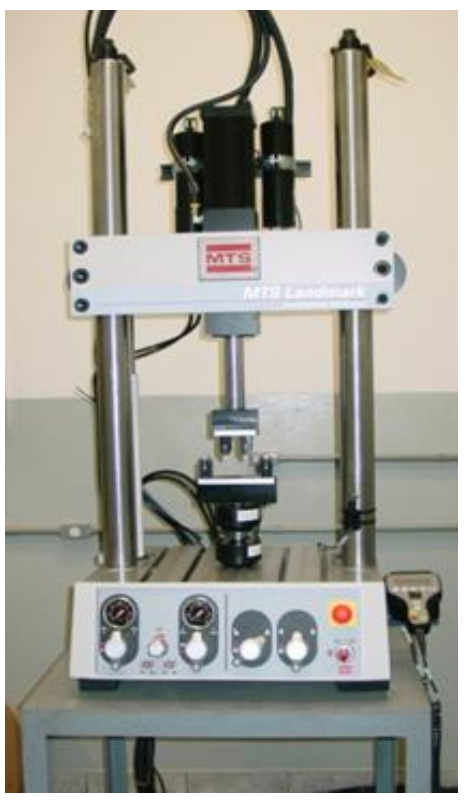

(b)

Figura 18 - (a) Dispositivo de ensaio de flexão a três pontos e (b) máquina universal servohidraúlica de ensaios mecânicos, MTS.

A velocidade de deslocamento foi de $5 \mathrm{~mm} / \mathrm{min}$ (Santos et al., 2015). Para o cálculo do módulo de ruptura, MOR, utilizou-se a equação 4:

$$
\mathrm{MOR}=\frac{3}{2} \cdot \frac{\mathrm{P}_{\max } \cdot \mathrm{S}}{\mathrm{b} \cdot \mathrm{w}^{2}}
$$

onde $P_{\max }$ é a força máxima atingida, $S$ é a distância entre os apoios e vale $64 \mathrm{~mm} \mathrm{e}$ b e w, são a largura e a altura do corpo-de-prova, respectivamente.

\subsubsection{Tenacidade à fratura (TFT)}

Os corpos-de-prova submetidos ao ensaio de tenacidade à fratura, (TFT), foram entalhados para se estabelecer o tamanho do defeito crítico e favorecer a propagação catastrófica da trinca, (corpo-de-prova entalhado). O entalhe foi plano, com $10 \%$ de profundidade da altura do corpo-de-prova, feito com um disco de corte diamantado de $500 \mu \mathrm{m}$ de espessura (Figura 19). 


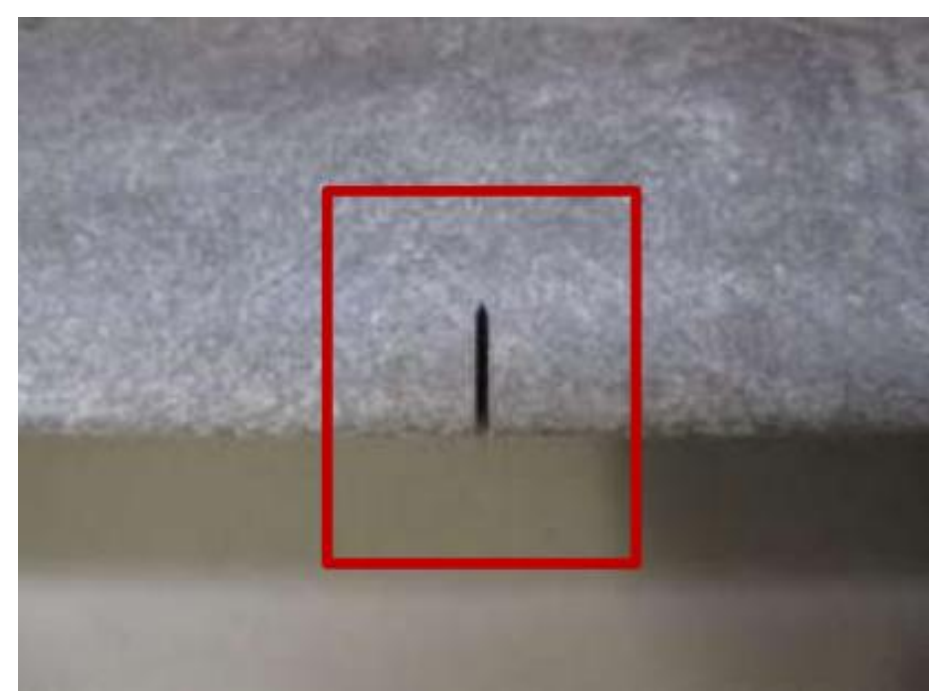

Figura 19 - Entalhe do corpo de prova para o ensaio de tenacidade à fratura. 10\% de profundidade da altura do corpo-de-prova.

Para a realização do ensaio, foi empregada a configuração de flexão a três pontos e utilizadas as equações que restringem as dimensões dos acessórios e do arranjo do ensaio, com base na norma ASTM-C1421-01b para cerâmicas avançadas.

A utilização da referida norma para a medida de tenacidade à fratura, de cerâmicas avançadas, justifica-se pela falta de documento normativo específico para se determinar TFT do fibrocimento. A escolha dessa norma se explica pela semelhança de comportamento mecânico frágil da matriz cerâmica com a da matriz cimentícia do fibrocimento, pela definição das dimensões dos corpos-de-prova, da distância entre os apoios e da velocidade de ensaio do deslocamento de atuador e, fundamentalmente, porque essa norma estabelece critérios para validar os resultados, pelo menos como comparativos. Um dos critérios para se determinar TFT, a curva força versus deslocamento indicou com precisão o início da propagação catastrófica de trinca, ou seja, a carga máxima atingida. Para tanto, o ensaio foi realizado na máquina universal de ensaios mecânicos MTS modelo 370.02 servohidraúlica, no Laboratório de Construções e Ambiência da FZEA USP.

O controle dinâmico da máquina servo hidráulica garante maior precisão na aquisição de tempo, de carga e de deslocamento do atuador em ensaios realizados em altas velocidades. Neste trabalho, a velocidade de deslocamento do atuador foi de $15 \mathrm{~mm} / \mathrm{min}$ (SANTOS et al., 2015). 
A partir das curvas carga, $\mathrm{P}$, vs. deslocamento, d, obtidas desse ensaio, foi extraído o valor da força máxima, $P_{\max }$, para cálculo do valor de TFT, com a equação 5:

$T F T=\frac{P \max }{b \cdot w^{\frac{1}{2}}} \cdot y(\alpha)$

onde y $(\alpha)$ é um fator geométrico. Para o ensaio com configuração de flexão a três pontos, com entalhe plano e $\alpha$ entre 0 e 1, y( $\alpha)$, de acordo com Sakai e Bradt (1993) e Santos et al. (2015), foi utilizada a equação 6:

$y(\alpha)=\frac{S}{w} \cdot\left[\frac{3 \alpha^{1 / 2}}{2(1-\alpha)^{3 / 2}}\right] \cdot\left[1,99-1,33 \alpha-\left(3,49-0,68 \alpha+1,35 \alpha^{2}\right) \cdot \frac{\alpha(1-\alpha)}{(1+\alpha)^{2}}\right]$

sendo que $S$ é a distância entre os apoios do suporte de flexão, $64 \mathrm{~mm}$, e w é o comprimento relativo do entalhe, que, por sua vez, é a razão entre o comprimento original do entalhe, an, e a altura do corpo-de-prova, w.

\subsubsection{Energia de fratura $(E F)$}

Dentre as propriedades mecânicas para inferir a interação entre fibras e matriz, destaca-se a energia de fratura (EF). Conceitualmente, a energia de fratura,

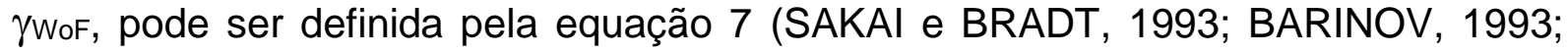
SANTOS et al., 2015):

$\gamma_{\mathrm{WoF}}=\gamma_{0}+\gamma_{\mathrm{p}}+\gamma_{\mathrm{R}}$

onde $\gamma_{0}$ é a energia de superfície intrínseca (resultante da quebra de ligações químicas), $\gamma_{p}$ é a energia proveniente de microdeformações plásticas na ponta da trinca e $\gamma_{\mathrm{R}}$ é a energia média resultante da interação da trinca com a microestrutura 
do material, principalmente no rastro da trinca, em materiais com matriz frágil. No caso de compósitos, $\gamma_{R}$ representa processos particulares que consomem energia, tais como atuações de pontes e arrancamentos (pull-out) de fibras e outros processos irreversíveis (RODRIGUES e SANTOS, 2004, 2005).

A energia de fratura deve ser obtida a partir de um ensaio de propagação estável de trinca. No início de propagação de trinca, a energia de deformação elástica armazenada não depende apenas da tenacidade à fratura, TFT, e do módulo de Young, E, do compósito, mas também de fatores como dimensões geométricas do corpo-de-prova e da profundidade do entalhe e da rigidez do equipamento de ensaio, incluindo o suporte de flexão. $O$ excesso de módulo elástico contribui para a aceleração da frente de propagação. Para a propagação de trinca em estado estacionário ser alcançada, a taxa de módulo elástico liberada deve ser sempre equivalente à da energia consumida para formar a fratura de duas superfícies.

Otimizar os parâmetros de teste (velocidade do atuador, rigidez da máquina, altura da amostra, profundidade do entalhe, por exemplo) facilita a obtenção de um crescimento estável de trinca. Para tanto, foi necessário utilizar uma máquina universal servohidraúlica de ensaios mecânicos com alta rigidez e controle de precisão de força e deslocamento do atuador (NAKAYAMA; ABE; BRADT, 1981; SAKAI e BRADT, 1993; SANTOS et al., 2015).

O esquema da Figura 20 ilustra, adicionalmente, os principais parâmetros que devem ser observados para se obter a estabilidade do sistema máquina e corpo-deprova: flexibilidade da máquina, $\mathrm{C}_{\mathrm{M}}$, e velocidade de deslocamento do atuador, $\mathrm{V}_{\mathrm{M}}$, dimensões do corpo de prova e sua flexibilidade, $\operatorname{CS}(\alpha)$, bem como a profundidade do entalhe. 


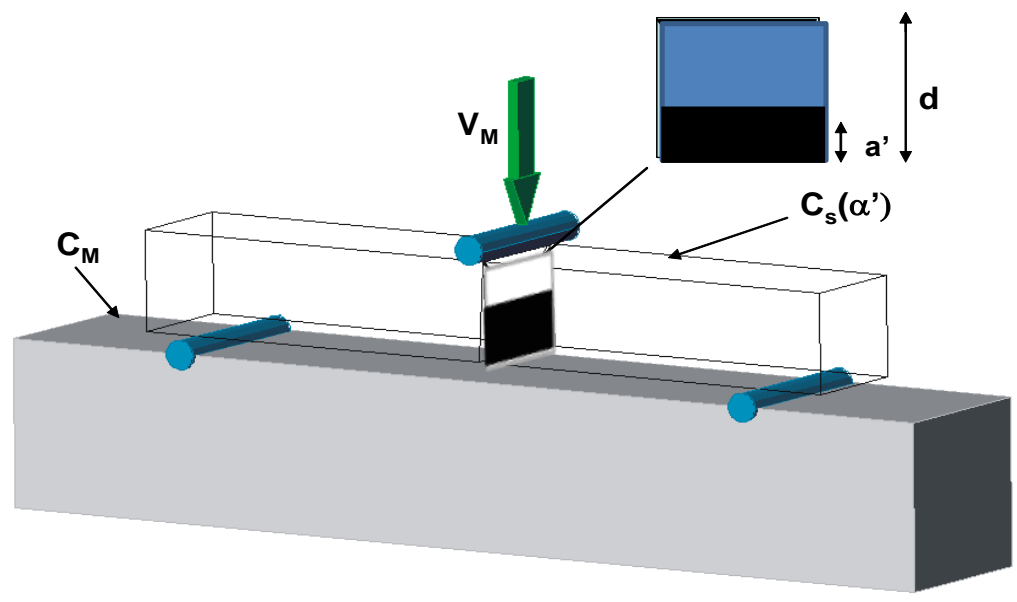

Figura 20 - Esquema de um sistema de flexão estática a três pontos, com um corpo de prova com entalhe plano. $C_{M}$ e $\operatorname{Cs}\left(\alpha^{\prime}\right)$ são as flexibilidades da máquina de ensaio e do corpo de prova, respectivamente. $\alpha$ ' é a razão entre a' e d e $V_{M}$ é a velocidade de deslocamento do atuador da máquina.

Neste trabalho, para medida da energia de fratura foi utilizada a configuração SENB (corpo-de-prova entalhado para flexão em três pontos), conforme Figura 21a.

A distância entre apoios foi de $64 \mathrm{~mm}$. O corpo-de-prova com entalhe plano com profundidade de $30 \%$ da altura do corpo foi confeccionado com disco diamantado com $500 \mu \mathrm{m}$ de espessura (Figura 21b). O ensaio foi realizado na máquina universal de ensaios mecânicos MTS modelo 370.02 servohidraúlica, no Laboratório de Construções e Ambiência da FZEA USP. A velocidade de deslocamento do atuador foi de $20 \mu \mathrm{m} / \mathrm{min}$ (SANTOS et al., 2015).

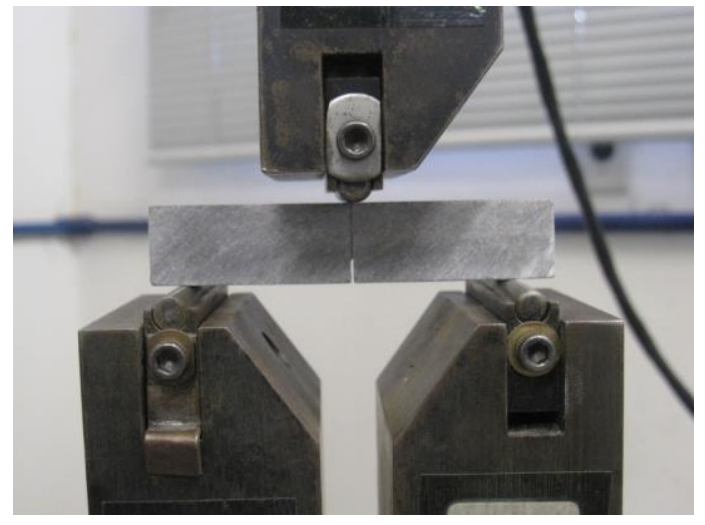

(a)

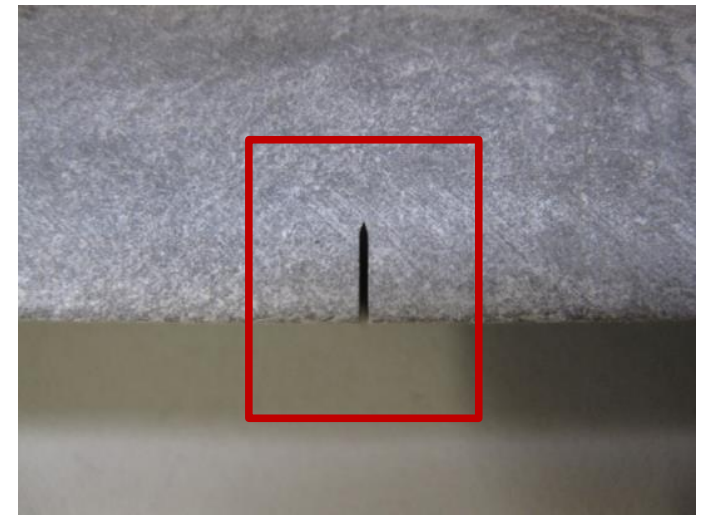

(b)

Figura 21 - (a) llustração do ensaio de flexão a três pontos e (b) detalhe do entalhe no corpo de prova. 
Para o cálculo da energia de fratura, $\gamma$ WoF, o trabalho realizado pela máquina para romper completamente o corpo de prova foi dividido pela área projetada da superfície de fratura, multiplicada por dois. A integração da curva forçadeslocamento do atuador, com auxílio do programa Origin $\AA$, foi feita até o ponto em que a força diminui para $5 \%$ da força máxima atingida no teste (RODRIGUES e SANTOS, 2004, 2005). Foram extraídos parâmetros mecânicos da curva forçadeslocamento tais como, flexibilidade, força máxima atingida, $F_{\max }$, e deslocamento máximo atingido, Deslmax, com o intuito de avaliar detalhadamente o valor de $\gamma$ woF. A determinação da flexibilidade foi abordada nos resultados e discussões.

\subsection{Caracterização Física}

Os valores de absorção de água ( $A A$ ), de porosidade aparente (PA) e de densidade aparente ${ }^{i^{*}}$ (DA) foram determinados pela média de 10 corpos-de-prova para cada formulação, seguindo os procedimentos especificados pela norma ASTM C 948-81 (1982).

A caracterização física dos compósitos foi realizada aos 7 dias de cura térmica e após os 200 ciclos de envelhecimento acelerado. A equação 8 foi utilizada para o cálculo da absorção de água, AA, em \%, dos compósitos:

$$
A A=\left(\frac{M_{s s s}-M_{\text {sec a }}}{M_{\text {sec a }}}\right) \cdot 100
$$

Onde $M_{s s s}$ é a massa do compósito saturado em água e com superfície seca e Mseca é a massa do compósito seco em estufa ventilada a $105^{\circ} \mathrm{C}$ por $48 \mathrm{~h}$.

A porosidade aparente, $\mathrm{PA}$, em $\%$ e a densidade aparente, DA, em $\mathrm{g} / \mathrm{cm}^{3}$, foram determinadas com as Eq. 9 e Eq. 10:

$$
P A=\left(\frac{M_{s s s}-M_{\text {sec a }}}{M_{s s s}-M_{i}}\right) \cdot 100
$$


$D A=\left(\frac{M_{\text {sec a }}}{M_{s s s}-M_{i}}\right) \cdot \rho$

Onde $\mathrm{Mi}_{\mathrm{i}}$ é a massa do compósito saturado imerso em água e $\rho$ é a densidade da água $\left(\mathrm{g} / \mathrm{cm}^{3}\right)$.

\subsection{Caracterização microstrutural}

\subsubsection{Nanoindentação (NI)}

As amostras foram cortadas em com disco de diamante de precisão e embutidos em poliacrilamida. Em seguida, as superfícies foram lixadas com uma sequência de lixas (grid \# 500, \# 1000, \# 2000 e \# 4000) e polidas em uma politriz de spray diamante com sequência $(9 \mu \mathrm{m}, 6 \mu \mathrm{m}$ e $3 \mu \mathrm{m})$. As análises foram realizadas em um nanoindentador da marca Agilent, modelo L-200, (Figura 22a), de medida rigidez contínua, configurado em $2 \mathrm{~nm}$ de amplitude harmónica, $45 \mathrm{~Hz}$ de frequência e usando um indentador diamante da marca Berkovich de formato piramidal (Figura 22b) com ângulo de 164ํㅡㄹ existente no Laboratório de Materiais do Departamento de Engenharia de Materiais da Universidade Politécnica de Valencia (UPV), Espanha. Os locais dos testes foram guiados por meio de um microscópio de luz óptica integrada. As análises foram programadas para alcançar a profundidade máxima de $500 \mathrm{~nm}$, realizadas com $8 \mathrm{~nm}$ de distância mínima entre os pontos de medição (DA SILVA; NĚMEČEK; ŠTEMBERK, 2014). Foram determinadas a dureza $(H)$ e 0 módulo elástico ( $E$ ) para cada região do compósito (matriz cimentícia, zona de transição fibra matriz, grãos anidros e fibra celulósica). Para cada região do compósito foram realizadas 10 repetições com 7 dias de cura térmica e 10 repetições após os 200 ciclos de envelhecimento acelerado. 


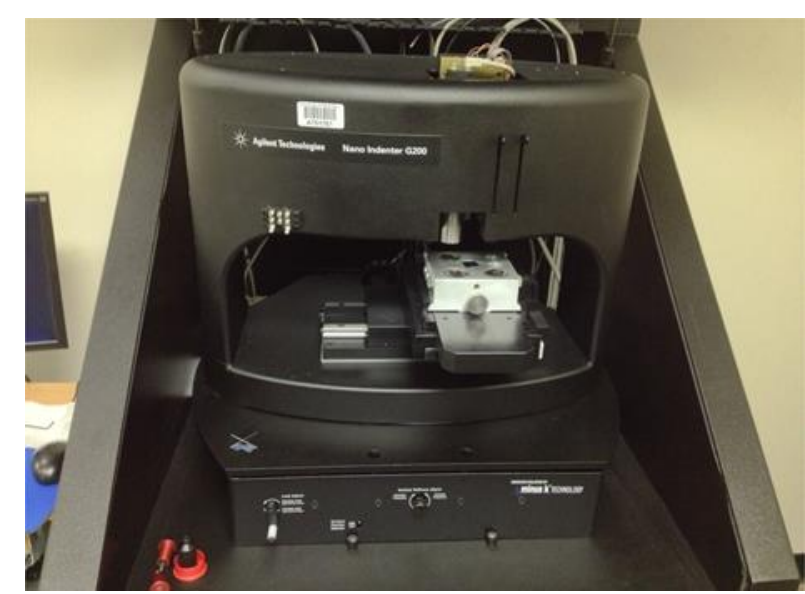

(a)

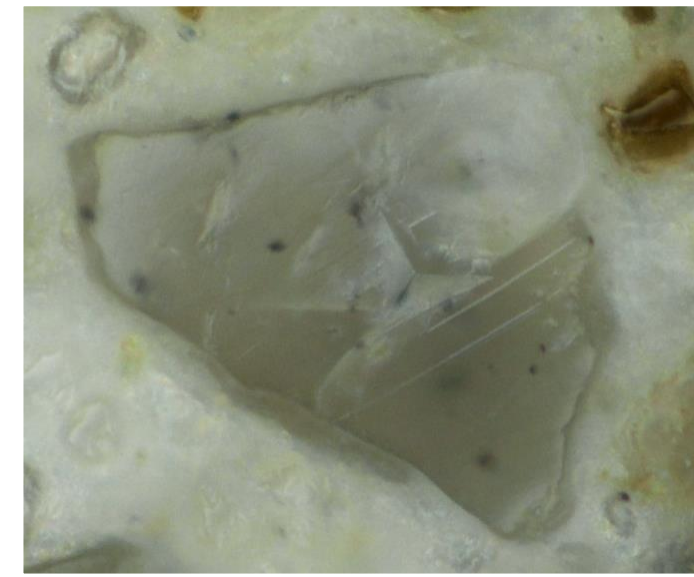

(b)

Figura 22 - (a) Detalhes da máquina de nanoindentação e (b) indentador com formato piramidal em um grão anidro.

\subsubsection{Microscopia eletrônica de varredura (MEV)}

O efeito das diferentes condições das fibras na microestrutura do compósito e na zona de transição entre a fibra e a matriz foi avaliado por microscopia eletrônica de varredura (MEV) com detector de elétrons retroespalhados (BSE) em superfícies cortadas e polidas de secções transversais dos compósitos. As imagens BSE permitem a fácil identificação de fases cimentícias, pelo contraste entre números atômicos. Áreas escuras e claras estão relacionadas a elementos leves e pesados respectivamente. A localização dos átomos de cálcio $(\mathrm{Ca})$, carbono $(\mathrm{C})$ e silício $(\mathrm{Si})$ na secção transversal dos compósitos foi realizada usando microanálises de fluorescência de raios-X com detector de energia dispersa (EDS) nas mesmas amostras com superfície polida.

Os procedimentos para preparação das amostras foram baseados em Tonoli et al. (2009b). A preparação das amostras para BSE e EDS foi realizada com o embutimento usando resina epóxi (MC-DUR1264FF). As amostras foram então lixadas com lixas de carbeto de silício $\left(S_{i} C\right)$ na sequência de granulometrias de 500 e 1000 durante 5 min cada uma, usando etanol (Struers DP-lubricant) como lubrificante. O polimento final foi realizado com pasta de diamante de diferentes granulometrias na seguinte sequência: $9 \mu \mathrm{m}, 6 \mu \mathrm{m}$ e $3 \mu \mathrm{m}$ durante 6 min cada uma. As amostras foram analisadas em um microscópio eletrônico LEO Leika S440 com aceleração de voltagem de $20 \mathrm{kV}$ e corrente em torno de $150 \mathrm{~mA}$. As análises com 
MEV's foram realizadas nos compósitos com 7 dias de cura térmica e após os 200 ciclos de envelhecimento acelerado.

\subsubsection{Microtomografia de raios- $X(M R X)$}

A técnica de microscopia por tomografia de raios $X$ de alta resolução foi utilizada a fim de analisar a presença, a direção e a distribuição das fibras e a presença e a distribuição de poros nos compósitos. A análise por MRX possibilitou a digitalização em 3D da distribuição das fibras no interior da matriz (GALLUCCl et al., 2007). A análise foi realizada utilizando-se o tomógrafo Xradia 510 Versa, da marca Zeiss, do Laboratório de Caracterização Tecnológica da Escola Politécnica da Universidade de São Paulo (LCT/POLI-USP). Os ensaios de MRX foram realizados nos compósitos após 7 dias de cura térmica.

\subsection{Analise estatística}

A combinação dos níveis dos fatores frações de fibras [\%F] (1\%; $2 \%$ ), comprimento das fibras [CF] $(6 \mathrm{~mm} ; 10 \mathrm{~mm})$, envelhecimento [Env] (7 dias [7d] - não envelhecido; 200 ciclos de envelhecimento acelerado [200C]) e tipo da fibra [TF] (polipropileno [PP]; Curauá [Cur]) forneceu 16 tratamentos [Tr] distintos, explicitados na Tabela 7. 
Tabela 7 - Tratamentos experimentais delineados.

\begin{tabular}{|c|c|c|c|c|c|c|c|c|c|}
\hline \multirow{2}{*}{ Formulação } & \multirow{2}{*}{ Tratamentos } & \multicolumn{2}{|c|}{$\% F$} & \multicolumn{2}{|c|}{ CF } & \multicolumn{2}{|c|}{ TF } & \multicolumn{2}{|c|}{ Env } \\
\hline & & $1 \%$ & $2 \%$ & $6 \mathrm{~mm}$ & $10 \mathrm{~mm}$ & PP & Cur & $7 d$ & $200 c$ \\
\hline FPP $1 \% 6$ mm & $\operatorname{Tr} 1$ & $x$ & & $x$ & & $x$ & & $x$ & \\
\hline FPP $1 \% 10 \mathrm{~mm}$ & $T r 2$ & $x$ & & & $x$ & $x$ & & $x$ & \\
\hline FPP $2 \% 6$ mm & $\operatorname{Tr} 3$ & & $x$ & $x$ & & $x$ & & $x$ & \\
\hline FPP $2 \% 10 \mathrm{~mm}$ & Tr4 & & $x$ & & $x$ & $x$ & & $x$ & \\
\hline $\mathrm{FC} 1 \% 6 \mathrm{~mm}$ & $\operatorname{Tr} 5$ & $x$ & & $x$ & & & $x$ & $x$ & \\
\hline $\mathrm{FC} 1 \% 10 \mathrm{~mm}$ & $\operatorname{Tr} 6$ & $x$ & & & $x$ & & $x$ & $x$ & \\
\hline $\mathrm{FC} 2 \% 6 \mathrm{~mm}$ & $\operatorname{Tr} 7$ & & $x$ & $x$ & & & $x$ & $x$ & \\
\hline $\mathrm{FC} 2 \% 10 \mathrm{~mm}$ & $\operatorname{Tr} 8$ & & $x$ & & $x$ & & $x$ & $x$ & \\
\hline FPP $1 \% 6 \mathrm{~mm}$ & Tr9 & $x$ & & $x$ & & $x$ & & & $x$ \\
\hline FPP $1 \% 10 \mathrm{~mm}$ & $\operatorname{Tr} 10$ & $x$ & & & $x$ & $x$ & & & $x$ \\
\hline FPP $2 \% 6 \mathrm{~mm}$ & $\operatorname{Tr} 11$ & & $x$ & $x$ & & $x$ & & & $x$ \\
\hline FPP $2 \% 10 \mathrm{~mm}$ & $\operatorname{Tr} 12$ & & $x$ & & $x$ & $x$ & & & $x$ \\
\hline FC $1 \% 6 \mathrm{~mm}$ & $\operatorname{Tr} 13$ & $x$ & & $x$ & & & $x$ & & $x$ \\
\hline $\mathrm{FC} 1 \% 10 \mathrm{~mm}$ & $\operatorname{Tr} 14$ & $x$ & & & $x$ & & $x$ & & $x$ \\
\hline $\mathrm{FC} 2 \% 6 \mathrm{~mm}$ & $\operatorname{Tr} 15$ & & $x$ & $x$ & & & $x$ & & $x$ \\
\hline $\mathrm{FC} 2 \% 10 \mathrm{~mm}$ & $\operatorname{Tr} 16$ & & $x$ & & $x$ & & $x$ & & $x$ \\
\hline
\end{tabular}

Do planejamento experimental completo (Tabela 7) foram investigadas propriedades físicas: absorção de água (AA), porosidade aparente (PA) e densidade aparente (DA) e mecânicas: módulo de ruptura (MOR), energia de fratura (EF), e tenacidade à fratura (TFT), sendo testadas 10 amostras por tratamento (repetições), totalizando 1120 determinações experimentais mais 70 outras referentes à formulação de referência (matriz não reforçada).

Com relação à reologia dos materiais fabricados, as propriedades investigadas foram a tensão de escoamento correspondente a velocidade $v_{0}\left(\sigma_{0}\right)$, efeito da velocidade na tensão de escoamento ( $\alpha$ ), tensão inicial de cisalhamento $(\mathrm{T})$ ), efeito da velocidade na tensão de cisalhamento $(\beta)$ e pressão de extrusão $(P)$. Para tanto, foram utilizados apenas os oito primeiros tratamentos da Tabela 7 (Tr1 a Tr8), não sendo considerado o fator envelhecimento acelerado nesse estudo. Ressalta-se que foram utilizadas 4 amostras por tratamento e por propriedade 
mecânica avaliada, resultando em 128 determinações, mais 16 outros referentes às mesmas propriedades dos materiais não reforçados (referência ou testemunha).

As propriedades mecânicas obtidas dos testes de nanoindentação nos materiais envelhecidos e não envelhecidos foram o módulo elástico $(E)$ e a dureza (H). Para tanto, foi investigada a influência de regiões específicas das amostras na obtenção dessas duas propriedades mecânicas. A Tabela 8 especifica as regiões estabelecidas nas amostras para a determinação dos valores das propriedades $\mathrm{E} \mathrm{e}$ $\mathrm{H}$, assim como do número de determinações obtidas experimentalmente por região e por propriedade mecânica, o que totalizou 260 determinações experimentais.

Tabela 8 - Regiões estipuladas nas amostras para a determinação dos valores de módulo elástico e de dureza dos ensaios de nanoindentação.

Regiões Específicas

Número de determinações por região e por propriedade

Não envelhecido (7d) Envelhecido (200c)

\begin{tabular}{ccc}
\hline Grãos Anidros & 10 & 10 \\
Matriz cimentícia & 10 & 10 \\
Fibra celulósica & 10 & 10 \\
Transição Fibra-Matriz & 10 & 10 \\
Fibra curauá-borda & 10 & 10 \\
Fibra curauá-centro & 10 & 10 \\
Fibra polipropileno & 5 & 5 \\
\hline
\end{tabular}

Para investigar a influência dos fatores individuais e da interação entre ambos nas propriedades físicas e mecânicas de interesse, foi utilizada a análise de variância (ANOVA), com o auxílio do software Minitab ${ }^{\circledR}$ versão 14. A ANOVA foi considerada ao nível de $5 \%$ de significância (a), e teve como hipótese nula $\left(\mathrm{H}_{0}\right)$ a equivalência das médias dos tratamentos e a não equivalência (de ao menos uma) como hipótese alternativa $\left(\mathrm{H}_{1}\right)$. Pela formulação da ANOVA, P-valor (probabilidade P) inferior ao nível de significância $(0,05)$ implica em rejeitar $\mathrm{H}_{0}$ (pelo menos uma média se difere das demais), aceitando-a em caso contrário (médias equivalentes).

Para validação da ANOVA, foram testadas a normalidade por propriedade (teste de Anderson-Darling $[A D]$ ), a homogeneidade da variância dos tratamentos (teste de Bartlett [Bt]) e a independência dos resíduos (gráfico de resíduos $\times$ ordem). 
Pela formulação dos testes de validação da ANOVA, P-valor superior ao nível de 5\% de significância implica que a propriedade apresenta normalidade na distribuição e homogeneidade de variâncias. A transformada de Johnson foi utilizada quando a distribuição para alguma resposta não apresentou normalidade.

Considerada significativa a interação entre fatores pela ANOVA para alguma das propriedades avaliadas, na sequencia foram utilizados gráficos de interação entre fatores, colaborando na interpretação dos efeitos de interação. No caso do fator (isoladamente) ser considerado significativo, o teste de comparações múltiplas de Tukey (teste de contraste de médias) foi utilizado para o agrupamento dos níveis d fator. No teste de Tukey, A denota o nível do fator com o maior valor médio da propriedade em questão, $\mathrm{B}$ o segundo maior valor médio e assim sucessivamente, e letras iguais implicam tratamentos com médias estatisticamente equivalentes.

No planejamento envolvendo os 16 tratamentos (Planejamento 1 propriedades físicas e mecânicas) e os 8 primeiros tratamentos (Planejamento 2 reologia), depois de compreendido os efeitos dos fatores e das interações entre ambos em cada propriedade investigada, a condição de referência foi adicionada ao grupo com 16 e 8 tratamentos, possibilitando, via a análise de variância, investigar as diferenças dos tratamentos para com a condição de referência.

A ANOVA foi utilizada também para investigar a influência das regiões estabelecidas nas amostras para os ensaios de nanoindentação (dureza e módulo elástico). No caso da não normalidade na distribuição, a ANOVA não paramétrica de Kruskal-Wallis foi utilizada em conjunto com o teste de comparações entre postos de Student-Newman-Keuls, também ao nível de 5\% de significância e sob as mesmas hipóteses da ANOVA paramétrica. 


\section{RESULTADOS E DISCUSSÕES}

\subsection{Fibras de reforço}

Uma questão importante na confecção dos compósitos é o empacotamento dos materiais particulados e a dispersão das fibras na matriz, assim como as características de cada matéria-prima. Por isso, para melhor entender os resultados relacionados com a ancoragem das fibras na matriz cimentícia, estas foram caracterizadas. As propriedades das fibras estudadas neste trabalho, curauá e polipropileno, estão listadas nas Tabelas 9 e 10 respectivamente.

Tabela 9 - Propriedade mecânicas, químicas e físicas das fibras de curauá (FIDELIS et al., 2013).

\begin{tabular}{cc}
\hline \multicolumn{2}{c}{ Mecânicas } \\
\hline Tensão máxima (MPa) & 550 \\
Módulo de Young (GPa) & 64 \\
\hline Químicas (análise bromatológica) \\
\hline Celulose (\%) & 68 \\
Hemicelulose $(\%)$ & 10 \\
Lignina $(\%)$ & 14 \\
\hline \multicolumn{1}{c}{ Físicas } \\
\hline Comprimento médio $(\mathrm{mm})$ & $0,00 \pm 0,88$ e $10,00 \pm 0,46$ \\
Seção de área $\left(\mathrm{mm}^{2}\right)$ & 0,1136 \\
Espessura $(\mu \mathrm{m})$ & $\sim 75$ \\
Densidade $\left(\mathrm{g} / \mathrm{cm}^{3}\right)$ & 1,42 \\
\hline
\end{tabular}

Os teores de celulose foram similares aos valores encontrados por Faruk et al. (2014) e Caraschi e Leão (2000), que encontraram 73\% e 71\% respectivamente. A lignina variou de $7,5 \%$ a $13 \%$ pelos mesmos autores. Nesse caso, deve ser considerado, além da variação natural das fibras, os métodos de quantificação. $O$ teor de celulose foi próximo ao valor encontrado por Caraschi e Leão (2000) de $70,7 \%$. 
Tabela 10 - Propriedades mecânicas e físicas das fibras de polipropileno.

\begin{tabular}{|c|c|}
\hline \multicolumn{2}{|c|}{ Mecânicas* } \\
\hline Tensão máxima (MPa) & 500 \\
\hline Módulo de Young (GPa) & 10 \\
\hline Alongamento (\%) & 19 \\
\hline \multicolumn{2}{|c|}{ Físicas } \\
\hline Comprimento médio (mm) & $6,00 \pm 0,10$ e $10,00 \pm 0,10^{*}$ \\
\hline Diâmetro médio ( $\mu \mathrm{m})$ & $\sim 13$ \\
\hline Densidade $\left(\mathrm{g} / \mathrm{cm}^{3}\right)$ & 0,92 \\
\hline
\end{tabular}

* Dados fabricante: Saint Gobain.

As Figuras 23a e 23b mostram a FC com forma aproximadamente elíptica e com superfície rugosa, que pode ajudar na ancoragem das fibras no compósito cimentício. Na Figura 23c, é possível observar as células unitárias da fibra e também os lumens (cavidades) dessas células (FIDELIS et al., 2013).

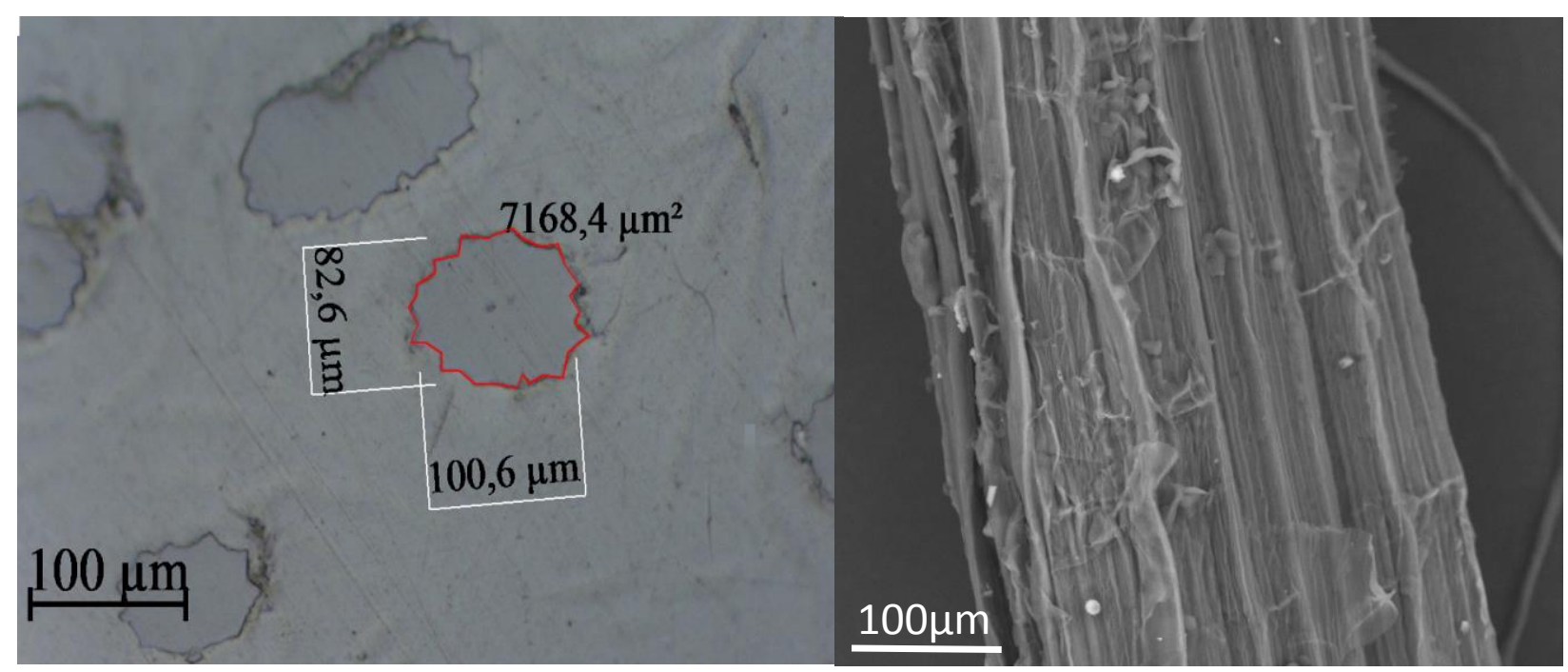

(a)

(b) 


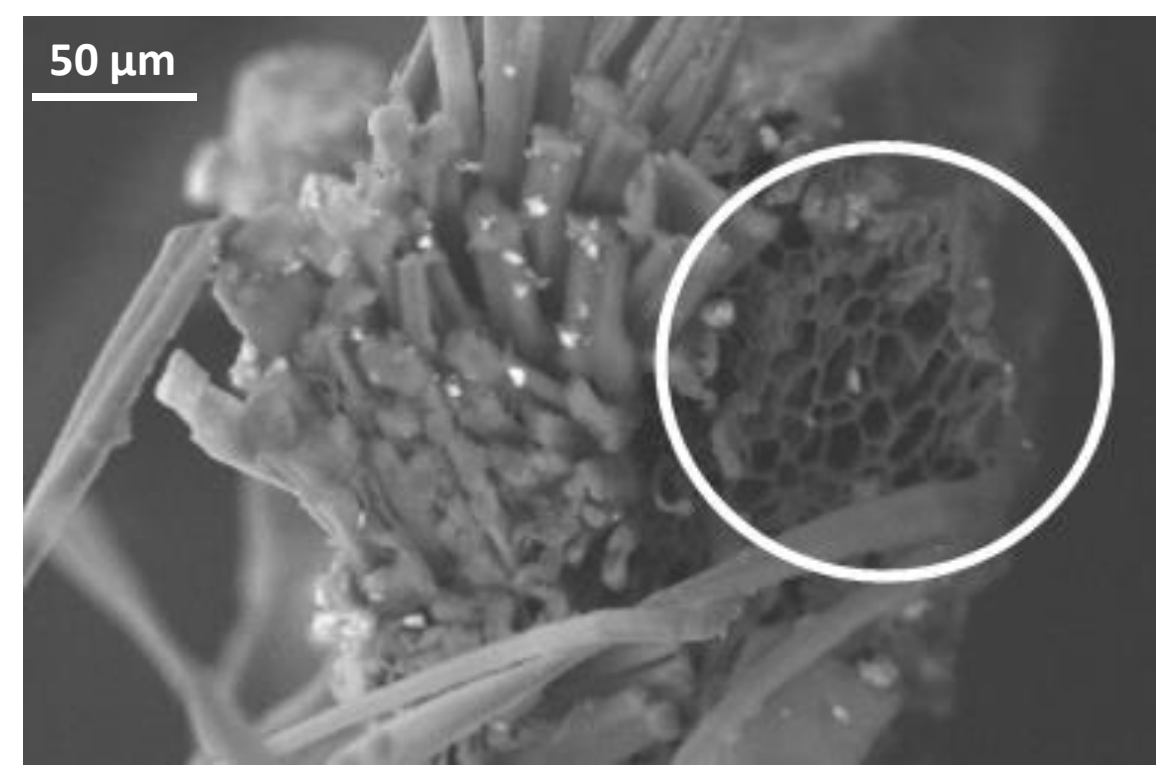

(c)

Figura 23 - Características morfológicas das FC observadas por meio de microscopia eletrônica de varredura. (a) com a fibra embutida em resina superfície lateral; (b) área de seção transversal e (c) secção transversal destacando os lumens irregulares.

As Figuras 24a e 24b apresentam as micrografias por MEV das fibras de polipropileno, que tem boa resistência química, a umidade e ao calor. As fibras de PP têm baixa densidade, alta resistência superficial e estabilidade dimensional. A FPP tem sido utilizada na indústria de fibrocimento (TEIXEIRA et al., 2014).
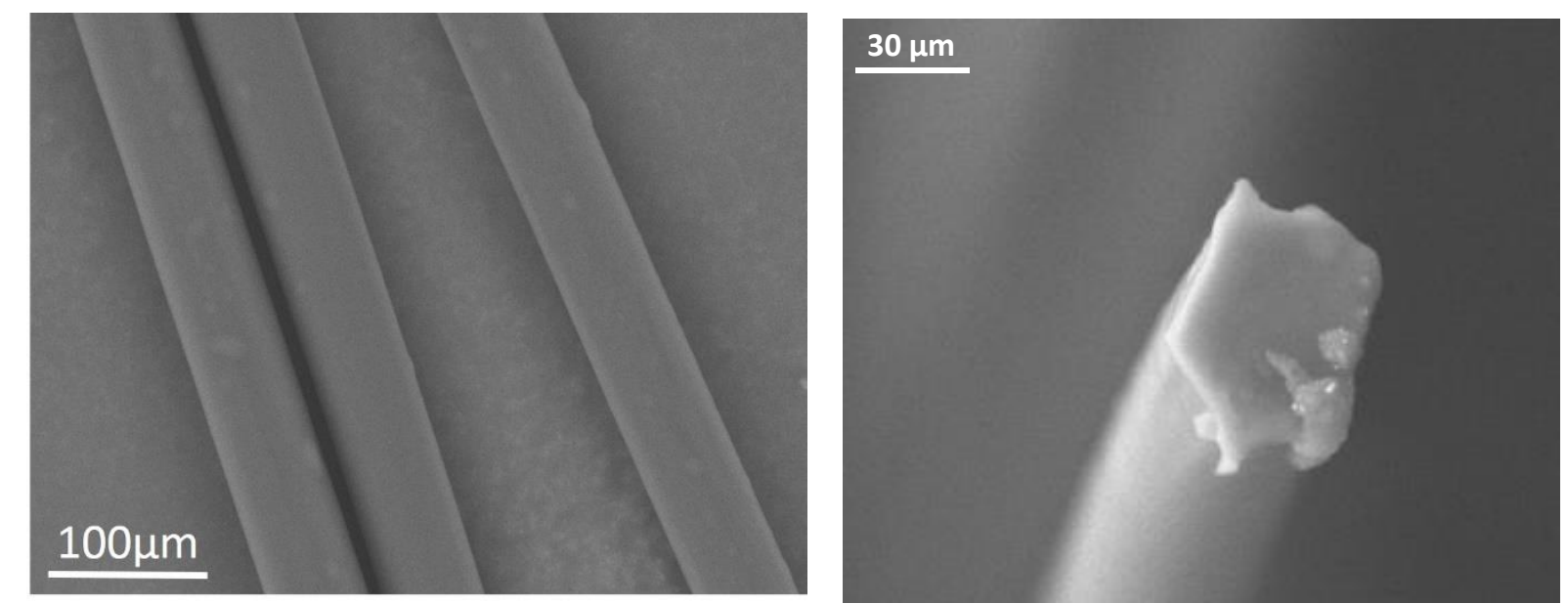

Figura 24 - (a) e (b) Características morfológicas de FPP observados por microscopia eletrônica de varredura. Observamos o amassamento provocado pelo corte da fibra. 


\subsection{Resultado reológico da pasta cimentícia}

\subsubsection{Técnica Squeeze flow}

As Figuras 25a e 25b mostram as influências dos teores e dos comprimentos das fibras, FC e FPP, respetivamente, no comportamento reológico das pastas cimentícias. No caso das pastas com FC, nota-se, como esperado, que, quanto maior o comprimento e/ou o teor de fibras, maior a quantidade de água necessária para manter o sistema coeso. As pastas cimentícias reforçadas com FC necessitaram de maior força para se deslocarem, e, portanto, com maior deslocamento em relação às pastas cimentícias reforçadas com FPP.

FC apresenta uma seção transversal com forma elíptica, com valor de área com variabilidade e superfície rugosa, como mostram a Tabela 9 e a Figura 23, respectivamente. Devido a essas características físicas, as FC mostraram dificuldade de fluir em um sistema com partículas, as quais são normalmente irregulares. Além disso, como as fibras são hidrofílicas, sequestram a água do sistema necessária para facilitar a movimentação das partículas. Observa-se que a

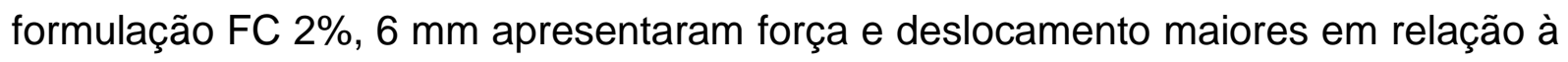
formulação FC $2 \%, 10 \mathrm{~mm}$. Isso pode ser explicado pelo fato que, em certo volume de fibra, existe maior número de filamentos de $6 \mathrm{~mm}$ do que de $10 \mathrm{~mm}$. Dessa forma, pastas com fibras de curauá de $6 \mathrm{~mm}$ apresenta maior números de fibras em relação as pastas com fibras de curauá $10 \mathrm{~mm}$. O maior número de fibras causa um maior travamento no sistema que induz a maior absorção de água isso ocasiona uma maior deslocamento e força entre a fibra e a matriz, na pasta.

Ao atingir um teor crítico de água, isto é, teor de água suficiente para a formação de pontes entre as partículas, ocorre um grande aumento na resistência ao cisalhamento devido à geração de forças capilares de atração entre as partículas; isto leva ao aumento da força necessária para o cisalhamento (OLIVEIRA et al., 2000). Outro fator que influencia o comportamento reológico é a granulometria e a morfologia dos grãos de cimento e do calcário (filler). Normalmente os grãos de cimento e calcário são rugosos e angulosos, o que provavelmente facilita o seu travamento, ou seja, a mistura atinge a fase de travamento dos grãos mais rapidamente, daí a maior necessidade de força para movimentar a pasta (MATTANA; MARON COSTA, 2009). 


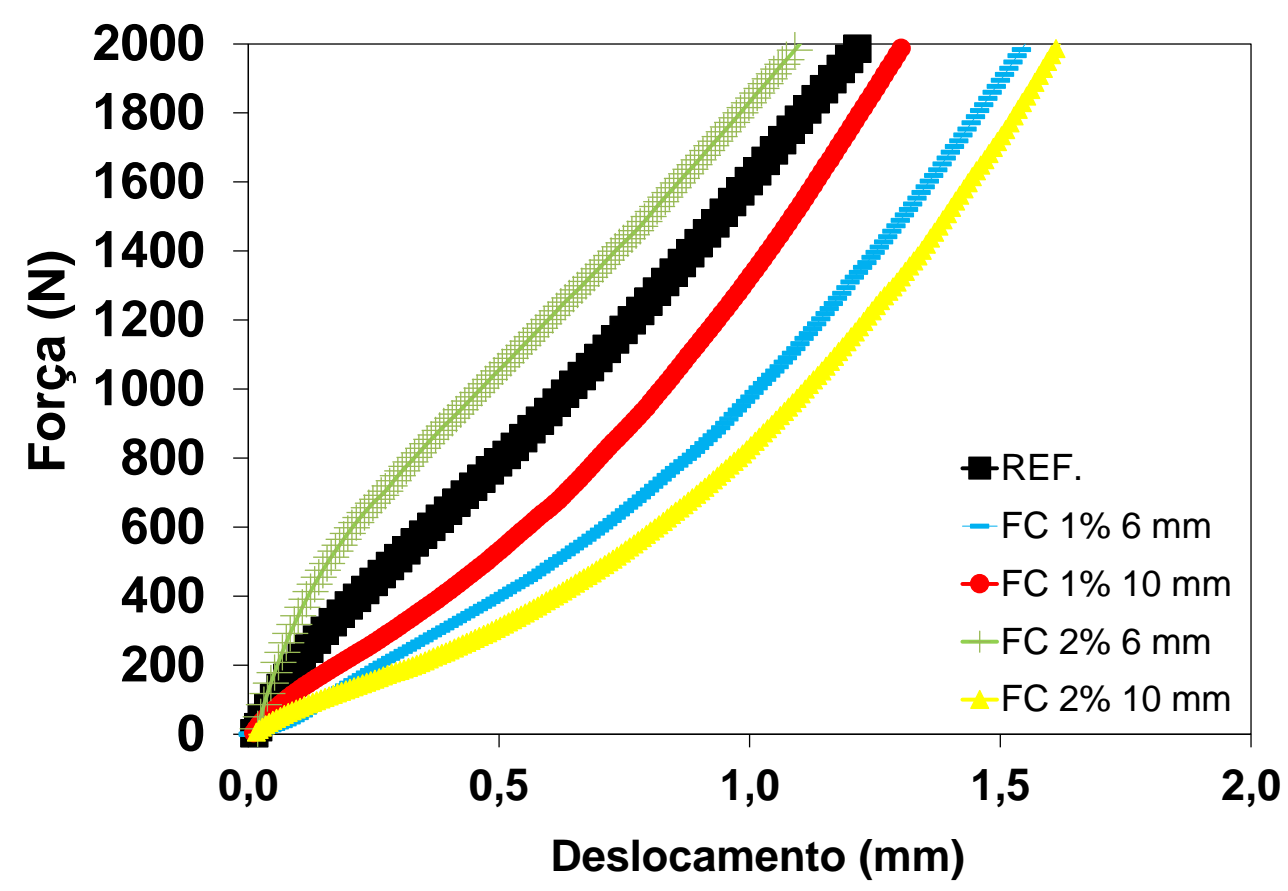

(a)

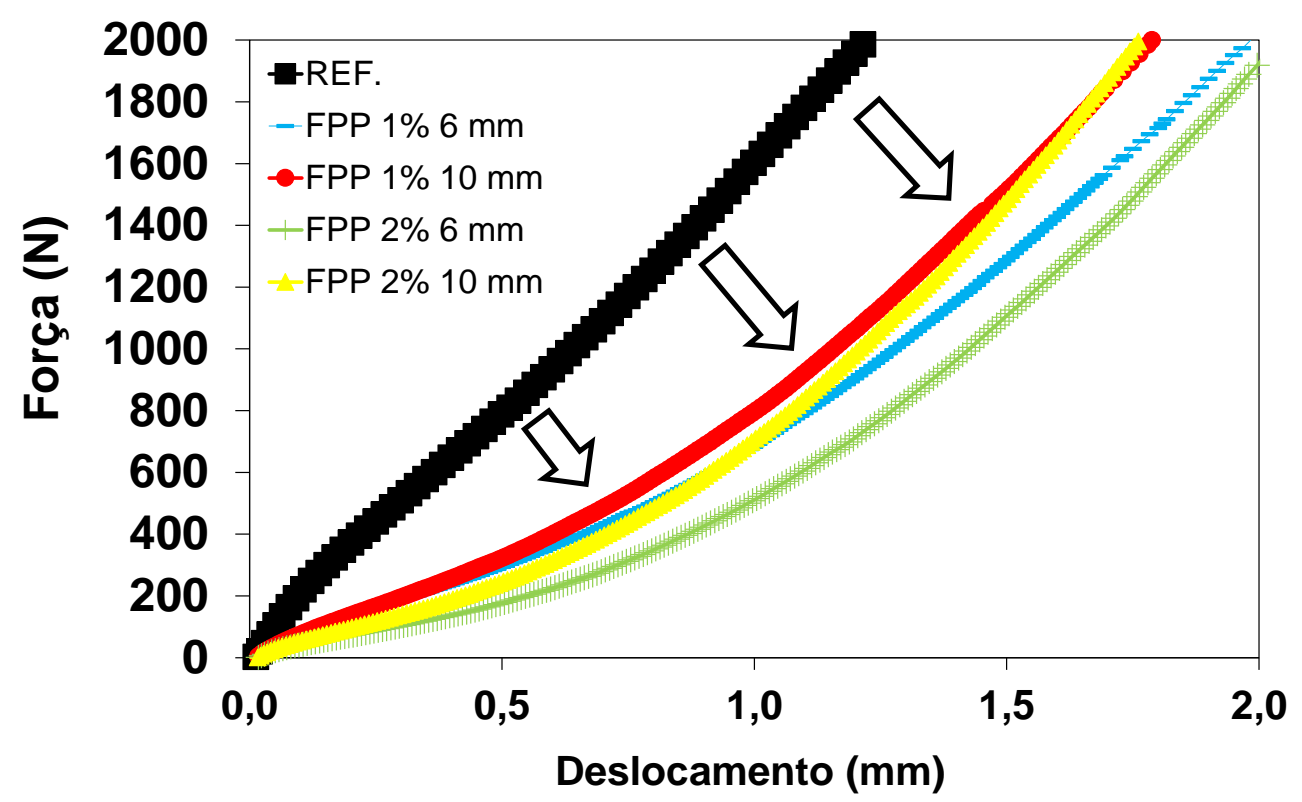

(b)

Figura 25 - Curvas obtidas por meio da técnica de Squeeze flow: das pastas com fibras. (a) FC e (b) FPP.

As pastas cimentícias reforçadas com FPP mostraram similaridade de comportamento entre os teores e comprimentos e menores forças e deslocamentos em relação às pastas com FC. Pastas com FPP apresentaram menor deslocamento devido à fibra ser hidrofóbica e, com isso, o sistema não perde água. Nesse caso, a 
água, como lubrificante, contribuiu para manter as partículas mais dispersas e consequentemente o sistema mais homogêneo.

A atuação dos aditivos reológicos também foi mais efetiva, pois o fluxo das partículas de cimento e calcário parece ter sido facilitado, e manteve a coesão do material reforçado com FPP (DNPM, 2011).

O sistema manteve a capacidade plástica de coesão das matérias-primas e de lubrificação entre as partículas do cimento e calcário, assim houve uma progressiva redução das forças necessárias para deformação do material. Dessa forma, as partículas movimentaram-se reduzindo os níveis de força, especialmente para as pastas de FPP $2 \% 10 \mathrm{~mm}$, que utilizaram maiores dosagens de água em relação ao cimento, apresentada na tabela 4.

\subsubsection{Técnica reômetro extrusor}

As médias e os desvios padrões dos parâmetros do reômetro extrusor são mostrados na Tabela 11. A Figura 26 apresenta a tensão de escoamento correspondente a velocidade zero $(\sigma 0)$ da pasta cimentícia que aumentou de 12,41 $\mathrm{kPa}$ (REF) para 19,88 kPa (FPP 2\% $10 \mathrm{~mm}$ ) e 26,87 kPa (FC 2\% $10 \mathrm{~mm}$ ). A relação água/cimento aumentou de 0,30 (REF) para 0,35 (FPP 2\% $10 \mathrm{~mm}$ ) e 0,36 (FC 2\% $10 \mathrm{~mm}$ ). Esses resultados podem ser atribuídos ao emaranhamento das FC devido às suas características físicas. Outro fator que contribuiu foi a maior quantidade de água com o aumento do teor de fibras, devido a uma maior absorção de água pela fibra de FC, o que sugere um resultado de tensão de escoamento maior em relação as pastas com FPP (LI; ZHANG; ZHOU, 2005). 
Tabela 11 - Resultados dos parâmetros do reômetro extrusor

\begin{tabular}{lccccc}
\hline \multicolumn{1}{c}{ Formulação } & $\sigma 0[\mathrm{kPa}]$ & $\alpha\left[\mathrm{kPa} . \mathrm{s} \cdot \mathrm{mm}^{-1}\right]$ & T0 $[\mathrm{kPa}]$ & $\beta\left[\mathrm{kPa} . \mathrm{s} . \mathrm{mm}^{-1}\right]$ & Pressão [kPa] \\
\hline Referência & $12,41 \pm 0,73$ & $0,074 \pm 0,026$ & $0,023 \pm 0,003$ & $0,00082 \pm 0,00015$ & $31,43 \pm 1,82$ \\
\hline FC $1 \% 6 \mathrm{~mm}$ & $20,65 \pm 2,71$ & $0,224 \pm 0,072$ & $0,047 \pm 0,007$ & $0,00012 \pm 0,00050$ & $57,36 \pm 8,65$ \\
\hline FC $1 \% 10 \mathrm{~mm}$ & $23,93 \pm 2,13$ & $0,622 \pm 0,127$ & $0,117 \pm 0,006$ & $0,00153 \pm 0,00050$ & $79,71 \pm 13,39$ \\
\hline FC $2 \% 6 \mathrm{~mm}$ & $21,02 \pm 2,50$ & $0,211 \pm 0,087$ & $0,077 \pm 0,007$ & $0,00147 \pm 0,00052$ & $64,59 \pm 14,20$ \\
\hline FC $2 \% 10 \mathrm{~mm}$ & $26,87 \pm 2,90$ & $0,737 \pm 0,131$ & $0,282 \pm 0,014$ & $0,00178 \pm 0,00038$ & $91,31 \pm 15,39$ \\
\hline FPP $1 \% 6 \mathrm{~mm}$ & $14,62 \pm 0,56$ & $0,147 \pm 0,069$ & $0,025 \pm 0,039$ & $0,00087 \pm 0,00024$ & $34,85 \pm 6,13$ \\
\hline FPP $1 \% 10 \mathrm{~mm}$ & $15,90 \pm 0,50$ & $0,148 \pm 0,027$ & $0,026 \pm 0,015$ & $0,00142 \pm 0,00053$ & $42,17 \pm 7,68$ \\
\hline FPP 2\% $6 \mathrm{~mm}$ & $16,09 \pm 1,58$ & $0,154 \pm 0,065$ & $0,015 \pm 0,010$ & $0,00123 \pm 0,00016$ & $34,25 \pm 7,71$ \\
\hline FPP 2\% 10 mm & $19,88 \pm 2,29$ & $0,244 \pm 0,092$ & $0,031 \pm 0,004$ & $0,00188 \pm 0,00027$ & $47,18 \pm 12,18$ \\
\hline
\end{tabular}

A Figura 27 apresenta o efeito do tipo, do comprimento e do teor da fibra na tensão inicial de cisalhamento ( $\mathrm{T} 0$ ). Na literatura, a tensão inicial de cisalhamento (T0) é influenciada por uma fina camada de lubrificação formada entre a pasta cimentícia e a parede da boquilha (ZHOU e LI, 2004). O limite de cisalhamento ( $\mathrm{TO}$ ) da parede da boquilha aumentou com a adição de FPP na pasta cimentícia, pelo fato de existir mais água disponível para a lubrificação em pastas reforçadas com FPP, que mostram resultados semelhantes em todas as formulações.

Pastas com FC apresentaram maiores resultados de $\mathrm{T} 0$ em comparação às pastas com FPP. As pastas com FC apresentaram maior tensão de cisalhamento porque a quantidade de água não foi suficiente para lubrificar todo o sistema que afetou o fluxo e reduziu a eficiência dos aditivos reológicos.

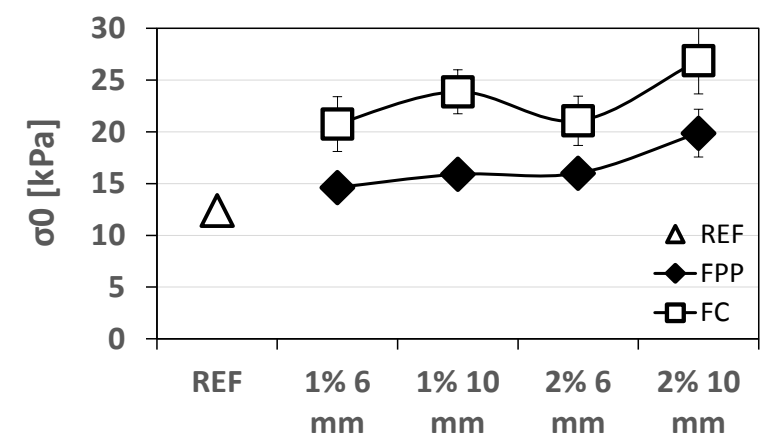

Figura 26 - Efeito da fibra na tensão de escoamento das pastas

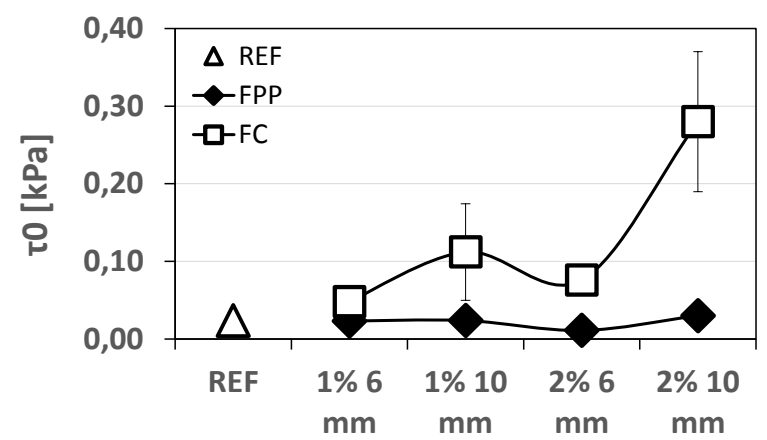

Figura 27 - Efeito da fibra na tensão inicial de cisalhamento das pastas 
A Figura 28 mostra o efeito do tipo, do comprimento e do teor da fibra nos resultados de velocidade na tensão de escoamento $(\alpha)$, que é uma medida que depende da resistência do fluxo do extrudado na entrada da boquilha. A Figura 29 apresenta o efeito do tipo, do comprimento e do teor da fibra na velocidade da tensão de cisalhamento $(\beta)$, que representa o comportamento dinâmico das tensões de cisalhamento, taxa que depende das propriedades da pasta cimentícia (NATH DAS; MADHUSOODANA; OKADA, 2002; ZHOU et al., 2013).

À medida que a quantidade e o comprimento das fibras foram aumentados de $1 \%$ para $2 \%$ e de $6 \mathrm{~mm}$ para $10 \mathrm{~mm}$, a tensão de escoamento $(\alpha)$ aumentou de $0,224 \mathrm{kPa}$ para $0,737 \mathrm{kPa}$ em pastas com $\mathrm{FC}$ e 0,147 $\mathrm{kPa}$ para 0,244 $\mathrm{kPa}$ em pastas com FPP respectivamente. Esperavam-se resultados maiores de tensão de escoamento com maiores teores de fibras, porém a formulação com $1 \% 10 \mathrm{~mm}$ apresentou resultados superiores em relação à formulação com $2 \% 6 \mathrm{~mm}$ para os reforços de FC, como mostrado na Figura 28. Isto resultou em um aumento da tensão de escoamento da pasta na boquilha devido à maior quantidade de água para ser consumida para lubrificar as partículas finas e a formação de uma rede mais consistente e densa causado pelo efeito de empacotamento das fibras.

$\mathrm{Na}$ Figura 29, o efeito do tipo, do comprimento e do teor da fibra nos resultados de tensão de cisalhamento ( $\beta$ ) não apresentaram diferenças entre as formulações tanto para as FC como para as FPP. De acordo com Nair et al. (2000), a incorporação de fibras na pasta cimentícia aumenta a interação entre fibra-matriz e provoca maior escoamento e menor cisalhamento, devido à presença de fibras não orientadas longitudinalmente ao longo da parede do barril na pasta com $10 \mathrm{~mm}$ de comprimento. 


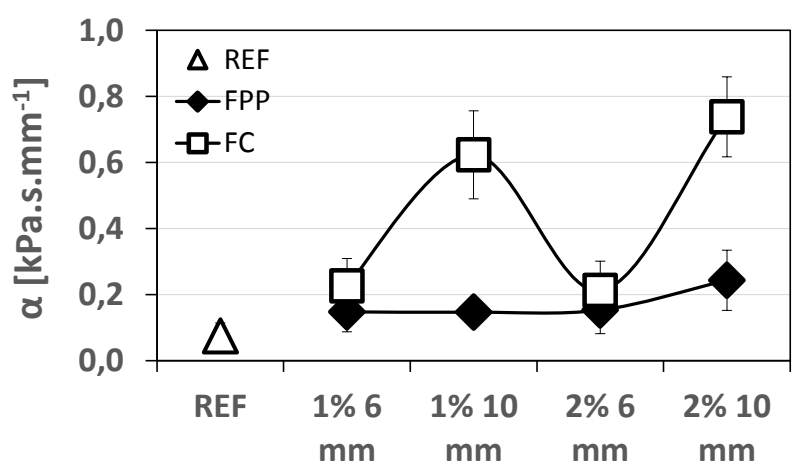

Figura 28 - Efeito da fibra na velocidade da tensão de escoamento das pastas

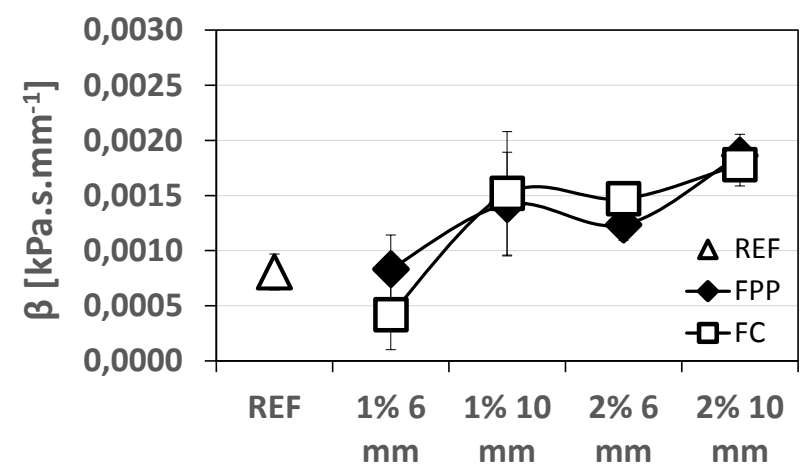

Figura 29 - Efeito da fibra na velocidade da tensão de cisalhamento das pastas

As pastas reforçadas com FC apresentaram aumento de pressão em relação às pastas com reforço de FPP mostrados na Figura 30. A pressão calculada é o efeito combinado de todos os parâmetros discutidos anteriormente. $\mathrm{Na}$ entrada da boquilha, a adição de fibras com maior comprimento pode aumentar o escoamento da pasta porque as colisões entre as partículas aumentam com o aumento da quantidade de fibras.

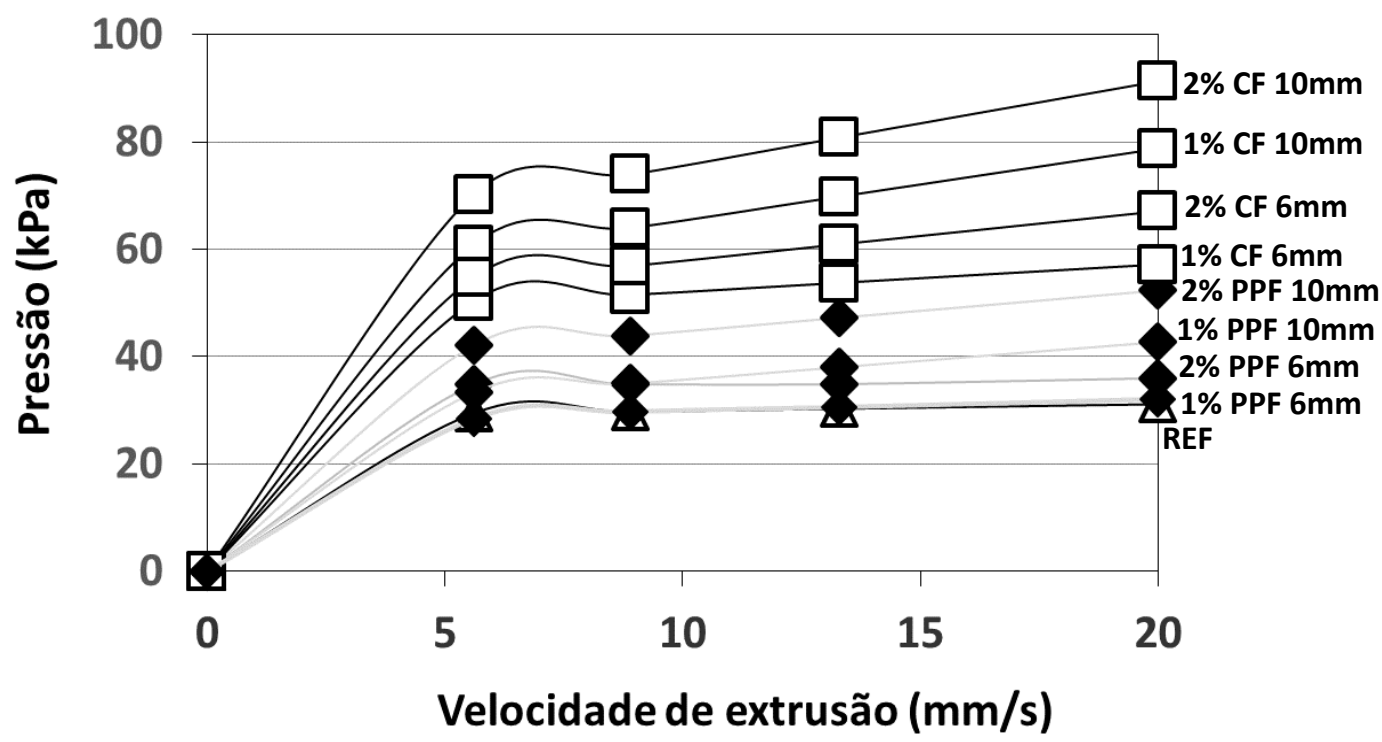

Figura 30 - Pressão de extrusão vs velocidade de extrusão das misturas

As partículas da pasta cimentícia tornam-se mais empacotadas, com tendência a ser mais rígidas. Isso causa o aumento da interação entre as fibras, que formam uma estrutura de rede maior e aumenta o trabalho necessário para alinhar 
as fibras na entrada da boquilha (SRINIVASAN; DEFORD; SHAH, 1999). Quando o comprimento da fibra foi alterado de $6 \mathrm{~mm}$ para $10 \mathrm{~mm}$, houve um aumento do escoamento em função da maior área de interação fibra-matriz, o que resulta em uma maior pressão na entrada da boquilha devido ao alinhamento das fibras na direção do fluxo apresentado no esquema da Figura 31. É por isso que as concentrações de fibras afetam as propriedades das pastas cimentícias na entrada da boquilha. Pastas cimentícias reforças com FC e FPP com teores de $2 \%$ e comprimento de $10 \mathrm{~mm}$ apresentaram maiores pressões.

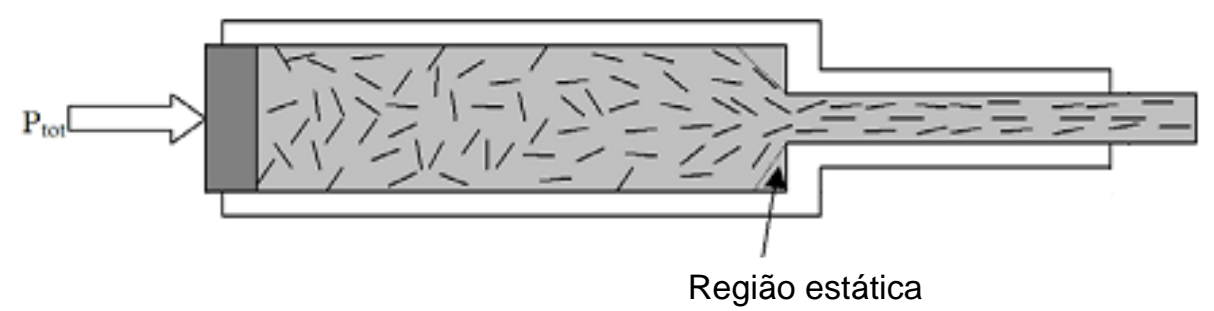

Figura 31 - Esquema da influência das fibras não orientadas no resultado da pressão de extrusão das pastas cimentícias (SRINIVASAN; DEFORD; SHAH, 1999)

Para facilitar a escolha dos melhores resultados dos parâmetros reológicos foi realizada análise estatística ANOVA.

A Tabela 12 apresenta os resultados dos testes de validação da ANOVA para cada uma das propriedades dos parâmetros reológicos referentes ao planejamento 2 - estudo reológico).

Tabela 12 - Resultados da ANOVA e validação para cada parâmetro reológico do Planejamento 2 - estudo reológico)

\begin{tabular}{ccc}
\hline \multirow{2}{*}{ Propriedades } & \multicolumn{2}{c}{ Validação ANOVA } \\
& AD $^{*}$ & $\mathbf{B t}^{*}$ \\
\hline$\sigma_{0}$ & 0,422 & 0,276 \\
$\alpha$ & 0,153 & 0,184 \\
To & 0,086 & 0,315 \\
$\beta$ & 0,370 & 0,481 \\
$\mathbf{P}$ & 0,229 & 0,359 \\
\hline
\end{tabular}


Das propriedades reológicas investigadas no Planejamento 2 - estudo reológico, apenas o efeito da velocidade na tensão de escoamento $(\alpha)$ e na tensão inicial de cisalhamento (T0) não apresentaram normalidade na distribuição, e assim como feito anteriormente, foi utilizada a transformada de Johnson, cujas funções de ajuste são expressas nas Equações 11 e 12, respectivamente, sendo $Y$ a variável dependente (variável transformada) e $X$ a variável independente (variável original).

$$
\begin{aligned}
& Y=4,41942+1,06444 \cdot \operatorname{Ln}(X-0,00417272) \\
& Y=2,49353+0,745878 \cdot \operatorname{Ln}(X-0,00417272)
\end{aligned}
$$

Da Tabela 12, pelos P-valores encontrados dos testes de Anderson-Darling e de Bartlett, por serem ambos superiores a $5 \%$, constata-se serem válidas as premissas da ANOVA. A Tabela 13 apresenta os resultados da ANOVA para cada propriedade investigada do Planejamento 2 - estudo reológico, sendo a interação entre os fatores representada pelo produto deles.

Tabela 13 - Resultados da ANOVA do Planejamento 2.

\begin{tabular}{cccccc}
$\begin{array}{c}\text { Fatores e } \\
\text { Interações }\end{array}$ & $\boldsymbol{\sigma}_{0}$ & $\boldsymbol{\alpha}$ & $\mathbf{T 0}$ & $\boldsymbol{\beta}$ & $\mathbf{P}$ \\
\hline$\% F^{*}$ & 0,164 & 0,123 & 0,000 & 0,069 & 0,154 \\
$\mathrm{CF}^{*}$ & 0,000 & 0,000 & 0,000 & 0,006 & 0,000 \\
$\mathrm{TF}^{*}$ & 0,000 & 0,000 & 0,000 & 0,263 & 0,000 \\
$\% \mathrm{~F} \times \mathrm{CF}$ & 0,098 & 0,103 & 0,000 & 0,791 & 0,533 \\
$\% \mathrm{~F} \times \mathrm{TF}$ & 0,475 & 0,987 & 0,000 & 0,538 & 0,370 \\
$\mathrm{CF} \times \mathrm{TF}$ & 0,182 & 0,000 & 0,000 & 0,276 & 0,080 \\
$\% F \times C F \times T F$ & 0,983 & 0,756 & 0,000 & 0,961 & 0,938
\end{tabular}

* \%F (teor de fibras), CF (comprimento de fibra), TF (tipo de fibra).

As Figuras 32 e 33 apresentam os gráficos de interação entre os fatores considerados significativos pela ANOVA para o efeito da velocidade na tensão de cisalhamento $(\alpha)$ e da tensão inicial de cisalhamento $(\mathrm{T} 0)$ respectivamente. A pasta 
cimentícia reforçada com fibras de $10 \mathrm{~mm}$ de comprimento apresentou um aumento significativo do parâmetro $(\alpha)$ em relação à pasta com fibras $6 \mathrm{~mm}$ de comprimento.

Esse resultado confirma que a maior quantidade de água consumida para lubrificar as partículas finas e a formação de uma microestrutura mais densa contribuíram para o aumento do cisalhamento.

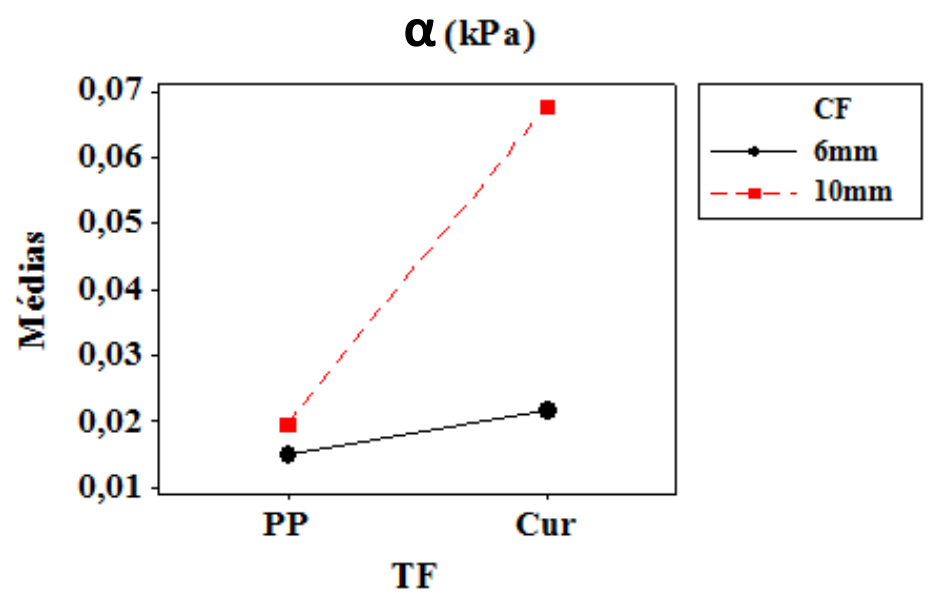

Figura 32 - Interação entre os fatores para o efeito da velocidade na tensão de cisalhamento.

A Figura 33 apresenta a tensão inicial de cisalhamento ( $\mathrm{T} 0$ ), que apresentou um aumento significativo com pasta de $\mathrm{FC} 2 \% 10 \mathrm{~mm}$ em relação às pastas com FPP. A água não foi suficiente para lubrificar todo o sistema, o que afetou o fluxo e reduziu a eficiência dos aditivos reológicos. 


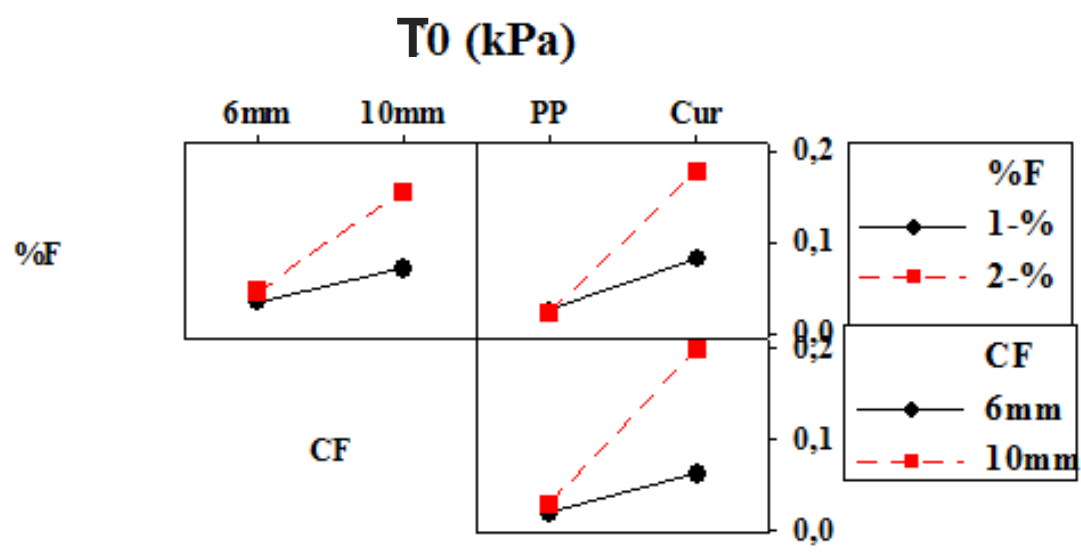

TF

Figura 33 - Interação entre os fatores para o efeito da tensão inicial de cisalhamento.

A Tabela 14 apresenta os resultados do teste de Tukey dos parâmetros reológicos dos materiais fabricados de acordo com os 8 tratamentos do Planejamento 2 - estudo reológico, sendo a $\bar{x}$ média e $\mathrm{Ag}$ os agrupamentos formados pelo teste de Tukey. Destacamos que os efeitos dos teores de fibras (\%F) não foram significativos nos parâmetros reológicos $\sigma 0, \alpha$, e $\beta$; somente para o parâmetro т0 foi encontrada diferença significativa. Em relação ao comprimento de fibra (CF), todos os parâmetros reológicos apresentaram diferença significativa, ou seja, as pastas com fibra de $10 \mathrm{~mm}$ de comprimento influenciaram os parâmetros reológicos. Par o tipo de fibra (TF), todos os parâmetros mostraram diferença significativa, exceto o parâmetro $\beta$. 
Tabela 14 - Resultados do teste de Tukey para os parâmetros reológicos do Planejamento 2 - estudo reológico

\begin{tabular}{cccccccc}
\hline \multirow{2}{*}{ Prop. } & Estat. & \multicolumn{3}{c}{$\% \mathrm{~F}$} & \multicolumn{2}{c}{ CF } & \multicolumn{2}{c}{ TF } \\
& & $\mathbf{1} \%$ & $\mathbf{2 \%}$ & $\mathbf{6 m m}$ & $\mathbf{1 0 m m}$ & PP & Cur \\
\hline \multirow{2}{*}{$\sigma_{0}(\mathrm{kPa})$} & $\bar{x}$ & 18,78 & 20,97 & 18,10 & 21,64 & 16,63 & 23,12 \\
& $\mathrm{Ag}$ & $\mathrm{A}$ & $\mathrm{A}$ & $\mathrm{B}$ & $\mathrm{A}$ & $\mathrm{B}$ & $\mathrm{A}$ \\
$\mathrm{\alpha}(\mathrm{kPa})$ & $\bar{x}$ & 0,029 & 0,034 & 0,018 & 0,044 & 0,017 & 0,042 \\
& $\mathrm{Ag}$ & $\mathrm{A}$ & $\mathrm{A}$ & $\mathrm{B}$ & $\mathrm{A}$ & $\mathrm{B}$ & $\mathrm{A}$ \\
& $\bar{x}$ & 0,054 & 0,101 & 0,041 & 0,115 & 0,025 & 0,131 \\
$\mathrm{~T} 0(\mathrm{kPa})$ & $\mathrm{Ag}$ & $\mathrm{B}$ & $\mathrm{A}$ & $\mathrm{B}$ & $\mathrm{A}$ & $\mathrm{B}$ & $\mathrm{A}$ \\
& $\bar{x}$ & 0,001 & 0,002 & 0,001 & 0,002 & 0,001 & 0,002 \\
$\beta(\mathrm{kPa})$ & $\mathrm{Ag}$ & $\mathrm{A}$ & $\mathrm{A}$ & $\mathrm{B}$ & $\mathrm{A}$ & $\mathrm{A}$ & $\mathrm{A}$ \\
& $\bar{x}$ & 53,52 & 59,33 & 47,76 & 65,09 & 39,61 & 73,24 \\
$\mathrm{P}(\mathrm{kPa})$ & $\mathrm{Ag}$ & $\mathrm{A}$ & $\mathrm{A}$ & $\mathrm{B}$ & $\mathrm{A}$ & $\mathrm{B}$ & $\mathrm{A}$ \\
\hline
\end{tabular}

Do estudo envolvendo a inclusão da condição de referência associada aos oito tratamentos do Planejamento 2 - estudo reológico, assim como ocorrido anteriormente, apenas a tensão de escoamento ( $\alpha$ ) e a tensão inicial de cisalhamento (то) não apresentaram normalidade na distribuição, sendo utilizada a transformada de Johnson para estas duas propriedades, cujas funções de ajuste são expressas nas Equações 13 e 14, respectivamente, sendo $Y$ a variável dependente (variável transformada) e $X$ a variável independente (variável original).

$$
\begin{gathered}
Y=0,820502+0,608841 \cdot \operatorname{Ln}[(X-0,00481406) /(0,122993-X)] \\
Y=-1,20408+0,498618 \cdot \operatorname{arcsenh}[(X-0,0199861) /(0,00311130)]
\end{gathered}
$$

Os P-valores dos testes de normalidade (Anderson-Darling) e de homogeneidade de variâncias (Bartlett) variaram nos intervalos de $[0,061,0,572] \mathrm{e}$ $[0,086,0,483]$, respectivamente, validando assim o modelo da ANOVA. A Tabela 15 apresenta os resultados do teste de Tukey (agrupamentos) dos 8 tratamentos mais 0 da condição de referência para as cinco propriedades mecânicas do Planejamento 2 - estudo reológico 
Tabela 15 - Resultados do teste de Tukey do Planejamento 2 - estudo reológico, com a inclusão da formulação de referência.

\begin{tabular}{lcccccc}
\hline \multicolumn{1}{c}{ Formulação } & Tratamentos & $\boldsymbol{\sigma}_{0}$ & $\boldsymbol{\alpha}$ & To & $\boldsymbol{\beta}$ & $\mathbf{P}$ \\
\hline Referência & Ref & E & AB & EF & C & E \\
FPP $1 \% 6 \mathrm{~mm}$ & Tr1 & E & B & EF & BC & DE \\
FPP $1 \% 10 \mathrm{~mm}$ & Tr2 & DE & B & EF & BC & CDE \\
FPP $2 \% 6 \mathrm{~mm}$ & Tr3 & CDE & B & F & BC & DE \\
FPP $2 \% 10 \mathrm{~mm}$ & Tr4 & BCD & B & DE & B & CDE \\
FC $1 \% 6 \mathrm{~mm}$ & Tr5 & BC & B & D & AB & BCD \\
FC $1 \% 10 \mathrm{~mm}$ & Tr6 & AB & A & B & AB & AB \\
FC $2 \% 6 \mathrm{~mm}$ & Tr7 & B & B & C & AB & BC \\
FC $2 \% 10 \mathrm{~mm}$ & Tr8 & A & A & A & A & A \\
\hline
\end{tabular}

Dos resultados estatísticos apresentados na Tabela 15, conclui-se que os melhores resultados dos parâmetros reológicos são aqueles que foram similares aos resultados da pasta cimentícia utilizada como referência, que apresentou baixos valores dos paramentos reológicos, facilitando o processo de extrudabilidade. Dessa forma, as pastas com reforço de FPP apresentaram os melhores resultados e podese concluir que a melhor formulação foi FPP $2 \% 6 \mathrm{~mm}$.

\subsection{Resultados mecânicos e físicos}

A Figura 34 apresenta as propriedades mecânicas dos compósitos cimentícios aos 7 dias de idade (7d) e após 200 ciclos de envelhecimento acelerado (200C). A Tabela 16 apresenta as médias e os desvios padrão dos resultados mecânicos e físicos dos compósitos cimentícios aos 7 dias de cura (7d) e após os 200 ciclos de envelhecimento de imersão e secagem (200C).

O módulo de ruptura (MOR) indica a resistência à tração na flexão, assim como a interação e a distribuição de tensões entre fibra-matriz. Compósitos cimentícios reforçados com FC apresentaram valores médios similares de MOR aos $7 \mathrm{~d}$, mas apresentaram valores médios inferiores em relação à referência, como mostra a Figura 34a. Para os compósitos reforçados com FC esperavam-se resultados distintos para cada teor de reforço e de comprimento. Além disso, 
esperavam-se valores médios de MOR maiores em relação à referência, devido à adição de fibras de FC que a princípio deveriam trabalhar como reforço. Esses resultados podem ter sido ocasionado pela deficiência da dispersão das fibras na matriz ou a falta de transferência de tensões entre a fibra e matriz. Após o envelhecimento de 200C, os valores médios de MOR dos compósitos aumentaram devido ao efeito combinado de melhor adesividade (aumento da ligação química) da FC na matriz cimentícia, do processo de hidratação continuado, principalmente, na interface fibra-matriz e petrificação ou mineralização dessas fibras (BENTUR e AKERS, 1989b).

Segundo Bentur e Akers (1989b), a petrificação ocorre em condições em que os produtos da hidratação do cimento migram para as regiões mais porosas, no interior das fibras (lumens e poros superficiais). Os valores médios de MOR encontrados neste trabalho são em torno de $16 \mathrm{MPa}$ para 7d e $20 \mathrm{MPa}$ após 200C para a formulação FC $1 \% 10 \mathrm{~mm}$. Esses valores são superiores aqueles encontrados em estudos anteriores, com compósitos cimentícios extrudados reforçados com fibra de sisal e de cana-de-açúcar, com os respectivos teores de $1 \%$ e $1,5 \%$ e com faixa de distribuição de comprimentos entre $15 \mathrm{~mm}$ a $18 \mathrm{~mm}$ e $10 \mathrm{~mm}$ a $15 \mathrm{~mm}$, que apresentaram, respectivamente, valores médios de MOR de $8 \mathrm{MPa}$ e $11 \mathrm{MPa}$ para 28 dias e $4 \mathrm{MPa}$ e $15 \mathrm{MPa}$ após 200 ciclos (SOTO et al., 2007; TEIXEIRA et al., 2012).

Compósitos reforçados com FPP apresentaram valores médios de MOR superiores em relação aos compósitos reforçados com FC. A formulação com FPP $2 \% 10 \mathrm{~mm}$ apresenta valor médio de MOR 36\% maior em relação à formulação com FPP 2\% 6 mm e 75\% maior em relação à formulação com FC 1\% 10 mm.

As FPP são hidrofóbicas e resistentes ao ambiente alcalino do cimento Portland, após a cura e o envelhecimento acelerado (200C) (TEIXEIRA et al., 2014; IKAI et al., 2010). Além disso, as FPP têm resistência à tração em torno de $500 \mathrm{MPa}$, alongamento de $19 \%$ na ruptura e diâmetro médio equivalente de $13 \mu \mathrm{m}$, além disso, o menor diâmetro fez com que o número de filamentos seja muito maior para o mesmo volume de fibras, como listado na Tabela 10. 


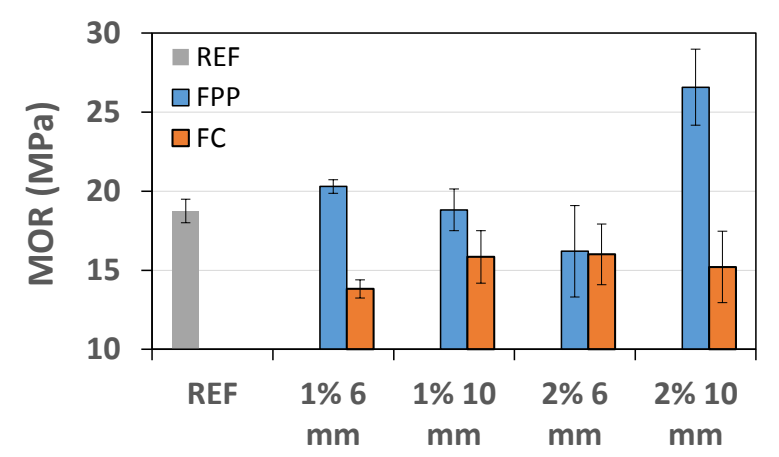

(a)

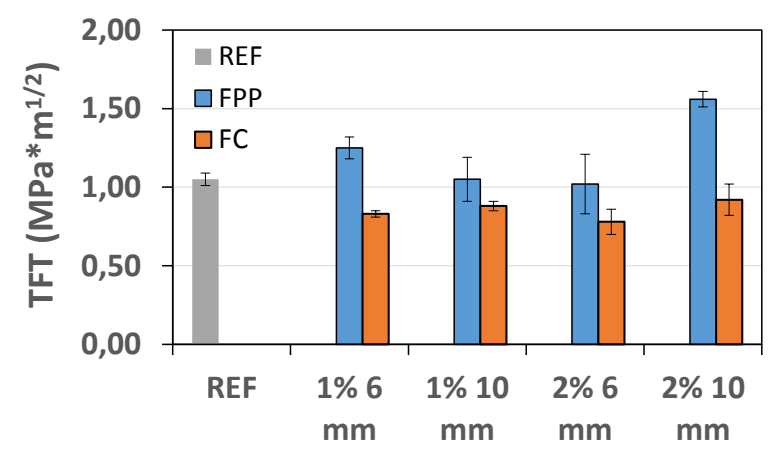

(c)

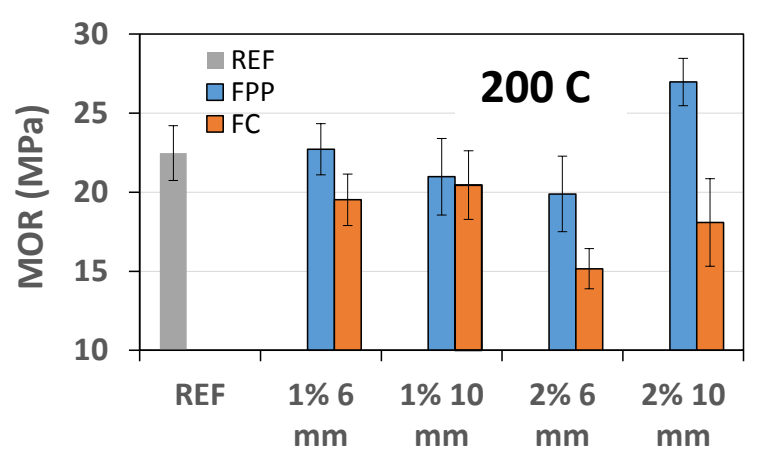

(b)

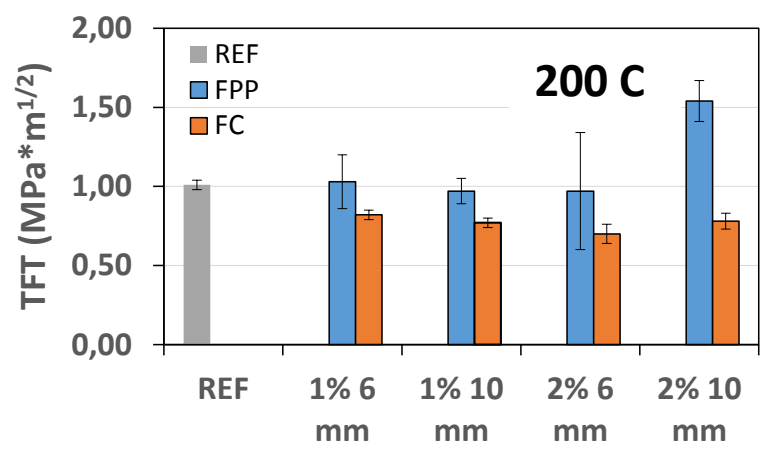

(d)

Figura 34 - Valores médios e desvio padrão de (MOR) módulo de ruptura (a) aos 7 dias (b) após 200 ciclos e (TFT) tenacidade a fratura (c) aos 7 dias (d) após 200 ciclos.

As Figuras 34c e 34d mostram o comportamento mecânico dos compósitos em relação à tenacidade à fratura (TFT), aos $7 d$ e após $200 \mathrm{C}$ respectivamente. As fibras têm pouca participação na composição do valor da TFT em compósitos com matriz frágil, pois este é obtido de um ensaio que promove um processo de fratura catastrófica, devido ao uso de alta velocidade de deslocamento do atuador, na ordem de $15 \mathrm{~mm} / \mathrm{min}$. Ou seja, o ensaio de TFT registra mais a resistência da matriz ao início da propagação da trinca do que as interferências das fibras durante a propagação da trinca principal.

Os valores médios de TFT foram semelhantes entre os compósitos reforçados com FC, mas apresentaram valores médios inferiores em relação à referência. Estes resultados podem estar associados a distribuição de defeitos na matriz produzidos por vários fatores, tais como a dificuldade de empacotamento das fibras na matriz com partículas e a interferência negativa no processo de hidratação do cimento provocado pela absorção de água pela FC. Levando-se em consideração os desvios 
padrão, os diferentes teores e comprimentos das fibras não influenciaram significativamente os valores médios da tenacidade à fratura.

Por outro lado, os valores médios de tenacidade à fratura entre os compósitos reforçados com FPP são similares e se mostraram superiores em relação aos compósitos com FC e referência, em várias condições de teor e de comprimento. Pode-se destacar o desempenho mecânico do compósito FPP $2 \% 10 \mathrm{~mm}$, tanto após a cura 7d quanto após o envelhecimento acelerado, como mostram as Figuras $34 \mathrm{c}$ e 34d. Para esse compósito, os valores médios do TFT aos $7 \mathrm{~d}$ e após os $200 \mathrm{C}$ foram aproximadamente de $1,56 \mathrm{MPa} \mathrm{m}^{1 / 2}$ e $1,54 \mathrm{MPa} \mathrm{m}^{1 / 2}$ respectivamente. Esses valores são superiores àqueles encontrados por Correia (2015), que trabalhou com compósitos extrudados reforçados com fibras celulósicas hibridas ( $8 \%$ de fibras celulósicas $+1 \%$ de nanofibras de bambu). Esses pesquisadores determinaram os valores médios de TFT em torno de 1,15 MPa $\mathrm{m}^{1 / 2}$ aos 28 dias, e 1,26 MPa m $\mathrm{m}^{1 / 2}$ após o envelhecimento acelerado de 200C. 
Tabela 16 - Valores médios e desvios padrão de módulo de ruptura (MOR), tenacidade a fratura (TFT), módulo elástico (ME), energia a fratura (EF), porosidade aparente (PA), absorção de água (AA) e densidade aparente (DA) dos compósitos reforçados com fibra de curauá (FC) e de polipropileno (FPP), com $6 \mathrm{~mm}$ e $10 \mathrm{~mm}$ de comprimento, nas condições aos 7 dias de cura e após 200 ciclos de envelhecimento acelerado.

\begin{tabular}{|c|c|c|c|c|c|c|c|}
\hline Compósito & Condição & MOR (MPa) & TFT $\left(\mathrm{MPa}^{*} \mathrm{~m}^{1 / 2}\right)$ & $\mathrm{EF}\left(\mathrm{J} / \mathrm{m}^{2}\right)$ & PA (\%) & $\mathrm{AA}(\%)$ & $\mathrm{DA}\left(\mathrm{g} / \mathrm{cm}^{3}\right)$ \\
\hline Referência & \multirow{9}{*}{7 dias } & $18,75 \pm 0,75$ & $1,05 \pm 0,04$ & $187,61 \pm 16,07$ & $27,47 \pm 0,34$ & $16,14 \pm 0,28$ & $1,702 \pm 0,013$ \\
\hline FPP $1 \% 6 \mathrm{~mm}$ & & $20,30 \pm 0,43$ & $1,25 \pm 0,07$ & $893,87 \pm 66,84$ & $27,40 \pm 0,26$ & $16,23 \pm 0,19$ & $1,689 \pm 0,005$ \\
\hline FPP $1 \% 10$ mm & & $18,82 \pm 1,32$ & $1,05 \pm 0,14$ & $808,92 \pm 110,59$ & $26,59 \pm 0,40$ & $15,69 \pm 0,34$ & $1,695 \pm 0,012$ \\
\hline FPP $2 \% 6 \mathrm{~mm}$ & & $16,20 \pm 2,89$ & $1,02 \pm 0,19$ & $1480,46 \pm 148,03$ & $27,85 \pm 0,91$ & $15,87 \pm 0,73$ & $1,756 \pm 0,051$ \\
\hline FPP $2 \% 10$ mm & & $26,58 \pm 2,40$ & $1,56 \pm 0,05$ & $1920,21 \pm 251,58$ & $30,92 \pm 0,52$ & $18,59 \pm 0,49$ & $1,664 \pm 0,026$ \\
\hline $\mathrm{FC} 1 \% 6 \mathrm{~mm}$ & & $13,82 \pm 0,57$ & $0,83 \pm 0,02$ & $108,20 \pm 13,58$ & $28,16 \pm 0,29$ & $16,49 \pm 0,20$ & $1,708 \pm 0,007$ \\
\hline FC $1 \% 10 \mathrm{~mm}$ & & $15,85 \pm 1,66$ & $0,88 \pm 0,03$ & $309,98 \pm 15,98$ & $29,78 \pm 0,84$ & $17,22 \pm 0,15$ & $1,729 \pm 0,055$ \\
\hline $\mathrm{FC} 2 \% 6 \mathrm{~mm}$ & & $16,01 \pm 1,92$ & $0,78 \pm 0,08$ & $102,05 \pm 9,05$ & $31,90 \pm 0,96$ & $18,48 \pm 0,72$ & $1,726 \pm 0,016$ \\
\hline FC $2 \% 10 \mathrm{~mm}$ & & $15,21 \pm 2,26$ & $0,92 \pm 0,10$ & $245,09 \pm 89,49$ & $29,31 \pm 0,59$ & $17,04 \pm 0,24$ & $1,720 \pm 0,031$ \\
\hline Referência & \multirow{9}{*}{200 ciclos } & $22,47 \pm 1,73$ & $1,01 \pm 0,03$ & $50,75 \pm 10,07$ & $27,95 \pm 0,79$ & $16,02 \pm 0,50$ & $1,745 \pm 0,009$ \\
\hline FPP $1 \% 6 \mathrm{~mm}$ & & $22,72 \pm 1,62$ & $1,03 \pm 0,17$ & $632,26 \pm 120,66$ & $28,14 \pm 0,54$ & $16,04 \pm 0,23$ & $1,754 \pm 0,012$ \\
\hline FPP $1 \% 10$ mm & & $20,98 \pm 2,42$ & $0,97 \pm 0,08$ & $817,19 \pm 104,64$ & $27,39 \pm 0,68$ & $15,67 \pm 0,32$ & $1,748 \pm 0,029$ \\
\hline FPP $2 \% 6$ mm & & $19,89 \pm 2,39$ & $0,97 \pm 0,37$ & $897,10 \pm 308,70$ & $26,60 \pm 0,66$ & $15,09 \pm 0,15$ & $1,764 \pm 0,050$ \\
\hline FPP $2 \% 10$ mm & & $26,97 \pm 1,50$ & $1,54 \pm 0,13$ & $1876,50 \pm 236,14$ & $30,23 \pm 0,84$ & $18,12 \pm 0,28$ & $1,669 \pm 0,033$ \\
\hline $\mathrm{FC} 1 \% 6 \mathrm{~mm}$ & & $19,52 \pm 1,63$ & $0,82 \pm 0,03$ & $45,67 \pm 4,28$ & $29,10 \pm 0,23$ & $16,73 \pm 0,14$ & $1,740 \pm 0,009$ \\
\hline $\mathrm{FC} 1 \% 10 \mathrm{~mm}$ & & $20,45 \pm 2,17$ & $0,77 \pm 0,03$ & $56,75 \pm 5,83$ & $30,54 \pm 0,72$ & $17,41 \pm 0,10$ & $1,754 \pm 0,044$ \\
\hline $\mathrm{FC} 2 \% 6 \mathrm{~mm}$ & & $15,16 \pm 1,27$ & $0,70 \pm 0,06$ & $20,18 \pm 2,51$ & $30,66 \pm 0,40$ & $17,77 \pm 0,27$ & $1,725 \pm 0,008$ \\
\hline FC $2 \% 10 \mathrm{~mm}$ & & $18,08 \pm 2,77$ & $0,78 \pm 0,05$ & $41,75 \pm 3,89$ & $30,31 \pm 0,39$ & $17,59 \pm 0,19$ & $1,723 \pm 0,027$ \\
\hline
\end{tabular}


A Figura 35 mostra as micrografias de corpos de prova com superfície polida dos compósitos da referência e reforçados com FC e com FPP, aos 7 dias de cura e após o envelhecimento acelerado (200C) respectivamente. Pode-se observar a microestrutura homogênea da matriz cimentícia, aos 7 dias de idade e mais densificada após 200C. O compósito com FC (Figura 35c-d) apresenta alta porosidade na interface fibra-matriz, ou seja, uma baixa adesividade. Esse fato está relacionado com o pobre empacotamento e absorção de água das fibras na matriz do compósito, o que induz aos baixos valores de MOR e de TFT em relação à referência e àqueles reforçados com FPP. No processo de mistura, os compósitos reforçados com FC utilizam mais água, o que promove maior formação de porosidade e interfere fortemente na relação a/c (água/cimento) e no empacotamento dessas matérias-primas na matriz.

A Figura 35d indica que a fibra vegetal sofre uma variação dimensional porque tende a perder água para o sistema da matriz cimentícia, que está por sua vez em processo de reidratação. Esse processo de variação dimensional promove um descolamento da fibra na matriz cimentícia. Consequentemente, prejudica a adesão entre a fibra e a matriz, o que por sua vez interfere no comportamento mecânico do compósito. Esse fenômeno de retração não foi observado na fibra de PP (Figuras 35e e 35f). 

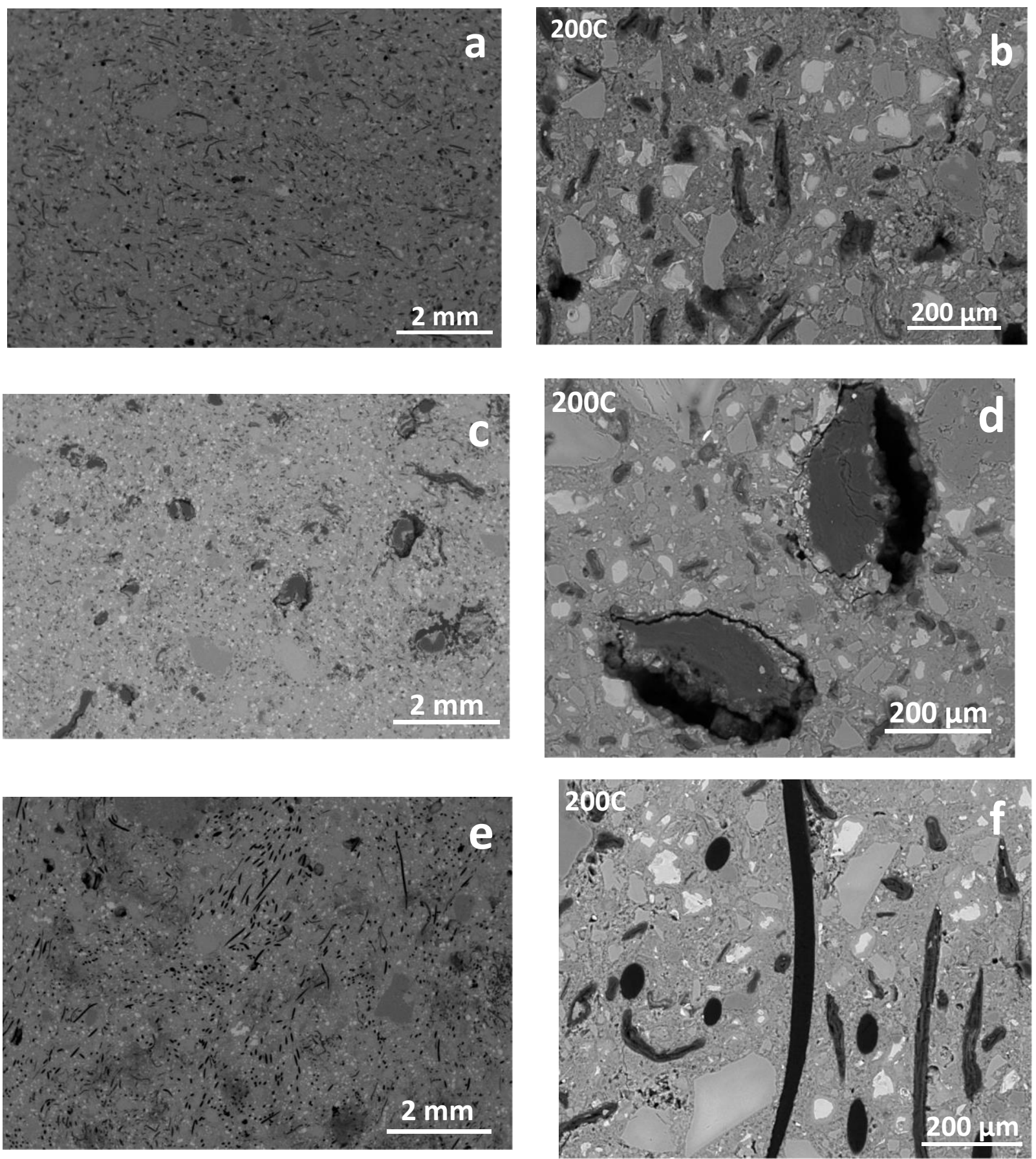

Figura 35 - Micrografias de superfície polida aos 7 dias e após 200C, respectivamente: ( $a$ e b) compósito referência; (c e d) compósito com FC e (e e f) com FPP.

As correlações dos valores médios de energia de fratura (EF) e os de trabalho relativo de propagação de trinca dos compósitos aos 7 dias e após $200 \mathrm{C}$ são mostradas nas Figuras 36a e 36b respectivamente. A EF representa a energia por unidade de área necessária para fraturar completamente o compósito em um 
processo de propagação de trinca quase estável. Ou seja, o ensaio de energia de fratura é realizado com uma velocidade de deslocamento do atuador na ordem de 10 $\mu \mathrm{m} / \mathrm{min}$ com o intuito de registrar a contribuição de todos os mecanismos de tenacificação promovidos principalmente pelas fibras, a partir das curvas força versus deslocamento. $O$ trabalho relativo de propagação é a razão entre o trabalho plástico e o trabalho elástico. Indica o grau de deformação pseudoplástico, ou seja, mostra o quanto a energia de fratura foi obtida pelo aumento de resistência ou pela capacidade de absorver energia.

Compósitos reforçados com FPP $2 \%$ apresentaram valores médios significativamente maiores de energias de fratura em relação ao com reforço com $1 \%$, para o mesmo comprimento de fibra aos 7 dias de cura. No entanto, para esses compósitos, após o envelhecimento acelerado, não é possível observar uma diferença significativa nos valores médios de trabalho relativo de propagação de trinca. De acordo com Rodrigues e Montardo, (2002), o teor de fibra confere maior energia pós-fissuração e menor dimensão das fissuras, desde que as fibras possam absorver as cargas adicionais causadas pelas fissuras. Em relação ao comprimento da fibra, os valores médios de energia de fratura dos compósitos com FPP com 10 $\mathrm{mm}$ são maiores em relação aos compósitos com $6 \mathrm{~mm}$ aos 7 dias. Entretanto, em relação ao trabalho relativo de propagação de fissuras, os compósitos com $6 \mathrm{~mm}$ apresentaram valores médios maiores do que aqueles com fibras de $10 \mathrm{~mm}$. Isso pode ser explicado que em certo volume da matriz existe um maior número de fibras de $6 \mathrm{~mm}$ do que fibras de $10 \mathrm{~mm}$. Dessa forma, o trabalho de propagação da fissura foi maior com fibras de 6 mm (BENTUR; MINDESS, 1990; DIAS, 2011). Após os 200 ciclos, os valores de EF dos compósitos FPP $2 \% 10 \mathrm{~mm}$ se manteve e o trabalho relativo de propagação aumentou, por outro lado, o valor de EF e o trabalho relativo de propagação do compósito FPP $2 \% 6 \mathrm{~mm}$ diminuiu em relação aos 7 dias. 0 compósito com $6 \mathrm{~mm}$ apresenta maior número de filamentos, o que leva a maiores defeitos e um empacotamento ineficiente em relação ao compósito com $10 \mathrm{~mm}$, que reduziu a EF e o trabalho de propagação de fissuras. 


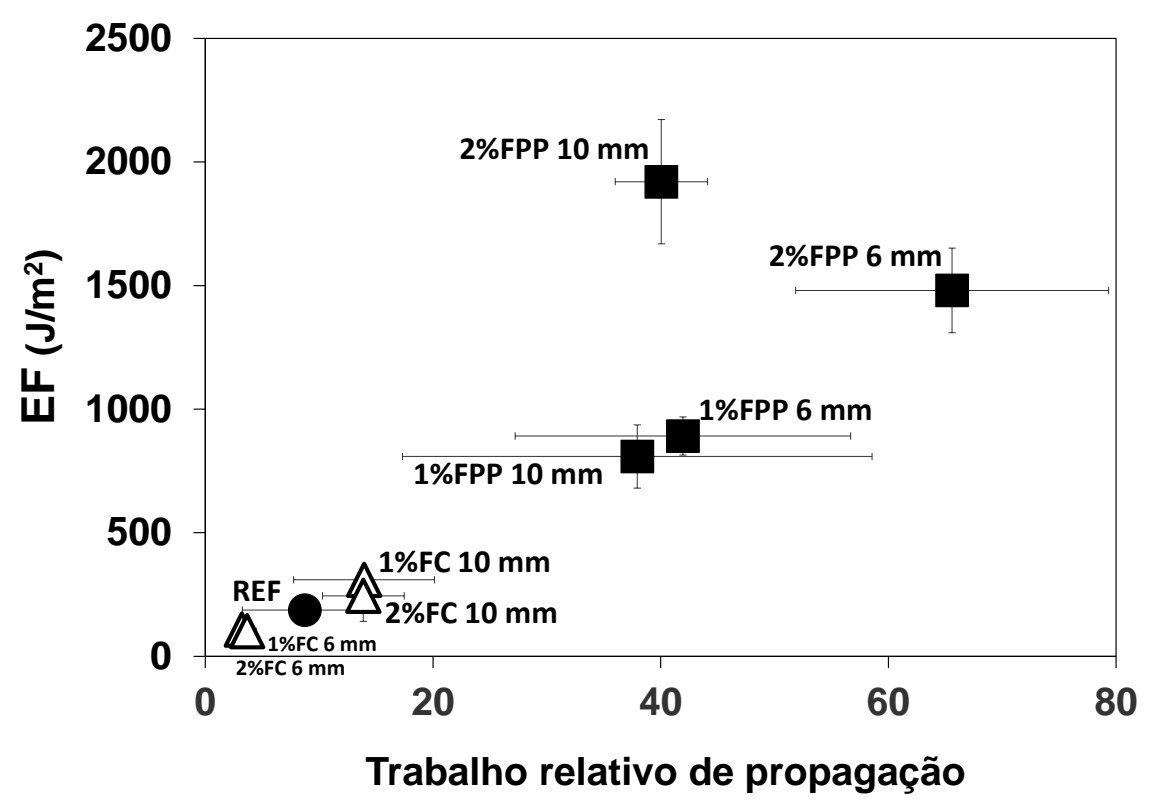

(a)

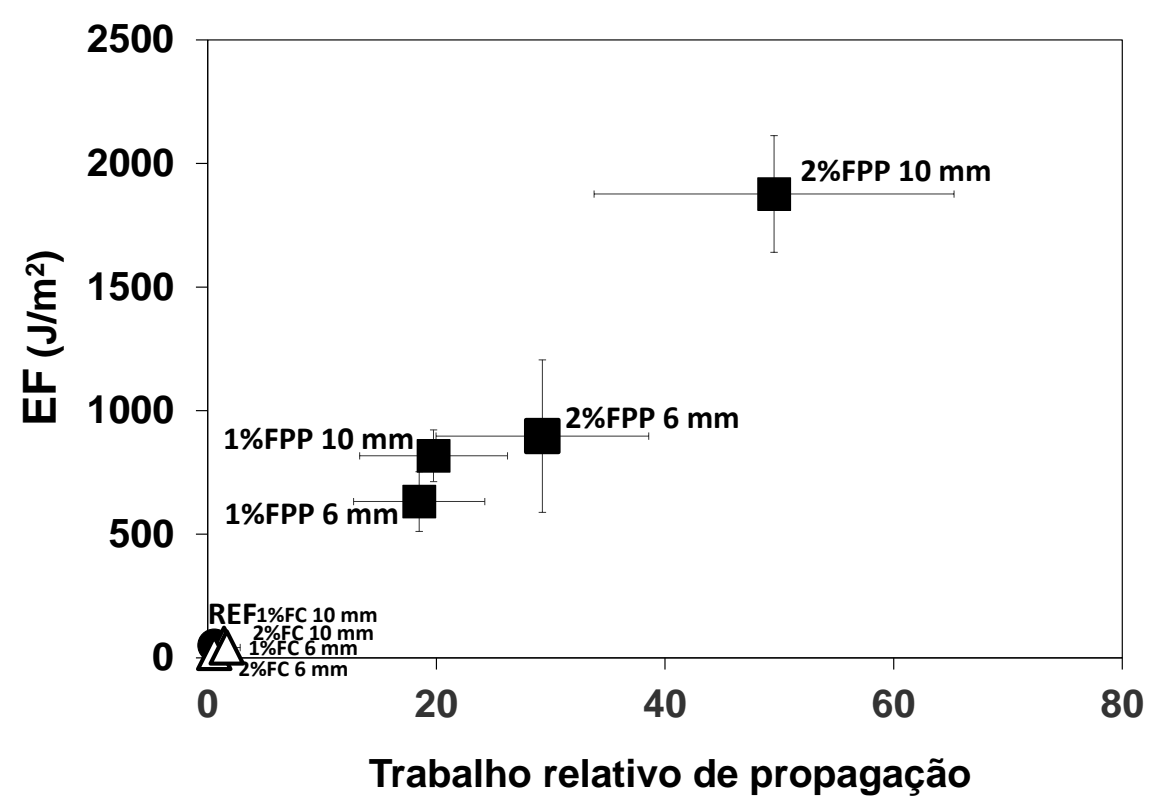

(b)

Figura 36 - Energia de fratura (EF) e trabalho relativo de propagação de fissura dos compósitos extrudados: (a) aos 7 dias; (b) após 200 ciclos de envelhecimento.

Compósitos com FC apresentaram comportamento mecânico significativamente diferente em relação à energia de fratura. Os compósitos com fibras com comprimento de $10 \mathrm{~mm}$ apresentaram melhores valores médios em relação àqueles com $6 \mathrm{~mm}$. Esse comportamento está ligado ao comprimento das fibras que define o grau de aderência entre fibras e a matriz cimentícia, ou seja, 
quanto menor for o comprimento da fibra, maior será a probabilidade de as fibras serem arrancadas sem gerar energia de atrito. Para uma dada tensão de cisalhamento superficial aplicada à fibra, esta será mais eficiente se o seu comprimento for capaz de permitir que a tensão cisalhante proporcione 0 desenvolvimento de uma tensão de tração igual à sua resistência à tração (BENTUR e MINDESS, 1990; TAYLOR, 1990). Os melhores valores médios de EF foram observados para compósitos com FPP 2\% PP $10 \mathrm{~mm}$ aproximadamente de 1950 $\mathrm{J} / \mathrm{m}^{2}$ e $1850 \mathrm{~J} / \mathrm{m}^{2}$, respectivamente, aos 7 dias e após envelhecimento acelerado (200C). Esses resultados podem ser explicados pelas micrografias das superfícies de fratura apresentadas nas Figuras 37b e 37d, dos compósitos com fibras FPP, aos $7 \mathrm{~d}$ e após 200C, respectivamente. Comparando-se as micrografias (Figuras 37b e 37d) nota-se que a interface entre fibras de PP e a matriz foi mantida após o envelhecimento acelerado.

Compósitos de FC 1\% $10 \mathrm{~mm}$ apresentaram valores médios de EF de 310 $\mathrm{J} / \mathrm{m}^{2}$ e $57 \mathrm{~J} / \mathrm{m}^{2}$, aos 7 dias e após os $200 \mathrm{C}$ respectivamente. $\mathrm{O}$ valor médio de $\mathrm{EF}$ aos 7 dias foi superior ao encontrado por Santos et al. (2015), que produziram compósitos extrudados reforçados com $2 \%$ de fibras celulósicas de eucalipto e $3 \%$ de fibras de sisal, com uma distribuição de comprimento entre 1 e $14 \mathrm{~mm}, 7$ dias de cura e exposto a carbonatação supercrítica acelerada no meio do processo de hidratação, com valor médio de EF de aproximadamente $230 \mathrm{~J} / \mathrm{m}^{2}$. No entanto, 0 valor de EF encontrado neste trabalho após o envelhecimento acelerado foi inferior ao valor de $170 \mathrm{~J} / \mathrm{m}^{2}$, provavelmente a carbonatação ajudou a reduzir a degradação da fibra, encontrado pelos pesquisadores mencionados anteriormente. Correia (2015) trabalhou com compósitos extrudados reforçados com fibras celulósicas hibridas ( $8 \%$ de fibras celulósicas $+1 \%$ de nanofibras de bambu) que apresentaram valores de EF em torno de $430 \mathrm{~J} / \mathrm{m}^{2}$ para 28 dias, mas apresentaram uma queda no valor para $271 \mathrm{~J} / \mathrm{m}^{2}$ após o envelhecimento acelerado de 200C. Com essa comparação, destaca-se a grande perda, de quase 375\% no valor energia de fratura dos compósitos reforçados com FC $1 \% 10 \mathrm{~mm}$, com valor de $57 \mathrm{~J} / \mathrm{m}^{2}$, após 200 ciclos de envelhecimento acelerado indicando uma forte fragilização. A redução no valor da energia de fratura indica que a degradação das fibras na matriz aumentou após o envelhecimento acelerado, ocasionando a ruptura das fibras, como ilustrado na Figura 37c. 


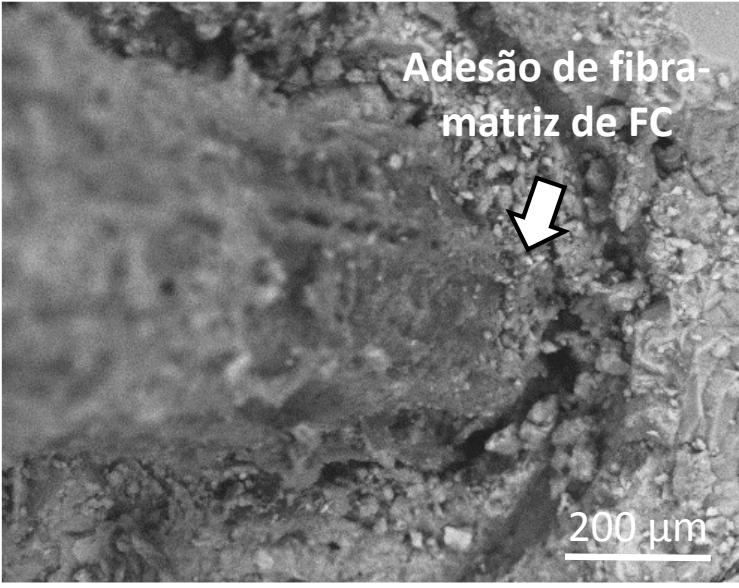

(a)

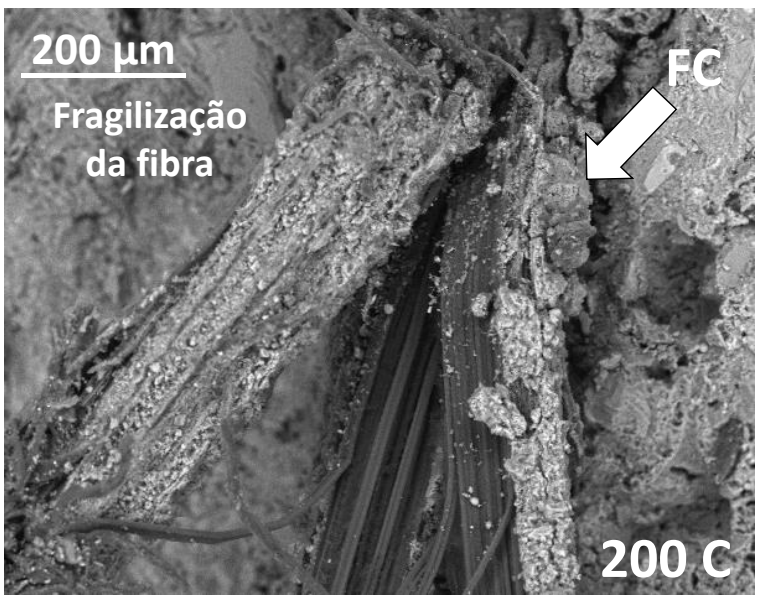

(c)

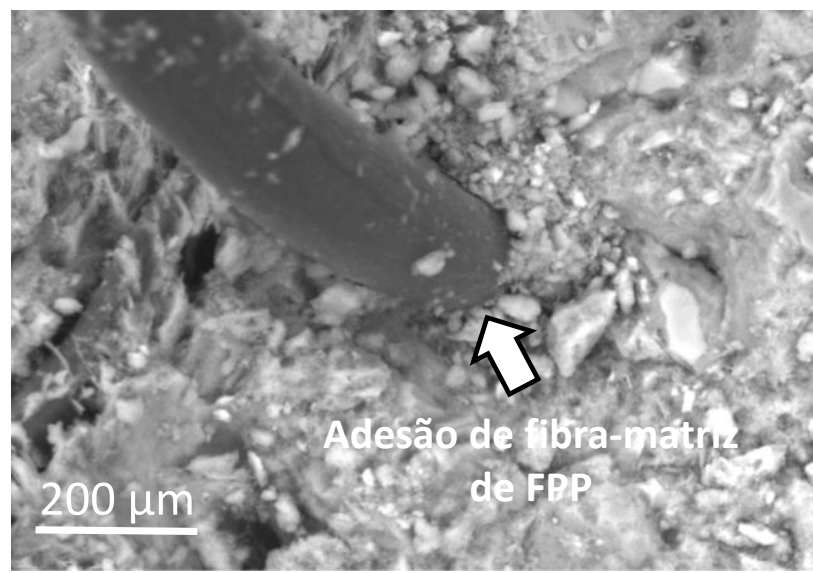

(b)

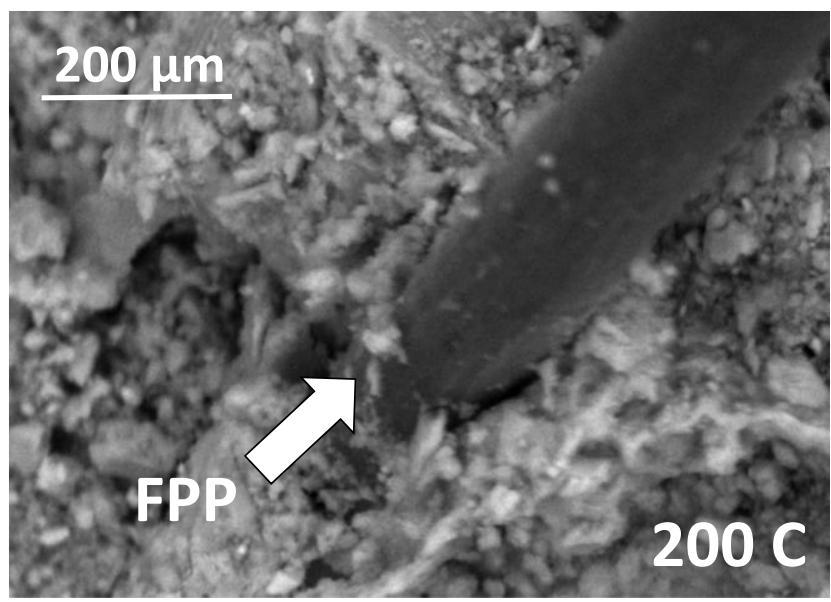

(d)

Figura 37 - Micrografias de MEV dos compósitos extrudados aos 7 dias e após 200 ciclos: (a e c) FC (setas mostram adesão fibra-matriz), respectivamente e (b e d) FPP (setas mostram a interface fibra-matriz), respectivamente.

Na Figura 38, estão os gráficos com os valores médios dos parâmetros físicos: porosidade aparente (PA), absorção de água (AA) e densidade aparente (DA) dos compósitos aos 7 dias e após os 200 ciclos, entre os níveis de reforços e comprimentos das fibras de curauá (FC) e de polipropileno (FPP).

Como era esperado, os compósitos reforçados com as FC possuem um caráter hidrofílico e apresentaram maios valores de PA e, como consequência, maior valor de AA, em comparação ao compósito sem fibras (referência). Em relação aos compósitos com FPP, fibras que não absorvem água, os valores de PA e AA foram similares em relação ao compósito de referência, exceto para formulação com $2 \%$ em peso de fibras com $10 \mathrm{~mm}$. Quando adicionamos mais fibras, principalmente as 
hidrofílicas ( $F C)$, com maiores comprimentos, a pressão de extrusão da pasta muda significativamente, como discutido anteriormente na seção 5.3 , a relação água/cimento aumenta, o que induz o aumento de poros e mais defeitos. Dessa forma, os compósitos com fibras, mesmo com fibras de PP, tendem a apresentar maiores absorções e porosidades aparentes. Esse fato foi observado em trabalhos anteriores, Teixeira et al. (2012) constataram que, ao adicionar mais fibras de bagaço de cana de açúcar em compósitos extrudados, aumentavam os valores de $P A$ e de AA.

A formulação com $\mathrm{FC} 2 \% 6 \mathrm{~mm}$ apresentou maior porosidade e absorção de água aparentes, possivelmente devido ao maior número de fibras por unidade de volume. A formulação FPP $2 \% 10 \mathrm{~mm}$, que contem fibras hidrofóbicas, conduzem a um empacotamento ineficiente do compósito e, assim, contribuiu para a maior porosidade e absorção de água da matriz (BEZERRA et al., 2006; TONOLI et al., 2011).

Os valores de densidade aparente dos compósitos com FC são maiores em relação aos compósitos com FPP. Este fato está diretamente relacionado com incorporação de FC com densidade específica de $1,45 \mathrm{~g} / \mathrm{cm}^{3}$ em relação à FPP com densidade específica de $0,92 \mathrm{~g} / \mathrm{cm}^{3}$. 


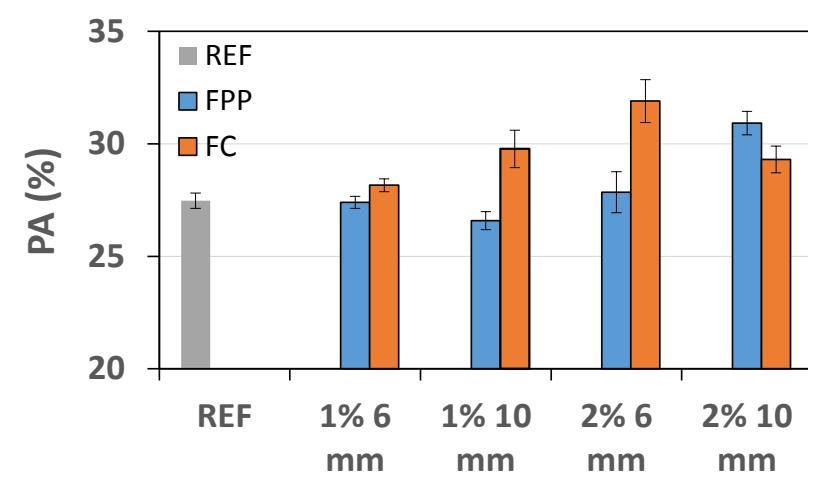

(a)

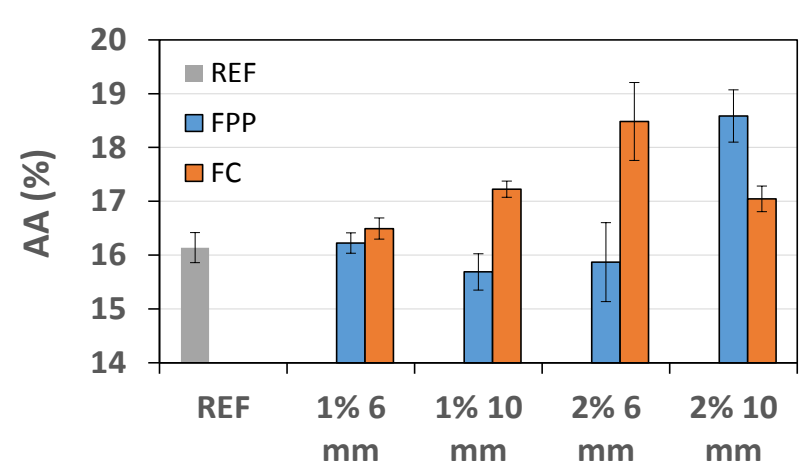

(c)

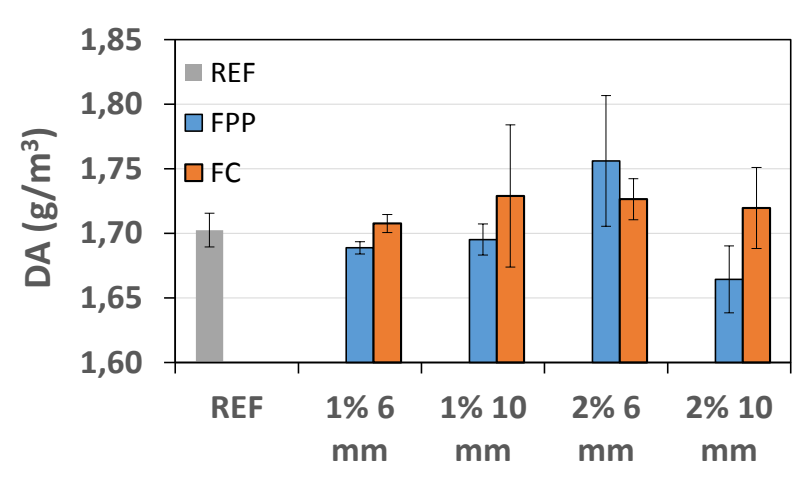

(e)

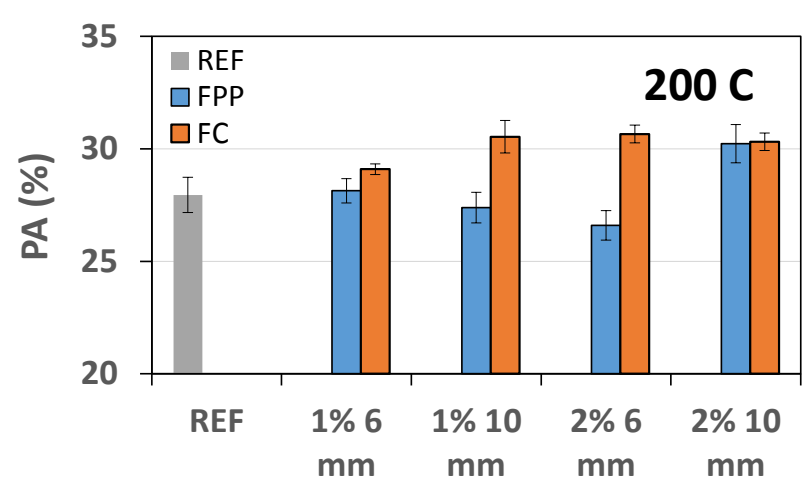

(b)

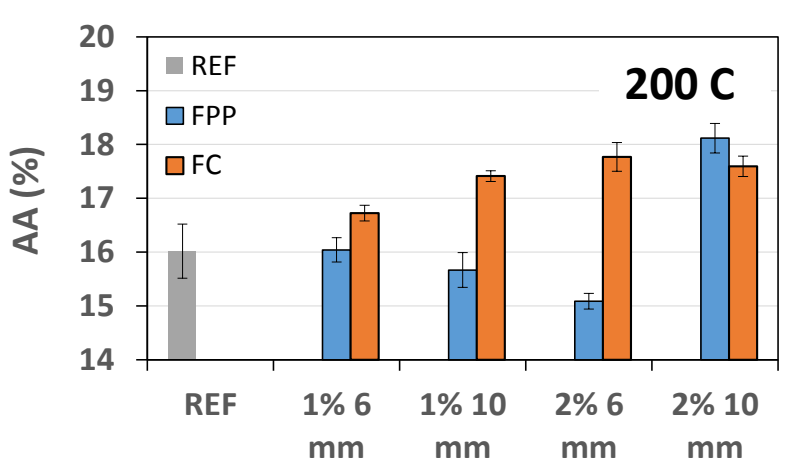

(d)

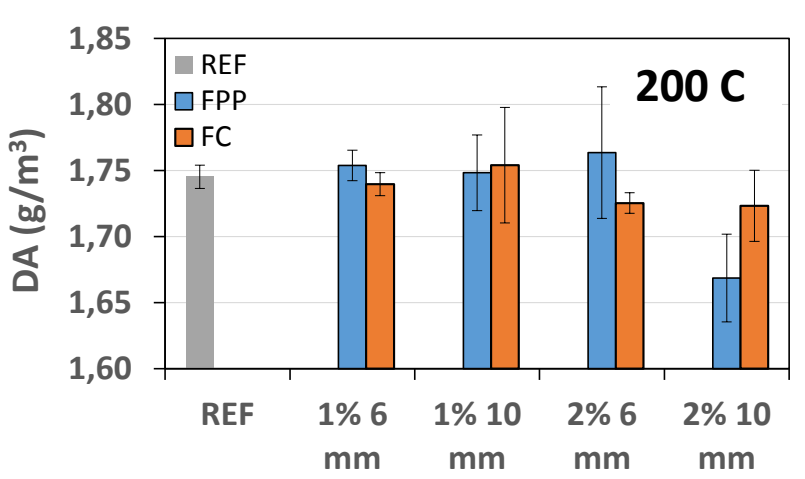

(f)

Figura 38 - Resultados da caracterização física dos compósitos: (PA) porosidade aparente (a) aos 7 dias e (b) após 200 ciclos; (AA) absorção de água (c) aos 7 dias e (d) após 200 ciclos; (DA) densidade aparente (e) aos 7 dias e (f) após 200 ciclos.

Todos os compósitos após o envelhecimento acelerado de 200C apresentaram diminuição dos valores de AA e PA e aumento dos valores de DA, o que pode ser atribuído ao preenchimento dos poros da matriz pela continuidade do processo de hidratação durante o envelhecimento acelerado, principalmente na formação de hidróxido de cálcio $\left(\mathrm{Ca}(\mathrm{OH})_{2}\right)$ e de silicato de cálcio hidratado (C-S-H) 
(SANTOS et al., 2015). Esses comportamentos foram encontrados em vários trabalhos que aplicaram envelhecimento acelerado de ciclos de imersão e secagem em compósitos cimentícios, tais como Soto et al. (2007); Dias (2011) e Teixeira et al. (2012). Esses pesquisadores trabalharam com compósitos extrudados com fibras vegetais e sintéticas.

Para facilitar a escolha das melhores formulações das propriedades mecânicas e físicas, foi realizada análise estatística ANOVA.

A Tabela 17 apresenta os resultados dos testes de validação da ANOVA para cada uma das propriedades físicas e mecânicas referentes ao Planejamento 1 estudo das propriedades mecânicas e físicas.

Tabela 17 - Validação ANOVA para cada propriedade mecânica e física do Planejamento 1 - estudo das propriedades mecânicas e físicas.

\begin{tabular}{lcc}
\multirow{2}{*}{ Propriedades } & \multicolumn{2}{c}{ Validação ANOVA } \\
& AD $^{*}$ & $\mathbf{B t}^{*}$ \\
\hline MOR & 0,283 & 0,123 \\
EF & 0,558 & 0,063 \\
TFT & 0,202 & 0,125 \\
ME & 0,671 & 0,423 \\
AA & 0,577 & 0,542 \\
DA & 0,615 & 0,486 \\
PA & 0,483 & 0,528 \\
\hline Teste estatístico Anderson-Darling (AD) e de Bartlett (Bt).
\end{tabular}

Como forma de apresentar os resultados dos testes de validação da ANOVA, procedimento realizado em cada propriedade investigada nesta pesquisa, a Figura 39 apresenta os resultados dos testes de normalidade (Anderson-Darling [AD]), homogeneidade de variâncias (Bartlett $[\mathrm{Bt}]$ ) e independência dos resíduos para a resistência à tração na flexão estática (MOR). 


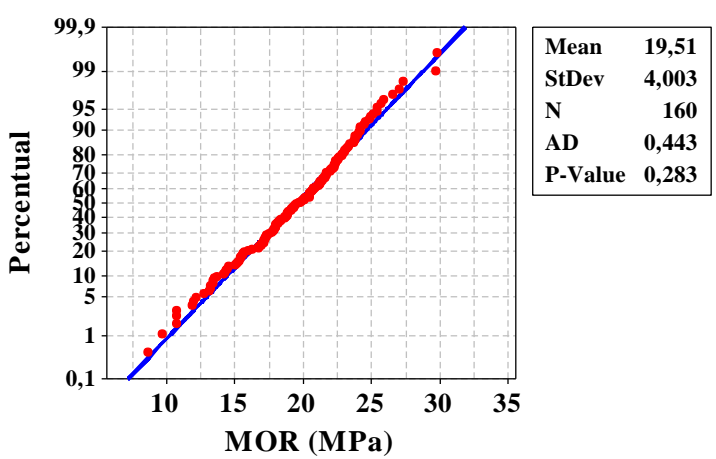

(a)

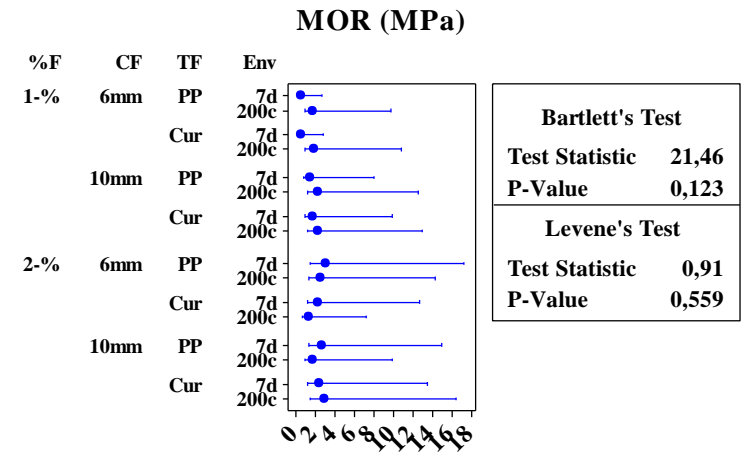

(b)

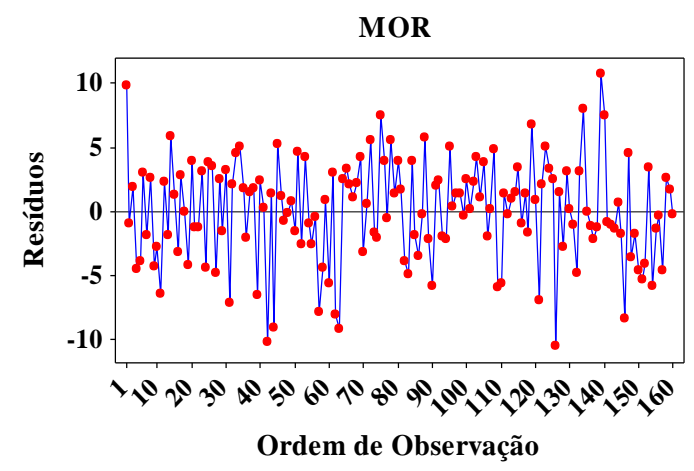

(c)

Figura 39 - Resultados de validação da ANOVA para o módulo de ruptura (MOR) referente ao Planejamento 1 - estudo das propriedades mecânicas e físicas (16 tratamentos) - normalidade (a), homogeneidade de variâncias (b) e independência dos resíduos (c).

Dentre todas as propriedades do Planejamento 1 - estudo das propriedades mecânicas e físicas, apenas a energia de Fratura (EF) não apresentou normalidade na distribuição dos dados originais, e para esta variável foi utilizada a transformada de Johnson, cuja função de transformação é expressa pela Equação 15, sendo $Y$ a variável dependente (variável transformada) e $X$ a variável independente (variável original).

$$
Y=0,878001+0,414675 \cdot \operatorname{Ln}[(X-15,8356) /(2256,07-X)]
$$

Atendidas as premissas da ANOVA no Planejamento 1 - estudo das propriedades mecânicas e físicas, a Tabela 18 apresenta os resultados da ANOVA 
para cada propriedade investigada, sendo a interação entre fatores representada pelo produto dos mesmos.

Tabela 18 - Resultados da ANOVA do Planejamento 1.

\begin{tabular}{|c|c|c|c|c|c|c|}
\hline $\begin{array}{l}\text { Fatores e } \\
\text { Interações }\end{array}$ & MOR & EF & TF & AA & DA & PA \\
\hline$\% \mathrm{~F}^{*}$ & 0,117 & 0,000 & 0,109 & 0,000 & 0,265 & 0,000 \\
\hline $\mathrm{CF}^{*}$ & 0,000 & 0,000 & 0,000 & 0,000 & 0,004 & 0,000 \\
\hline $\mathrm{TF}^{*}$ & 0,000 & 0,000 & 0,000 & 0,000 & 0,214 & 0,000 \\
\hline Env $^{*}$ & 0,000 & 0,082 & 0,123 & 0,182 & 0,001 & 0,095 \\
\hline$\% \mathrm{~F} \times \mathrm{CF}$ & 0,000 & 0,000 & 0,000 & 0,000 & 0,000 & 0,072 \\
\hline$\% \mathrm{~F} \times \mathrm{TF}$ & 0,000 & 0,000 & 0,000 & 0,203 & 0,757 & 0,207 \\
\hline$\%$ FxEnv & 0,001 & 0,152 & 0,524 & 0,016 & 0,088 & 0,000 \\
\hline CF $\times$ TF & 0,071 & 0,086 & 0,109 & 0,000 & 0,000 & 0,000 \\
\hline CFxEnv & 0,420 & 0,056 & 0,986 & 0,011 & 0,631 & 0,077 \\
\hline TFxEnv & 0,063 & 0,243 & 0,944 & 0,021 & 0,139 & 0,277 \\
\hline$\% \mathrm{~F} \times \mathrm{CF} \times \mathrm{TF}$ & 0,081 & 0,058 & 0,063 & 0,078 & 0,095 & 0,084 \\
\hline$\% \mathrm{~F} \times \mathrm{CF} \times \mathrm{Env}$ & 0,228 & 0,169 & 0,761 & 0,056 & 0,636 & 0,059 \\
\hline$\% F \times T F \times E n v$ & 0,123 & 0,097 & 0,188 & 0,301 & 0,528 & 0,154 \\
\hline CF $\times$ TF $\times$ Env & 0,411 & 0,073 & 0,209 & 0,281 & 0,875 & 0,252 \\
\hline$\% \mathrm{~F} \times \mathrm{CF} \times \mathrm{TF} \times \mathrm{Env}$ & 0,346 & 0,425 & 0,551 & 0,123 & 0,913 & 0,195 \\
\hline
\end{tabular}

A Figura 40 apresenta as interações consideradas significativas pela ANOVA referente aos valores do módulo de ruptura (MOR), energia de fratura (EF) e tenacidade a fratura (TFT) dos compósitos do Planejamento 1 - estudo das propriedades mecânicas e físicas.

Os compósitos fabricados com $2 \%$ de fibras apresentaram melhores resultados de MOR com o aumento do comprimento de $6 \mathrm{~mm}$ para $10 \mathrm{~mm}$. Para teor de $1 \%$ de fibra, existe uma similaridade entre os compósitos reforçados com filamentos de $6 \mathrm{~mm}$ e $10 \mathrm{~mm}$. Tal comportamento justifica-se pelo maior efeito de reforço, o compósito apresenta um número maior de fibras e existem uma maior área de contato com a matriz cimentícia, como mostrado na Figura 40a. 
A Figura 40b apresenta os compósitos produzidos com $1 \%$ e $2 \%$ de FC que sofreram uma redução nos resultados de MOR em relação aos compósitos produzidos com $1 \%$ e $2 \%$ de FPP. Essa redução está relacionada à mineralização das fibras vegetais. Após os 200 ciclos, a estrutura do compósito tem um aumento nos valores de MOR devido à reidratação dos produtos de hidratação, dessa forma preenchendo os poros do cimento, melhorando a interface fibra matriz e aumentando os valores de MOR, conforme mostrado na Figura 40c.

Os compósitos fabricados com $2 \%$ de fibras apresentaram melhores resultados de EF com o aumento do comprimento de $6 \mathrm{~mm}$ para $10 \mathrm{~mm}$. Os compósitos fabricados com $1 \%$ de fibra mostram um pequeno aumento entre os compósitos reforçados com fibras de $6 \mathrm{~mm}$ e $10 \mathrm{~mm}$ de comprimento. A Figura 40b apresenta os compósitos produzidos com FC com 1\% e $2 \%$ que sofreram uma redução nos resultados de EF em relação aos compósitos produzidos com 1\% e 2\% de FPP. As fibras vegetais sofrem a mineralização, fenômeno que a fibra absorve água altamente alcalina com produtos de hidratação do cimento durante o processo de cura, que pode induzir o enrijecimento das fibras e pode levar a perdas significativas de MOR (BENTUR e MINDESS, 1990).

As Figuras $40 \mathrm{f}$ e $40 \mathrm{~g}$ apresentam os resultados de TFT. Compósitos fabricados com $2 \%$ de fibras com $10 \mathrm{~mm}$ de comprimento mostram um aumento em relação aos compósitos com 2\% de fibras com $6 \mathrm{~mm}$. Compósitos com 1\% $6 \mathrm{~mm}$ apresentaram melhor resultado em relação aos compósitos com $1 \% 10 \mathrm{~mm}$. Com relação às fibras, os compósitos com FC apresentaram menores resultados em relação aos compósitos com FPP. 


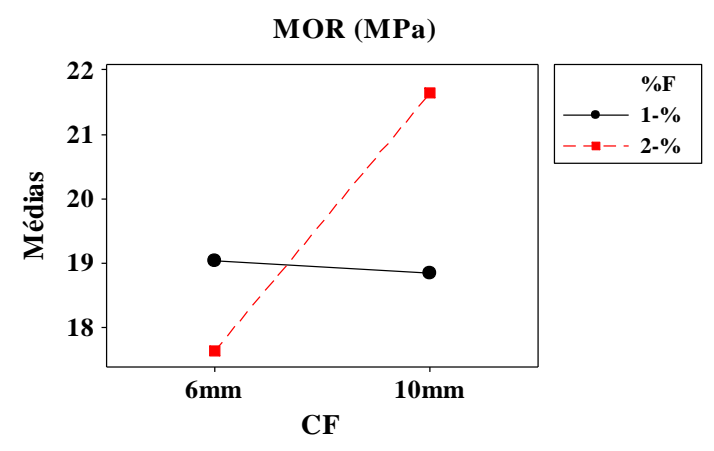

(a)

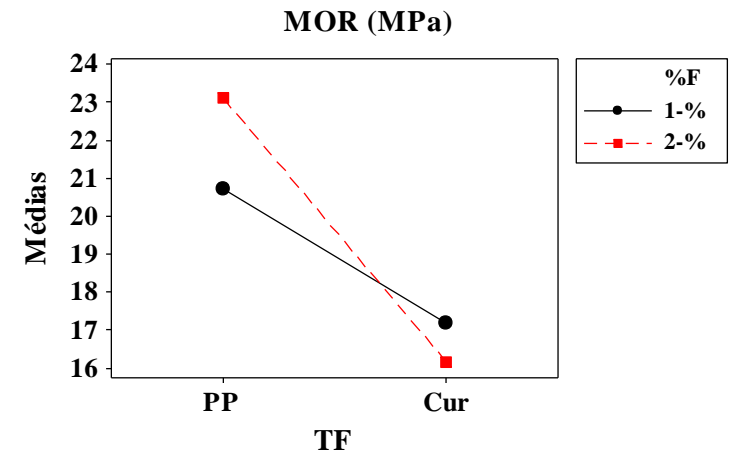

(b)

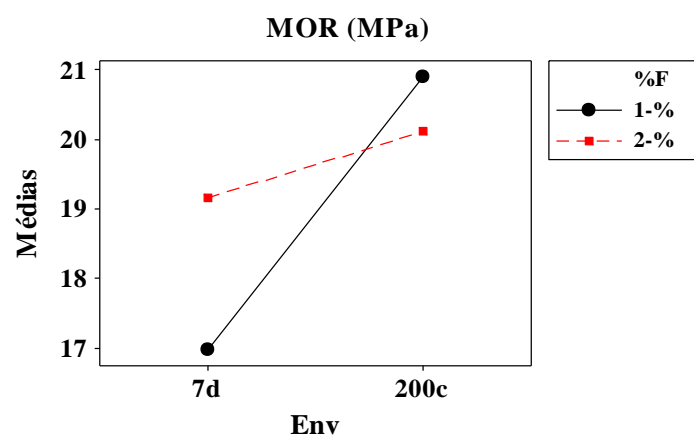

(c)

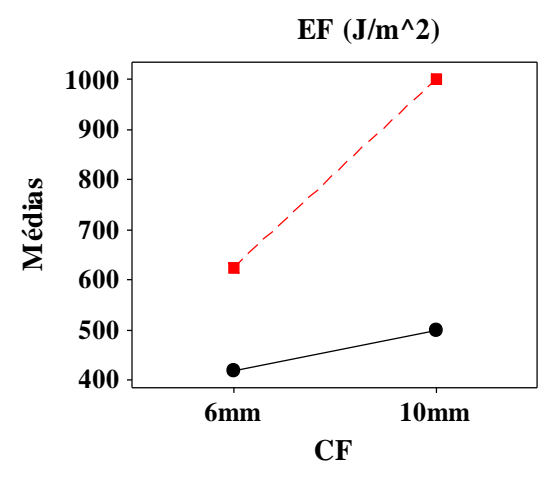

(d)

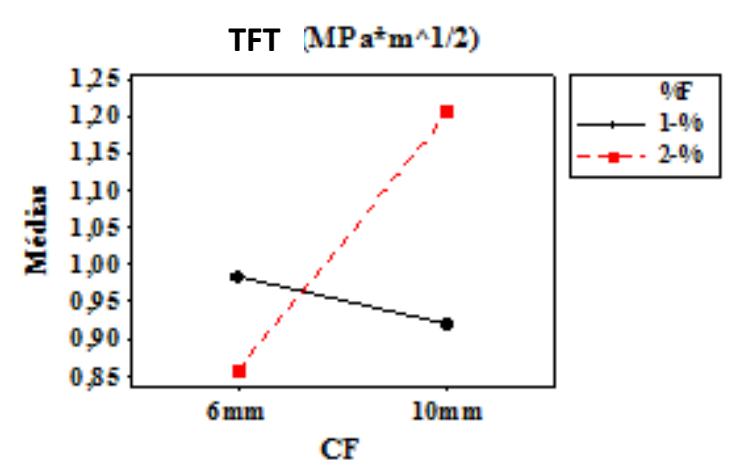

(f)

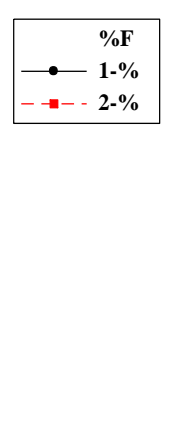

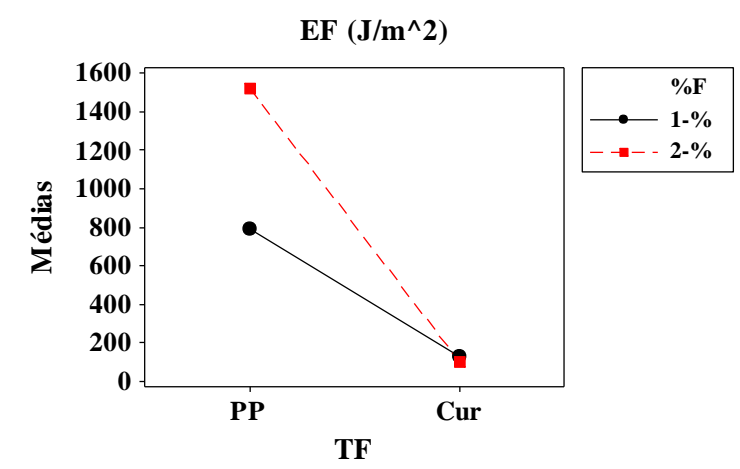

(e)

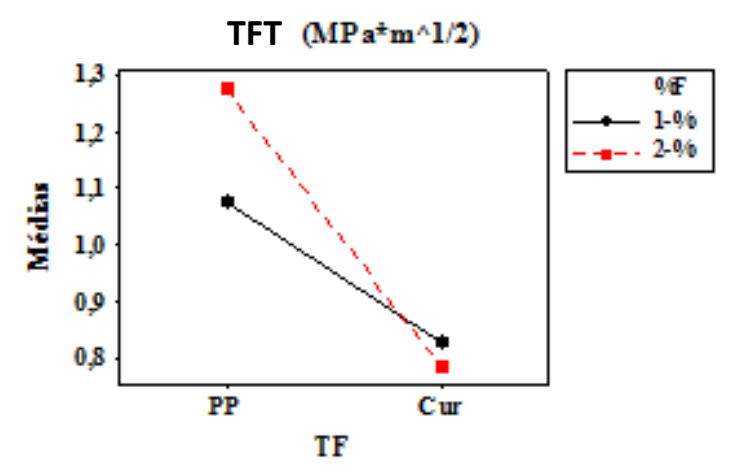

(g)

Figura $40-(a, b$ e c) interação entre fatores para o módulo de ruptura (MOR); (d e e) interação entre fatores para energia de fratura $(E F)$ e ( $f$ e $g$ ) interação entre fatores para a tenacidade a fratura (TFT) do Planejamento 1 - estudo das propriedades mecânicas e físicas. 
A Figura 41 apresenta a interação entre fatores considerados significativos pela ANOVA para porosidade aparente (PA), absorção de água (AA) e densidade aparente (DA) do Planejamento 1 - estudo das propriedades mecânicas e físicas. Compósitos fabricados com $1 \%$ e $2 \%$ de fibras com $10 \mathrm{~mm}$ apresentaram maiores resultados de AA em relação aos compósitos com 1\% e 2\% de fibras com $6 \mathrm{~mm}$ devido ao maior comprimento da fibra que apresenta maiores imperfeições na estrutura da matriz de cimento, ocasionando maior AA.

Com relação aos 200 ciclos, houve uma diminuição com $2 \%$ de fibras e uma similaridade com $1 \%$ de fibras, além disso também houve um aumento com $10 \mathrm{~mm}$ de comprimento e diminuiu com fibras de $6 \mathrm{~mm}$ após 200 ciclos. Já com FC apresentou uma similaridade e com FPP apresentou um pequeno decréscimo do resultado. 


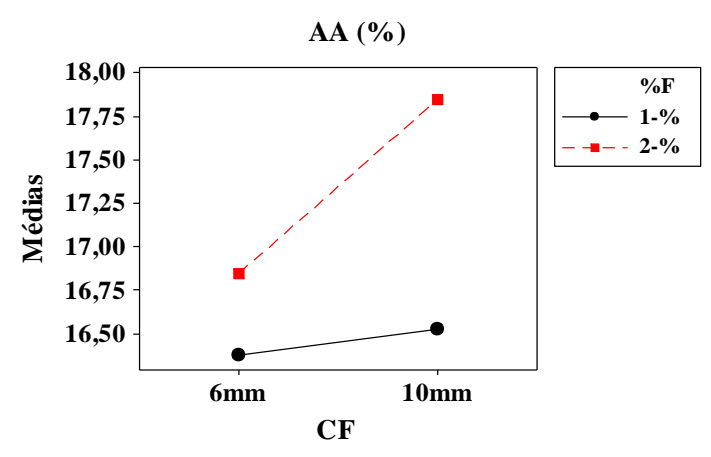

(a)

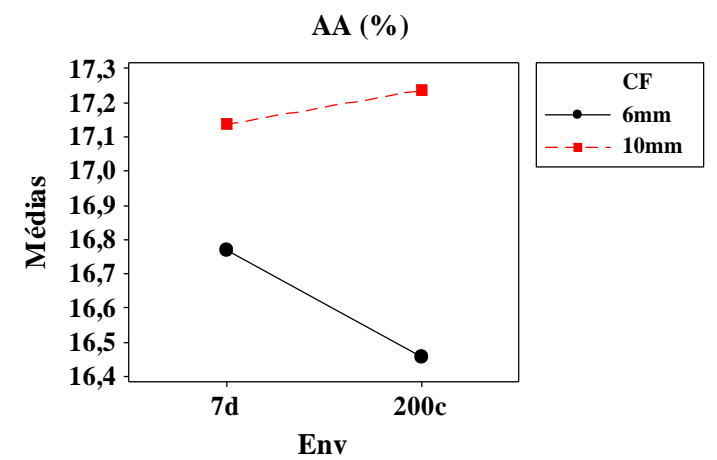

(c)

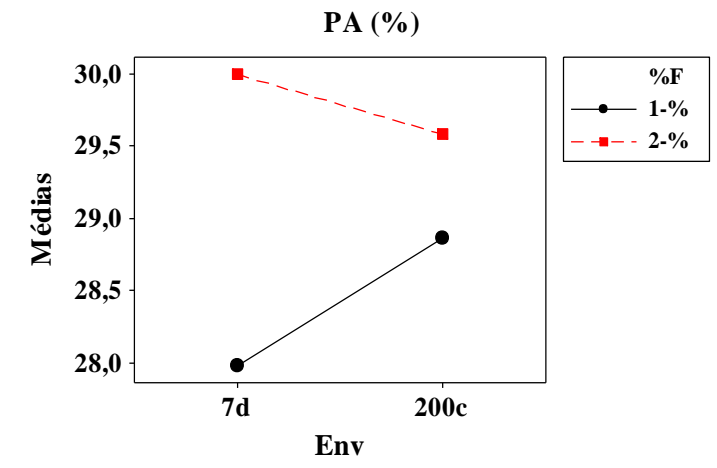

(e)

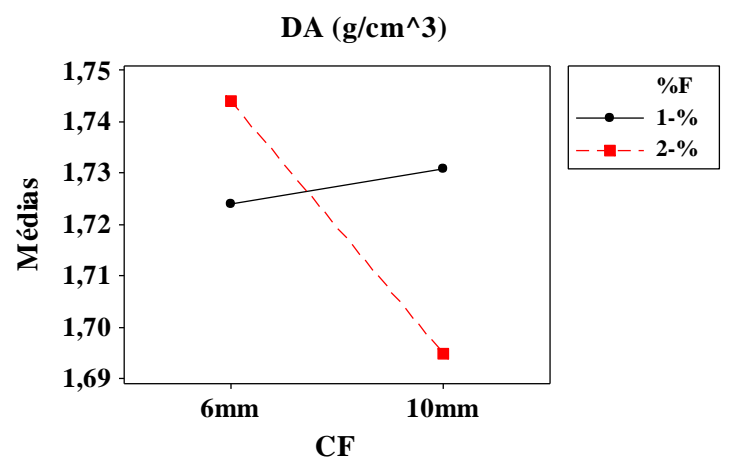

(g)

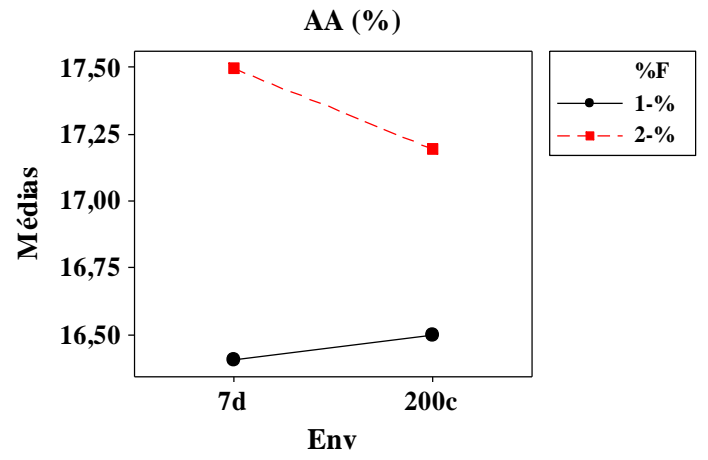

(b)

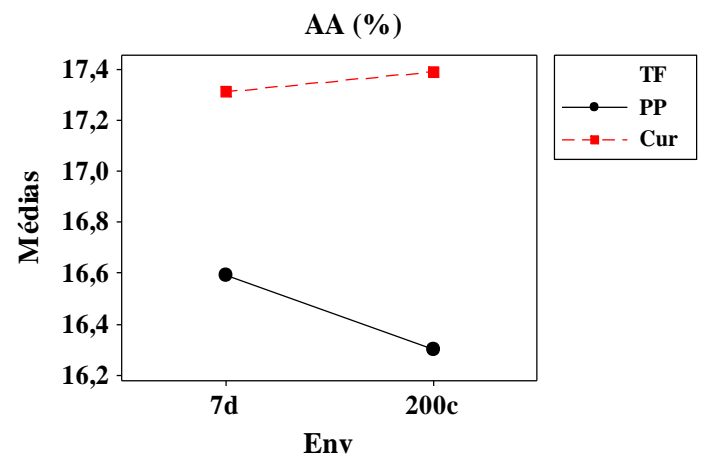

(d)

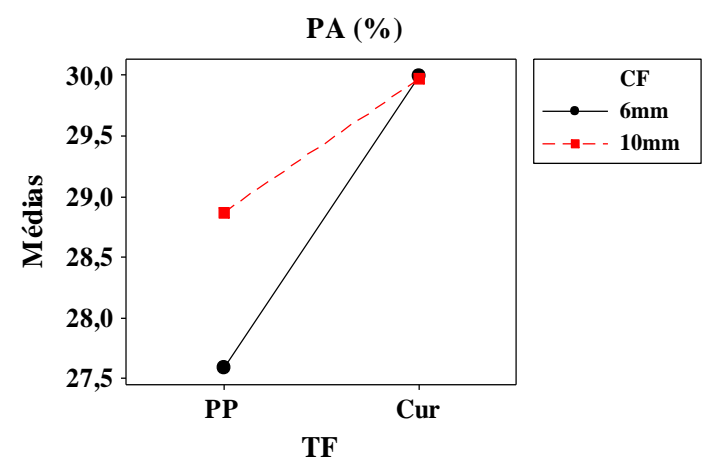

(f)

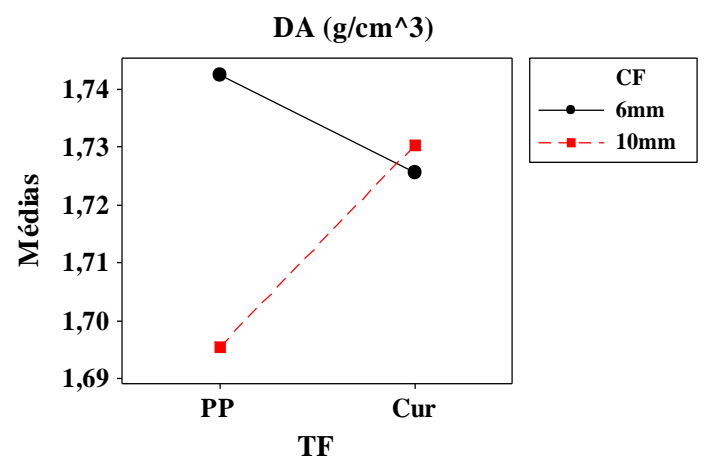

(h)

Figura 41 - (a, b, c e d) interação entre fatores para porosidade aparente (PA); (e e f) interação entre fatores para absorção de água (AA) e ( $f$ e g) interação entre fatores para a densidade aparente (DA) do Planejamento 1. 
Compósitos com 2\% $6 \mathrm{~mm}$ apresentaram diminuição nos valores de densidade em relação aos compósitos com 2\% $10 \mathrm{~mm}$. Os compósitos com $1 \% 6$ $\mathrm{mm}$ e $1 \% 10 \mathrm{~mm}$ mantiveram os resultados de DA estáveis. Fibras de FPP $10 \mathrm{~mm}$ apresentaram resultados menores em relação às FC $10 \mathrm{~mm}$. Compósitos com FPP 6 $\mathrm{mm}$ apresentaram um aumento nos valores de DA em relação aos compósitos com FC $6 \mathrm{~mm}$.

Compósitos com $2 \%$ de fibras com $7 \mathrm{~d}$ apresentaram maiores resultados de AA em relação aos compósitos com $2 \%$ de fibras após $200 \mathrm{C}$. Compósitos com $1 \%$ de fibras 7 dias após 200 ciclos apresentaram melhores resultados de PA em comparação aos compósitos com $1 \%$ de fibras nas primeiras idades (7d).

A Tabela 19 apresenta os resultados do teste de Tukey das propriedades físicas e mecânicas dos materiais fabricados de acordo com os 16 tratamentos do Planejamento 1 - estudo das propriedades mecânicas e físicas, sendo a $\bar{x}$ média e Ag os agrupamentos formados pelo teste de Tukey.

Em geral, os compósitos com teores de $2 \%$ de fibras, comprimento de $10 \mathrm{~mm}$ e com fibras de polipropileno apresentaram os melhores resultados significativos nas propriedades mecânicas. Compósitos nas condições de 7 dias e 200 ciclos de envelhecimento não apresentaram diferenças significativas. Os compósitos com teores de $2 \%$ de fibras, comprimento de $10 \mathrm{~mm}$ e com fibras de curauá apresentaram os maiores resultados significativos nas propriedades físicas, exceto nos compósitos com FC 2\% com 6 mm de comprimento. 
Tabela 19 - Resultados do teste de Tukey para as propriedades físicas e mecânicas do Planejamento 1.

\begin{tabular}{|c|c|c|c|c|c|c|c|c|c|}
\hline \multirow{2}{*}{ Prop. } & \multirow{2}{*}{ Estat. } & \multicolumn{2}{|c|}{$\% F$} & \multicolumn{2}{|c|}{ CF } & \multicolumn{2}{|c|}{ TF } & \multicolumn{2}{|c|}{ Env } \\
\hline & & $1 \%$ & $2 \%$ & $6 \mathrm{~mm}$ & $10 \mathrm{~mm}$ & PP & Cur & $7 d$ & $200 c$ \\
\hline \multirow{2}{*}{$\begin{array}{l}\text { MOR } \\
\text { (MPa) }\end{array}$} & $\bar{x}$ & 18,94 & 19,64 & 18,33 & 20,25 & 21,91 & 16,67 & 18,07 & 20,51 \\
\hline & $\mathrm{Ag}$ & A & A & B & A & $A$ & B & B & A \\
\hline \multirow{2}{*}{$\mathrm{EF}\left(\mathrm{J} / \mathrm{m}^{2}\right)$} & $\bar{x}$ & 458,7 & 812,7 & 522,1 & 749,3 & 1155,6 & 115,8 & 728,6 & 542,9 \\
\hline & $A g$ & B & A & B & A & A & B & $A$ & $A$ \\
\hline \multirow{2}{*}{$\begin{array}{c}\mathrm{TF} \\
\left(\mathrm{MPa} \cdot \mathrm{m}^{1 / 2}\right)\end{array}$} & $\bar{x}$ & 0,95 & 1,03 & 0,91 & 1,06 & 1,18 & 0,80 & 1,04 & 0,95 \\
\hline & $A g$ & A & A & B & A & A & B & A & A \\
\hline \multirow{2}{*}{ AA (\%) } & $\bar{x}$ & 16,45 & 17,34 & 16,61 & 17,19 & 16,45 & 17,35 & 16,95 & 16,85 \\
\hline & $A g$ & B & A & B & A & B & A & A & A \\
\hline \multirow{2}{*}{$\begin{array}{c}\text { DA } \\
\left(\mathrm{g} / \mathrm{cm}^{3}\right)\end{array}$} & $\bar{x}$ & 1,73 & 1,72 & 1,73 & 1,71 & 1,72 & 1,73 & 1,71 & 1,74 \\
\hline & $A g$ & A & A & A & B & A & A & B & A \\
\hline \multirow{2}{*}{ PA (\%) } & $\bar{x}$ & 28,42 & 29,79 & 28,79 & 29,42 & 28,23 & 29,98 & 28,99 & 29,22 \\
\hline & $\mathrm{Ag}$ & B & A & B & A & B & A & A & A \\
\hline
\end{tabular}

Com o intuito de investigar os efeitos dos 16 tratamentos em relação à formulação de referência (matriz não reforçada por fibras e não envelhecida) para as propriedades físicas e mecânicas do Planejamento 1 - estudo das propriedades mecânicas e físicas, assim como comentado anteriormente, foi utilizada a análise de variância. A única propriedade que não apresentou normalidade na distribuição foi a energia de fratura, porém foi encontrada uma transformada de Johnson adequada (Equação 16).

$$
Y=0,903147+0,428797 \cdot \operatorname{Ln}[(X-15,6758) /(2266,64-X)]
$$

Os P-valores dos testes de normalidade (Anderson-Darling) e de homogeneidade de variâncias (Bartlett) variaram nos intervalos de [0,096, 0,482] e $[0,067,0,658]$, respectivamente, validando assim o modelo da ANOVA. A Tabela 20 apresenta os resultados do teste de Tukey (agrupamentos) dos 16 tratamentos mais o de referência para as seis propriedades físicas e mecânicas do Planejamento 1 estudo das propriedades mecânicas e físicas. 
Tabela 20 - Resultados do teste de Tukey do Planejamento $1 \mathrm{com}$ a inclusão da formulação de referência.

\begin{tabular}{|c|c|c|c|c|c|c|c|}
\hline Formulação & Tratamentos & MOR & EF & TF & AA & DA & PA \\
\hline Referência & Ref & CDE & $\mathrm{D}$ & $C D$ & $\mathrm{GHI}$ & $A B C$ & $\mathrm{GHI}$ \\
\hline FPP $1 \% 6 \mathrm{~mm}$ & Tr1 & $\mathrm{BC}$ & $\mathrm{C}$ & B & $\mathrm{GHI}$ & $\mathrm{BCD}$ & GHI \\
\hline FPP $1 \% 10 \mathrm{~mm}$ & Tr2 & $\mathrm{BCD}$ & $\mathrm{C}$ & $\mathrm{BC}$ & IJ & $\mathrm{BCD}$ & 1 \\
\hline FPP $2 \% 6 \mathrm{~mm}$ & Tr3 & $\mathrm{BCD}$ & $\mathrm{B}$ & $\mathrm{BCD}$ & HIJ & $A B$ & $\mathrm{FGHI}$ \\
\hline FPP $2 \% 10 \mathrm{~mm}$ & Tr4 & $B C$ & A & A & A & D & $A B$ \\
\hline $\mathrm{FC} 1 \% 6 \mathrm{~mm}$ & Tr5 & $\mathrm{F}$ & $\mathrm{D}$ & $\mathrm{CDE}$ & $\mathrm{FGH}$ & $A B C D$ & $\mathrm{EFGH}$ \\
\hline $\mathrm{FC} 1 \% 10 \mathrm{~mm}$ & Tr6 & $\mathrm{EF}$ & $\mathrm{D}$ & $\mathrm{CDE}$ & DEF & $A B C D$ & $B C D$ \\
\hline $\mathrm{FC} 2 \% 6 \mathrm{~mm}$ & Tr7 & DEF & $\mathrm{D}$ & DE & A & $A B C D$ & A \\
\hline FC $2 \% 10 \mathrm{~mm}$ & Tr8 & $\mathrm{EF}$ & $\mathrm{D}$ & CDE & DEF & ABCD & CDE \\
\hline \multicolumn{8}{|c|}{$200 \mathrm{C}$} \\
\hline FPP $1 \% 6$ mm & $\operatorname{Tr} 9$ & $A B$ & C & $\mathrm{BCD}$ & $\mathrm{GHI}$ & $A B$ & EFG \\
\hline FPP $1 \% 10 \mathrm{~mm}$ & Tr10 & $\mathrm{BC}$ & $\mathrm{C}$ & $\mathrm{CDE}$ & HIJ & $A B$ & $\mathrm{GHI}$ \\
\hline FPP 2\% 6 mm & Tr11 & $\mathrm{BCD}$ & $\mathrm{C}$ & CDE & $J$ & A & $\mathrm{HI}$ \\
\hline FPP $2 \% 10 \mathrm{~mm}$ & Tr12 & A & $A$ & A & $A B$ & $C D$ & $\mathrm{BC}$ \\
\hline FC $1 \% 6 \mathrm{~mm}$ & $\operatorname{Tr} 13$ & $\mathrm{BCD}$ & $\mathrm{D}$ & CDE & EFG & $A B C$ & DEF \\
\hline $\mathrm{FC} 1 \% 10 \mathrm{~mm}$ & Tr14 & A & $\mathrm{D}$ & DE & BCDE & $A B$ & $A B C$ \\
\hline $\mathrm{FC} 2 \% 6 \mathrm{~mm}$ & $\operatorname{Tr} 15$ & EF & $\mathrm{D}$ & E & $\mathrm{ABC}$ & $A B C D$ & $A B$ \\
\hline $\mathrm{FC} 2 \% 10 \mathrm{~mm}$ & Tr16 & $\mathrm{CDE}$ & $\mathrm{D}$ & $\mathrm{CDE}$ & BCD & $A B C D$ & BCD \\
\hline
\end{tabular}

Por meio dos resultados estatísticos apresentados na Tabela 20, pode-se concluir que os melhores resultados das propriedades mecânicas são aqueles que apresentam a letra $\mathrm{A}$ ou as letras mais próximas. Dessa forma, o melhor resultado foi o da formulação do compósito reforçado com $2 \%$ de fibra de polipropileno com 10 $\mathrm{mm}$ de comprimento aos 7 dias de idade e após 200 ciclos de envelhecimento. Com relação ao reforço de fibra vegetal, o compósito reforçado com $1 \%$ de fibra de curauá com $10 \mathrm{~mm}$ de comprimento após 200 ciclos apresentou o melhor resultado. 


\subsection{Resultados microestruturais}

\subsubsection{Nanoindentação (NI)}

As Figuras 42a até 42c e 43a até 43d apresentam as micrografias dos pontos nanoindentados ao longo das microestruturas do compósito cimentício, aos 7 dias e após 200 ciclos de envelhecimento acelerado respectivamente. Os pontos numerados entre 1-10 (Figura 42a e 43a) representam o grão anidro, os pontos 1120 (Figura 42a e 43a) representam a matriz cimentícia hidratada, os pontos 21-30 (Figura 42a e 43b) representam a fibra celulósica, os pontos 31-40 (Figura 42a e 43c) representam a interface fibra matriz, os pontos 41-50 (Figura 42b e 43c) representam a borda da fibra de curauá, os pontos 51-60 (Figura 42b e 43c) representam o centro da fibra de curauá e os pontos 61-65 (Figura 42c e 43d) representam a fibra de polipropileno. Os valores individuais do módulo de elasticidade $(E)$ adquiridos para cada ponto são mostrados nas Figuras 44b e 44d; enquanto que os valores individuais de dureza $(H)$ são apresentados nas Figuras 44a e 44c. Os pontos utilizados na nanoindentação foram entre 100 a $300 \mathrm{~nm}$ de profundidade, devido à superfície irregular das amostras e para evitar erros nos cálculos (DA SILVA; NĚMEČEK; ŠTEMBERK, 2014). 


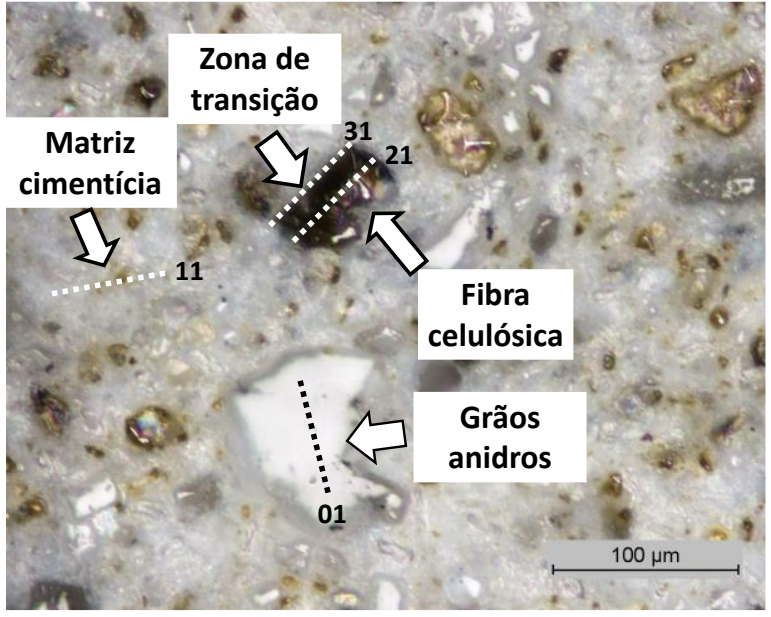

(a)

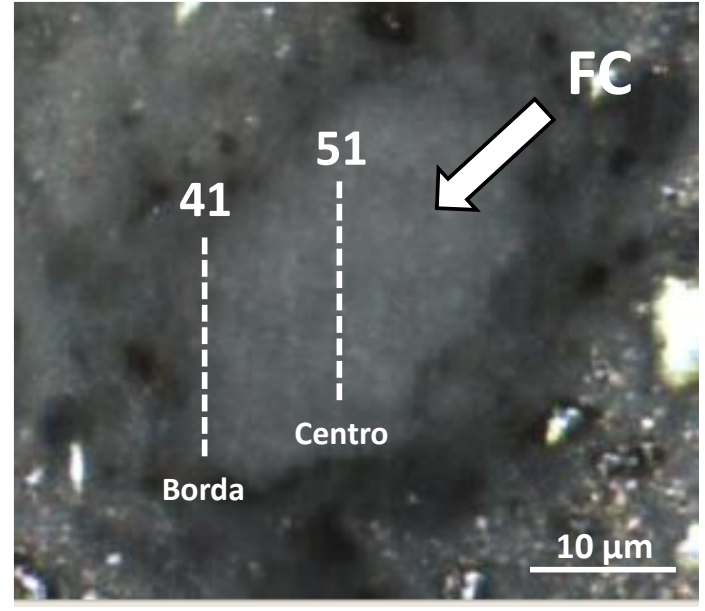

(b)

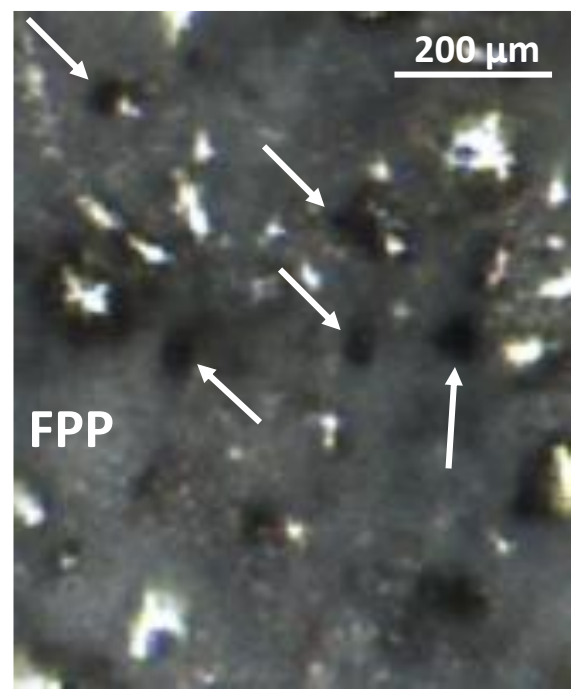

(c)

Figure 42 - (a, b e c) Micrografia óptica de pontos de nanoindentação em linha e aleatórios aplicadas em diferentes estruturas (grão anidro, matriz cimentícia, fibra celulósica, zona de transição, borda das fibras de curauá, centro das fibras de curauá e fibras de polipropileno) ao longo do compósito extrudado com 7 dias. 


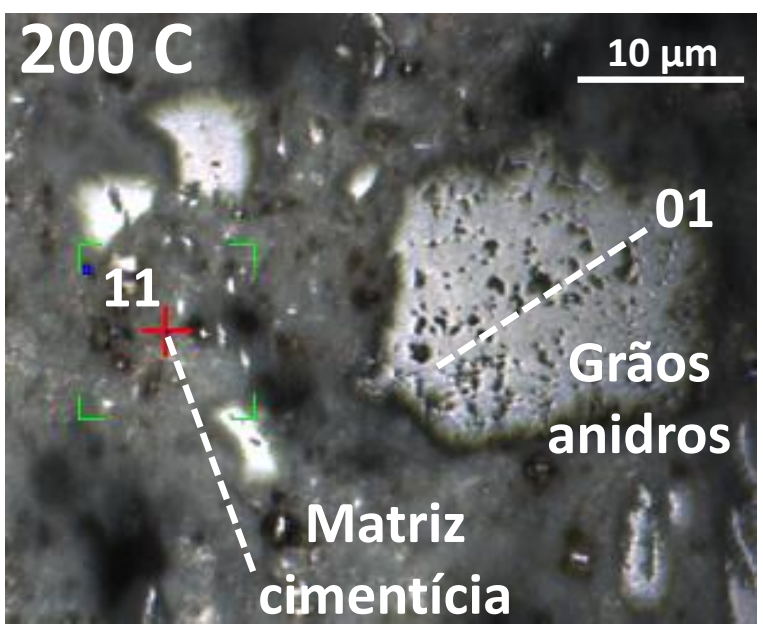

(a)

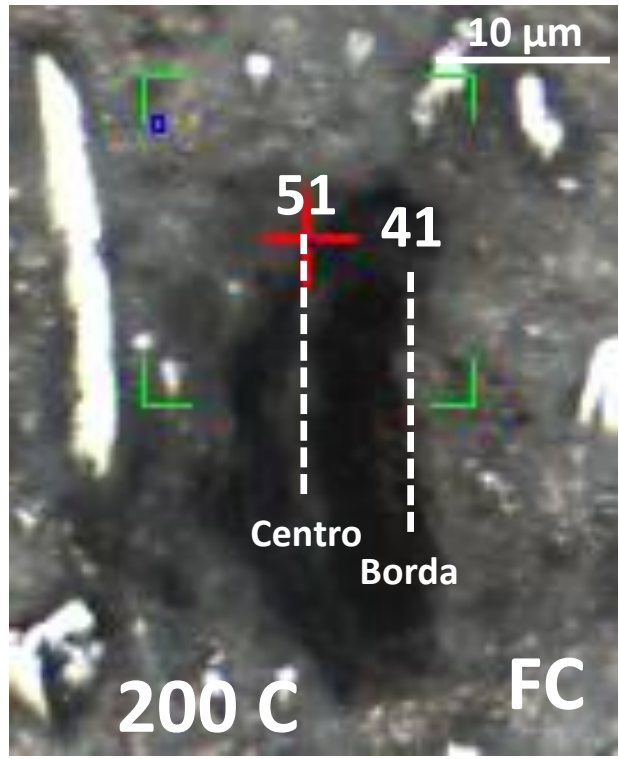

(c)

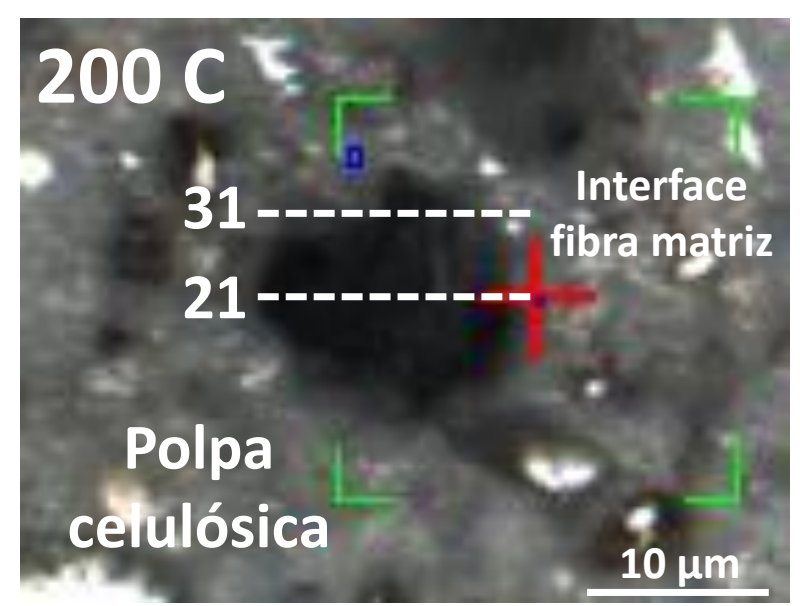

(b)

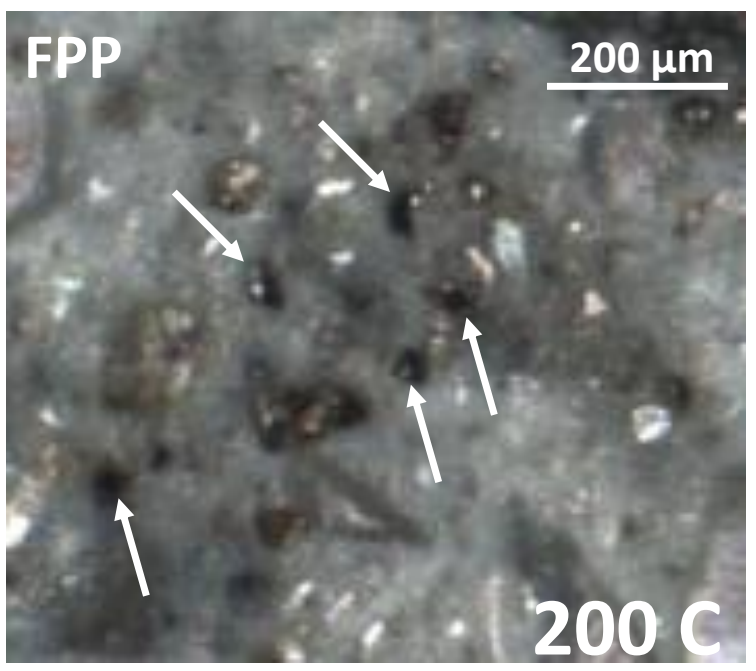

(d)

Figura 43 - (a, b, c e d) Micrografia óptica de pontos de nanoindentação em linha e aleatórios aplicadas em diferentes estruturas (grão anidro, matriz cimentícia, fibra celulósica, zona de transição, borda das fibras de curauá, centro das fibras de curauá e fibras de polipropileno) ao longo do compósito extrudado após 200 ciclos. 

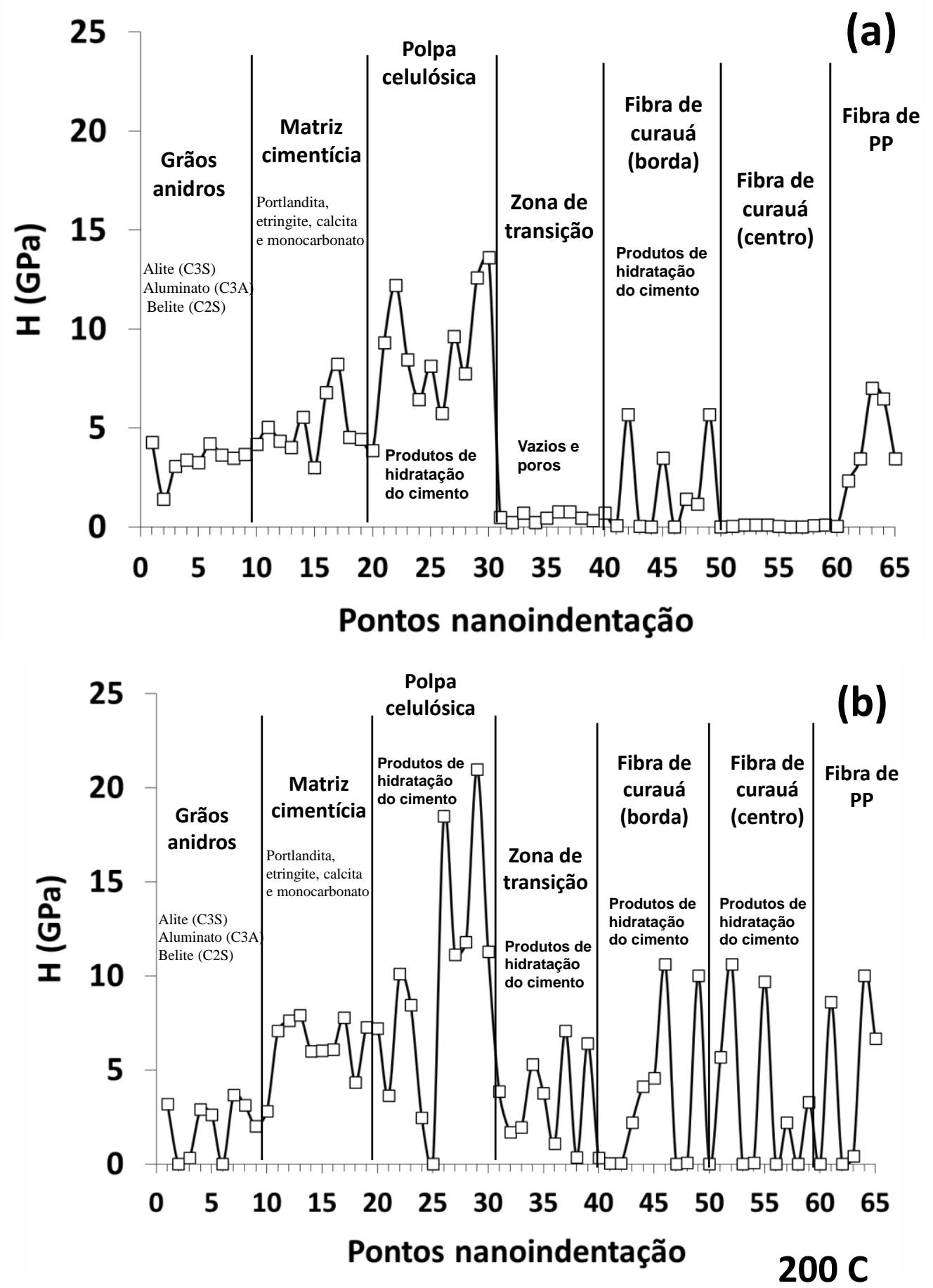

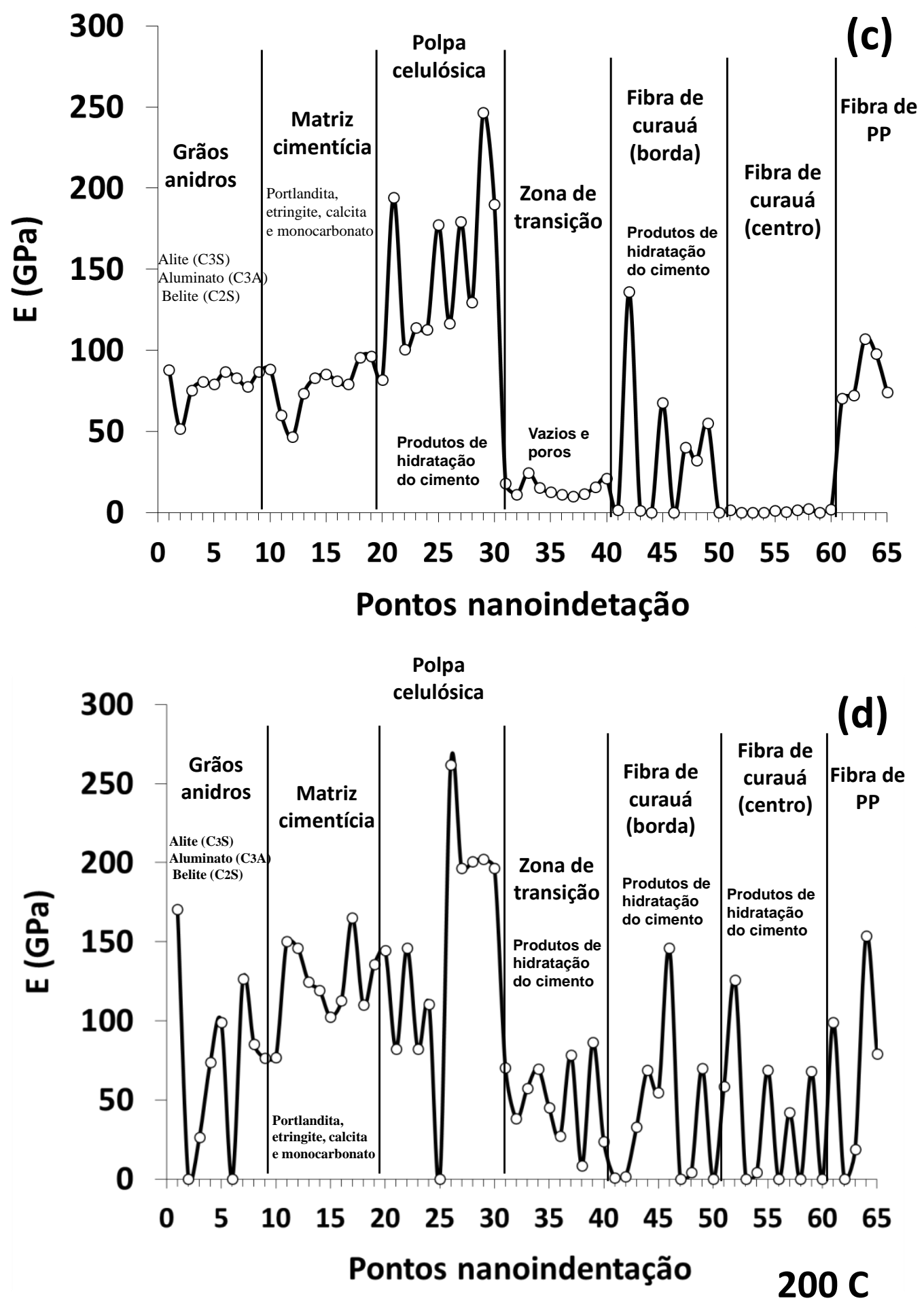

Figura 44 - Valores individuais de dureza $(H)$ e de módulo elástico $(E)$ para cada ponto de nanoindentação aplicados em diferentes estruturas (grão anidro, matriz cimentícia, fibras celulósicas, fibras de curauá (FC), fibras de polipropileno (FPP), zona de transição entre fibra e matriz): (a e c) compósito extrudado com 7 dias e (b e d) compósito extrudado após 200 ciclos. 
A Tabela 21 lista os valores médios e desvios padrões de módulo elástico e da dureza obtidas a partir da nanoindentação nas diferentes regiões estudadas da microestrutura do compósito. A Tabela 22 apresenta os resultados estatísticos de todos os compósitos, aos 7 dias e após 200 ciclos.

Os pontos de nanoindentação conduzidos na matriz cimentícia, como ilustra a Figura 42a, apresentaram valor de módulo de elasticidade em torno de $78 \mathrm{GPa}$ e de dureza em torno de $5 \mathrm{GPa}$ aos 7 dias de cura. Estes resultados são semelhantes do estudo de Da Silva et al., (2014), que estudaram nanoindentação em amostras de compósitos cimentícios com cinza volante após 21 dias de cura. A matriz tem grandes quantidades de produtos de hidratação e normalmente apresentam fases de C-S-H e de calcita, como componentes principais, que têm relativa rigidez e baixa porosidade. Após 200 ciclos, a matriz cimentícia apresentou um aumento de 35\% de dureza e $65 \%$ do módulo elástico devido à reidratação do cimento, mas não apresentou diferença significativa em relação ao compósito aos 7 dias de cura.

Outras fases, como, por exemplo, $\mathrm{Ca}(\mathrm{OH})_{2}$ e etringita são estruturas complexas e com baixo fator de empacotamento, o que pode explicar o baixo valor de módulo de elástico de $15 \mathrm{GPa}$ e de dureza de 0,5 GPa, principalmente nos pontos correspondentes à zona de transição, entre a matriz e a fibra celulósica. Estes valores de módulo elástico e de dureza são semelhantes àqueles encontrados no estudo de Wang et al. (2009). Eles aplicaram a técnica de nanoindentação para avaliar matriz de concreto reforçado com fibras de aço. Os valores de dureza próximo da zona de transição são menores em relação à região da matriz, que também está relacionada com a porosidade mais elevada nesta região de interface, o que resulta na baixa adesividade entre fibra e matriz e, consequentemente, prejudica a resistência mecânica do compósito (IGARASHI; BENTUR; MINDESS, 1996; MEČEK; KABELE; BITTNAR, 2004).

A Tabela 22, mostra que os valores variaram na zona de transição de $15 \mathrm{GPa}$ para 50 GPa para o módulo elástico e 0,51 GPa para 3,18 GPa para a dureza, para os compósitos aos 7 dias e após 200 ciclos respectivamente. Essa variação de valores está relacionada com a densificação da microestrutura. 
Tabela 21 - Valores médios e desvios padrões de módulo elástico (E) e de dureza (H) obtidos para cada estrutura do compósito pela técnica de nanoindentação.

\begin{tabular}{lccc}
\hline \multicolumn{1}{c}{ Estrutura } & Condição & Módulo elástico (GPa) & Dureza (GPa) \\
\hline Grãos anidros & $79,78 \pm 10,86$ & $3,46 \pm 0,83$ \\
Matriz cimentícia & $78,26 \pm 14,44$ & $4,98 \pm 1,45$ \\
Fibra celulósica & $156,12 \pm 45,53$ & $9,39 \pm 2,52$ \\
Zona de transição & 7 dias & $15,04 \pm 4,60$ & $0,51 \pm 0,21$ \\
Borda fibra curauá & $33,37 \pm 42,02$ & $1,75 \pm 2,22$ \\
Centro fibra curauá & $0,94 \pm 0,85$ & $0,06 \pm 0,04$ \\
Fibra polipropileno & $84,35 \pm 15,10$ & $4,54 \pm 1,86$ \\
\hline Grãos anidros & $73,48 \pm 53,80$ & $2,06 \pm 1,42$ \\
Matriz cimentícia & $131,10 \pm 19,35$ & $6,73 \pm 1,05$ \\
Fibra celulósica & $147,87 \pm 74,42$ & $9,83 \pm 6,31$ \\
Zona de transição & 200 ciclos & $50,47 \pm 24,75$ & $3,18 \pm 2,35$ \\
Borda fibra curauá & $37,92 \pm 45,51$ & $3,16 \pm 3,94$ \\
Centro fibra curauá & $36,73 \pm 41,11$ & $3,15 \pm 3,94$ \\
Fibra polipropileno & $70,17 \pm 55,57$ & $5,14 \pm 4,16$ \\
\hline
\end{tabular}

Outra observação importante deste estudo em escala nanométrica está relacionada com o processo de hidratação dos grãos de cimento do compósito cimentício. A incorporação de água durante a mistura dos constituintes do compósito apresenta grãos de cimento hidratados que têm números atómicos médios e grãos de cimento que não foram completamente hidratados (grãos anidros) Em seguida, é obtido forte contraste entre os grãos que não reagiram (anidros) e os que reagiram (hidratos) (ROSSETTO; SOUZA; PANDOLFELLI, 2009). Os dados para o grão anidro estão listados na Tabela 21 e mostram que o valor de módulo de elástico foi em torno de $80 \mathrm{GPa}$ e de dureza em torno de 3,5 $\mathrm{GPa}$, que não foram significativamente diferentes dos valores médios da matriz hidratada, dos compósitos aos 7 dias. Velez et al. (2001) também estudaram nanoindentação em cimento Portland e não encontraram diferenças nos valores de dureza e de módulo elástico em fases anidras, tais como alita $\left(\mathrm{C}_{3} \mathrm{~S}\right)$, aluminato de cálcio $\left(\mathrm{C}_{3} \mathrm{~A}\right)$ e belita $\left(\mathrm{C}_{2} \mathrm{~S}\right)$. 
Após 200 ciclos, ocorreu uma redução no valor de dureza e de módulo elástico do grão anidro em relação aos 7 dias, possivelmente devido à continuidade do processo de hidratação, recirculação de água em conjunto com a temperatura, que promove a dissolução do grão, como pode ser observado na Figura 43a, em que se constata um desgaste superficial na sua estrutura (TAYLOR, 1990).

A água de poro, altamente alcalina, dentro da interface entre a fibra e matriz pode induzir as fibras celulósicas e vegetais ao endurecimento por meio de mineralização. Ela ocorre porque as fibras são hidrofílicas e absorvem a água rica em produtos de hidratação do cimento, dessa forma, esses produtos de hidratação precipitam nas fibras, levando ao fenômeno da mineralização proposto em outros trabalhos (BENTUR e AKERS, 1989b; TOLÊDO FILHO et al., 2000; MOHR; NANKO; KURTIS, 2005). Esta precipitação de produtos de hidratação do cimento nas fibras se explica os maiores valores de módulo elástico (GPa 144) e de dureza ( $9 \mathrm{GPa}$ ) aos 7 dias e após 200 ciclos observado os pontos de nanoindentação estão relacionadas com as fibras celulósicas. As fibras de curauá absorveram produtos de hidratação do cimento tanto na borda quanto no centro aos 7 dias e após 200 ciclos destacados na Figura 42b e 43c.

O aumento da rigidez das fibras de celulose constitui um inconveniente porque promove a perda da capacidade dessas fibras reforçar e de tenacificar a matriz cimentícia. Este resultado pode explicar o baixo valor de resistência a tração na flexão e ao aumento da rigidez de compósitos reforçados com fibras de celulose amplamente relatado na literatura (TONOLI et al., 2009b; TONOLI et al., 2013).

Figura 45a ilustra os produtos de hidratação na matriz cimentícia e dentro da parede celular das fibras celulósicas. Os espectros de EDS (Figura 45b) nos pontos 1 (superior) e 2 (parte inferior) mostram as grandes quantidades de Si e Ca para as fibras celulósicas. 


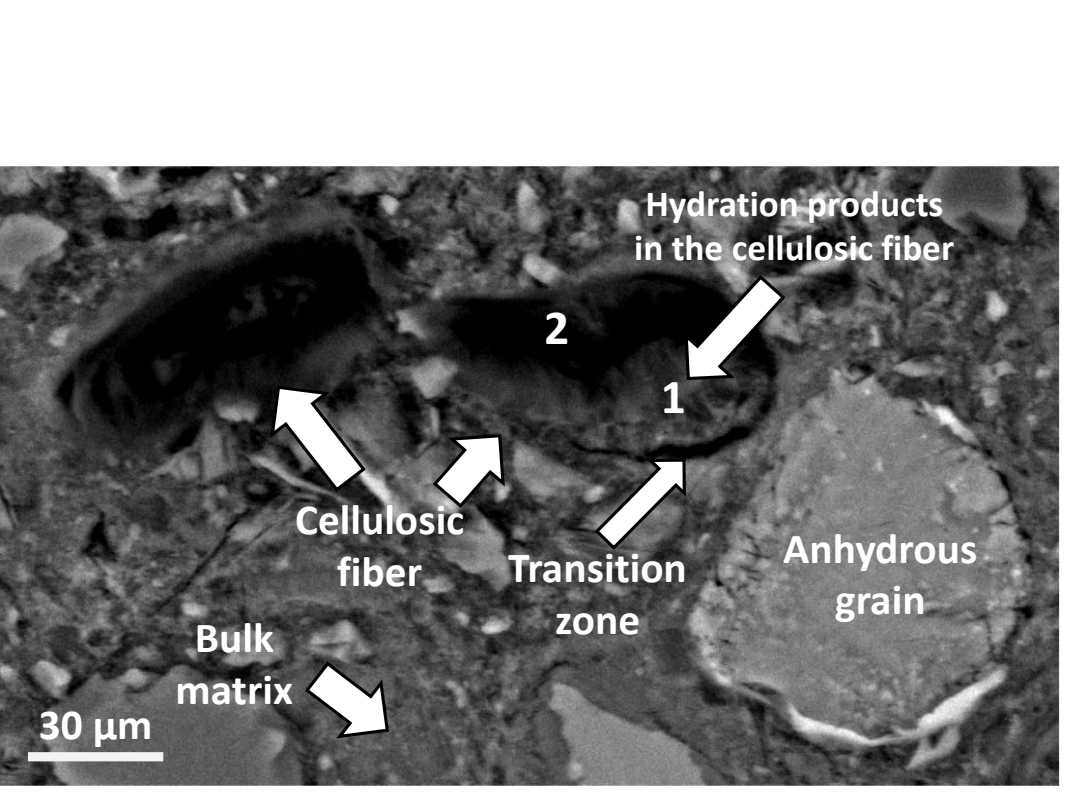

(a)

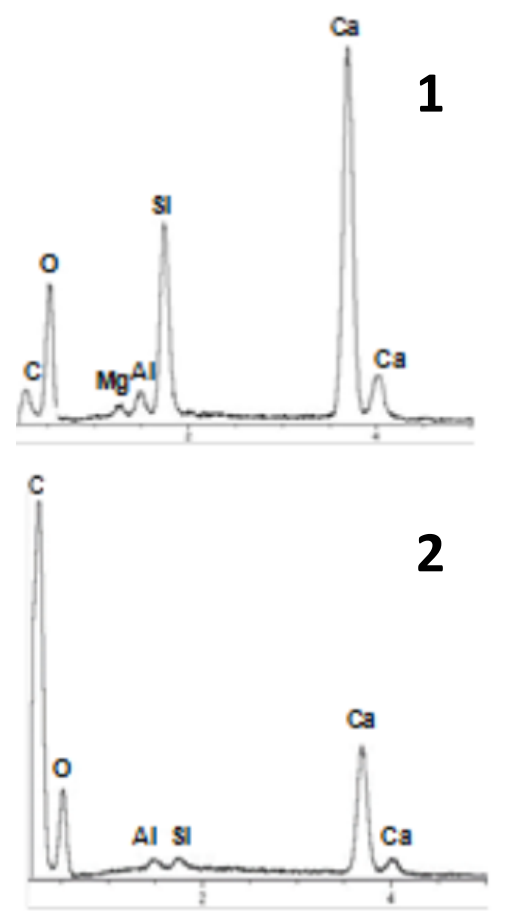

(b)

Figura 45 - (a) Micrografias de microscopia eletrônica de varredura (MEV) de espalhamento de elétrons (BSE) da seção transversal polida de um compósito extrudado; e (b) espectros de dispersão de energia (EDS) dos pontos 1 e 2 nas micrografias.

Dos valores de módulo elástico $(E)$ e de dureza $(H)$ provenientes dos ensaios de nanoindentação (em função das 7 regiões arbitradas nas amostras) para a condição de material envelhecido e sem envelhecimento, observa-se que ambas as propriedades mecânicas não apresentaram normalidade nas distribuições. Mesmo com o uso da transformada de Johnson, não foi possível encontrar transformadas para os resultados obtidos. Esse resultado implica em uso da ANOVA (não paramétrica) de Kruskal-Wallis e do teste de comparações múltiplas entre postos de Student-Newman-Keuls. A Tabela 22 apresenta o resultado da ANOVA para os valores de módulo elástico e de dureza. 
Tabela 22 - Resultados da ANOVA dos valores de módulo elástico e de dureza.

\begin{tabular}{ccccc}
\hline \multirow{2}{*}{ Região } & \multicolumn{2}{c}{7 dias } & \multicolumn{2}{c}{200 ciclos } \\
& E (GPa) & H (GPa) & E (GPa) & H (GPa) \\
\hline Grãos anidros & $\mathrm{B}$ & $\mathrm{BC}$ & $\mathrm{BC}$ & $\mathrm{B}$ \\
Matriz cimentícia & $\mathrm{B}$ & $\mathrm{B}$ & $\mathrm{AB}$ & $\mathrm{AB}$ \\
Fibra celulósica & $\mathrm{A}$ & $\mathrm{A}$ & $\mathrm{A}$ & $\mathrm{A}$ \\
Zona de transição & $\mathrm{C}$ & $\mathrm{D}$ & $\mathrm{C}$ & $\mathrm{B}$ \\
Borda fibra curauá & $\mathrm{C}$ & $\mathrm{CD}$ & $\mathrm{C}$ & $\mathrm{B}$ \\
Centro fibra curauá & $\mathrm{C}$ & $\mathrm{D}$ & $\mathrm{C}$ & $\mathrm{B}$ \\
Fibra de polipropileno & $\mathrm{B}$ & $\mathrm{B}$ & $\mathrm{ABC}$ & $\mathrm{AB}$ \\
\hline P-valor & 0,000 & 0,000 & 0,000 & 0,004 \\
GL & 6 & 6 & 6 & 6 \\
H & 50,341 & 49,198 & 28,318 & 19,037 \\
\hline
\end{tabular}

Os valores de $\mathrm{E}$ e $\mathrm{H}$ das fibras de polipropileno não apresentaram diferença significativa, aos 7 dias e após os 200 ciclos pelo fato de as fibras serem inertes. Vale ressaltar as dificuldades encontradas em fazer os pontos de nanoindentação devido ao seu pequeno diâmetro. Em geral, após os 200 ciclos, houve uma mudança nos resultados de nanoindentação nas estruturas dos compósitos cimentícios analisadas em comparação aos 7 dias. Esse comportamento em escala microestrutural corrobora com os resultados obtidos em escala macro, tais como propriedades mecânicas dos compósitos estudados neste trabalho.

\subsubsection{Microscopia eletrônica de varredura (MEV)}

A Figura 46 mostra as micrografias (MEV) dos compósitos reforçados com FPP e com EDS destacando os pontos de elementos químicos predominantes na estrutura cimentícia das respectivas estruturas. As áreas escuras na imagem (associadas ao baixo número atômico dos elementos químicos predominantes) correspondem às secções longitudinais das fibras.

No ponto 1, identifica-se a fibra de polipropileno com o predomínio de carbono em sua estrutura. No ponto 2, destaca-se um grão com um alto índice de cálcio proveniente da formulação que utilizou cerca de $27 \%$ de calcário na mistura. No 
ponto 3 , destaca-se o grão anidro que não foi totalmente hidratado, em que predominam os elementos $\mathrm{Si}$ e $\mathrm{Ca}$. $\mathrm{O}$ ponto 4 apresenta claramente um grão formado de constituintes do cimento. No ponto 5 , são mostradas as fibras celulósicas com alto índice de cálcio e silício, evidenciando que a fibra absorveu água de hidratação do cimento, resultado similar ao apresentado por Tonoli (2009), que estudou fibra celulósica de eucalipto. 

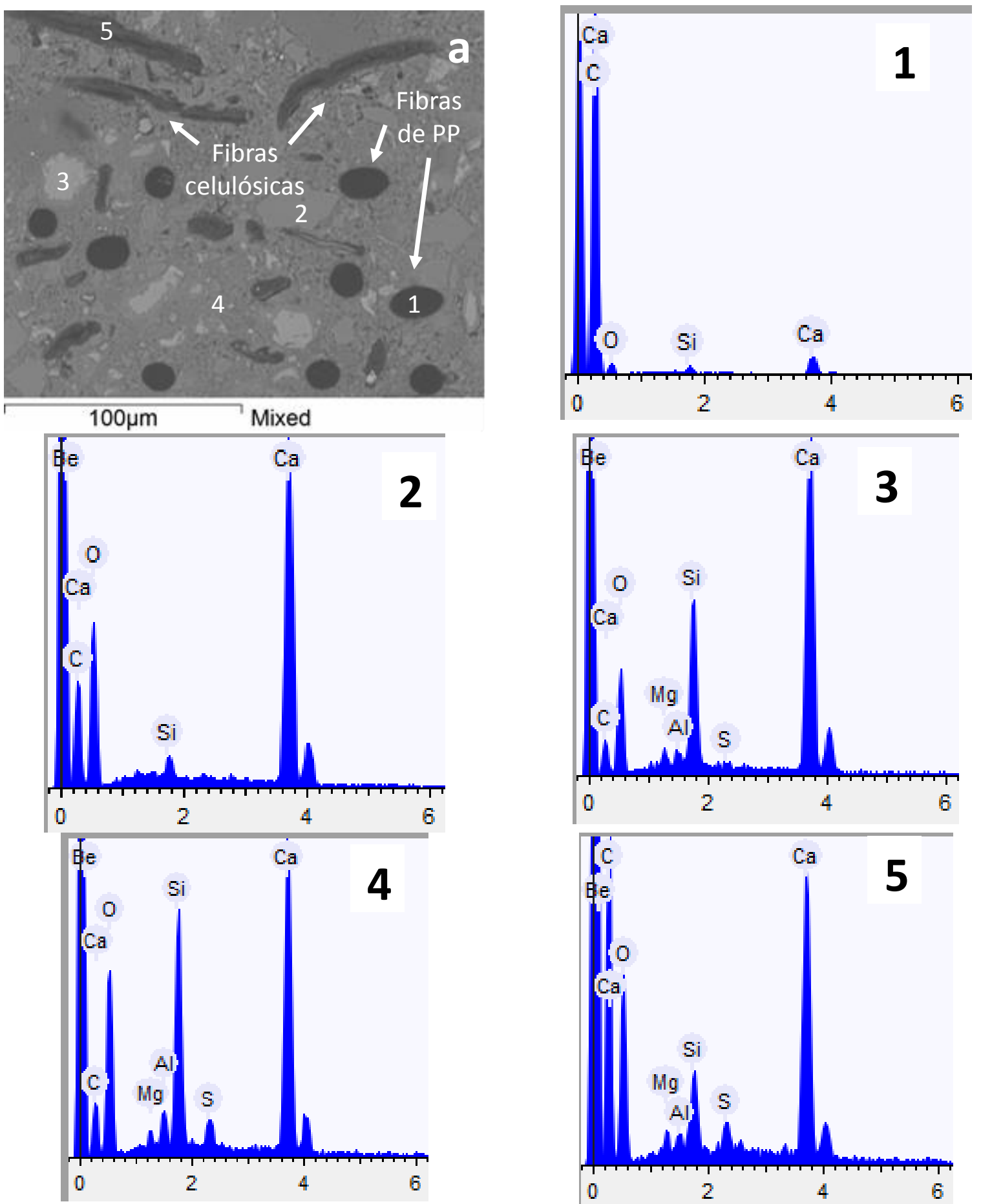

Figura 46 - Imagem (a) de microscopia eletrônica de varredura (MEV-BSE) de superfícies polidas de compósitos reforçados com PP e pontos de análises de EDS que estão sinalizados nas imagens (pontos 1 a 5): (1) fibra de Polipropileno (FPP); (2) calcário; (3) grão anidro; (4) matriz cimentícia e (5) fibra celulósica. 
$\mathrm{Na}$ Figura $47 \mathrm{a}$, observa-se, com a seta ao redor da $\mathrm{FC}$, ocorreu à variação dimensional da fibra em função do seu teor de umidade. Os poros resultantes levam a maior absorção de água, maior porosidade e baixa resistência.

Savastano e Agopyan (1999) explicam que o melhor desempenho é conseguido pela melhor aderência de fibra/matriz. A melhor adesão se consegue pela redução da porosidade e pela menor concentração de Portlandita (cristais de hidróxido de cálcio) nas proximidades da fibra.
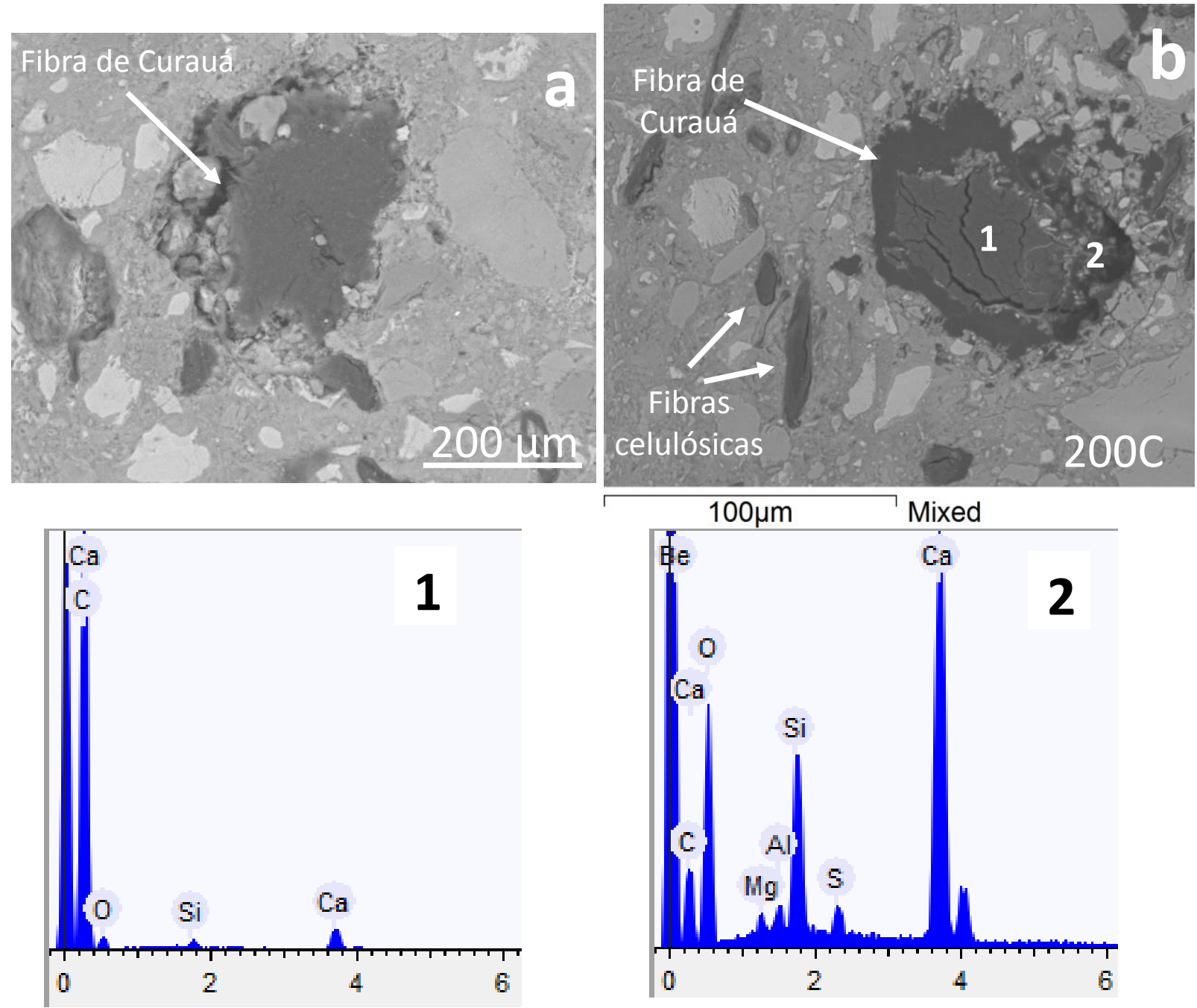

Figura 47 Micrografia de microscopia eletrônica de varredura (MEV-BSE) de superfícies polidas de compósitos reforçados com FC: (a) FC (seta indica adesão fibra-cimento) e (b) FC após 200C com pontos de análises de EDS que está sinalizado na imagem (ponto 1 e 2).

Na Figura 47b, após 200 ciclos, observa-se a melhor adesão da fibra na matriz. $O$ ponto 1 mostra que, na parte central da fibra, não foram encontrados 
produtos de hidratação do cimento como indicado pelo EDS, pela grande presença de C. No entanto, no ponto 2, a borda da fibra apresenta os principais elementos químicos do cimento, silício e cálcio (MACVICAR; MATUANA; BALATINECZ, 1999). Também podem ser observados, pelo EDS, elementos químicos, como, $\mathrm{Al}, \mathrm{S}$, e Mg. Este fenômeno pode ser associado à mineralização de fibras como indicado por Bentur; Akers, (1989a). Com a imersão em água, os íons livres formados pela dissolução das fases cimentícias do cimento Portland penetraram no lúmen das fibras, levando à formação de etringita/monosulfatos e de hidróxido de cálcio $\mathrm{Ca}(\mathrm{OH})_{2}$ (MACVICAR; MATUANA; BALATINECZ, 1999). Batic et al. (2000) mostraram que a re-precipitação de etringita em microtrincas e em poros do compósito cimentício pode ocorrer sob condições normais (temperatura ambiente) de cura. Essa formação tem sido previamente sugerida como um dos mecanismos de degradação das fibras dentro da matriz de cimento (MOHR; NANKO; KURTIS, 2005) (MOHR; BIERNACKI; KURTIS, 2006). Assim, o desempenho mecânico diminui drasticamente após os ciclos de envelhecimento.

\subsubsection{Microtomografia de raios- $X(M R X)$}

As Figuras 48 a 50 apresentam os resultados das micrografias por meio do microtomógrafo de raios-X dos compósitos de referência, CF $2 \% 6$ mm, CF 2\% 10 mm, FPP 2\% $6 \mathrm{~mm}$ e FPP 2\% $10 \mathrm{~mm}$, respectivamente. A Figura 48a apresenta micrografia da amostra referência, destacando o sentido do fluxo da extrusora pela direção da seta. Em corte perpendicular da amostra, Figura 48b, destacam-se também as fibras celulósicas na cor azul, Figura 48c, poros e espaços vazios (cores diferentes foram destacadas de acordo com o tamanho dos poros ou vazios) na Figura 48d. Nota-se que as fibras celulósicas estão bem distribuídas no interior da amostra do compósito, como também os poros e vazios. 


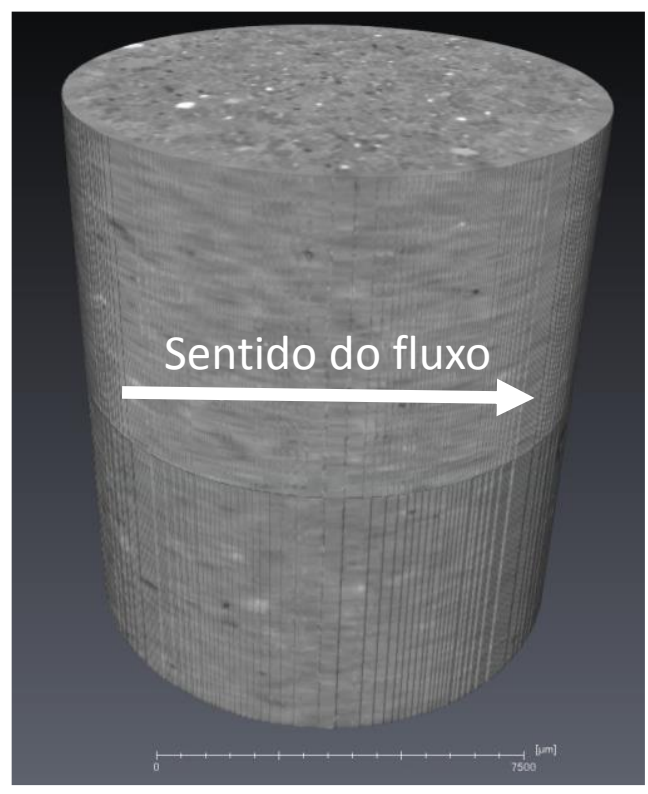

(a)

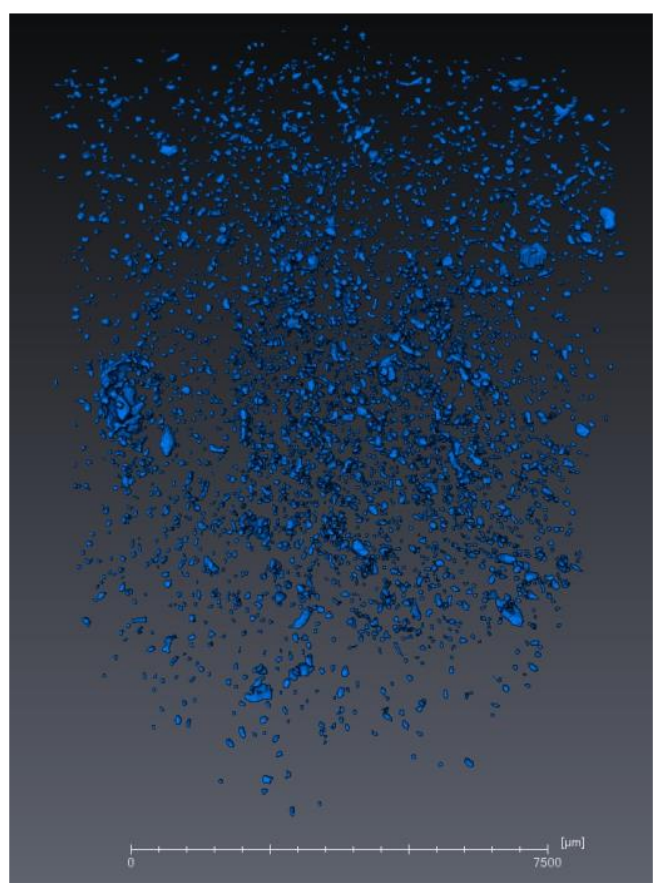

(c)

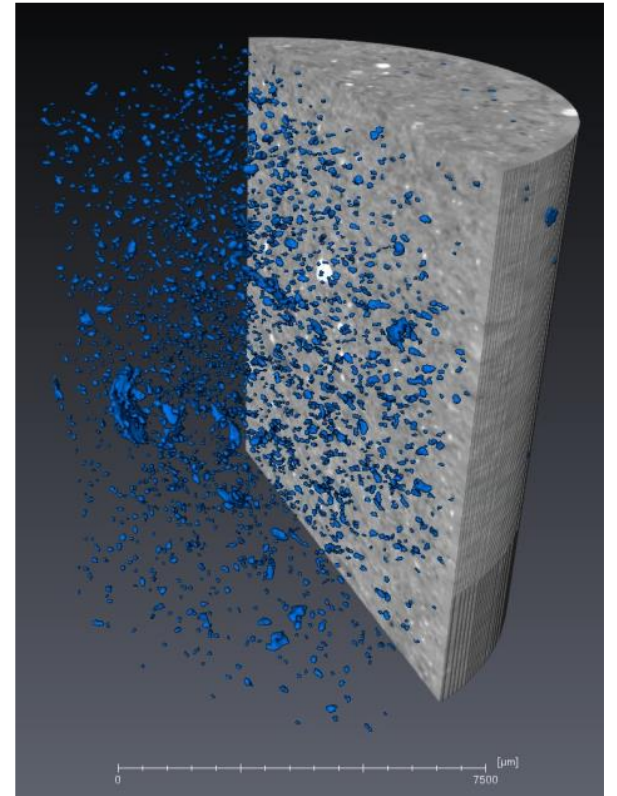

(b)

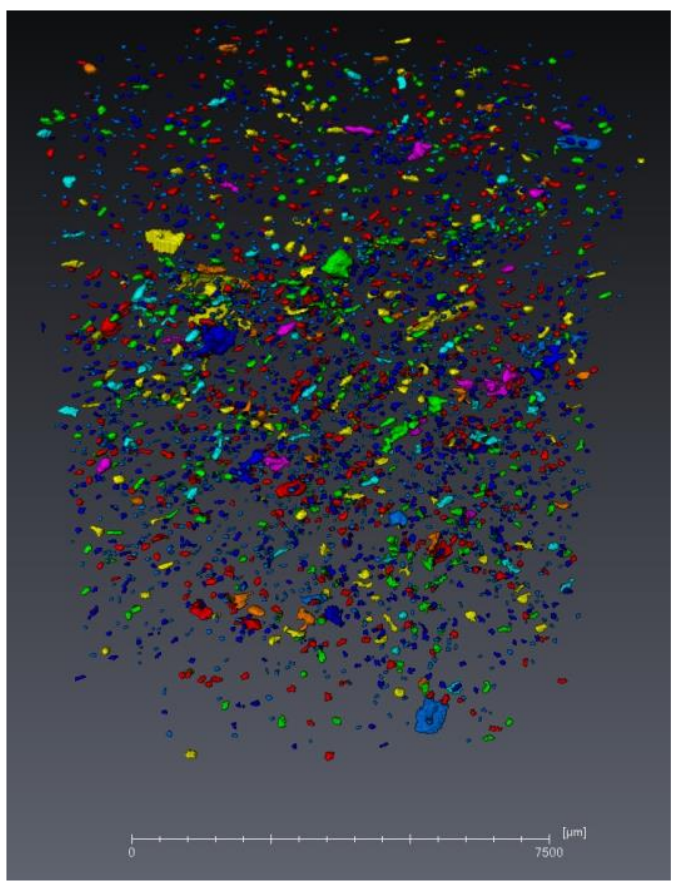

(d)

Figura 48 - (a) Micrografia por meio do microtomógrafo de raio-X da amostra referência que destaca o sentido do fluxo pela direção da seta (b) corte perpendicular da amostra; (c) destacando as fibras celulósicas na cor azul e (d) poros e espaços vazios (cores diferentes foram destacadas de acordo com o tamanho dos poros ou vazios).

A Figura 49a destaca a seta indicando a direção do fluxo da extrusora do compósito 2\% FC $6 \mathrm{~mm}$. As fibras de curauá com $6 \mathrm{~mm}$ de comprimento, em sua grande maioria, posicionam-se no sentido da direção do fluxo da extrusora, 
facilitando o fluxo da mistura no seu interior. Essa informação corrobora com os resultados reológicos apresentados, indicando menor tensão de escoamento. A Figura 49b destaca, na cor vermelha, as redes de poros e apresenta os espaços vazios conectados entre si.

A Figura 49c apresenta a amostra dos compósitos FC 2\% $10 \mathrm{~mm}$. Pode-se notar que, na alteração de comprimento das fibras de $6 \mathrm{~mm}$ para $10 \mathrm{~mm}$, existe uma mudança na configuração das direções das fibras, com as mesmas se apresentando em várias direções, opondo-se à direção do fluxo da extrusora, o que provoca maior tensão de escoamento em relação aos compósitos com FC $2 \% 6 \mathrm{~mm}$, como discutido nos resultados reológicos. Na Figura 49d, compósitos com FC 2\% 10 mm apresentam maiores números de poros e espaços vazios em relação ao compósito com FC $6 \mathrm{~mm}$. Dessa forma, o compósito 2\% FC $10 \mathrm{~mm}$ apresentam maiores valores de AA e PA em relação aos compósitos $2 \%$ FC $6 \mathrm{~mm}$, corroborando com os resultados físicos apresentados. 


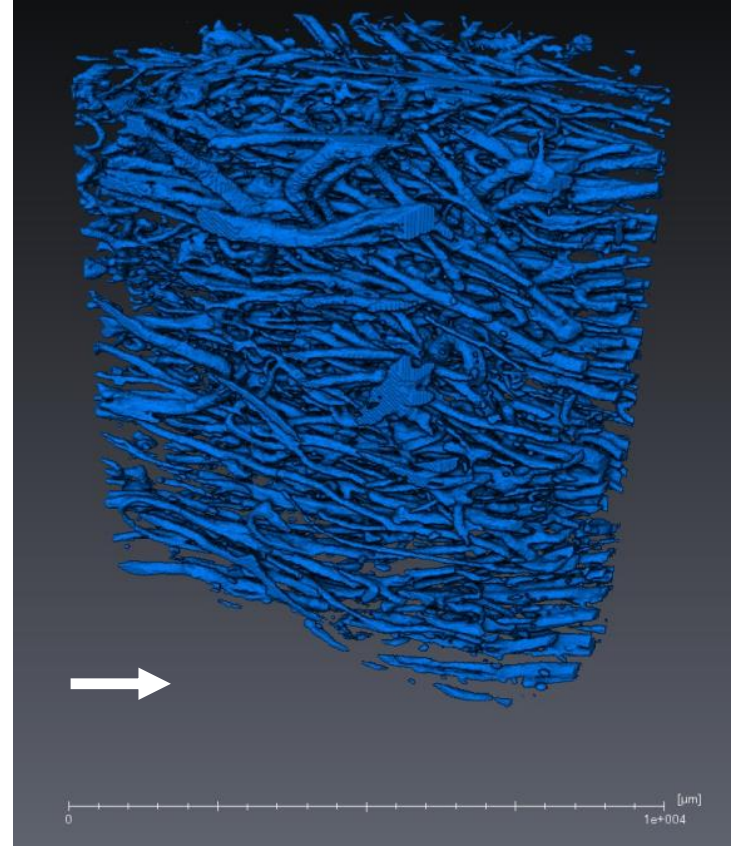

(a)

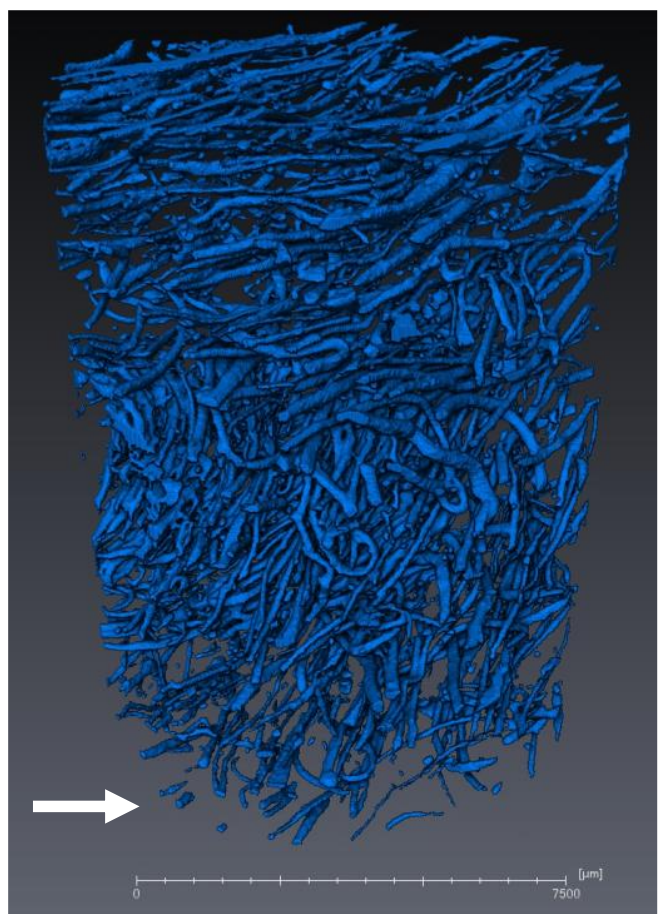

(c)

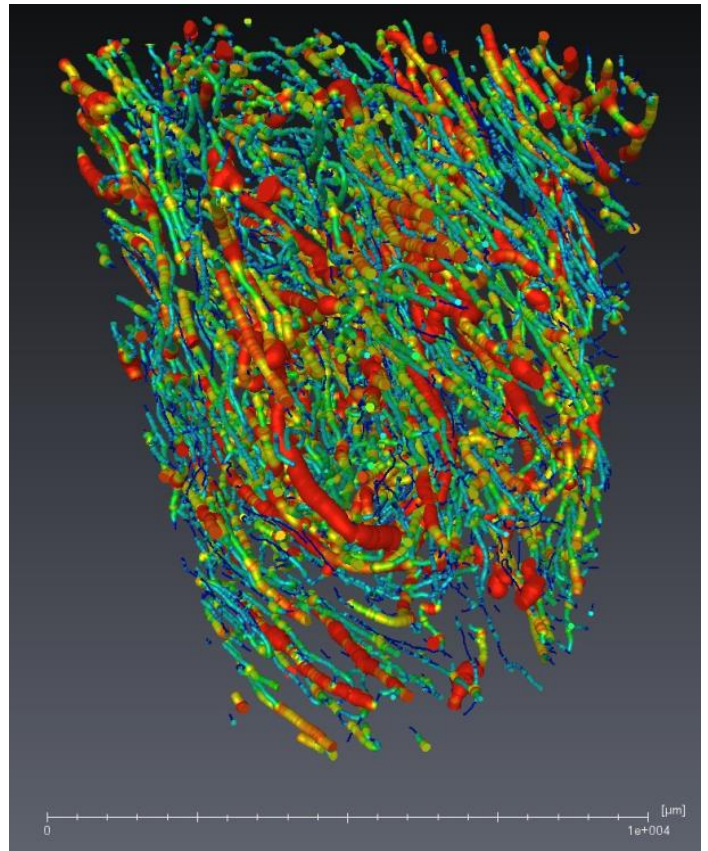

(b)

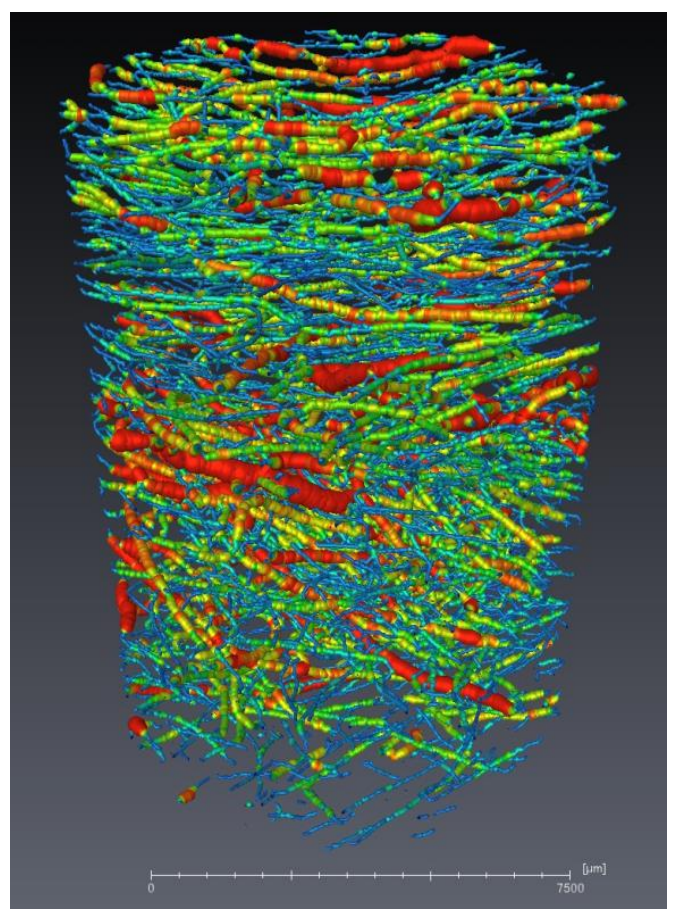

(d)

Figura 49 - (a e c) Micrografia por meio do microtomógrafo de raio-X da amostra FC $2 \% 6 \mathrm{~mm}$ e FC $2 \% 10 \mathrm{~mm}$, respectivamente, que destaca o sentido do fluxo pela direção da seta destacando as fibras de curauá na cor azul e (b e d) poros e espaços vazios (cores diferentes foram destacadas de acordo com o tamanho dos poros ou vazios). 
A Figura 50a apresenta os compósitos com FPP 2\% de $6 \mathrm{~mm}$ com poros e vazios mais distribuídos e não interligados (não permeáveis) como nos compósitos com fibras de curauá.

A Figura 50b apresenta os compósitos com FPP 2\% de $10 \mathrm{~mm}$. Observa-se grande mudança na estrutura ao alterar as fibras de $6 \mathrm{~mm}$ para $10 \mathrm{~mm}$ de comprimento. De acordo com Gallucci et al. (2007), dois tipos distintos de informação quantitativa podem-se extrair dessas imagens: o primeiro diz respeito a parâmetros globais como, por exemplo, volume; o segundo se refere aos parâmetros morfológicos como, por exemplo, conectividade. Dessa forma, notam-se poros de grandes diâmetros, mais tortuosos, destacados na cor vermelha da amostra do compósito FC 2\% 6 mm em relação ao compósito FC $2 \% 10$ mm, das Figuras 49b e $49 \mathrm{~d}$, respectivamente. No compósito de FC $2 \% 10 \mathrm{~mm}$ existem mais conexões de poros de diâmetro menores, possuiu um arranjo mais preenchido em relação aos compósitos FC 2\% $6 \mathrm{~mm}$. Dessa forma, os compósitos FC $2 \% 6 \mathrm{~mm}$ podem evidenciar maiores valores de AA e PA apresentadas na Tabela 19. Nos compósitos reforçados com FPP não se observam esses tipos de poros devido à morfologia da fibra de polipropileno.

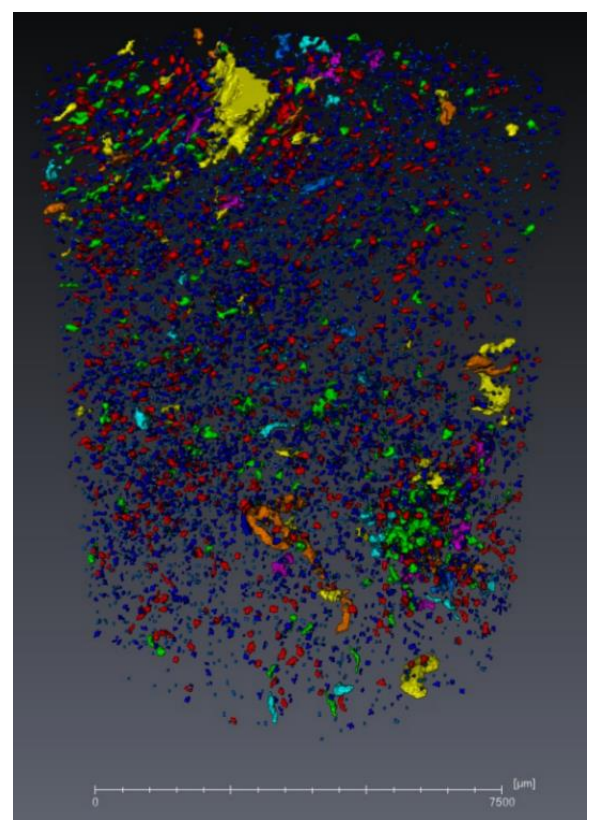

(a)

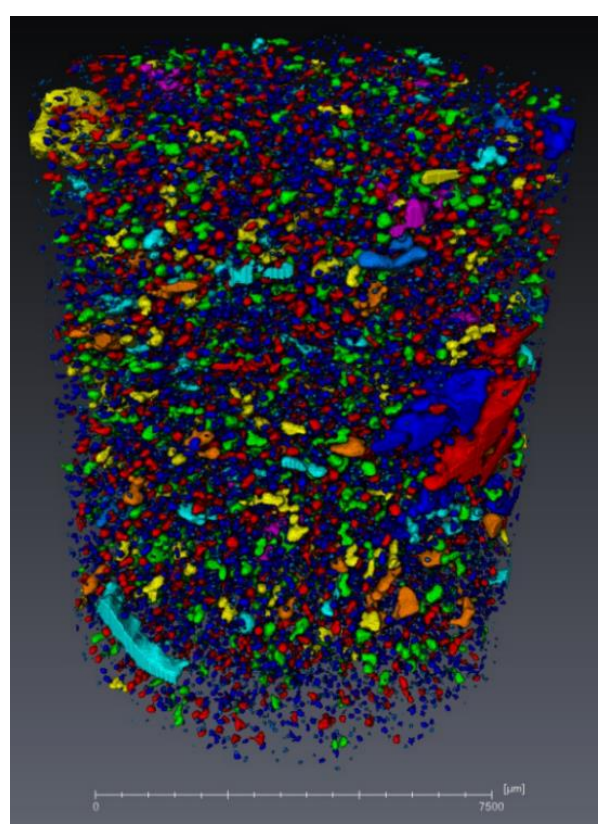

(b)

Figura 50 - (a e b) Micrografia por meio do microtomógrafo de raio-X da amostra FPP 2\% $6 \mathrm{~mm}$ e FPP 2\% $10 \mathrm{~mm}$, respectivamente, que destaca os poros e espaços vazios (cores diferentes foram destacadas de acordo com o tamanho dos poros ou vazios) 


\section{CONCLUSÕES}

Os resultados obtidos neste trabalho mostram que reologia, desempenho físico-mecânico e microestrutura dos compósitos são diretamente influenciados pelas propriedades físicas, químicas, morfológicas das fibras de curauá e de polipropileno. Destaca-se a importância e a conveniência de se conhecer o desempenho dos compósitos nas idades iniciais e a longo prazo (após ciclos de envelhecimento acelerado). Algumas considerações finais sobre cada estudo realizado no presente trabalho são apresentadas:

Reologia: Pasta cimentícia reforçada com fibra de curauá apresentou maior força e menor deslocamento para fluir e maiores valores dos parâmetros reológicos devido ao sequestro de água promovido pela fibra. Outro fator considerado foi a morfologia devido a sua variabilidade dimensional que prejudica o fluxo da mistura no interior da extrusora. Vale ressaltar que o comprimento da fibra influenciou mais diretamente os parâmetros reológicos do que o teor, como a maior pressão para extrudar. Em geral, os melhores resultados reológicos foram alcançados pelos compósitos reforçados com fibras de polipropileno, de acordo com as análises estatísticas. A melhor formulação apresentada foi a pasta cimentícia reforçada com $2 \%$ de fibra de polipropileno com $6 \mathrm{~mm}$ de comprimento.

Resultados mecânicos: Os compósitos cimentícios reforçados com fibras de curauá apresentaram desempenho mecânico inferior em relação aos compósitos reforçados com fibra de polipropileno. Entretanto, os compósitos reforçados com curauá alcançaram resultados superiores em comparação com trabalhos disponíveis na literatura. A fibra de curauá sofreu processo de mineralização durante a cura (absorção de água com produtos de hidratação do cimento) que, consequentemente, levou a fibra perder suas propriedades. Os teores de fibras não influenciaram diretamente 0 desempenho mecânico. Fibras com maiores comprimentos apresentaram melhores resultados mecânicos. Após os 200 ciclos de envelhecimento acelerado, os resultados mecânicos dos compósitos reforçados com as fibras de curauá foram melhores, em razão da reidratação do cimento, que preencheu os poros, densificando a sua estrutura, que melhorou a zona de transição fibra matriz. Por outro lado, o envelhecimento favoreceu a mineralização da fibra, o que diminuiu drasticamente o desempenho mecânico dos compósitos com curauá 
em comparação com trabalhos da literatura. Dessa forma, os melhores resultados foram os obtidos para compósitos reforçados com polipropileno, destacando-se a formulação $2 \%$ de fibra de polipropileno com $10 \mathrm{~mm}$ de comprimento.

Resultados físicos: os compósitos com maiores teores de fibra e com maiores comprimentos de fibra apresentaram aumento de absorção de água e de porosidade aparente. Após 200 ciclos de envelhecimento, os resultados não apresentaram diferença significativa em relação aos 7 dias de cura.

Resultados microestruturais: as fibras celulósicas apresentaram maiores resultados de dureza e módulo elástico na estrutura do compósito cimentício. Matriz cimentícia, grãos anidros, fibra de polipropileno não influenciaram significativamente os resultados de dureza e módulo elástico. Resultados de dureza e módulo elástico no centro da fibra de curauá, na borda da fibra de curauá e na zona de transição fibra matriz não apresentaram diferenças significativas. Após os 200 ciclos, os resultados de dureza e módulo elástico foram superiores em relação aos 7 dias, mas não apresentaram diferenças significativas na estrutura do compósito cimentício. As fibras celulósicas apresentaram maiores durezas após 200 ciclos, devido à mineralização. Microscopia eletrônica de varredura das fibras de curauá de superfície de fratura apresentaram elementos químicos provenientes do cimento dentro da fibra. Também apresentou descolamento das fibras da matriz cimentícia indicando desempenho mecânico baixo. Na micrografia de por meio de microtomografia de raios $-X$ apresentaram fibras de curauá com $6 \mathrm{~mm}$ comprimento mais arranjadas na direção do fluxo da mistura no interior da extrusora facilitando o movimento e assim menores resultados nos parâmetros reológicos em relação as fibras com $10 \mathrm{~mm}$ de comprimento. Compósito com fibras de curauá de $6 \mathrm{~mm}$ apresentou mais poros com maiores diâmetros e mais tortuoso em relação ao compósito com fibras de $10 \mathrm{~mm}$, que apresentou mais poros com menores diâmetros e possui um arranjo mais preenchido que evidência menor absorção de água e porosidade. Finalizando, a melhor formulação do estudo foi o compósito reforçado com fibra de polipropileno com $10 \mathrm{~mm}$ de comprimento. Com esses resultados nos encoraja a utiliza-los em construções em ambientes internos como forro, divisórias e em ambientes externos como telhas devido à conservação dos resultados mecânicos e de durabilidade apresentado após 200 ciclos de envelhecimento. Apesar dos compósitos produzidos com fibras de curauá 
apresentarem resultados inferiores aos compósitos produzidos com fibras de polipropileno, existe a possibilidade de seu emprego em ambientes internos. Novos testes deverão ser empregados para otimizar os resultados

\subsection{Sugestões para trabalhos futuros}

Estudo para a substituição de aditivos sintéticos por adições minerais para realizar a mesma função reológica, acarretando barateamento do produto final.

Estudo de homogeneização de materiais cimentícios com reforço utilizando baixa relação a/c.

Avaliar métodos para determinar teor mínimo de modificador reológico para extrusão.

Estudo aprofundado de tamanho de partículas para promover melhor empacotamento de partículas que reduza de uso de modificadores reológicos.

Utilizar outros tratamentos químicos na fibra vegetal, a fim de se evitar a variação dimensional da fibra melhorando a zona de transição fibra matriz e diminuir a mineralização. 


\section{REFERÊNCIAS BIBLIOGRÁFICAS}

AGOPYAN, V. Materiais reforçados com fibras para a construção civil nos países em desenvolvimento: uso de fibras vegetais. 1991. 204 p. Livre Docência. Escola Politécnica, Universidade de São Paulo, 1991.

AGOPYAN, V. et al. Developments on vegetable fibre-cement based materials in São Paulo, Brazil: An overview. Cement and Concrete Composites, v. 27, n. 5, p. 527-536, 2005.

AGOPYAN, V.; SAVASTANO JR, $\mathrm{H}$. Uso de materiais alternativos à base de fibras vegetais na construção civil: experiência brasileira. In: SEMINÁRIO IBEROAMERICANO DE MATERIALES FIBRORREFORZADOS, 1.,1997, Cali.; Anais...REUNIÓN PROYECTO PIP VIII.5 CYTED, 3.,1997, Cali: Universidad del Valle, 1997. p. 23-40.

AïTCIN, P. C. Concreto de alto desempenho. Tradução de Geraldo G. Serra. São Paulo: PINI, 2000.667p.

ANTUNES, R. P. N.; JOHN, V.; PILEGGI, R. G. Propriedades Reológicas De Argamassas Avaliada Por Squeeze-Flow. VI Simpósio Brasileiro de Tecnologia de Argamassas. Anais...Florianópolis: SBTA, 2005. p. 158-179.

ARAÚJO, C. R.; PERLAZA, L. C.; MOTHÉ, C. G. Thermal properties of commercial and castor oil polyurethane composites with curauá fiber. Fourth International SYMPOSIUM ON NATURAL POLYMERS AND COMPOSITES. Anais...São Paulo: 2002

ASTM C 948-81. American Society for Testing and Materials. ASTM C 948-82: Test method for dry and wet bulk density, water absorption, and apparent porosity of thin sections of glass-fibre reinforced concrete. West Conshohocken, PA, USA. 1982.

ASTM-C1421-01b. American Society for Testing and Materials, Standard Test Method for Determination of Fracture Toughness of Advanced, ASTM-C1421-01b, Philadelphia, 2001.

BALAGURU, P. Thin Reinforced Concrete Products and Systems. ACl ed.Detroit: [s.n.]. 
BALAGURU, P. N.; SHAH, S. P. Fibre reinforced cement composites. New York: McGraw-Hill, 1992. 531p.

BARINOV, S. M. Work of fracture determination for brittle materials. J. Mat. Sci. Letters, v. 12, p. 674-676, 1993.

BARNES, H. A.; HUTTON, J. F.; WALTERS, K. In: An introduction to rheology, Elsevier Science Publishers B. V.,. Amsterdam, The Netherlands. 1989.

BARTOS, P. Review paper: Bond in fibre reinforced cements and concretes. International Journal of Cement Composites and Lightweight Concrete, v. 3, n. 3, p. 159-177, ago. 1981.

BATIC, O. R. et al. Secondary ettringite formation in concrete subjected to different curing conditions. Cement and Concrete Research, v. 30, n. 9, p. 1407-1412, set. 2000 .

BENBOW, J. J.; BRIDGWATER, J. The cutting of paste extrudates. Chemical Engineering Science, v. 48, n. 17, p. 3088-3091, 1993.

BENBOW, J. J.; JAZAYERI, S. H.; BRIDGWATER, J. The flow of pastes through dies of complicated geometry. Powder Technology, v. 65, n. 1-3, p. 393-401, 1991.

BENTUR, A.; AKERS, S. A. S. The microstructure and ageing of cellulose fibre reinforced cement composites cured in a normal environment. International Journal of Cement Composites and Lightweight Concrete, v. 11, n. 2, p. 99-109, 1989a.

BENTUR, A.; AKERS, S. A. S. The microstructure and ageing of cellulose fibre reinforced autoclaved cement composites. International Journal of Cement Composites and Lightweight Concrete, v. 11, n. 2, p. 111-115, 1989b.

BENTUR, A.; MINDESS, S. Fibre reinforced cementitious composites. Elsevier Applied Science, England, 1990. 449 pp.

BENTUR, S.; MINDESS, A. Fibre Reinforced Cementitous Composites. 2nd ed. London, New York: Taylor \& Francis, 2007, 625 p. 
BETIOLI, A. M. et al. Caracterização reológica de pasta cimentícia: associação de técnicas complementares. Ambiente Construído, v. 9, n. 4, p. 37-48, 2009.

BEZERRA, E. M. et al. The effect of different mineral additions and synthetic fiber contents on properties of cement based composites. Cement and Concrete Composites, v. 28, n. 6, p. 555-563, 2006.

BLACKBURN, S.; LAWSON, T. A. Mullite-Alumina Composites by Extrusion. Journal of the American Ceramic Society, v. 75, n. 4, p. 953-957, abr. 1992.

BRAUN, D. B.; ROSEN, M. R. Commercially Available Rheology Modifiers. In: Rheology Modifiers Handbook. Elsevier, 1999. p. 71-191.

CARASCHI, J. C.; LEÃTO, A. L. Characterization of Curaua Fiber. Molecular Crystals and Liquid Crystals Science and Technology. Section A. Molecular Crystals and Liquid Crystals, v. 353, n. 1, p. 149-152, 2000.

CARDOSO, F. A.; PILEGGI, R. G.; JOHN, V. M. CARACTERIZAÇÃO REOLÓGICA DE ARGAMASSAS PELO MÉTODO DE SQUEEZE-FLOW. VI Simpósio Brasileiro de Tecnologia de argamassa. Anais...Florianópolis: 2005.

CARVALHO, A. et al. Argamassa industrializada: influência do tipo de misturador, quantidade de água e tempo de mistura nas características e propriedades no estado fresco e endurecido. Encontro Nacional de Tecnologia do Ambiente Construído, X,. Anais...ANTAC, São Paulo, 2004.

CASALI, J. M. et al. Avaliação da influência do processo de mistura na resistência à compressão de argamassas para assentamento de alvenaria estrutural. Simpósio Brasileiro de Tecnologia das Argamassas, IV, ANTAC. Anais...Brasília: 2001.

CHEN, Z. C. et al. Effect of particle packing on extrusion behavior of paste. Journal of Materials Science, v. 35, n. 21, p. 5301-5307, 2000.

CORREIA, V. C. Produção de celulose nanofibrilada a partir de polpa organossolve de bambu para nanoreforço de compósitos cimentícios. 2015. 167f. Tese (Doutorado) - Faculdade de Zootecnia e Engenharia de Alimentos, Universidade de São Paulo, Pirassununga, 2015. 
COUTTS, R. S. P. Air-cured woodpulp, fibre/cement mortars. Composites, v. 18, n. 4, p. 325-328, 1987.

COUTTS, R. S. P. Wood fibre reinforced cement composites. ((Ed.) In: SWAMY, R.N., Ed.). Natural fibre reinforced cement and concrete. Anais...Glasgow:Blackie,1988. p.208-242. (Concrete Technology and Design, 5): 1988.

D’ALMEIDA, A.; TOLEDO FILHO, R.; MELO FILHO, J. Cement composites reinforced by short curaua fibers. Revista Materia, v. 15, n. 2, p. 153-159, 2010.

DA SILVA, R. V. et al. Desenvolvimento de um compósito laminado híbrido com fibras natural e sintética. Matéria (Rio de Janeiro), v. 13, n. 1, p. 154-161, 2008.

DA SILVA, W. R. L.; NĚMEČEK, J.; ŠTEMBERK, P. Methodology for nanoindentation-assisted prediction of macroscale elastic properties of high performance cementitious composites. Cement and Concrete Composites, v. 45, p. 57-68, 2014.

DELVASTO, S. et al. Effect of fique fibre surface chemical treatments on the physical and mechanical properties of the fibre subjected to aggressive mediums. In: Conferência Brasileira de Materiais e Tecnologia Não-convercinais: Habitações e Infra-estrutura de Interesse Social. Anais...- 2004, Pirassununga. Brasil-NOCMAT. Pirassununga, SP: 2004.

DIAS, C. Fibrocimentos com gradação funcional. 2011. 156f. Tese (Doutorado) Engenharia de Construção Civil e Urbana. Universidade de São Paulo, São Paulo, 2011.

DIAS, C. M. R.; SAVASTANO JR., H.; JOHN, V. M. Exploring the potential of functionally graded materials concept for the development of fiber cement. Construction and Building Materials, v. 24, n. 2, p. 140-146, 2010.

DNPM. DEPARTAMENTO NACIONAL PRODUTOS MINERAIS, Bentonita, 2011. Sumario mineral, 2011.

EMBRAPA - EMPRESA BRASILEIRA DE PESQUISA AGROPECUÁRIA. Notícias EMBRAPA Amazonia Oriental: Pesquisas com curauá dão suporte à indústria. Novembro/ 2007. Disponível em: 
http://www.cpatu.embrapa.br/noticias/2007/novembro/4a-semana/pesquisascomcuraua-dao.

EN 494. EUROPEAN COMMITTEE FOR STANDARDIZATION. EN 494: fibrecement profiled sheets and fittings for roofing - products specification and test methods. London, UK.: BSI - British Standards Institution, 1994.

FARUK, O. et al. Progress Report on Natural Fiber Reinforced Composites. Macromolecular Materials and Engineering, v. 299, n. 1, p. 9-26, jan. 2014.

FIDELIS, M. E. A. et al. The effect of fiber morphology on the tensile strength of Natural fibers. Journal of Materials Research and Technology., v. 2, n. 2, p. 149157, 2013.

GALLUCCI, E. et al. 3D experimental investigation of the microstructure of cement pastes using synchrotron X-ray microtomography. Cement and Concrete Research, v. 37, n. 3, p. 360-368, 2007.

GLATTHOR, A.; SCHWEIZER, D. Rheological Lab Testing of Building Formulations. ConChem International Exhibition \& Conference. Anais...1994. Verlag Ziolkowsky, Augsburg.: 1994.

GRAM, H. E. Durability of natural fibres in concrete. Swedish cement and concrete research institute. CBI Research, Stockholm, n. 1-83, p. 255, 1983.

GRAM, H. E. Durability of natural fibres in concrete. (R. N. SWAMY, Ed.)Natural fibre reinforced Cement and Concrete. Anais...Glasgow: Blackie, (Concrete Technology and Design, 5): 1988.

GRAY, R. J. Analysis of the effect of embedded fibre length on fibre debonding and pull-out from an elastic matrix - Part 2 Application to a steel fibre-cementitious matrix composite system. Journal of Materials Science, v. 19, n. 5, p. 1680-1691, 1984.

GRAY, R. J.; JOHNSTON, C. D. The influence of fibre-matrix interfacial bond strength on the mechanical properties of steel fibre reinforced mortars. International Journal of Cement Composites and Lightweight Concrete, v. 9, n. 1, p. 43-55, 1987. 
HANNANT, D. J. Durability of cement sheets reinforced with fibrillated polypropylene networks. Magazine of Concrete Research, v. 35, n. 125, p. 197-204, 12 jan. 1983.

HÖLZGEN, M.; QUIRMBACH, P. Extrusion in ceramics. In: FRANK HÄNDLE (Ed.). Engineer materials and processes. Berlin, Germany: p. 233-244. 2007.

HORST, G. G. Extrusion of FRC products: technology and practical aspects. In: INTERNATIONAL CONFERENCE INORGANIC-BONDED WOOD AND FIBER COMPOSITE MATERIALS. Anais..., v 8., Sun Valley, 2002. Sun Valley, Idaho, USA, 2002.

IGARASHI, S.; BENTUR, A.; MINDESS, S. Microhardness testing of cementitious materials. Advanced Cement Based Materials, v. 4, n. 2, p. 48-57, 1996.

IKAI, S. et al. Asbestos-free technology with new high toughness polypropylene (PP) fibers in air-cured Hatschek process. Construction and Building Materials, v. 24, n. 2, p. $171-180,2010$.

KRAUS, J. et al. A célula vegetal. In: IN. APPEZZATO-DA-GLÓRIA, B. CARMELLOGUERREIRO, S. M. (Ed.). . Anatomia Vegetal. Anatomia Vegetal. 2.ed.. Viçosa: Editora da Universidade Federal de Viçosa, p. 32-67, 2006.

KUDER, K. G.; SHAH, S. P. Processing of high-performance fiber-reinforced cementbased composites. Construction and Building Materials, v. 24, n. 2, p. 181-186, 2010.

LEÃO, A.; ROWELL, R.; TAVARES, N. Applications of natural fibres in automotive industry in Brazil - thermoforming process. (P. N. Prasad, Ed.) Science and Technology Polymers and Advanced Materials. Anais..., Plenum Press, New York 1998.

LI, Z. J.; MU, B.; CHUI, S. N. C. Systematic study of properties of extrudates with incorporated metakaolin or silica fume. ACI Materials Journal., v. 96, n. 5, p. 574579, 1999.

LI, Z. J.; MU, B.; CHUI, S. N. C. Static and dynamic behavior extruded sheets with short fibers. Journal of Materials in Civil Engineering, v. 13, n. 4, p. 248-254, 2001. 
LI, Z.; ZHANG, Y.; ZHOU, X. Short Fiber Reinforced Geopolymer Composites Manufactured by Extrusion. Journal of Materials in Civil Engineering, v. 17, n. 6, p. 624-631, 2005.

LOPES, C. M.; LOBO, J. M. S.; COSTA, P. Formas farmacêuticas de liberação modificada: polímeros hidrifílicos. Revista Brasileira de Ciências Farmacêuticas, v. 41, n. 2, p. 143-154, 2005.

MACVICAR, R.; MATUANA, L. M.; BALATINECZ, J. J. Aging mechanisms in cellulose fiber reinforced cement composites. Cement and Concrete Composites, v. 21, n. 3, p. 189-196, jan. 1999.

MANGAT, P. S.; AZARI, M. M. Shrinkage of Steel Fibre Reinforced Cement Composites. Materials and Structures/Materiaux et Constructions, v. 21, n. Compendex, p. 163-171, 1988.

MATTANA, J. A.; MARON COSTA, M. R. M. Caracterização Reológica de Argamassas pelo Método de Squeeze-Flow. In: VIII Simpósio Brasileiro de tecnologia das argamassas. Anais...Curitiba, 2009.

MEČEK, J.; KABELE, P.; BITTNAR, Z. Nanoindentation based assessment of micromechanical properties of fibre reinforced cementitious composite. 6th RILEM Symposium on Fibre Reinforced Concrete (FRC). Anais...BEFIB, 2004, Varenna, Italy, 2004, pp. 401-410.

MEHTA, P. K.; MONTEIRO, P. J. M. Concreto estrutura, propriedades e materiais. São Paulo: Editora PINI, 1994.

MIN, B. H.; ERWIN, L.; JENNINGS, H. M. Rheological behaviour of fresh cement paste as measured by Squeeze flow. Journal of Materials Science, v. 29, n. 5, p. 1374-1381, 1994.

MINDESS, S. Fibre reinforced concrete challenges and prospects. (E. N. Banthia and S. Mindess, Ed.)Fibre reinforced concrete. Anais...Univ. of British Columbia, Vancouver, Canada. 1993. p.1-11.

MINDESS, S.; ODLER, I.; SKALNY, J. Significance to concrete performance of interfaces and bond: challenges of the future. INTERNATIONAL CONGRESS ON THE CHEMISTRY OF CEMENT. Anais...Rio de Janeiro: Abla, 1986. v.1, p.151-157. 
MOHR, B. J.; BIERNACKI, J. J.; KURTIS, K. E. Microstructural and chemical effects of wet/dry cycling on pulp fiber-cement composites. Cement and Concrete Research, v. 36, n. 7, p. 1240-1251, 2006.

MOHR, B. J.; NANKO, H.; KURTIS, K. E. Durability of kraft pulp fiber-cement composites to wet/dry cycling. Cement and Concrete Composites, v. 27, p. 435448, abr. 2005.

NAGELE, E. W. The Transient Zeta Potential of Hydrating Cement. Chemical Engineering Science, v. 44, n. 8, p. 1637-1645, 1989.

NAIR, K. C. M. et al. Rheological behavior of short sisal fiber- reinforced polystyrene composites. Composites: Part A: Applied Science and Manufacturing., v. 31, n. 11, p. 1231-1240, 2000.

NAKAYAMA, J.; ABE, H.; BRADT, R. C. Crack stability in the work-of-fracture test: refractory applications. Journal of American Ceramic Society, v. 64, n. 11, p. 671675, 1981.

NATH DAS, R.; MADHUSOODANA, C. D.; OKADA, K. Rheological studies on cordierite honeycomb extrusion. Journal of the European Ceramic Society, v. 22, n. 16, p. 2893-2900, 2002.

NBR 5733. ASSOCIAÇÃO BRASILEIRA DE NORMAS TÉCNICAS. NBR 5733: cimento Portland de alta resistência inicial, especificação. Rio de Janeiro, Brazil, 1983. $5 p$.

OLIVEIRA, I. et al. Dispersão e empacotamento de partículas: Princípios e aplicações em processamento cerâmico. São Paulo/SP: Ed. Fazendo Arte, 2000. 224p.

ÖZKAN, N. et al. Rheological analysis of ceramic pastes. Journal of the European Ceramic Society, v. 19, n. 16, p. 2883-2891, 1999.

PADE, C.; GUIMARAES, M. The CO2 uptake of concrete in a 100 year perspective. Cement and Concrete Research, v. 37, n. 9, p. 1348-1356, 2007. 
PELED, A.; SHAH, S. P. Processing Effects in Cementitious Composites: Extrusion and Casting. Journal of Materials in Civil Engineering, v. 15, n. 2, p. 192-199, 2003.

PEMATEC TIANGEL. Projeto Curauá. Disponível em: http://www.pematec.com.br/curaua.htm., 2013.

PEREIRA, C. L. Aproveitamento do resíduo do de coco verde para a produção de compósitos destinados à construção rural. 2012. 135f. Faculdade de Zooctecnia e Engenharia de Alimentos - Universidade de São Paulo. Pirassununga, São Paulo, 2012.

PETER, M. A. et al. Competition of several carbonation reactions in concrete: A parametric study. Cement and Concrete Research, v. 38, n. 12, p. 1385-1393, 2008.

PETROU, M. F. et al. Influence of mortar rheology on aggregate settlement. ACI Structural Journal, v. 97, n. 4, p. 479-485, 2000.

PICANÇO, M. D. S.; GHAVAMI, K. Comportamento à compressão de argamassas reforçadas com fibras vegetais da Amazônia. Engenharia Civil, v. 61, n. 1, p. 13-18, 2008.

PILEGGI, R. G. Ferramentas para o estudo e desenvolvimento de concretos refratários. 2001. 187p. Tese (Doutorado em Ciência e Engenharia de Materiais), Universidade Federal de São Carlos. São Carlos/SP. 2001.

PORTER, M. Técnicas para el análisis de los sectores industriales y de la competencia. In: 23 ed. México: Compañía Editora Continental, 1998.

QIAN, X. et al. Fiber alignment and property direction dependency of FRC extrudate. Cement and Concrete Research, v. 33, n. 10, p. 1575-1581, 2003.

RAMACHANDRAN, V. S. Concrete science. In: IN: RAMACHANDRAN, V. S.; BEAUDOIN, J. J. (Ed.). Handbook of analytical techniques in concrete science and technology - principles, techniques and applications. New Jersey: Noyes Publication; New York: Willian Andrew Publishing,1999. 934p. 
RAMOS, L. P. Fundamentals involved in pretreating and hydrolysing of lignocellulosic materials. In: INTERNATIONAL SEMINAR ON BIOMASS FOR ENERGY PRODUCTION (INTERBIO), 2001, Rio de Janeiro. Anais...Rio de Janeiro, RJ: Centro de Nacional de Referência em Biomassa, 2001, 14 p.

RODRIGUES, J. A.; SANTOS, S. F. Brittle-ductile transition of alumina-glass castables. In: 47th. International Colloquium on Refractories: Refractories for Metallurgy, 2004, Aachen. PROCEEDINGS OF THE 47TH. INTERNATIONAL COLLOQUIUM ON REFRACTORIES: REFRACTORIES FOR METALLURGY. Anais...Düsseldorf: Verlag Stahleisen GmbH. 2004, p. 81-84.

RODRIGUES, J. A.; SANTOS, S. F. The energy of fracture of refractories at high temperatures. In: 48th. International Colloquium on Refractories: Refractories for Metallurgy, 2005, Aachen. PROCEEDINGS OF THE 48TH. INTERNATIONAL COLLOQUIUM ON REFRACTORIES: REFRACTORIES FOR METALLURGY. Anais...Düsseldorf : Verlag Stahleisen GmbH p. 190-193, 2005.

RODRIGUES, P. P. F.; MONTARDO, J. P. A. Influência da adição de fibras de polipropileno nas propriedades dos concretos para pisos e pavimentos. $44^{\circ}$ Congresso Brasileiro do Concreto. Anais...Instituto Brasileiro do Concreto IBRACON. Belo Horizonte, 2002.

ROMA, L. C.; MARTELLO, L. S.; SAVASTANO JR., H. Evaluation of mechanical, physical and thermal performance of cement-based tiles reinforced with vegetable fibers. Construction and Building Materials, v. 22, n. 4, p. 668-674, 2008.

ROSSETTO, H. L. Contribuições Para a Ciência E Engenharia Dos Materiais Cimentícios: Processamento. 124f. 2007. Escola de Engenharia de São Carlos, Instituto de Física de São Carlos, Instituto de Química de São Carlos, Universidade de São Paulo, São Carlos. 2007.

ROSSETTO, H. L.; SOUZA, M. F. DE; PANDOLFELLI, V. C. Adesão em materiais cimentícios: "In-built nanotechnology ". Cerâmica, v. 55, p. 199-205, 2009.

SAKAI, M.; BRADT, R. C. Fracture toughness testing of brittle materials. International Materials. Reviews, v. 38, n. 2, p. 53-78, 1993.

SANTOS, S. F. et al. Effect of colloidal silica on the mechanical properties of fibercement reinforced with cellulosic fibers. Journal of Materials Science, v. 49, n. 21, p. 7497-7506, 2014. 
SANTOS, S. F. et al. Supercritical carbonation treatment on extruded fibre-cement reinforced with vegetable fibres. Cement and Concrete Composites, v. 56, p. 8494, 2015.

SATYANARAYANA, K. G.; GUIMARÃES, J. L.; WYPYCH, F. Studies on lignocellulosic fibers of Brazil. Part I: Source, production, morphology, properties and applications. Composites Part A: Applied Science and Manufacturing, v. 38, n. 7, p. 1694-1709, 2007.

SAVASTANO, JR, H.; AGOPYAN, V. Transition zone studies of vegetable fibrecement paste composites. Cement and Concrete Composites, v. 21, n. 1, p. 4957, 1999.

SAVASTANO JR., H. Zona de transição entre fibras e pasta de cimento Portland: caracterização e inter-relação com as propriedades mecânicas do compósito. 205f. 1992. Escola Politécnica da Universidade de São Paulo, São Paulo, 1992.

SAVASTANO JR., H.; DANTAS, F. A. Z.; AGOPYAN, V. Materiais reforçados com fibras: correlação entre a zona de transição fibra-matriz e as propriedades mecânicas.São Paulo: IPT/Pini, 1994. 56p. (Publicação IPT 2158 - Boletim 67)., 1994.

SAVASTANO JR., H.; SANTOS, S. F. Materiais de Construção Civil e Princípios de Ciência e Engenharia de Materiais. Produtos de Fibrocimento. São Paulo: Ipsis Gráfica e Editora, 2007, v. 2, p. 983-1005.

SAVASTANO JR., H.; WARDEN, P. G.; COUTTS, R. S. P. Brazilian waste fibres as reinforcement for cement-based composites. Cement and Concrete Composites, v. 22, n. 5, p. 379-384, 2000.

SAVASTANO JR., H.; WARDEN, P. G.; COUTTS, R. S. P. Potential of alternative fibre cements as building materials for developing areas. Cement and Concrete Composites, v. 25, n. 6, p. 585-592, 2003.

SHAH, S. P. Fibre reinforced concrete. In: IN: KONG, F. K.; COHEN, E.; ROLL, E. F. (Ed.). Handbook of structural concrete. (Eds.). New York: McGraw-Hill Book Company, 1983. p. 1968. 
SHAO, Y. et al. Wood fibre - cement composites by extrusion. Canadian Journal of Civil Engineering, v. 27, n. 3, p. 543-552, 2000.

SHAO, Y.; MARIKUNTE, S.; SHAH, S. P. Extruded fiber-reinforced composites. Concrete International, v. 17, n. 4, p. 48-52, 1995.

SHAO, Y.; SHAH, S. Mechanical properties of PVA fiber reinforced cement composites fabricated by extrusion processing. ACl materials Journal, n. 94, p. 555-563, 1997.

SHEN, B. Experimental approaches for determining rheological properties of cement-based extrudates. 124p. 2003. Programa de Pós-Graduação da Universidade de Ciências e Tecnologia de Hong Kong, Hong Kong, (em inglês)., 2003.

SOROUSHIAN, P. et al. Durability and moisture sensitivity of recycled wastepaperfiber-cement composites. Cement and Concrete Composites, v. 16, n. 2, p. 115128, 1994.

SOROUSHIAN, P.; MARIKUNTE, S. Statistical Evaluation of Long-Term Durability Characteristics of Cellulose Fiber Reinforced Cement Composites. ACI Materials Journal, v. 91, n. 6, 1995.

SOTO, Y. J. M. Adequação de formulações para a produção de placas de fibrocimento por extrusão. 201p. 2010. Tese (Doutorado em Engenharia Civil). Escola Politécnica - Universidade de São Paulo., 2010.

SOTO, Y. J. M. et al. Prospective study on vegetable wastes as reinforcement in extruded fibre-cement. International Conference on Non-Conventional Materials and Technologies: Ecological Materials and technologies for Sustainable Constructions. Anais..., 2007, Maceió. Anais do Brasil-NOCMAT. (Abmtenc) Maceió, 2007.

SPINACÉ, M. A S. et al. Characterization of lignocellulosic curaua fibres. Carbohydrate Polymers, v. 77, n. 1, p. 47-53, 2009.

SRINIVASAN, S.; DEFORD, D.; SHAH, P. S. The use of extrusion rheometry in the development of extrudate fibre-reinforced cement composites. Concrete Science and Engineering, v. 1, n. 11, p. 26-36, 1999. 
STICKLEN, M. B. Plant genetic engineering for biofuel production: towards affordable cellulosic ethanol. Nature Reviews Genetics, v. 9, n. 6, p. 433-443, jun. 2008.

TAKASHIMA, $H$. et al. A design approach for the mechanical properties of polypropylene discontinuous fiber reinforced cementitious composites by extrusion molding. Engineering Fracture Mechanics, v. 70, n. 7-8, p. 853-870, 2003.

TANESI, J.; FIGUEIREDO, A. Materiais com fibras de polipropileno para construção civil. Congresso Internacional de não tecidos e tecidos técnicos. Anais...1999.

TAYLOR, H. F. W. Cement chemistry. London: Academic press, 1990, 475p.

TEIXEIRA, R. S. et al. Extruded Cement Based Composites Reinforced with Sugar Cane Bagasse Fibres. Key Engineering Materials, v. 517, p. 450-457, 2012.

TEIXEIRA, R. S. et al. Different ageing conditions on cementitious roofing tiles reinforced with alternative vegetable and synthetic fibres. Materials and Structures, v. 47, n. 3, p. 433-446, 2014.

TOLÊDO FILHO, R. D. et al. Durability of alkali-sensitive sisal and coconut fibres in cement mortar composites. Cement and Concrete Composites, v. 22, n. 2, p. 127143, 2000.

TONOLI, G. et al. Effect of eucalyptus pulp refining on the performance and durability of fibre-cement composites. Journal of Tropical Forest Science., v. 25, n. 3, p. 400-409, 2013.

TONOLI, G. H. D. et al. Performance and Durability of Cement Based Composites Reinforced with Refined Sisal Pulp. Materials and Manufacturing Processes, v. 22, n. 2, p. 149-156, 2007.

TONOLI, G. H. D. et al. Effect of fibre morphology on flocculation of fibre-cement suspensions. Cement and Concrete Research, v. 39, n. 11, p. 1017-1022, 2009a.

TONOLI, G. H. D. et al. Cellulose modified fibres in cement based composites. Composites Part A: Applied Science and Manufacturing, v. 40, n. 12, p. 20462053, 2009b. 
TONOLI, G. H. D. Fibras curtas de eucalipto para novas tecnologias em fibrocimento. 128p. 2009. Tese (Doutorado) - Escola de Engenharia de São Carlos, Universidade de São Paulo, São Carlos., 2010.

TONOLI, G. H. D. et al. Eucalyptus pulp fibres as alternative reinforcement to engineered cement-based composites. Industrial Crops and Products, v. 31, n. 2, p. 225-232, 2010.

TONOLI, G. H. D. et al. Hybrid Reinforcement of Sisal and Polypropylene Fibers in Cement-Based Composites. Journal of Materials in Civil Engineering, v. 23, n. 2, p. 177-187, 2011.

VELEZ, K. et al. Determination by nanoindentation of elastic modulus and hardness of pure constituents of Portland cement clinker. Cement and Concrete Research, v. 31 , n. 4, p. 555-561, 2001.

WANG, X. H. et al. Application of nanoindentation testing to study of the interfacial transition zone in steel fiber reinforced mortar. Cement and Concrete Research, v. 39, n. 8, p. 701-715, 2009.

WEINEKÖTTER, R.; GERICKE, H. Mixing of solids. Springer; 1st ed Zürich, Switzerland, 2000.156p.

YANG, M.; JENNINGS, H. M. Influences of mixing methods on the microstructure and rheological behavior of cement paste. Advanced Cement Based Materials, v. 2, n. 2, p. 70-78, 1995.

YANG, M.; NEUBAUER, C. M.; JENNINGS, H. M. Interparticle Potential and Sedimentation Behavior of Cement Suspensions: Effects of Admixtures. Advanced Cement Based Materials, v. 8, n. 1, p. 17-27, jul. 1998.

ZAH, R. et al. Curauá fibers in the automobile industry - a sustainability assessment. Journal of Cleaner Production, v. 15, n. 11-12, p. 1032-1040, 2007.

ZHOU, X. et al. Rheology of semi-solid fresh cement pastes and mortars in orifice extrusion. Cement and Concrete Composites, v. 37, n. 1, p. 304-311, 2013. 
ZHOU, X.; LI, Z. Characterization of rheology of fresh fiber reinforced cementitious composites through ram extrusion. Materials and Structures, v. 38, n. 275, p. 1724, 2004. 